\title{
Influence of Intestinal Microbiota in Celiac Disease Pathogenesis and Risk
}

Presented by:

Marta Olivares Sevilla

Supervised by:

Dr. Yolanda Sanz Herranz

November 2015

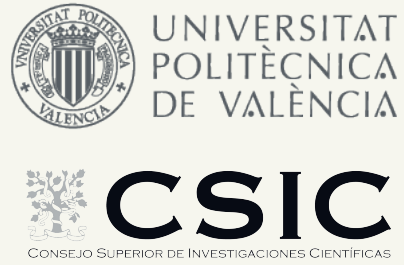





\title{
Influence of Intestinal Microbiota in Celiac Disease Pathogenesis and Risk
}

\author{
Presented by: \\ Marta Olivares Sevilla \\ Supervised by: \\ Dr. Yolanda Sanz Herranz
}

Valencia, November 2015 

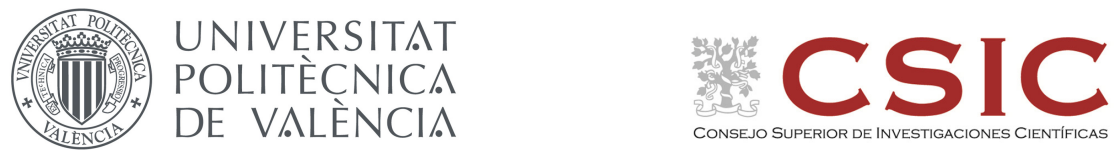

Dra. Yolanda Sanz Herranz, Profesora de Investigación del Consejo Superior de Investigaciones Científicas en el Instituto de Agroquímica y Tecnología de Alimentos

Hace constar que:

La memoria titulada "Influence of Intestinal Microbiota in Celiac Disease Pathogenesis and Risk" que presenta Marta Olivares Sevilla para optar al grado de Doctor por la Universidad Politécnica de Valencia, ha sido realizada en el del Instituto de Agroquímica y Tecnología de Alimentos (IATA-CSIC) bajo su dirección y que reúne las condiciones para ser defendida por su autora.

Valencia, 28 de Octubre de 2015

Fdo. Yolanda Sanz Herranz 
A mis padres y mi hermana 


\section{Agradecimientos}

Esta Tesis es el resultado de casi 6 ańos de trabajo en los que he tenido la suerte de conocer a muchísimas personas que forman parte de esta tesis y de mi vida.

En primer lugar, me gustaría dar las gracias al programa JAE del CSIC por la concesión de la beca predoctoral que he disfrutado durante estos años.

Mi agradecimiento más especial es para Yolanda, por darme esta gran oportunidad y por descubrirme el mundo de las bacterias que viven en nuestro cuerpo. Gracias por tu confianza, cercanía y por estar siempre de buen humor. He aprendido muchísimo contigo y te lo agradeceré siempre.

También me gustaría darle las gracias a Moisés, por su tiempo y su dedicación durante mis primeros años. A todos mis compañeros del laboratorio, que han sido y son tantos que no los puedo enumerar, por toda la ayuda, consejos y los innumerables buenos momentos. A Luis Izquierdo por estar siempre disponible para ayudarnos con la estadística. Y en general, a todo el personal del IATA y del SCSIE que, de una u otra manera, también han contribuido a esta tesis.

Gracias a Ludmila Tuckova y a Jana Cinova de la Academia de las Ciencias de la República Checa, y a Nina Lin de la Universidad de Michigan, por su bienvenida y atención durante mi estancia en sus laboratorios.

En esta tesis también hay mucho trabajo de clínicos y personal de diversos hospitales que han colaborado en la recolección de muestras. En este sentido, Gemma Castillejo del Hospital Universitario de Reus merece una mención especial.

Gracias a Guille y todos los chicos de Obsolete Letterpress por ayudarme con la maquetación y la portada de esta tesis.

Por último, gracias a mis amigos por las bromas sobre mi trabajo. Y con especial carińo, gracias a mis padres por creer en mí de manera incondicional, y a mi hermana Alicia por sus inteligentes consejos. 


\section{ABSTRACT}

Celiac disease (CD) is a chronic enteropathy triggered by cereal gluten proteins in genetically predisposed individuals. The etiology is strongly associated with the genes of the human leukocyte antigen (HLA) encoding the DQ2/DQ8 molecules. Most CD patients carry this genotype but this is also present in the $40 \%$ of the general population and only a small percentage develops the disease. Thus, the HLA-DQ genotype is necessary but not solely responsible for the disease development. Gluten is the main environmental trigger but its intake neither fully explains the onset nor its clinical manifestations. Other environmental factors (e.g. early feeding practices, infections, intestinal microbiota) have been associated with the risk of developing CD.

The only treatment for CD patients is the adherence to a gluten free diet (GFD), but the compliance with this dietary strategy is complicated because gluten is present in many foods. Therefore, the identification of modifiable environmental factors that contribute to $\mathrm{CD}$ onset is critical for the development of strategies to reduce its incidence.

Observational studies in CD patients revealed imbalances in the intestinal microbiota which could contribute to the pathogenesis of the disease. It has been proposed that these imbalances are not only a secondary consequence of the disease but could also be a predisposing factor. To understand whether gut microbiota imbalances play a role in $\mathrm{CD}$ onset and pathogenesis, in vitro, animal and human prospective and intervention studies have been conducted in the context of the present PhD Thesis.

The global aim of this Thesis has been to improve the understanding of the role played by intestinal microbiota in the pathogenesis and risk of $\mathrm{CD}$, and the possibilities of contributing to disease prevention and treatment by modulating gut 
microbiota composition. Chapter $\mathbf{1}$ includes two in vitro studies investigating the influence of components of the gut microbiota (bifidobacteria and enterobacteria) on the maturation and functions of immunocompetent cells (dendritic cells), and on gluten toxicity in the intestinal epithelium (Caco-2 cells). We have observed that some Bifidobacterium strains are able to reduce the activation of dendritic cells and ameliorate the toxicity of gluten on intestinal epithelial cells.

In Chapter 2 the effects of the administration of Bifidobacterium longum CECT 7347 was evaluated in an in vivo model of gluten induced enteropathy in newborn rats, resulting in a reduced proinflammatory cytokine production in the small intestine and $\mathrm{CD}^{+}{ }^{+} \mathrm{T}$ cell numbers in peripheral blood.

Chapter 3 includes two observational studies in humans to unravel whether breast-feeding and human milk composition and/or the host genotype (HLADQ) are related to the microbiota, thereby influencing the later development of $\mathrm{CD}$. We concluded that both factors may contribute to the early intestinal colonization of the infant, influencing the Bifidobacterium spp. numbers. Human milk composition also varies in $\mathrm{CD}$ and non-CD mothers, modifying the supply of bifidobacteria and protective immune factors to the offspring.

Finally, in Chapter 4 we have studied the potential beneficial effects of the administration of $B$. longum CECT 7347 in addition to the GFD to children with newly diagnosed CD. This study demonstrates that the bifidobacteria slightly reduces serum inflammatory markers and restored the gut microbiota composition. 


\section{RESUMEN}

La enfermedad celíaca (EC) es una enteropatía crónica de carácter autoinmune que sufren individuos genéticamente predispuestos tras la ingesta de gluten. La etiología está asociada con los genes del sistema "Antígeno Leucocitario Humano" (HLA) que codifican las moléculas DQ2/DQ8. Los pacientes con EC presentan este genotipo, sin embargo este también está presente en $\sim 40 \%$ de la población general y sólo un pequeño porcentaje desarrolla la enfermedad. Por lo tanto, el genotipo HLA-DQ resulta necesario pero no suficiente para que se desarrolle la enfermedad. El gluten es el principal desencadenante pero su ingesta tampoco explica su desarrollo ni sus manifestaciones clínicas. Otros factores ambientales (p.e. la lactancia, infecciones, microbiota intestinal) se han asociado con el riesgo de desarrollar la EC.

El único tratamiento para los pacientes celíacos es el seguimiento de una dieta exenta de gluten (DEG), sin embargo su cumplimiento es complicado debido a que el gluten está presente en la mayoría de los alimentos procesados. Por ello, la identificación de factores ambientales modificables que contribuyan al desarrollo de la enfermedad, resulta fundamental para desarrollar estrategias que permitan reducir su incidencia.

Estudios observacionales realizados en pacientes con la EC, han demostrado la existencia de desequilibrios en su microbiota intestinal, que podrían contribuir a la patogénesis de la enfermedad. Se ha propuesto que estos desequilibrios no son sólo una consecuencia secundaria de la EC, sino que podrían ser un factor predisponente. Para entender si la microbiota está implicada en el desarrollo y patogénesis de la EC, en la presente Tesis se han desarrollado estudios in vitro, con animales y estudios prospectivos y de intervención en humanos.

El objetivo de esta Tesis ha sido avanzar en el conocimiento de la función que la microbiota intestinal desempeña en la patogénesis de la EC, así como, acerca de las posibilidades de tratar o prevenir esta enfermedad mediante la modulación de 
la composición de la microbiota intestinal.

El Capítulo 1 incluye dos estudios in vitro en los que se ha estudiado la influencia de componentes de la microbiota intestinal (bifidobacterias y enterobacterias) en la maduración y las funciones de células inmunocompetentes (células dendríticas), y en la toxicidad del gluten en el epitelio intestinal (células Caco-2). Hemos observado que algunas cepas de Bifidobacterium son capaces de reducir la activación de las células dendríticas y de reducir la toxicidad del gluten sobre el epitelio intestinal.

El Capítulo 2 incluye el estudio de los efectos de la administración de B. longum CECT 7347 en un modelo de enteropatía inducida por gluten en ratas recién nacidas, observándose una reducción de citoquinas proinflamatorias en el intestino y de células T $\mathrm{CD} 4^{+}$en sangre periférica.

El Capítulo 3 incluye dos estudios observaciones en humanos en los que se ha investigado si la lactancia y composición de la leche materna y/o el genotipo (HLA-DQ) están relacionados con la microbiota y, si así, podrían influir en el desarrollo de la EC. Concluimos que ambos factores contribuyen a la colonización intestinal del niño en los primeros meses de vida, afectando especialmente al número de Bifidobacterium spp.. La composición de la leche maternal varía entre madres celíacas y sanas, lo que podría modificar el aporte de bifidobacterias y factores inmunológicos protectores al lactante.

Por último, el Capítulo 4 incluye el estudio del potencial efecto beneficioso de la administración de B. longum CECT 7347 junto con la DEG en niños recién diagnosticados de EC. Este estudio demuestra que la bifidobacteria reduce ligeramente los marcadores inflamatorios en sangre periférica y contribuye a restablecer la composición de la microbiota intestinal. 


\section{RESUM}

La malaltia celíaca $(\mathrm{MC})$ és una enteropatia crònica provocada per les proteïnes del gluten de cereals en individus predisposats genèticament. L'etiologia està fortament associada amb els gens de l'antigen leucocitari humà (HLA). Pacients amb $\mathrm{MC}$ son portadors d'aquest genotipus però també està present en aproximadament el $40 \%$ de la població general i només un petit percentatge (1-3\%) desenvolupa la malaltia. Per tant, HLA-DQ genotip és necessària, però no l'únic responsable. El gluten és el principal desencadenant ambiental però la seva ingesta no explica completament l'inici ni les seves manifestacions clíniques. Altres factors ambientals, com la microbiota intestinal, s'han associat amb el risc de desenvolupar la MC.

Els estudis observacionals en pacients amb MC van revelar desequilibris en la microbiota intestinal que podrien contribuir a la patogènesi de la malaltia. $S$ 'ha proposat que aquests desequilibris no només són una conseqüència secundària de la malaltia, si no que també podrien ser un factor de predisposició. Per entendre si els desequilibris de la microbiota intestinal podrien tenir un paper en l'aparició de $\mathrm{MC}$, un estudi prospectiu amb el gen en risc la família està en marxa.

L'únic tractament per als pacients amb MC és l'adherència a una dieta lliure de gluten, però el seu compliment és complicat a causa del gluten present en molts aliments. La identificació de factors ambientals modificables que contribueixen a l'aparició de CD és fonamental per a les estratègies de desenvolupament que porten a una reducció de la incidència. Aquest pot ser el cas per als components de la microbiota intestinal, l'adquisició podria ser modulada per factors ambientals i dietètics. L’objectiu global de la tesi és desentranyar els coneixements actuals sobre el paper exercit per la microbiota intestinal en la patogènesi de l'MC, i les possibilitats de contribuir a la prevenció i tractament de la malaltia mitjançant la modulació de la composició de la microbiota intestinal.

En el Capítol 1 hem estudiat l'ús de models in vitro de la influència de la microbiota intestinal durant la maduració i funcions del sistema immunològic (cèlllules 
dendrítiques), i les interaccions entre el gluten i l'intestí i la resposta de l'epiteli intestinal resultant d'aquesta interacció. Hem observat que algunes cepes de $B i$ fidobacterium són capaç de reduir l'activació del sistema immune i millorar la resposta nociva de l'epiteli intestinal a l'estimulació amb gluten.

En el Capítol 2 hem estudiat els efectes de l'administració d'una cepa de Bifidobacterium (B. longum CECT 7347) per a un model animal de rates nounades. El tractament amb els bacteris es va associar amb una reducció en la producció de citoquines proinflamatòries i la resposta immune de cèlllules T CD4 ${ }^{+}$.

En el Capítol 3 es va descriure que alguns genotipus (HLA-DQ genotip) i factors ambientals (llet materna) influeixen en la colonització intestinal primerenca, especialment en Bifidobacterium spp., que poden influir en l'aparició de MC més tard.

Finalment, en el Capítol 4 s'ha estudiat l'efecte probiòtic de l'administració de B. longum CECT 7347 en xiquets que acaben de ser diagnosticats d'MC i el seu paper en el restabliment de la salut intestinal. 


\section{TABLE OF CONTENTS}

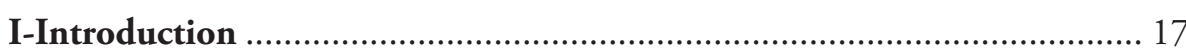

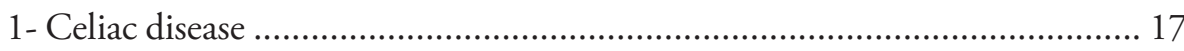

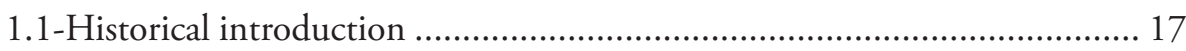

1.2-Definition and classification of celiac disease ........................................... 18

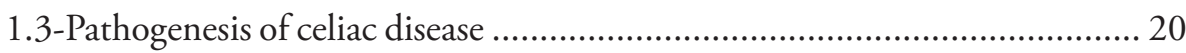

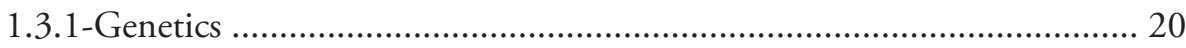

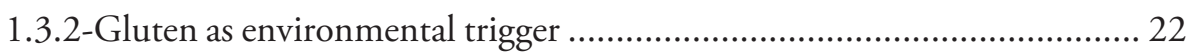

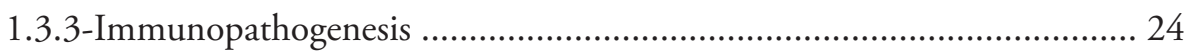

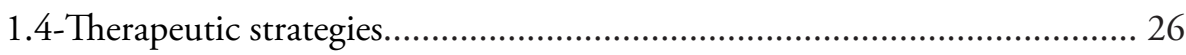

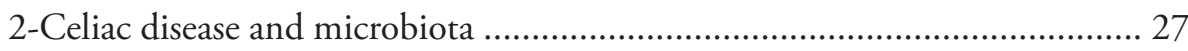

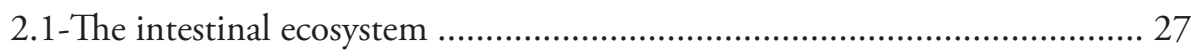

2.2- Early factors influencing gut microbiota and CD risk ............................. 28

2.3-Influence of intestinal microbiota in CD pathogenesis ............................. 31

2.4-Mechanism of action of intestinal microbiota in CD ............................... 34

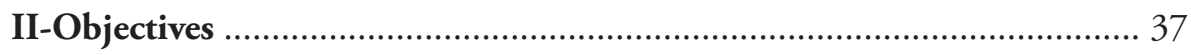

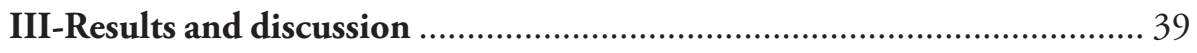

\section{Chapter 1}

Modulation of phenotypic and functional maturation of dendritic cells by intestinal bacteria and gliadin: relevance for celiac disease ...................................... 41 
Influence of Bifidobacterium longum CECT 7347 and gliadin peptides on intestinal epithelial cell proteome

\section{Chapter 2}

Bifidobacterium longum CECT 7347 modulates immune responses in a gliadin-induced enteropathy animal model 87

\section{Chapter 3}

Human milk composition differs in healthy mothers and mothers with celiac disease

The HLA-DQ2 genotype selects for early intestinal microbiota composition in infants at high risk of developing coeliac disease

\section{Chapter 4}

Double-blind, randomised, placebo-controlled intervention trial to evaluate the effects of Bifidobacterium longum CECT 7347 in children with newly diagnosed coeliac disease

IV-General discussion

V-Conclusions

References

Abbreviations 


\section{I - INTRODUCTION}

\section{1-Celiac disease}

\section{1-Historical introduction}

Celiac disease (CD) likely appeared with one of the first environmental changes associated with human civilization, the development of the agriculture and the introduction of cereals in the human diet. In the first century of Common Era (C.E.) Cappadoce provided the first description of the common manifestation of the disease (chronic diarrhea, abdominal distension and cachexia) and used the term "Koliakos" to name the subjects suffering from this disorder. The etiology of the disease was not discover until the 1950, when the Dutch pediatrician W. K. Dicke associated the CD symptoms with the consumption of bread and proposed a diet without these cereals to the patients, who showed a clear improvement (1).

In 1957, the development of the Crosby-Kugler capsule to obtain biopsies from the small bowel mucosa, allowed M. Shiner studying duodenal biopsies and demonstrating the typical villous atrophy that characterizes the disease (2). Then, A. Ferguson described the massive infiltration of the small intestinal epithelium by lymphocytes and helped to complete the histological picture of CD (3). In the early 1960, family studies showed the contribution of predisposing genetic factors (4); and 10 years later, new diagnostic tools were developed, based on the detection of circulating immunoglobulin (Ig)-G and IgA antibodies against gluten and the autoantigen tissue transglutaminase (tTG) that underscored the immune-mediated nature of the disease (5). The identification of the human leukocyte antigen (HLA)-DQ2 and HLA-DQ8 as the major predisposing factors $(6,7)$ and their role in the development of an intestinal inflammatory $\mathrm{CD}^{+} \mathrm{T}$ lymphocyte response to gluten was crucial to establish the link between the trigger environmental factor and the major predisposing genes (8).

Despite the huge advances in the understanding of CD pathogenesis, many piec- 
es of the puzzle remain to be assembled. It is unclear why only a small subset of individuals with the HLA genotype develops the disease and which are the roles of different environmental factors in the onset of the disease. It also remains to be unraveled why the incidence of $\mathrm{CD}$ is globally increasing, a phenomenon that cannot be solely explained by improvements in the diagnosis. It is also unclear why some subjects develop CD very early in infancy after the first exposures to gluten; meanwhile others do so lately in the adulthood.

\section{2-Definition and classification of celiac disease}

The members of the European Society for Pediatric Gastroenterology, Hepatology, and Nutrition (ESPGHAN) group in the year 2012 established the new guidelines for the diagnostic criteria of CD (9). The working group decided to define $\mathrm{CD}$ as an immune-mediated systemic disorder elicited by gluten in genetically susceptible individuals and characterized by the presence of a variable combination of gluten-dependent clinical manifestations, CD-specific antibodies, HLA-DQ2 or HLA-DQ8 haplotypes, and enteropathy. CD specific antibodies comprise autoantibodies against tissue transglutaminase 2 (tTG-2), endomysial antibodies (EMA), and antibodies against deamidated forms of gliadin peptides. In these guidelines, it is also indicated that intestinal biopsy may be omitted in symptomatic children with high level of serological markers and HLA-DQ2 or HLA-DQ8 positive. In all other cases, the intestinal biopsy is required in order to avoid misdiagnosis (9).

The ESPGHAN group also reviewed the classifications of $\mathrm{CD}$ and distinguished two forms of clinical manifestation: with "gastrointestinal symptoms and signs" and with "extra-intestinal symptoms and signs". In the first form symptoms such as chronic, diarrhea, abdominal pain, or distension were considered; while the second manifestation included symptoms such as anemia, neuropathy, decreased bone density, or increased risk of fractures. Also, three specific denominations of the clinical manifestations of the disease were established when the defined symptomatology is not sufficient:

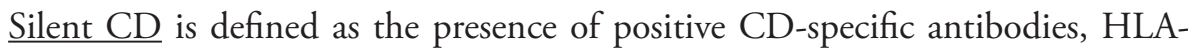


DQ2/DQ8 genotype, and small-bowel biopsy findings that are compatible with CD but without sufficient symptoms and signs to warrant clinical suspicion of CD.

Latent CD is defined by the presence of compatible HLA-DQ2/DQ8 genotype but without enteropathy in a patient who has had a gluten-dependent enteropathy at some point in his or her life. The patient may or may not have symptoms and may or may not have CD-specific antibodies.

Potential CD is defined by the presence of CD-specific antibodies and compatible HLA-DQ2/DQ8 genotype but without histological abnormalities in duodenal biopsies. The patient may or may not have symptoms and signs and may or may not develop a gluten-dependent enteropathy later.

Originally, CD was thought to affect to almost exclusively white Europeans, but now it is known to be widely distributed worldwide and seems to have followed the mankind wheat consumption and the migratory flows (10). The prevalence of the disease ranks between 1 to $3 \%$ of the general population $(11,12)$, even though the existence of the sub-clinical forms described above makes difficult the diagnosis and underestimates the incidence, often represented by an iceberg in which the no symptomatic cases are underwater (Figure 1). Some estimations indicate that only 1 of every 5-9 affected individuals is correctly diagnosed and

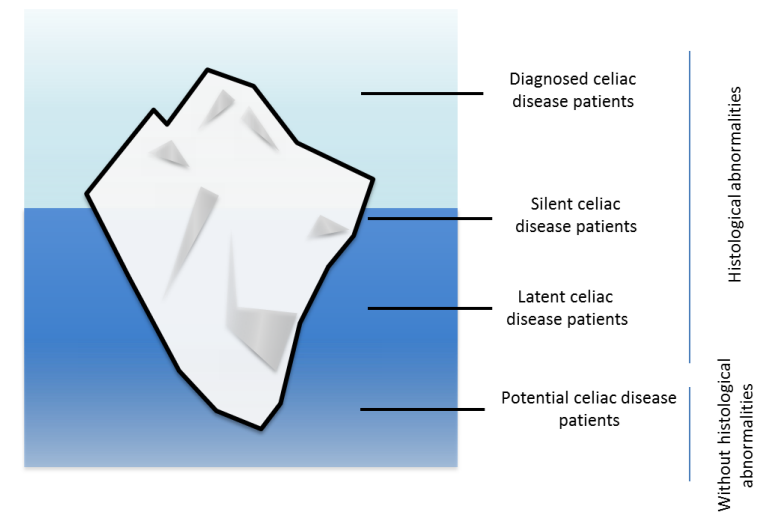

Figure 1: The clinical presentation of CD is often described as an iceberg model. The tip of the iceberg constitutes the diagnosed fraction of $\mathrm{CD}$ patients and the part underwater those who are undiagnosed. 
treated.

\section{3-Pathogenesis of celiac disease}

$\mathrm{CD}$ is a multifactorial disorder involving genetic and several environmental factors. The disease is strongly associated with the HLA genes that codify the expression of the HLA-DO2/DQ8 heterodimers in the surface of the antigen presenting cells (APC). Most CD patients present this genotype; however this is also present in $-40 \%$ of the general population and only a small percentage (1$3 \%)$ finally develops the disease $(11,12)$. Thus, the genotype HLA-DQ2/DQ8 is needed but it's no sufficient to explain the onset of CD (13). Currently, nonHLA genes are known to be involved as described below. Gluten intake is the environmental factor responsible for the manifestation of the disease; however, the number of patients diagnosed during the adulthood after many years of gluten exposure is increasing demonstrating that gluten intake may not be the only trigger (14). Epidemiological studies indicate that other factors may increase or reduce the risk of developing $\mathrm{CD}$. The amount and timing of gluten introduction to the infant diet, the type of delivery, the milk feeding practices, the incidence of infections and the intestinal microbiota composition have been proposed to influence the CD risk. However, no conclusive results have been obtained so far (reviewed in 15).

\subsection{1-Genetics}

Different studies in siblings have demonstrated the strong genetic component of $\mathrm{CD}$, showing a concordance of around $80 \%$ in monozygotic twins versus less than $20 \%$ among dizygotic twins, and $10 \%$ in first degree relatives of CD patients (1618). HLA-DQ has been the locus more widely studied in the context of $C D$. The HLA-DQ genes encode molecules expressed on the surface of the APCs involved in the recognition of the gluten peptides. It has been described that approximately $90-95 \%$ of CD patients carry HLA-DQ2 heterodimers formed by a $\beta$-chain encoded by HLA-DQB $1 * 2$ allele (either ${ }^{*} 0201$ or ${ }^{*} 0202$ ) and an $\alpha$-chain encoded by HLA-DQA $1 * 05$ allele. HLA-DQB ${ }^{*} 02$ and HLA-DQA1*05 alleles can be inherited in cis (when both are present on one parental chromosome), or in 
trans (when the $\alpha$ - and $\beta$-chains are encoded by chromosomes from each parent). The remaining percentage (5-10\%) of patients express the HLA-DQ8 heterodimer formed by $\beta$ and $\alpha$-chains encoded by HLA-DQB ${ }^{*} 0302$ allele and HLA DQA $1{ }^{*} 0301$ allele, respectively. HLA-DQ2 and HLA-DQ8 molecules share peptides binding motifs characterized by a preference for hydrophobic and negatively charged amino acids, such as the deaminated gluten peptides (Figure 2).
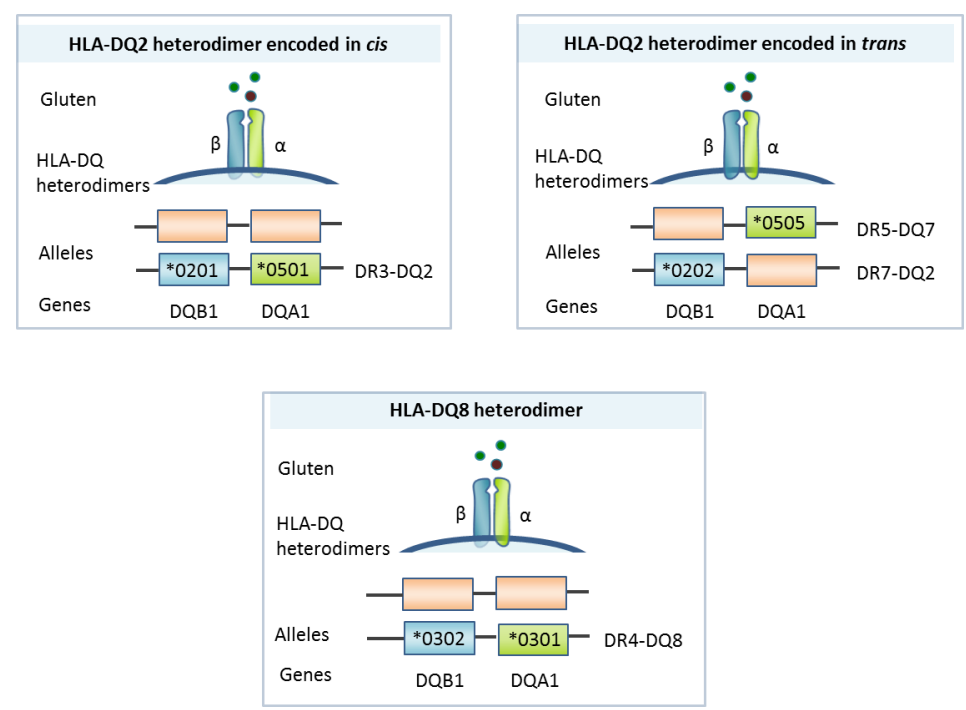

Figure 2: Representation of genes, combination of alleles (haplotypes) and codified HLA-DQ or HLA-DQ8 heterodimers ( $\alpha$ and $\beta$ chanis). Celiac disease patients who are DR3 or DR5/DR7 express the same molecule: HLA-DQ2. The genes DQB1 and DQA1 can be inherited in cis (in the same parental chromosome), or in trans (when the $\alpha$ - and $\beta$-chains are encoded by the corresponding chromosome from each parent). CD patients who are DR4 express the molecule HLA-DQ8. Adapted from Dieli-Crimi et al., 2015 (19).

Over the last decades, different genetic studies have been performed in order to reveal all the genetic factors involved in CD. Nowadays, CD is well established as a polygenic disease with a complex non-Mendelian pattern of inheritance. So far, 58 genetic variants located within 36 non-HLA regions have also been associated with the susceptibility to suffer from $\mathrm{CD}$, being located only 3 of these variants on protein coding regions and the remaining variants located in non-coding regulatory regions and intergenic regions of unknown function. Thus, CD onset is influenced by the accumulation of risk due to HLA and non-HLA genes together 
with different environmental factors (reviewed in 19).

\subsection{2-Gluten as environmental trigger}

In 1950, wheat was described as causal agent (antigen) of the CD (1). Then, barley and rye grains were described as toxic for CD patients. Still there are controversies about the possible toxic effects of oats (reviewed in 20). Because of the ubiquity of wheat in the diet and the controversy with oats, both cereals have been the most widely studied. The gluten fraction soluble in alcohol and characterized by having a high content in proline is denominated prolamin; while the fraction insoluble in alcohol is the glutenin. Prolamin proteins are named more specifically based on the cereal where they come from. Thereby in wheat, barley and rye, the prolamins are called gliadin, hordein and secalin, respectively. Gliadin, hordein and secalin have a high proline and glutamine content. These particular amino acid residues confer to these proteins a partial resistance to the proteolytic digestion since gastric, pancreatic and brush border enzymes are deficient in prolyl-endopeptidases with the consequent accumulation of immunogenic peptides in the intestinal lumen (21). However, the relatively poor digestion of these proteins alone is not sufficient to cause $\mathrm{CD}$, and indeed there is no known difference between healthy individuals and susceptible CD subjects in their ability to digest gluten proteins (22).

In the small intestine gliadin peptides interact with the CXCR3 receptor that leads to the release of zonulin (a regulatory protein of the tight junctions between enterocytes) that, in turn, increases intestinal permeability. This mechanism may facilitate the passage of gluten peptides by the paracellular pathway to the lamina propria (23). Besides, gluten peptides can also cross the intestinal barrier using the ability of enterocytes to capture molecules from the luminal space, through the so-called transcellular route via transcytosis. For instance, the translocation of the 33-mer peptide (p57-89 from the $\alpha$-gliadin) can occur by transcytosis regulated by interferon (IFN)- $\gamma$. This uptake has been observed to be higher in untreated CD than in controls and CD patients on a GFD (24). Moreover other peptides, such as the p31-49 from the $\alpha$-gliadin, can be transported intact through an abnormal retrotranscytosis process mediated by secretory immuno- 
globulin A (sIgA) and the CD71 receptor (25). In normal conditions, this receptor plays a major role in iron uptake and metabolism, and it is only expressed in the basolateral membrane of enterocytes and mainly in the crypts. In active CD, CD71 is massively upregulated and expressed in the apical membrane of enterocytes where the sIgA1-gliadin complexes present in the lumen can bind and translocate intact into the lamina propria (25). This mechanism, seen in patients with active $\mathrm{CD}$ but not in controls or treated patients, represents an exception to the well-characterized protective effect of sIgA in the mucosal surface, where it binds antigens and facilitates their secretion in faeces (reviewed in 26). Interestingly, some authors have proposed that the over-expression of CD71 receptor is probably due to iron deficiency, which is frequent in CD patients (27).

In recent years the role of the alterations in the intestinal permeability in $\mathrm{CD}$ is attracting attention as may be one of the first events that precede the onset of the disease. Nevertheless, gluten is also known to activate an inflammatory response with production of cytokines that cause gut barrier disruption, creating a vicious-circle where both mucosal inflammation and the leaky gut influence one another as explained below.

The patter and timing of gluten introduction into the infant's diet has been considered as one of the critical factors that determines CD risk. In this regard, two independent intervention studies have investigated whether there is a window of opportunity to introduce gluten into the diet that confers protection against $\mathrm{CD}$ in genetically predisposed individuals. One randomized double-blinded intervention study (PreventCD) in which infants at genetic risk of developing CD (HLA-DQ positive) ( $n=944$ ) received a small dose of gluten or a placebo daily between 4-6 months of age, showed no differences between groups in the prevalence of CD at 3 years of age (28). The second study (CELIPREV) found that the introduction of gluten at 12 months (compared to 6 months) in infants genetically predisposed to develop $\mathrm{CD}(\mathrm{n}=832)$ may delay the onset of the disease but does not modified its incidence at 5 years of age (29).

Regarding CD in the adulthood, a recent study in mice with altered stress-related behavior and premature immune senescence suggests that aging and an 
altered-stress response play a role in the $\mathrm{CD}$ susceptibility through the altered immune response to gluten and intestinal bacteria (30).

\subsection{3-Immunopathogenesis}

The immunopathogenic process of CD involves both innate (gluten direct effect on the epithelium and innate immune cells) and adaptive immunity (through the lamina propria $\mathrm{CD}^{+}$and $\mathrm{CD} 8^{+} \mathrm{T}$ lymphocytes) (Figure 3).

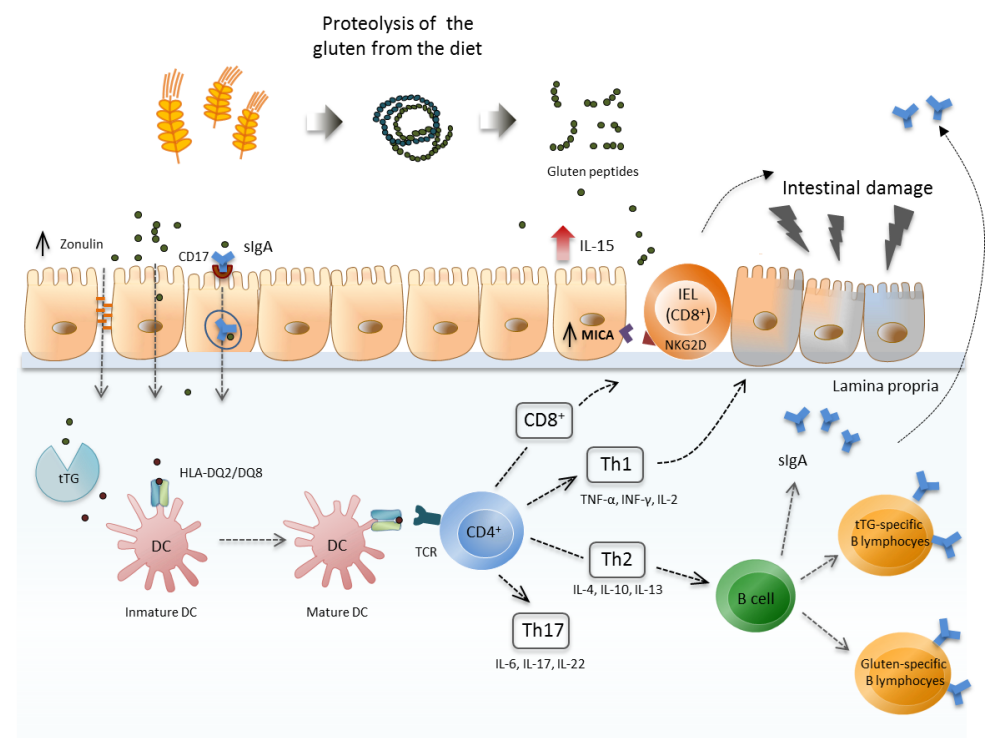

Figure 3: Schematic representation of CD pathogenesis Some gluten peptides cross the intestinal epithelium and can be deamidated by the tissue transglutaminase ( $\mathrm{tTG}$ ), which increases their ability to bind the HLA-DQ2/DQ8 molecules of APCs and to trigger an adaptive immune response, involving Th1, Th2 and Th17 cells that lead to the release of pro-inflammatory cytokines and the production of $\mathrm{CD}$ antibodies; other gluten peptides activate an innate immune response by interacting with epithelial cells and APCs and, thus, triggering the production of the pro-inflammatory cytokines In particular, IL-15 increases the expression of the MICA molecule in epithelial cell surface and triggers activation of intraepithelial lymphocytes through engagement of NKG2D, leading to an innate-like cytotoxicity toward epithelial cells and enhanced $\mathrm{CD} 8^{+} \mathrm{T}$ cell-mediated adaptive response, contributing to villous atrophy. Adapted from Olivares and Sanz, 2015 (31).

Regarding the adaptive immune response, once gluten peptides reach the lamina propria though the different mechanisms described above, the enzyme tTG de- 
aminates the glutamine residues (positively charged) to glutamic acid (negatively charged). The HLA-DQ2 and HLA-DQ8 molecules expressed in the surface of the APCs (basically dendritic cells) have in their peptide binding groove several "pockets" that favor binding of negatively charged residues. Thus, tTG significantly increases the affinity and the capture of gliadin peptides, constituting a key factor in the CD pathogenesis (reviewed in 32).

APCs are very efficient at internalizing gluten peptides and, then, displaying some of the fragments on their surface. The specific gluten epitopes that can be displayed by a person's APCs depend on the set of antigen-presenting molecules encoded by that person's genome within the HLA locus. The union HLA-DQgluten on the surface of the APCs is recognized by the T cell receptor (TCR) presented on the surface of the $\mathrm{CD}^{+}{ }^{+} \mathrm{T}$ lymphocytes, triggering the activation of $\mathrm{CD}^{+} \mathrm{T}$ lymphocytes into the pro-inflammatory $\mathrm{T}$ helper $(\mathrm{Th}) 1$ profile with the release of mainly IFN- $\gamma$, as well as tumor necrosis factor (TNF)- $\alpha$ and interleukin (IL)-2; and also the Th17 response with the release of IL-6, IL-17A and IL-22 (reviewed in 32).

These cytokines cause tissue damage and the loss of the normal intestinal architecture through the infiltration of $\mathrm{CD}^{+}{ }^{+} \mathrm{T}$ lymphocytes and the release of metalloproteinases (reviewed in 32). Activated $\mathrm{CD}^{+} \mathrm{T}$ lymphocytes can also drive a Th2-type response that leads to the release of other cytokines (IL-4, IL-10, IL-13). The Th2-type response leads to clonal expression of differentiated B lymphocytes into plasma cells (effector B cells) that produce anti-transglutaminase and anti-gliadin antibodies (33) which induce changes in the cytoskeleton and the structure of the enterocytes. Overall, this causes the development of typical lesions of $\mathrm{CD}$, with crypt hyperplasia and villous atrophy (reviewed in 32).

Furthermore, it has been recently described that certain peptides present toxic actions on the epithelium not related to the adaptive response mediated by $\mathrm{T}$ lymphocytes. These peptides induce the release of IL-15 by enterocytes, dendritic cells and macrophages. In turn, this cytokine induces the expansion of intraepithelial lymphocytes (IELs) and the adquisition of a natural killer cell phenotype. IL-15 also induces the expression of the stress MICA molecule (MHC class I 
chain-related molecule A) in the epithelial cells. Finally, the binding of the MICA to the NKG2D receptors on the lymphocytes with natural-killer activity $\left(\mathrm{CD} 8^{+}\right.$ IELs) promotes the destruction of enterocytes (34).

\section{4-Therapeutic strategies}

Life-long gluten exclusion from the diet is the only available treatment for CD patients. In all cases, CD patients should exclude wheat, barley, rye and oats and derivatives from the diet. After two weeks of adherence to a gluten free diet (GFD), an improvement in symptoms is observed; then, the serological normalization appears between 6-12 months and the recovery of the intestinal villi around two years after the adherence to the diet depending on the severity of the disease and the age (reviewed in 35).

However, this dietary restriction often affects the social life of CD patients, limits the variety of food choices in their diets and it is difficult to maintain because gluten is present in most of the processed foods. The progress in the understanding of the molecular and cellular events involved in the abnormal response to gluten has led to the development of alternative or complementary therapeutic strategies to the GFD. Briefly, some of the alternatives that are being investigated are described below.

- Prolyl-endopeptidases and glutamine-endopeptidases from bacterial and fungi sources to break down the resistant immunogenic gluten peptides and detoxify gluten (36).

- Inhibition of the tTG activity to reduce the affinity of the gluten peptides for the HLA-DQ2/DQ8 molecules (37)

- Blockade the HLA-DQ2/DQ8 molecules using synthetic peptides agonists that compete with gluten peptides for the binding sites of the HLA-DQ molecules (38).

- Immunomodulation by the induction of anti-inflammatory cytokines (IL-10) (39) or by the administration of antagonists of pro-inflammatory cytokines such 
as IL-15 (40) or TNF- $\alpha$ and IL-18 (41).

\section{2-Celiac disease and microbiota}

\section{1-The intestinal ecosystem}

It has been estimated that the intestine harbors $10^{13}$ to $10^{14}$ microorganisms (42), which means that the bacterial cells in the intestine are ten times more numerous than the total number of human body cells. Additionally, the collective genome of the microbiota, named microbiome, contains at least 100-fold more genes than the complete human genome $(42,43)$. The intestinal microbiota is considered to play numerous functions in the human body, including metabolic, protective and structural functions (Figure 4). Despite the important role that the intestinal microbiota seems to play in human health, it is not known yet which are the components of the microbiota that are responsible for specific conditions and those that provide protection from disease. Cultivation techniques have limited resolution because only a small fraction (20-40\%) of the intestinal bacterial species is able to grown using culture-based techniques $(45,46)$. In this context, the development and use of high-throughput DNA sequencing platforms applied to $16 \mathrm{~S}$ rRNA gene and metagenomic analyses have rapidly increased the understanding of the taxonomy and diversity of the human intestinal microbiota and

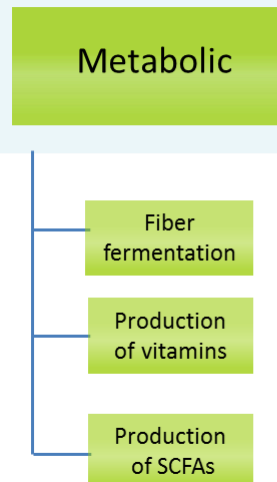

of SCFAs
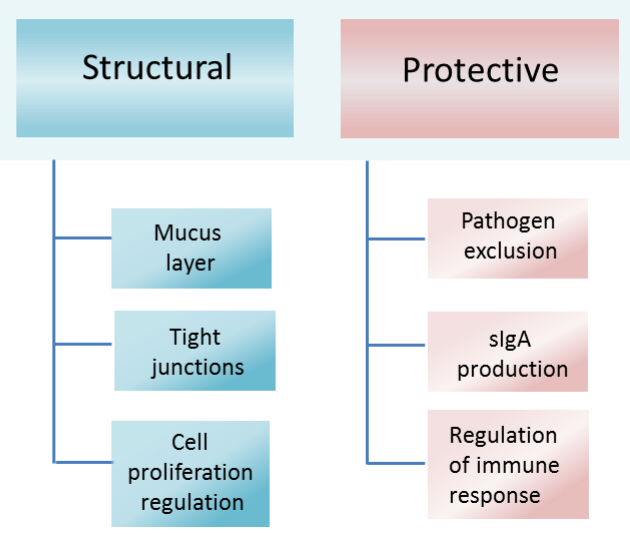

Figure 4: Main functions of the intestinal microbiota impacting on the human health. Adapted from Grenham et al., 2011 (44). 
their relationship with health and disease.

$16 \mathrm{~S}$ rRNA and metagenomic studies have revealed that the majority of gut microbiota sequences belong to the Bacteria, which is the predominant kingdom in the human adult gut $(45,46)$. Despite the complexity of the human intestinal ecosystem, the majority of the bacteria belong to 6 dominating phyla Bacteroidetes, Firmicutes, Actinobacteria, Proteobacteria, Verrucomicrobia, and Fusobacteria. Actinobacteria is the most abundant phylum in infants because of the predominant colonization by the genus Bifidobacterium in the first stages of life (47, 48), meanwhile Firmicutes and Bacteroidetes dominate the intestinal microbiota of the adult population $(45,49)$.

\section{2-Early factors influencing gut microbiota and CD risk}

The primary colonization of the intestinal tract begins at birth with the acquisition of microbes from the environment, mainly from the maternal vagina and the skin. It is a dynamic process that involves interactions of co-occurrence and exclusion between intestinal bacteria, reflecting life events of the newborn and undergoing changes until the first 2-3 years of age when the microbiome starts to converge toward an adult-like profile $(47,50)$. The intestinal colonization process leads to the acquisition and establishment of a protective microbiota that could modulate the risk of developing immune-mediated diseases in adulthood (51). This influence is mediated by the interactions between the gut microbiota, the diet and immune system, which are crucial for the development of tolerance towards harmless antigens from the diet and the commensal microbiota and appropriate defenses against pathogens.

Perinatal and early postnatal environmental factors influencing the microbiota composition have been associated with CD susceptibility (Figure 5). The greater risk of children born by caesarean section of developing $\mathrm{CD}$ (53) might be related to the delay in intestinal colonization by bifidobacteria and the reduced bacterial diversity observed in caesarean-born compared to naturally-delivered infants (54). Longer breast-feeding and particularly maintenance of breast-feeding when gluten is introduced seem to reduce the risk of developing $\mathrm{CD}$ or, at least, delay 
its onset in most case-control retrospective studies included in the meta-analysis by Akobeng et al. (55). Also, feeding practices involving the gradual introduction of gluten simultaneous to breastfeeding were proposed as the protective factor responsible for reducing $\mathrm{CD}$ prevalence in one birth cohort compared to the "Swedish CD epidemic" cohort (56). However, other prospective epidemiological and intervention studies failed to find a protective effect of breast-feeding in either CD autoimmunity or biopsy proven $\operatorname{CD}(57,58)$. This inconsistency could be due to the lack of control of other confounding variables that have not been systematically investigated so far.

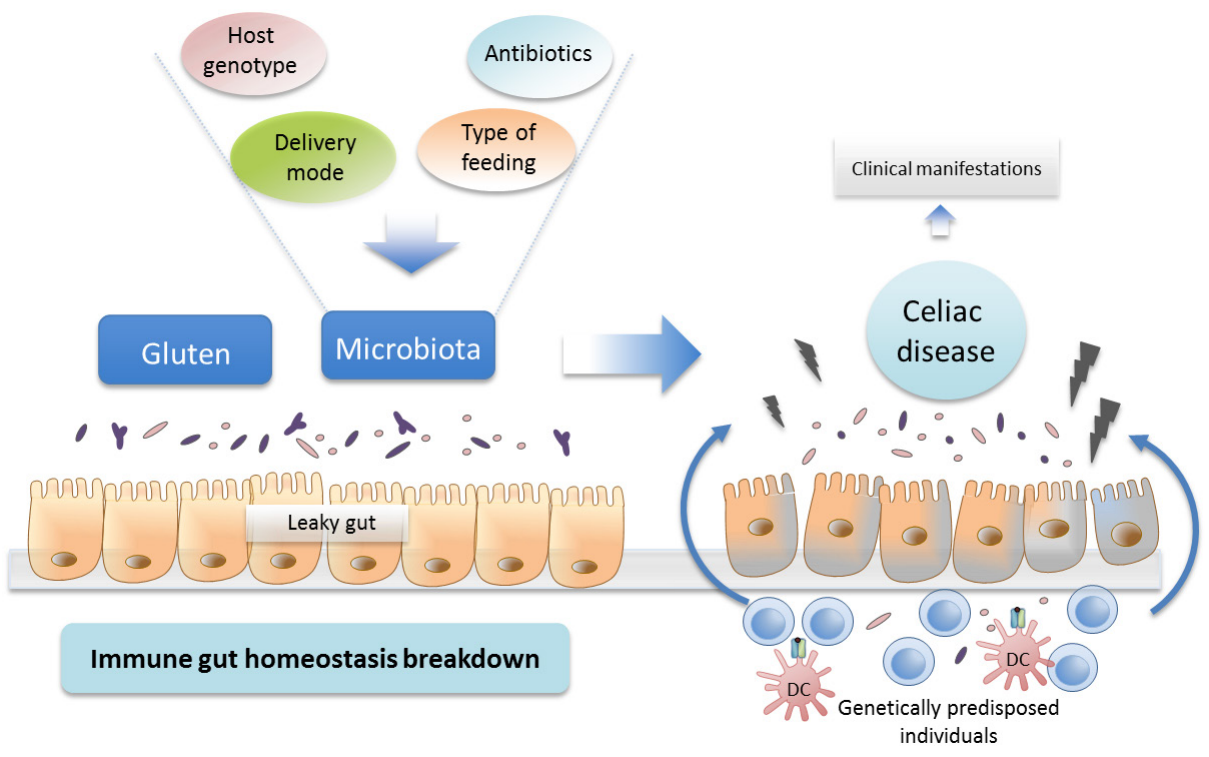

Figure 5: Proposed model for CD pathogenesis. Specific host genetic make-up and environmental factors could promote the colonization of pathobionts and reduce symbionts, thus leading to dysbiosis. Dysbiosis may contribute to disrupting the immune homeostasis and gut integrity, thereby favoring CD onset or aggravating the pathogenesis. Adapted from Cenit et al., 2015 (52).

Duration of breast-feeding could be associated with a reduced or delayed exposure of the newborn to dietary gluten, which might contribute to the protective effect of breast milk. Plausibly bioactive breast milk components may also be involved in the potential protective effect of breast-feeding on CD development. For instance, breast milk seems to be a main source of bacteria for the infant's gut 
$(59,60)$ and of human milk oligosaccharides (HMOs), which promote colonization of Bifidobacterium spp.. This could explain the differences observed between the intestinal microbiota of breast-fed and formula-fed infants (61-63). Besides human milk provides many others bioactive substances involved in passive immune protection and in immunological development of the neonate (64).

On the other hand, a positive association between antibiotics use and subsequent development of $\mathrm{CD}$ has been found in a case-control study when the histopathology data of nearly 3,000 subjects with CD were linked to the Swedish Prescribed Drug Register (65). Based on these results, the authors concluded that antibiotics intake may increase the risk of suffering $\mathrm{CD}$ due to their profound impact on intestinal microbiota. However, this association was not found when the exposure to antibiotics during pregnancy and the development of $\mathrm{CD}$ in the offspring was investigated (66), although this last study was most probably underpowered for this purpose.

The host genotype has also been described to influence the composition of the human gut microbiota and modulate the phenotype (67). In the case of CD, a prospective study in a cohort of 164 infants with a family history of the disease reported associations between genetic risk (HLA-DQ) and alterations in the intestinal microbiota composition (68-70). The HLA-DQ2/DQ8 genotype and the type of feeding (maternal or formula) influenced in conjunction the intestinal colonization analyzed by fluorescence in situ hybridization (FISH), real time PCR and denaturing gradient gel electrophoresis (DGGE) techniques (68-70). In addition, specific decreases in Bifidobacterium spp. and B. longum and increases Staphylococcus spp. were associated with higher genetic risk of developing CD irrespective of milk-feeding type (69).

In conclusion a number of epidemiological studies indicate that several perinatal and early postnatal factors influence the intestinal microbiota composition and participate in conjunction to modulate $\mathrm{CD}$ risk. However, there are no large prospective studies revealing how the differences in the intestinal microbiota ac- 
quisition in early life might ultimately protect or contribute to the development of CD.

\section{3-Influence of intestinal microbiota in CD pathogenesis}

Several observational studies in children and adults with CD have shown alterations in the intestinal microbiota composition compared to control subjects (Table 1). Our studies using molecular quantitative methods, such as FISH and quantitative PCR, found reduced numbers of Bifidobacterium spp. and B. longum and increased numbers of Bacteroides spp. in stools and duodenal biopsies of CD patients untreated and treated with a GFD compared to control subjects (71, 72). Also enterobacteria and staphylococci numbers were higher in untreated $\mathrm{CD}$ patients than in controls, but these differences were almost restored in CD subjects on a long-term GFD (72). Likewise, other studies in children reported increased prevalence of Bacteroides vulgatus and Escherichia coli in CD biopsies before and after the GFD by temporal temperature gradient gel electrophoresis (TTGE) compared to controls (73) and lower numbers of Lactobacillus and Bifidobacterium and higher numbers of Bacteroides, Staphylococcus and enterobacteria in stools of children with CD compared to healthy controls (77). Other studies performed by DGGE of the microbiota of adults clustered the dominant microbial communities of healthy individuals together and separated from those of untreated CD patients (76). However, the above study reported an increased prevalence in Bifidobacterium bifidum in patients with active CD as opposed to the lower bifidobacteria numbers detected in CD patients in our studies (71, $72,77)$ or the absence of differences reported in another study (79). In Sweden, an early study with samples collected in 1985-1996 revealed that rod-shaped bacteria were frequently associated with the mucosa of CD patients; both in the active phase and treated with a GFD, as detected by scanning electron microscopy (SEM) (74). Later, these SEM analyses were complemented with $16 \mathrm{~S}$ rDNA sequencing to identify the bacterial communities detected in the samples of the Swedish epidemic (1985-1996) and in a new cohort of patients (2004-2007) (75). Only one CD biopsy collected during 2004-2007 contained rod-shaped bacteria in contrast to the frequency described in the samples of the Swedish 


\begin{tabular}{|c|c|c|c|c|c|c|c|c|c|c|c|}
\hline 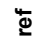 & $\bar{\kappa}$ & $\mathcal{N}$ & $\stackrel{2}{\sim}$ & $\stackrel{\text { N }}{\text { s }}$ & $\stackrel{2}{\stackrel{2}{2}}$ & $\stackrel{\circ}{R}$ & $\hat{\imath}$ & 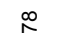 & $\stackrel{R}{R}$ & $\triangleright$ & $\bar{\infty}$ \\
\hline 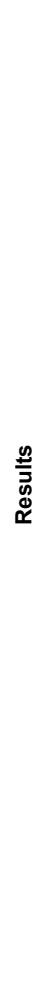 & 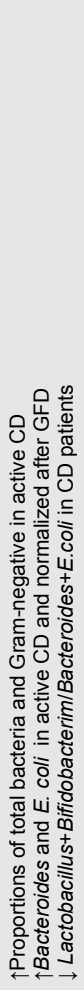 & 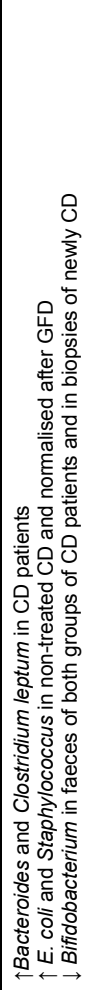 & 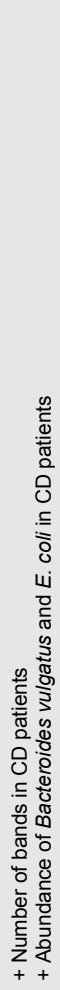 & 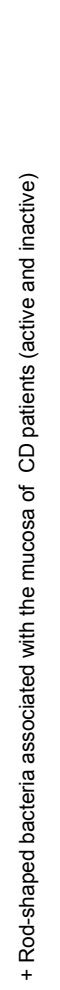 & 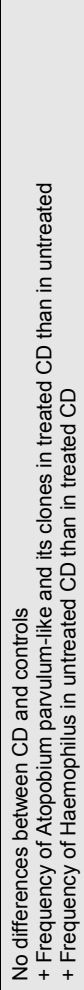 & 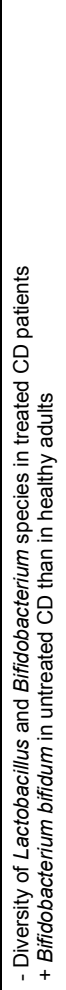 & 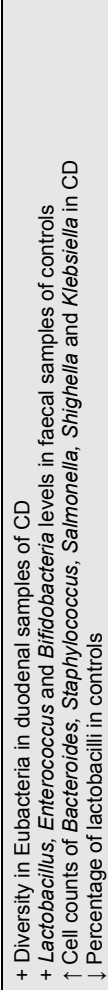 & 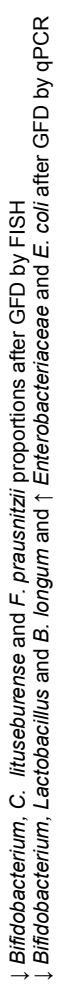 & 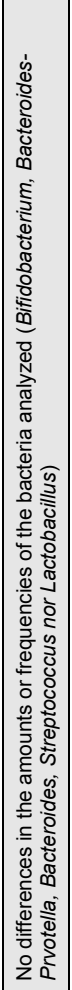 & 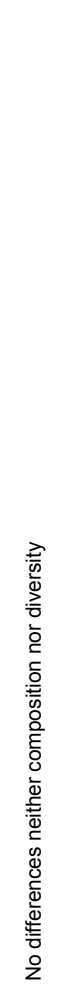 & 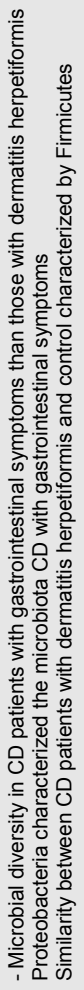 \\
\hline 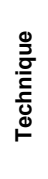 & 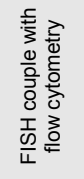 & 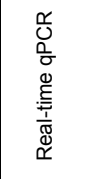 & $\begin{array}{l}\text { U. } \\
\stackrel{F}{E}\end{array}$ & $\sum_{\infty}$ & 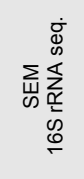 & $\begin{array}{l}\text { யु } \\
\text { ठ }\end{array}$ & 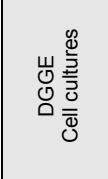 & 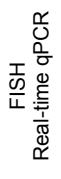 & 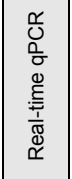 & $\begin{array}{l}\frac{\dot{\rho}}{0} \\
\frac{0}{0} \\
\frac{0}{0} \frac{0}{0} \\
\frac{0}{0} \\
\frac{\gamma}{0} \\
\frac{0}{0}\end{array}$ & 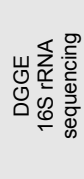 \\
\hline $\begin{array}{l}\frac{0}{0} \\
\frac{\tilde{E}^{\circ}}{\omega}\end{array}$ & 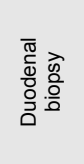 & 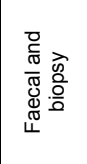 & 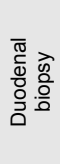 & $\begin{array}{l}\frac{\infty}{0} \\
\frac{0}{0} \\
\frac{0}{0} \\
\frac{0}{0} \\
\frac{\sigma}{0} \\
\frac{5}{9}\end{array}$ & 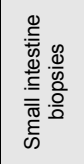 & 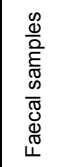 & 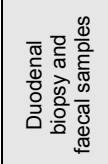 & 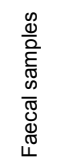 & 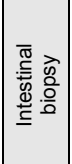 & 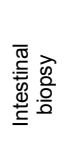 & 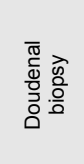 \\
\hline 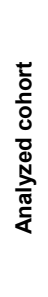 & 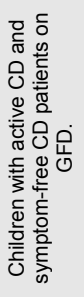 & 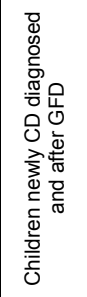 & 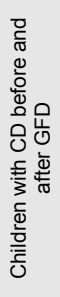 & 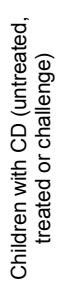 & 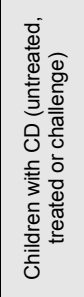 & 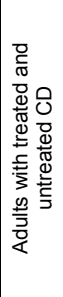 & 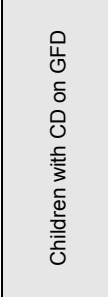 & 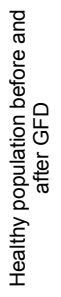 & 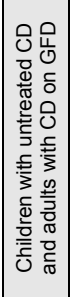 & 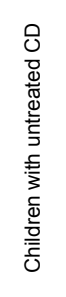 & 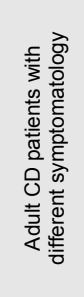 \\
\hline
\end{tabular}


epidemic, invalidating the initial theory that these bacteria were causative factors of the CD epidemic.

The analysis of metabolites derived from intestinal microbiota activity has also revealed significant differences between treated CD patients and healthy controls and suggests that there is a metabolic signature for the CD microbiome (76, 77). One recent study reported that CD patients with gastrointestinal symptoms had different microbiota composition when compared with controls and patients with dermatitis herpetiformis, suggesting that the microbiota may play a role in the manifestation of the disease (81). Dysbiosis of the gut microbiota has been also associated with persistent gastrointestinal symptoms in treated CD patients (82).

Nevertheless, we should also mention that other authors report no differences in mucosa-associated duodenal microbiome composition and diversity using a 16S-23S rRNA interspacer region-based profiling method (80). There is also lack of consensus and understanding of what constitutes a CD-promoting microbiota. A deeper characterization of the CD microbiota by isolating bacterial strains and analyzing their pathogenic features (83-85) showed that the $E$. coli clones belonging to virulent phylogenetic groups (B2 and D) isolated from untreated and treated CD patients presented a higher number of virulence genes encoding for P fimbriae, capsule K5 and hemolysin than those isolated from healthy controls (83). Also, the abundance of the species Bacteroides fragilis coding for metalloproteases was increased in both untreated and treated CD patients, and thus could presumably play a pathogenic role in CD (84). The isolation and identification of clones belonging to the genus Staphylococcus also revealed that the species S. epidermidis carrying the $m e c A$ gene (methicillin resistant gene) was more abundant in the CD patients (treated and untreated) than in controls (85).

The only treatment for CD is the adherence to a life-long GFD, which implies important dietary changes. These dietary differences also seem to cause changes in the intestinal microbiota composition and in the immune response to the altered microbiota in vitro. In healthy adults the GFD caused shifts in gut microbiota composition, characterized by reduced numbers of Bifidobacterium spp., $B$. 
longum and the Lactobacillus group, and increased numbers of Enterobacteriaceae and E. coli (78). This led to suggest that GFD should be considered as an environmental factor that may contribute to shaping the microbiota composition in treated CD patients (78).

\section{4-Mechanism of action of intestinal microbiota in CD}

The microbiota could contribute to the etiopathogenesis of $\mathrm{CD}$ by at least three mechanisms: by mediating host-microbe interactions that influence the immune function and the intestinal barrier; and providing proteolytic activities that influence the generation of immunogenic peptides from gluten (Figure 6).

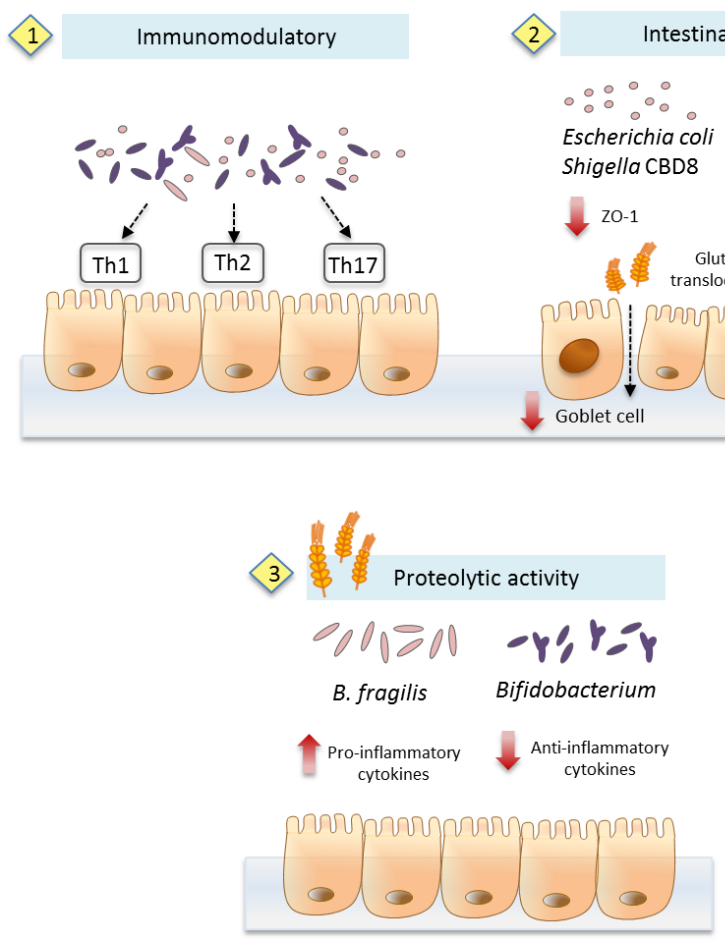

Figure 6: Schematic representation of the potential role of intestinal microbiota .The microbiota could contribute to the etiopathogenesis of $\mathrm{CD}$ by (1) the modulation of the immune function, (2) mediating host-microbe interactions which could influence the intestinal barrier, or (3) providing proteolytic activities that influence the generation of toxic and immunogenic peptides from gluten.

1- Gut bacteria present immunomodulatory properties that may exert a harmful or beneficial effect on the host's health. For instance, it has been described that a 
mixture of isolated bacteria from CD patients (Prevotella spp., Lachnoanaerobaculum umeaense and Actinomyces graevenitzii) induced IL-17A mRNA expression in ex vivo biopsies of intestinal mucosa of CD patients (86). It was hypothesized that those bacteria could modulate the IL-17 response by helping to break-down the gluten tolerance (86). On the other hand and as an opposite potential effect of the intestinal microbiota, B. longum CECT 7347 and B. bifidum CECT 7365 reduced the inflammatory response (IFN- $\gamma$ and TNF- $\alpha$ ) observed in peripheral blood mononuclear cells (PBMCs) exposed to faeces of CD patients (87).

2- Gut bacteria can also strengthen or damage the intestinal integrity. For instance, CD-triggers (gliadin and IFN- $\gamma$ ) decreased the goblet cell numbers in intestinal loops of inbred Wistar-AVN rats, and the presence of enterobacteria isolated from CD patients (E. coli CBL2 and Shigella CBD8) aggravated this effect (88). By contrast, B. bifidum CECT 7365 increased the number of goblet cells and the production of inhibitors of metalloproteinases, and also reduced gliadin translocation to the lamina propria, which could contribute to gut mucosal protection (88). Changes in tight junctions were measured and meanwhile the exposure to B. bifidum CECT 7365 together with gliadin and IFN- $\gamma$ increased ZO-1 levels, the addition of $E$. coli CBL2 reduced ZO-1 levels (88). Other probiotic bacteria such as $L$. rhamnosus $\mathrm{GG}$ have shown to contribute in vitro to the maintenance of normal intestinal permeability in Caco-2 cells exposed to gliadin (89).

3- Gut microbiota provide proteolytic activities to break-down gluten peptides. As described above, some gluten peptides resist gastrointestinal digestion and disturb the intestinal homeostasis (90). This may facilitate the access of gluten to the lamina propria and their interaction with immune cells. In vitro studies indicate that the proteolytic activity of the intestinal microbiota may modify gluten peptides differently, increasing or reducing their toxicity. B. fragilis strains isolated from CD patients when incubated with gliadin generated immunogenic peptides that preserved or increased the production of TNF- $\alpha$, and showed increased ability to permeate through Caco-2 cells (91). Meanwhile, different Bifidobacterium spp. and especially B. longum CECT 7347 attenuated the pro-inflammatory response of gliadin-derived peptides after the in vitro digestion (84). 


\section{II - OBJETIVES}

The general objective of this Doctoral Thesis was to study the influence of the intestinal microbiota and specific components on $\mathrm{CD}$ pathogenesis and risk.

In order to achieve this main objective, the following specific objectives were proposed:

1. To evaluate the in vitro effects of different bifidobacteria and enterobacteria identified in CD patients on the regulation of the production of proinflammatory markers and the proteomic response to gliadins in cell cultures.

2. To evaluate the in vivo effect of the administration of a strain of the genus $B i$ fidobacterium in an animal model of gliadin induced enteropathy.

3. To investigate the potential role of environmental and genetic factors on breast-milk composition of healthy mothers and mothers with $\mathrm{CD}$, and on the intestinal colonization process in a cohort of healthy children at family risk of developing $\mathrm{CD}$.

4. To evaluate the effect of the administration of a Bifidobacterium strain on the intestinal ecosystem and immunological markers in children newly diagnosed with CD. 


\section{III - RESULTS AND DISCUSSION \\ Chapter 1}

- Modulation of phenotypic and functional maturation of dendritic cells by intestinal bacteria and gliadin: relevance for celiac disease.

- Influence of Bifidobacterium longum CECT 7347 and gliadin peptides on intestinal epithelial cell proteome 


\section{Modulation of phenotypic and functional maturation of dendritic cells by intestinal bacteria and gliadin: relevance for celiac disease}

G. De Palma ${ }^{1}$, J. Kamanova ${ }^{2}$, J. Cinova ${ }^{2}$, J., M. Olivares ${ }^{1}$, H. Drasarova ${ }^{2}$ L. Tuckova $^{2}$ and Y. Sanz

J Leukoc Biol (2012) 92, 1043-1054.

\footnotetext{
${ }^{1}$ Microbial Ecology and Nutrition Research Group, Institute of Agrochemistry and Food Technology, National Research Council (IATA-CSIC), Valencia, Spain; ${ }^{2}$ Institute of Microbiology, Dept Immunology, Academy of Sciences of the Czech Republic, Prague.
} 


\section{ABSTRACT}

Dendritic cell (DC) maturation and functions are influenced by microbial and environmental stimuli, which could contribute to immune dysfunction. Here, we have investigated the role of enterobacteria (E. coli CBL2 and Shigella CBD8) isolated from celiac disease (CD) patients, bifidobacteria (B.longum CECT 7347 and B. bifidum CECT 7365) and gliadins on phenotypic and functional features of monocyte-derived dendritic cells (MDDCs) and in co-culture with Caco-2 cells. The ultimate goal of our study is to understand the roles played by specific components of the gut microbiota in CD. Enterobacteria induced marked alterations in MDDCs morphology, inducing podosome dissolution and dendrites, and activated MDDC adhesion and spreading. Enterobacteria also induced inflammatory cytokine production (IFN- $\gamma$, TNF-a, IL-12), partially resembling the gliadin-induced Th1-type cytokine profile. B. longum CECT 7347 and B. bifidum CECT 7365 induced minor MDDCs morphological changes, and activated adhesion and spreading and inflammatory cytokine production to a lesser extent compared to enterobacteria. B. longum CECT 7347 also induced lower CD86 and CD40 expression on MDDCs than the two enterobacteria. The aforementioned bifidobacterial strain also reduced gliadin-induced IFN- $\boldsymbol{\gamma}$ production and increased IL-10 secretion when both stimuli were combined. Similar trends were detected for MDDCs co-cultured with Caco-2 cells. B. longum CECT 7347 reversed the gliadin-reduced ZO-1 expression in Caco-2 cells. Thus, our results suggest that specific components of the gut microbiota may influence phenotypic and functional maturation of DCs differently, and their interactions with epithelial cells. This could ultimately define the role of DCs in celiac disease progression.

Keywords: dendritic cells, celiac disease, bifidobacteria, enterobacteria, gliadin 


\section{INTRODUCTION}

Celiac disease (CD) is a chronic inflammatory disorder of the small intestine characterized by an aberrant immune response to gluten proteins (gliadin) in genetically predisposed individuals. The disease is caused by the interaction between genetic and environmental factors (1). CD shows a strong association with Human Leukocyte Antigen (HLA)DQ genes, with most patients carrying a variant of DQ2 or DQ8. The association between HLA and $\mathrm{CD}$ is stronger than for other HLAlinked diseases, contributing 53\% to disease risk (1). Dietary gluten is the key environmental factor involved in the disease. Gluten proteins are rich in proline and glutamine residues, making them resistant to proteolytic degradation within the gastrointestinal tract and good substrates for the enzyme tissue transglutaminase. This enzyme deamidates glutamine into negatively charged glutamic acid, increasing the affinity of gluten peptides for HLADQ2 and HLA-DQ8 molecules of antigen presenting cells (APCs) $(2,3)$. Both innate and adaptive immune responses contribute to triggering mucosal inflammation in the patients (3). CD is described as a Th-1 cell mediated disorder because Th1type cytokines are overproduced in intestinal CD mucosa (4). Moreover, Th17 cells contribute to the ongoing inflammation in CD (5). IL-21, which is a Th 17 cell-derived cytokine promoting Th17 cell development, is also overproduced in CD. This cytokine is also associated with the local production of IFN- $\gamma$ by CD4+ Th1 cells (6). More recently, the presence of gluten-specific IL17Aproducing cells secreting IL-21 and high levels of IL-22 and regulated by TGF $\beta$ through a RORC- and IRF-4-dependent mechanism had been reported in duodenal biopsies of $\mathrm{CD}$ patients (7). In active CD patients, gut permeability is also increased and related to dysfunction of the intercellular junction between epithelial cells due to reorganization and changes in expression of tight junction (TJ) related proteins (1).

This pathological process leads to typical histological characteristics of $\mathrm{CD}$, including small intestinal mucosal villous atrophy, crypts hyperplasia, abnormal surface epithelium and increased infiltration of the lamina propria and intraepithelial compartments with inflammatory cells (8). Currently, the only way to normalize the typical clinical manifestations of the disease is to adhere to a life-long gluten-free diet, although some patients continue having gastrointestinal symptoms and tissue lesions and, especially, in refractory $\mathrm{CD}$ the activation of intraepithelial lymphocytes is not controllable with this diet and this situation can turn into $\mathrm{T}$ cell lymphoma (3).

Dendritic cells (DCs) are professional antigen presenting cells (APCs), which play a key role in intestinal 
immune homeostasis, maintaining tolerance towards commensal microbes and generating appropriate immune responses against pathogens and antigens (9). Intestinal DCs are found in close association with epithelial cells and concentrated at sites of antigen entry (10). There are several possible routes by which DCs pick up antigens. One is after the transport of antigens to the lamina propria by transcytosis through $\mathrm{M}$ cells present in the follicle-associated epithelium of the Peyer's Patches. Another is by direct sampling of the antigens from the intestinal lumen by DCs, which can form TJ-like structures with intestinal epithelial cells and project dendrites through the epithelial cell layer and into the lumen $(10,11)$. Untreated celiac disease mucosa harbors elevated numbers of activated DCs (12) and has recently been reported that those DCs are in fact newly recruited monocytes expressing CD14+CD11c+ whose accumulation is specific to $\mathrm{CD}$ and precedes changes in mucosal architecture (13). Moreover, in vitro studies reported that gliadins are able to induce phenotypic and functional maturation of DCs (14) as well as migration (15).

There have also been recent suggestions of the potential role of bacteria in the pathogenesis of $\mathrm{CD}$ as patients have an unbalanced gut microbiota composition in comparison with controls (16-19). Our previous research has shown that immune responses of monocytes to gliadins and IFN- $\gamma$ can be regulated by specific intestinal bacteria, which could contribute to the Th1-type cytokine profile characteristic of the disease differently (20). Moreover, our studies report that different intestinal bacteria distinctly affect the permeability of the intestinal mucosal layer and the architecture of the epithelium layer in rat intestinal loops exposed to gliadin and IFN- $\gamma$ (21).

The aim of this study was to investigate the interactions of monocyte-derived DCs (MDDCs) with different intestinal bacteria (commensal and potential pathogens) in combination, or not, with gliadins, and co-cultured, or not, with Caco-2 cells. The effect on MDDCs morphology, adhesion and spreading, cytokine production and cell surface marker expression were determined. The ultimate purpose of our research is to gain a better understanding of the possible contribution of different intestinal bacteria to $\mathrm{CD}$, based on their effects on the immune response to the main celiac disease trigger (gliadin).

\section{MATERIALS AND METHODS}

\section{Gliadin fragments}

Peptic fragments of gliadin (Sigma, St Louis, MO) were prepared using pepsin agarose gel (ICN, Biomedicals, Ohio) as previously described (22). Protein concentrations were 
measured by Bicinchoninic acid assay (BCA Protein assay, Pierce, Rockford, IL).

\section{Bacterial strains and culture conditions}

The following strains were used in the study: B. longum CECT 7347 (IATA-ES1), B. bifidum CECT 7365 (IATA-ES2), Shigella CBD8 and E. coli CBL2. B. longum CECT 7347 and B. bifidum CECT 7365 were previously isolated from healthy human feces and identified, as previously described (23-24). E. coli CBL2 was isolated from symptomfree CD patients and Shigella CBD8 was isolated from untreated $C D$ patients, as previously described (25). Bifidobacteria were grown routinely in de Man, Rogosa and Sharpe (MRS) broth (Scharlau Chemie SA, Barcelona, Spain) with 0.05\% cysteine (MRS-C) and incubated at $37^{\circ} \mathrm{C}$ under anaerobic conditions (AnaeroGen; Oxoid, Basingstoke, UK) for $22 \mathrm{~h}$. Enterobacteria were routinely grown in Violet Red Bile Dextrose (VRBD) agar or Brain Heart broth (Scharlau Chemie SA, Barcelona, Spain) at $37^{\circ} \mathrm{C}$ for $24 \mathrm{~h}$ under aerobic conditions.

Cells were harvested by centrifugation $(6,000 \mathrm{~g}$ for $15 \mathrm{~min})$ at stationary growth phase, washed twice in phosphate buffered saline (PBS, $130 \mathrm{mM}$ sodium chloride, 10 $\mathrm{mM}$ sodium phosphate, $\mathrm{pH}$ 7.4), and re-suspended in PBS containing $20 \%$ glycerol. Aliquots of these suspensions were frozen in liquid nitrogen and stored at $-80^{\circ} \mathrm{C}$ until used. The number of live cells after storage was determined by colonyforming unit (CFU) counting on MRS-C or VRBD agar after $48 \mathrm{~h}$ incubation in optimal conditions. For all strains tested, more than $90 \%$ cells were alive upon thawing and no significant differences were found during storage time (4 months). One fresh aliquot was thawed for every new experiment to avoid variability in $\mathrm{CFU} / \mathrm{ml}$ between experiments.

\section{Monocyte-derived DC (MDDC) isolation and stimulation}

MDDCs were generated as previously described (14). Briefly, peripheral blood mononuclear cells (PBMCs) were isolated from buffy coats of healthy donors (provided by the Department of Blood Transfusion at Thomayer's Hospital, Prague, Czech Republic) by centrifugation over a Ficoll density gradient (Amersham Biosciences, Piscataway, NJ) and adjusted to $3 \times 10^{6}$ cells $/ \mathrm{ml}$ in $75-$ $\mathrm{cm}^{2}$ plastic culture flasks (Corning, Costar, Madrid, Spain) in RPMI 1640 medium (BioWhittaker, Lonza, Belgium), supplemented with $10 \%$ fetal bovine serum (FBS) (BioWhittaker, Lonza, Belgium), $2 \mathrm{mM}$ L-glutamine, $100 \mu \mathrm{g} / \mathrm{ml}$ streptomycin and 100 $\mathrm{U} / \mathrm{ml}$ penicillin (Sigma, Madrid, Spain). After $2 \mathrm{~h}$, the non-adherent fraction of cells was washed away thoroughly and the isolated adherent monocytes were incubated with $500 \mathrm{U} / \mathrm{ml}$ GM-CSF (Immunotools, 
Friesoythe, Germany) and 20 $\mathrm{ng} / \mathrm{ml}$ recombinant human IL-4 (Immunotools, Friesoythe, Germany) in RPMI 1640 medium (BioWhittaker, Lonza, Belgium), supplemented with $10 \%$ fetal bovine serum (FBS) (BioWhittaker, Lonza, Belgium), $2 \mathrm{mM}$ L-glutamine, 100 $\mu \mathrm{g} / \mathrm{ml}$ streptomycin and $100 \mathrm{U} / \mathrm{ml}$ penicillin (Sigma, Madrid, Spain) at $37^{\circ} \mathrm{C}$ under $5 \% \mathrm{CO}_{2}$. After 5-6 days, the generated MDDCs were harvested and seeded at $1 \mathrm{x}$ $10^{6} \mathrm{cell} / \mathrm{s} / \mathrm{ml}$ in 24-well flat-bottom polystyrene microtiter plates (Corning, Costar, Madrid, Spain). Then, cells were incubated for 24 hours with the following stimuli: gliadin $(100 \mu \mathrm{g} / \mathrm{ml})$ or bacterial cell suspensions $\left(10^{6} \mathrm{CFU} / \mathrm{ml}\right)$ alone or in combination with gliadin. Purified lipopolysaccharide (LPS) from Salmonella enterica subsp. enterica serotype Typhimurium (Sigma, St. Louis, MO) was used at a concentration of $1 \mu \mathrm{g} / \mathrm{ml}$ as a positive control. Non-stimulated PBMCs were also evaluated as controls of basal cytokine production. All reagents were tested by the E-toxate test for LPS (Sigma) and shown to be below the limit of detection $(2 \mathrm{pg} / \mathrm{ml})$. Cells were used for the experiments and cell culture supernatants were collected by centrifugation, fractionated in aliquots, and stored at $-20^{\circ} \mathrm{C}$ until cytokines were analyzed. Every stimulus was assayed in duplicate in six different experiments.

\section{Determination of cell adhesion and spreading}

Impedance measurements using xCelligence system in E-plates (Roche, Mannheim, Germany) were used to determine MDDCs adhesion and spreading. E-plates were coated with fibronectin $(20 \mu \mathrm{g} / \mathrm{ml}$, Roche) in PBS for $1 \mathrm{~h}$ at room temperature, washed with PBS and background was determined in $80 \mu \mathrm{l}$ of medium using Real-Time Cell Analyzer (RTCA) station. Subsequently, 100 1 of the MDDC suspension $\left(1 \times 10^{5}\right.$ cells/well), and $20 \mu \mathrm{l}$ of stimulus (20 $\mu \mathrm{g}$ of gliadin, $10^{5} \mathrm{CFU}$ bacterial cells, $0.2 \mu \mathrm{g}$ of LPS, $5 \mu \mathrm{g}$ of poly I:C or a cocktail of cytokines) were added. Cells in E-plates were placed in the RTCA station for $24 \mathrm{~h}$ cultivation at $37^{\circ} \mathrm{C}$ in a $5 \% \mathrm{CO}_{2}$ atmosphere. Impedance was measured every 5 min for an initial $5 \mathrm{~h}$ period of cultivation, and every $15 \mathrm{~min}$ for the remaining period of $19 \mathrm{~h}$. Impedance is a measure of the relative change in the electrical impedance at a certain frequency $\left(f_{\mathrm{n}}\right)$ and was represented by the cell index $(\mathrm{CI})$ values $\left(\left(\mathrm{R}_{\mathrm{i}}-\mathrm{R}_{0}\right)\right.$ $(\mathrm{Ohm}) / 15(\mathrm{Ohm}) ; \mathrm{R}_{0}$ : background resistance, $R_{i}$ : individual time point resistance). Increase in cell spreading and adhesiveness leads to an increase in impedance, as cells attached on the electrode sensor surfaces act as insulators and, vice versa, cell detachment or rounding up leads to decrease in impedance. All experiments were performed in triplicate. 
Fluorescence microscopy of the actin cytoskeleton

For fluorescence microscopy of the DC cytoskeleton, coverslips were coated with fibronectin $(20 \mu \mathrm{g} /$ $\mathrm{ml}$, Roche) in PBS for $1 \mathrm{~h}$ at room temperature. Then, $2 \times 10^{5}$ MDDCs were seeded on fibronectin-coated coverslips and treated with the desired agents for $24 \mathrm{~h}$ at $37^{\circ} \mathrm{C}$ in a $5 \% \mathrm{CO}_{2}$ atmosphere before being fixed with $4 \%$ paraformaldehyde in PBS (20 min, RT). Cells were permeabilized with $0.1 \%$ Triton $\mathrm{X}-100$ in PBS (5 min), and incubated with TRITC-conjugated phalloidin $(0.5 \mu \mathrm{g} / \mathrm{ml}$, Sigma) in $2 \%$ BSA-PBS for $30 \mathrm{~min}$ to detect $\mathrm{F}$-actin. Images were taken using an Olympus CellR fluorescence microscope.

Flow cytometry analysis of cellsurface markers

MDDCs were stained with the following monoclonal antibodies at optimal concentrations: CD11callophycocyanin, CD14-APC-alexa fluor 750, CD83-PE (CALTAG), CD86-PE (Immunotech), CD40FITC and HLA-DR-FITC (Pharmingen). MDDCs from migration assays were stained for surface expression of CCR7 with CCR7-PE Ab (R\&D System, Minneapolis). Cells were also incubated with irrelevant antibodies at the same concentration and isotype. After two washing steps, the cells were resuspended in icecold PBS with $0.1 \% \mathrm{NaN}_{3}$ or fixed with $2 \%$ paraformaldehyde, and surface markers were analyzed by flow cytometry (BD FACS Vantage SE, San Jose, California). Staining with Hoechst (Invitrogen, Gibco) was performed to assess cell viability. Data were analyzed using CellQuest software (BD Bioscience).

\section{Enzyme linked immunosorbent assay (ELISA)}

Cytokine concentrations of cell supernatants were measured by enzyme-linked immunosorbent assay (ELISA) kits according to the manufacturer's instructions. The cytokines analyzed were IL-10, IL12, TNF-a, IFN- $\gamma$ (DuoSet Kit, R\&D System, Minneapolis), IL-15 (eBioscience, San Diego, CA, USA) and IL-21 (Biolegend, San Diego, CA, USA).

\section{Gene expression by Reverse- Transcription (RT) PCR}

The mRNA expression of the TJ proteins $\mathrm{ZO}-1$ and occludin was analyzed by RT-PCR in Caco-2 and in MDDCs cultured alone or with Caco-2 cells as described below. Total RNA extraction was conducted with RNeasy mini kit (Qiagen, Madrid, Spain) according to the manufacturer's instructions. Total RNA was reversely transcribed to cDNA with ImProm-II Reverse Transcription System (Promega, Madison, Wisconsin, USA) according to the manufacturer's instructions. cDNA was then amplified with LightCycler $^{\circledR} 480$ SYBR Green I Master mix (Roche, 
Barcelona, Spain) in a LightCycler ${ }^{\circledR}$ 480 Real-Time PCR System (Roche, Barcelona, Spain) using the primers shown in Table 1. The primers for occludin were designed using the Pubmed Primer Blast designing tool and the corresponding accession number is NM 002538.2. Data were normalized referring to glyceraldehyde-3-phosphate dehydrogenase (GAPDH) expression and analyzed with the $\Delta \Delta \mathrm{C}_{\mathrm{t}}$ method.

\section{Caco- 2 cell culture and co-cultures}

The human enterocyte-like cell line Caco-2 was obtained from European Cell Culture collection (ECACC, 86010202, Salisbury, UK) and cultured in Dulbecco's Modified Eagle Medium (DMEM) Glutamax, containing $10 \%$ of inactivated $\left(56^{\circ}\right.$ C for $30 \mathrm{~min}$ ) fetal bovine serum (FBS) (Gibco, Barcelona, Spain), 100 $\mu \mathrm{g} / \mathrm{ml}$ streptomycin and $100 \mathrm{U} / \mathrm{ml}$ penicillin (Sigma), 1\% concentrated nonessential amino acid solution (Sigma) and 1\% HEPES solution (Lonza, Madrid, Spain). For cocultures, $3.5 \times 10^{5}$ Caco- 2 cells were seeded on the apical compartment of $6.5 \mathrm{~mm}$ Transwell ${ }^{\bullet}$ polycarbonate inserts (24 wells, $3 \mu \mathrm{m}$ membrane pore size) (Corning, Costar, Madrid, Spain) and cultivated for $10 \pm 2$ days. During cell growth and differentiation, the medium in both compartments was replaced three times a week. Confluence was controlled by measurement of transepithelial electrical resistance (TEER; Millicell ERS Ohmmeter, Millipore, Madrid, Spain) and by visually detecting cell layer integrity under the microscope. Co-culture experiments of differentiated Caco-2 cells and MDDCs were performed in duplicate in five independent experiments. On day 10-12, MDDCs were added (1 x $10^{6}$ cells per well) in the basolateral compartment of the transwell, while Caco-2 cells were previously cultured in the apical compartment. The stimuli were added to the apical compartment representing the intestinal epithelium. Controls of basal cytokine production by non-stimulated cells were run simultaneously in each assay. The following stimuli were added:

Table 1. Primers used in the study to analyze gene expression by RT-PCR.

\begin{tabular}{ccc}
\hline Target gene & \multicolumn{1}{c}{ Sequence (5'-3') } & References \\
\hline ZO-1 & ATCCCAAATAAGAACAGAGC & $(11)$ \\
& GGCGTTACATCTAATAAAGC & \\
\hline Occludin & GGTGTGGGAAGCAGGACCGC & This study \\
& GGAGAGGTGGACGCGGGAGT & \\
\hline GAPDH & CCACCCATGGCAAATTCCATGGCA & $(27)$ \\
& TCTAGACGGCAGGTCAGGTCCACC & \\
\hline
\end{tabular}


gliadin $(100 \mu \mathrm{g} / \mathrm{ml}), \quad$ bacterial cell suspension $\left(10^{6} \mathrm{CFU} / \mathrm{ml}\right)$ or bacterial cell suspension $\left(10^{6} \mathrm{CFU} /\right.$ $\mathrm{ml})$ plus gliadin $(100 \mu \mathrm{gg} / \mathrm{ml})$. Purified lipopolysaccharide (LPS) from Salmonella enterica subsp. enterica serotype Typhimurium (Sigma, St. Louis, MO) was used at a concentration of $1 \mu \mathrm{g} / \mathrm{ml}$ as positive control. Supernatants were collected after 24 hours and were stored at $-20^{\circ} \mathrm{C}$ until cytokines were analyzed. Cells were also recovered and immediately kept at $-80^{\circ} \mathrm{C}$ for further RNA extraction and gene expression analyses.

\section{Statistical analyses}

Statistical analyses were performed using SPSS version 17.0 software (SPSS Inc, Chicago, IL, USA). The Levene test was run in order to establish the homogeneity of variances and data distribution. Data distribution was not normal and variances were not homogeneous; therefore, Mann-Whitney U test was used to assess the effect of each variable. Data are expressed as medians and quartiles. Significant differences were established at a $P$ value less than 0.05 .

\section{RESULTS}

\section{MDDC morphologic changes after interaction with intestinal bacteria} Actin cytoskeleton is known to be crucially involved in cell adhesion and spreading, which in turn influence DC activation and maturation. Therefore, we evaluated the possible rearrangements of the actin cytoskeleton of MDDCs after stimulation with different intestinal bacteria (commensal and pathogens). As previously reported and shown in Figure 1, non-stimulated immature MDDCs exhibited the classical podosome structures, characterized by the actin-dense core which is surrounded by ring of cytoskeletal proteins $(28,29)$. On the contrary, gliadin fragments caused podosome dissolution and cytoskeletal remodeling as shown in Figure 1. Interestingly, MDDCs stimulated with B. bifidum CECT 7365 for $24 \mathrm{~h}$ were morphologically similar to nonstimulated cells. In a cell fraction stimulated with $B$. longum CECT 7347 for $24 \mathrm{~h}$, podosome dissolution was observed, although a substantial portion of B. longum-stimulated cells still exhibited morphology similar to unstimulated cells or cells stimulated with B. bifidum CECT 7365. In contrast, MDDCs stimulated with Shigella CBD8 and E. coli CBL2 presented complete loss of podosomes and a strong amount of actin-rich protrusions, as observed for LPStreated cells (Figure 1). MDDCs treated with LPS $(1 \mu \mathrm{g} / \mathrm{ml})$ for $24 \mathrm{~h}$ also displayed an evident induction of actin-rich protrusions (dendrites) and complete podosome dissolution. However, the enterobacteria-treated cells appeared more spread with irregular shapes, comparing to more cell-rounded morphology induced 

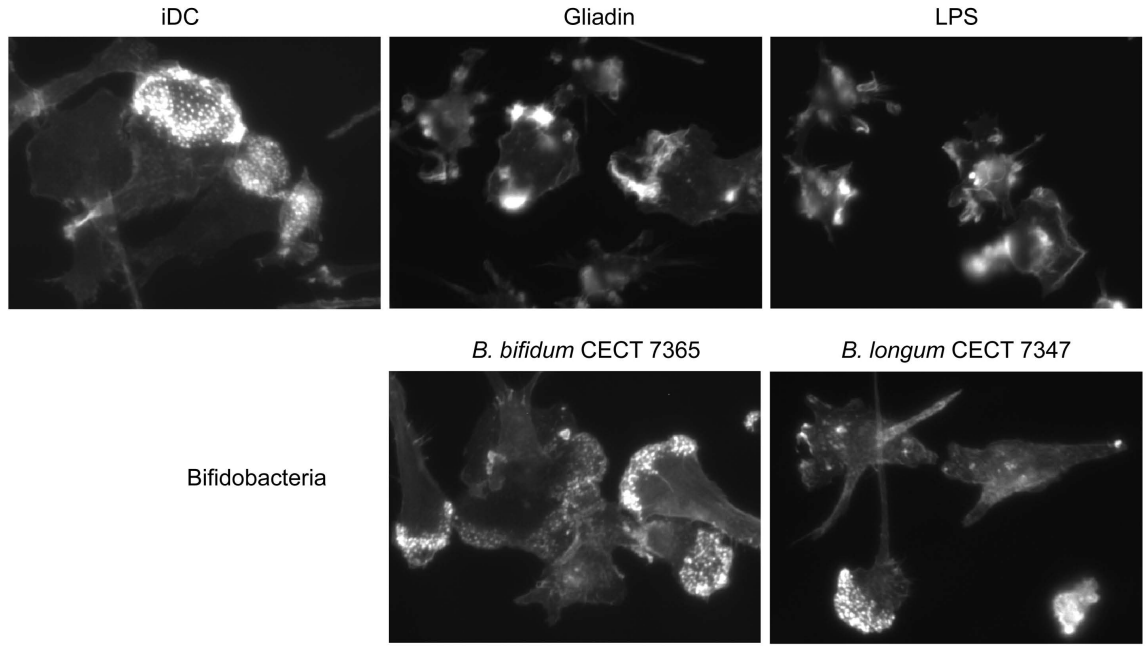

B. longum CECT 7347
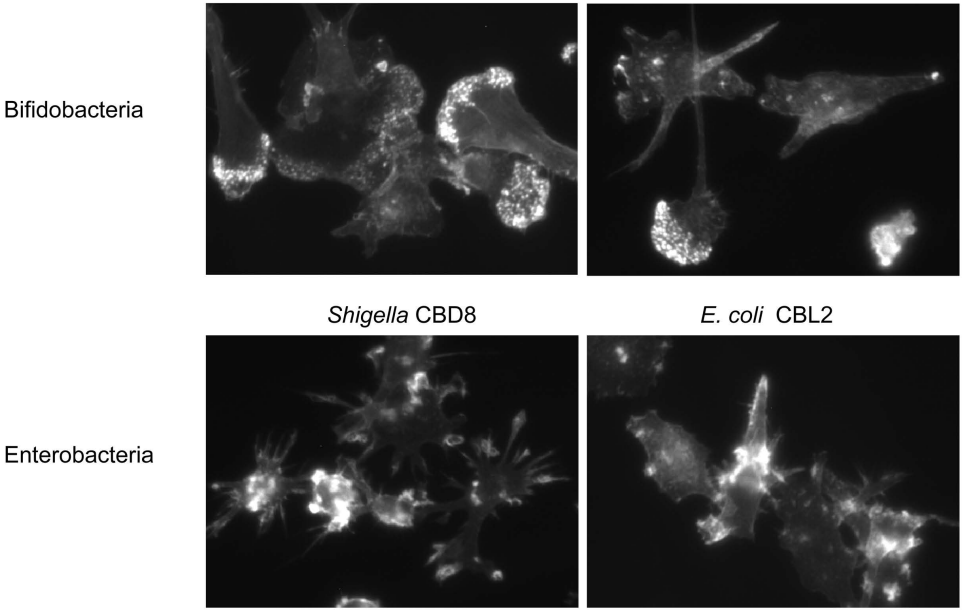

E. coli CBL2

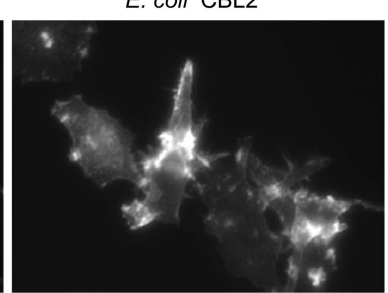

Figure 1. Morphology and cytoskeletal remodeling in MDDCs plated on fibronectin-coated coverslips and under the effect of different stimuli: Immature MDDCs (iDC), gliadin (100 $\mu \mathrm{g} / \mathrm{ml})$, LPS $(1 \mu \mathrm{g} / \mathrm{ml})$, B. bifidum CECT 7365 (10 $\left.{ }^{6} \mathrm{CFU}\right)$, B. longum CECT 7347 (10 $\left.0^{6} \mathrm{CFU}\right)$, Shigella CBD8 $\left(10^{6} \mathrm{CFU}\right)$ and E. coli CBL2 $\left(10^{6} \mathrm{CFU}\right)$ for $24 \mathrm{~h}$.

by LPS. The observed changes seem to be in line with those observed with the dynamic monitoring of cell adhesion and spreading described below. The enterobacteria seemed to induce cytoskeletal remodeling and mediate the morphological transition from immature DC to mature DC, whereas activation of MDDCs by bifidobacteria was weaker.

\section{MDDC adhesion and spreading influenced by intestinal bacteria} DC activation and maturation affects cell adhesion and spreading $(30,31)$. Therefore, to characterize the immunoregulatory potential of different intestinal bacteria (commensal and potential pathogens), we further sought to non-invasively determine their impact on MDDC adhesion and 
spreading. To achieve this aim, impedance measurements were employed using the $\mathrm{xCelligence}$ system in fibronectin-coated E-plates. Indeed, the interaction of cells with fibronectin-coated microelectrodes in the E-plate generates an impedance change reflected in the CI that is proportional to the number of adhered cells and overall morphology and adhesion quality of the cells (31). The stimulation of DCs with maturation-inducing agents (e.g. a cocktail of pro-inflammatory cytokines, LPS, gliadins or poly $\mathrm{I}: \mathrm{C})$ resulted in a rapid increase in CI values corresponding to elevated cell adhesion and spreading when compared to non-stimulated cells. Within $24 \mathrm{~h}$, however, the CI of stimulated DC dropped below the CI of control cells due to progressing maturation and cell rounding up (representative example shown in Figure 2A). It should be noted that the absolute CI values differ among individual donors (e.g. for iDC ranges from 0.5.to 1.2). However, the pattern of induced changes in response to tested components was very similar across various donors (see representative experiments Fig. 2, B and C). Importantly, addition of bifidobacteria ( $B$. longum CECT 7347 and B. bifidum CECT 7365) led to a slight increase in cell adhesion (Figure 2B), while exposure to enterobacteria (E. coli CBL2 and Shigella CBD8) yielded greater activation of cell adhesion and spreading (Figure 2C). Although the
CI curves of enterobacteria exhibited a maximum which was followed by CI decrease, they did not generally drop below the CI of control cells within $24 \mathrm{~h}$ (6 experiments out of 9). Overall, the results indicate stronger activation of MDDCs by enterobacteria than by bifidobacteria consistently with data demonstrated in Figure 1. When gliadins were added to bifidobacteria, a slight increase in MDDC adhesion and spreading was observed, compared to stimulation with bifidobacteria alone. In contrast, the addition of gliadins to enterobacteria did not significantly change their response curves (data not shown).

\section{MDDCs cytokine production in response to intestinal bacteria and gliadin}

Cytokine production by MDDCs after stimulation with cell suspensions of different bacterial strains is shown in Figure 3. All the stimuli applied induced a higher production of IL-10, IL-12 and TNF- $\boldsymbol{a}(P \leq$ 0.001-0.001) in comparison with control cells. However, only Gramnegative bacteria (E. coli CBL2 and Shigella CBD8) and LPS induced a greater secretion of IFN- $\boldsymbol{\gamma}$ than non-stimulated cells $(P \leq 0.001$ 0.028). Gliadin also increased IFN- $\boldsymbol{\gamma}$ secretion to a greater extent than $B$. bifidum CECT 7365 ( $\mathrm{P}=0.025)$. When comparing different bacterial strains, the Gram-negative bacteria Shigella CBD8 induced a greater secretion of IL-12, TNF-a and 

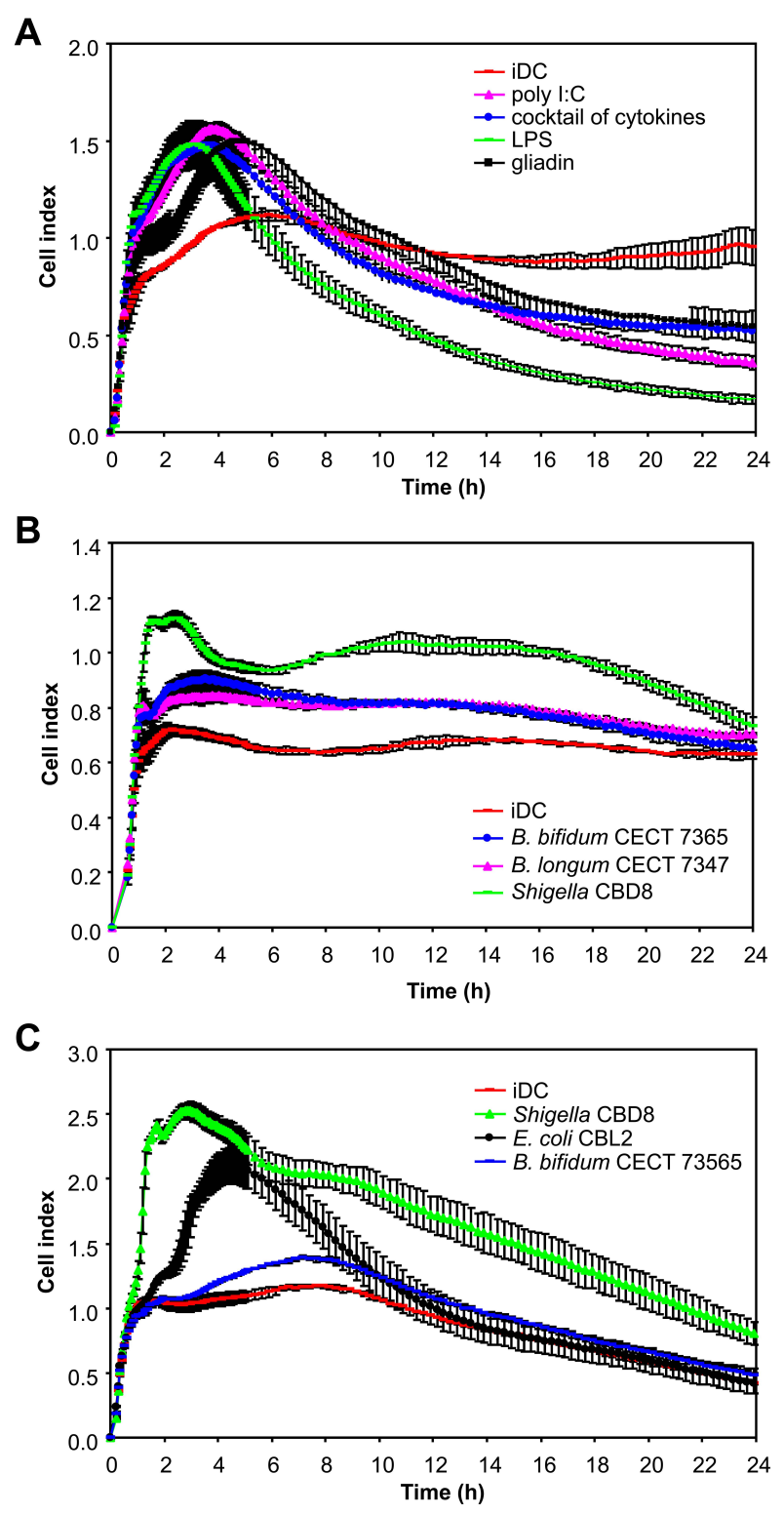

Figure 2. Representative data are shown for the different attachment and spreading of MDDCs (from 3 different donors) under different stimuli, in a $24 \mathrm{~h}$ time-course experiment. The attachment and spreading of MDDCs is expressed as CI/Time (see Materials and Methods). iDCs form donor A were exposed to gliadin, LPS; polyI:C and cocktail of cytokines; from donor B to bifidobacteria and from C to enterobacteria; Shigella CBD8 was used with B and C cells for comparison. 

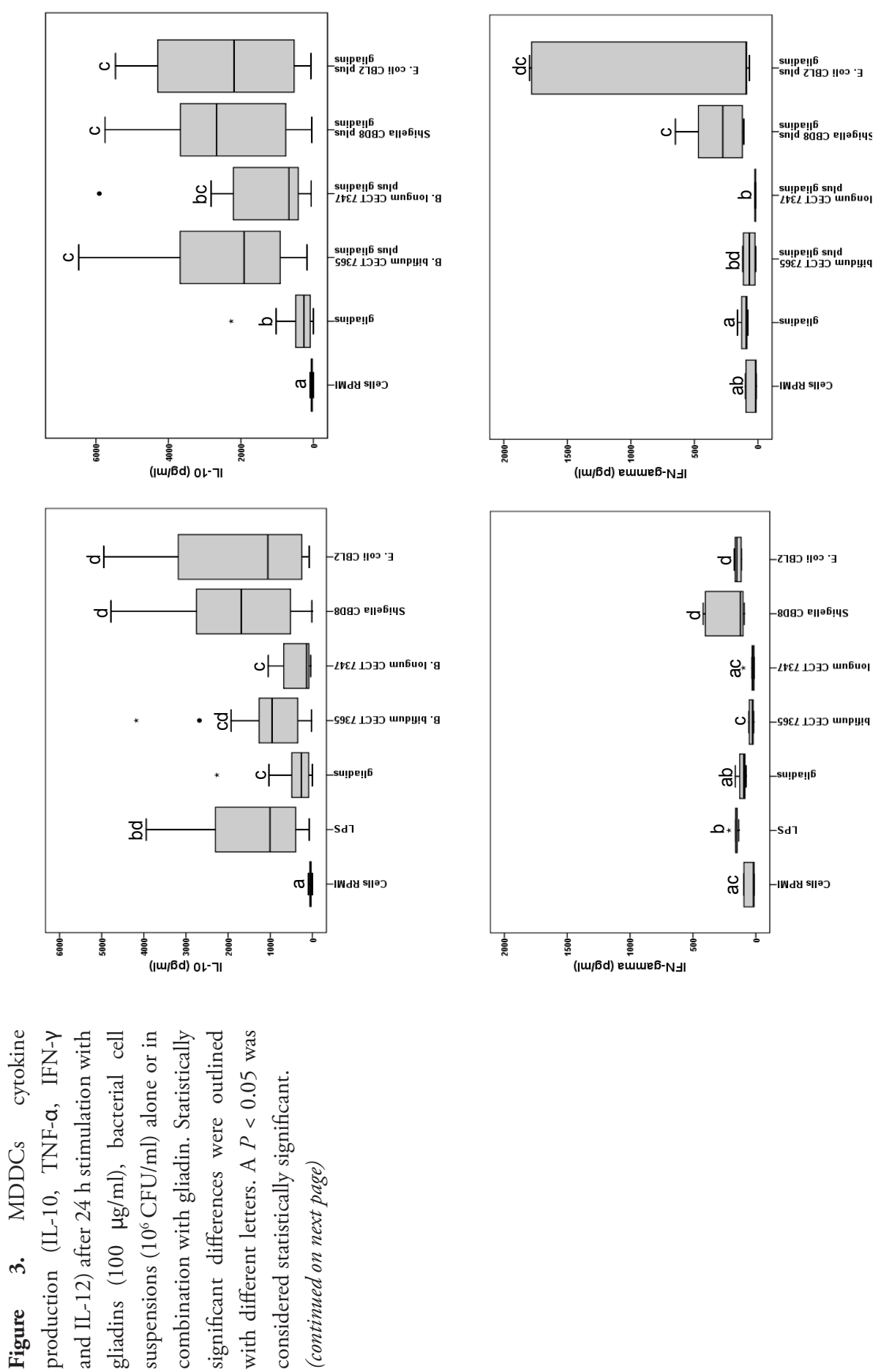

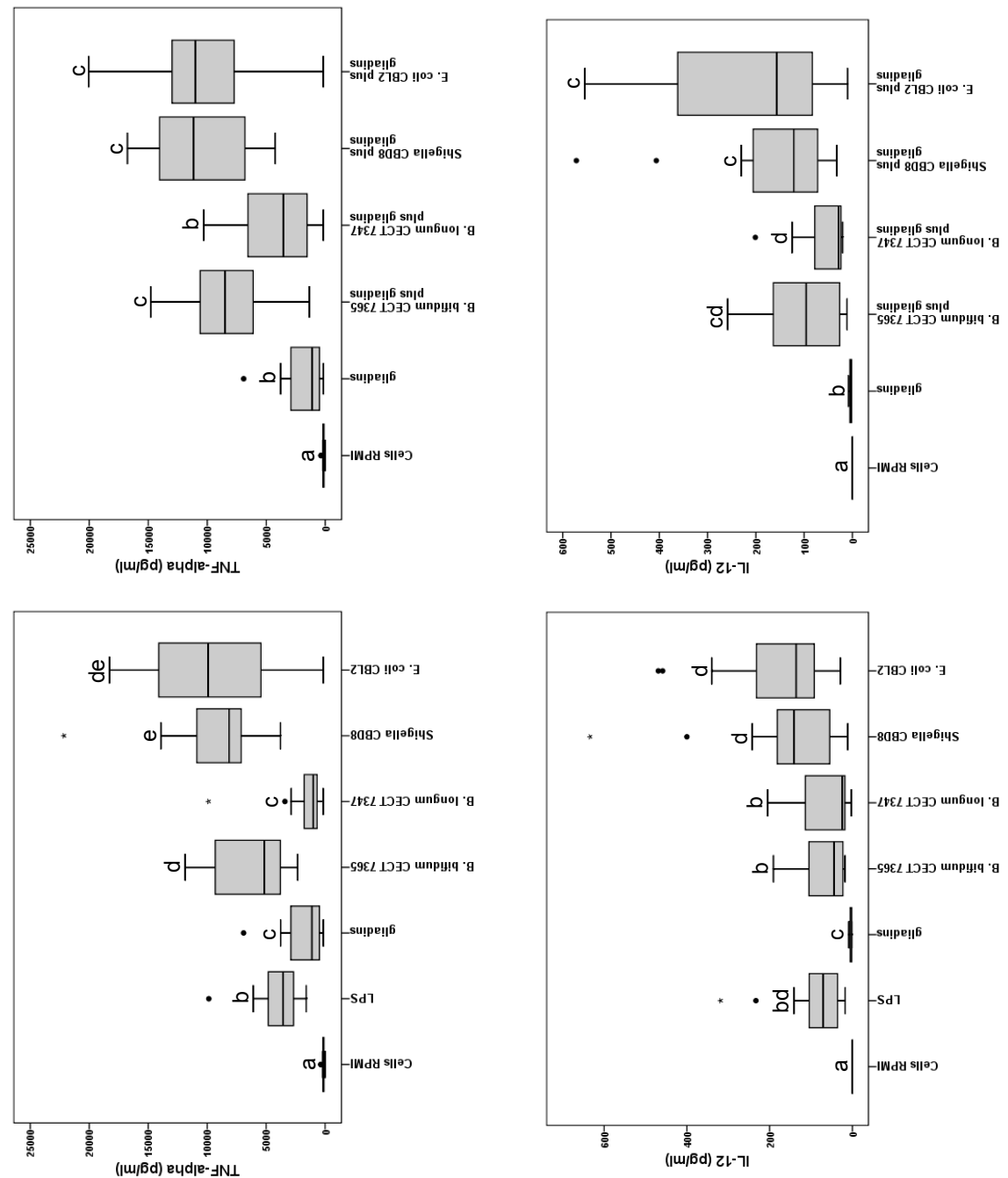

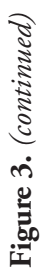


IFN- $\gamma$ than the Gram-positives $B$. bifidum CECT 7365 and B. longum CECT $7347(P=0.028$ and $P=$ $0.025, P=0.028$ and $P<0.001, P=$ 0.009 and $P=0.016$, respectively). Similarly, the Gram-negative bacteria E. coli CBL2 induced a greater secretion of IL-12 and IFN- $\gamma$ than $B$. bifidum CECT 7365 ( $P=0.004$ and $P=0.006$, respectively) and $B$. longum ( $P=0.004$ and $P=0.006$, respectively). Moreover, E. coli CBL2 induced a greater secretion of TNF- $a$ than $B$. longum CECT $7347 \quad(P=0.003)$. Shigella CBD8 and E. coli CBL2 also induced a greater secretion of IL-10 than $B$. longum CECT 7347 ( $P=0.018)$. B. longum CECT 7347 induced lower production of TNF- $a$ than B. bifidum CECT $7365 \quad(P<0.001)$. IL-21 secretion was extremely low and no differences were detected between the different stimuli applied (data not shown). IL15 was not detected in supernatants of stimulated MDDCs.

Cytokine production by MDDCs after stimulation with cell suspensions of different bacterial strains combined with gliadins is also shown in Figure 3. The effects of stimulating MDDCs with bacterial strains plus gliadins on cytokine production were similar to those exerted by the bacterial strains alone with some exceptions; the Grampositive B. longum CECT 7347 plus gliadins reduced the IFN- $\gamma$ production induced by gliadins alone $(P=0.010)$. Furthermore, $B$. longum CECT 7347 induced higher secretion of IL-10 when combined with gliadin than when used as sole stimulus $(P=0.045)$. No differences were detected for the other strains.

\section{MDDCs surface molecule expression in response to intestinal bacteria and gliadin}

MDDCs surface molecule expression is shown in Figure 4. Expression of all surface molecules, HLA-DR, CD-86, CD-40 and CD-83, was up-regulated by all stimuli applied when compared with non-stimulated cells $(P<0.001-0.009)$. The Gramnegative bacteria Shigella CBD8 and $E$. coli $\mathrm{CBL} 2$ induced higher CD-86 and CD-40 expression than B. longum CECT $7347 \quad(P=0.002$ -0.007). B. bifidum CECT 7365 induced higher HLA-DR, CD-86, CD-40 and CD-83 expression than B. longum CECT $7347 \quad(P=0.002$ $-0.009)$. All stimuli combined with gliadins upregulated the expression of all surface markers in comparison with non-stimulated cells and the effects were similar to those exerted by the bacterial strains alone. $B$. bifidum CECT 7365 and Shigella CBD8 plus gliadins induced higher CD-86 and CD-83 expression than gliadins alone $(P=0.008-0.046)$. Likewise, E. coli CBL2 plus gliadins also induced higher CD-86 than gliadins alone $(P=0.033)$. 

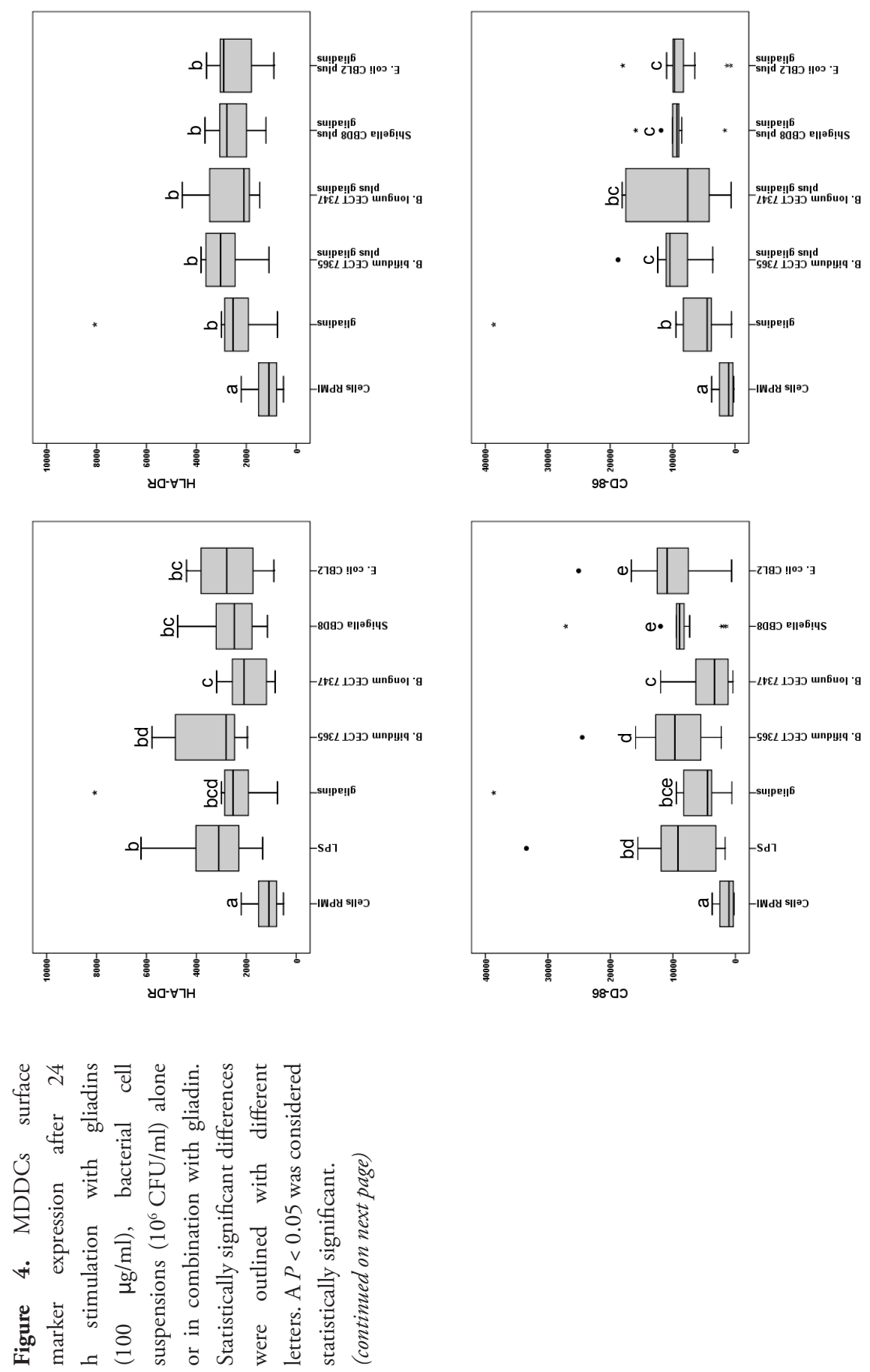

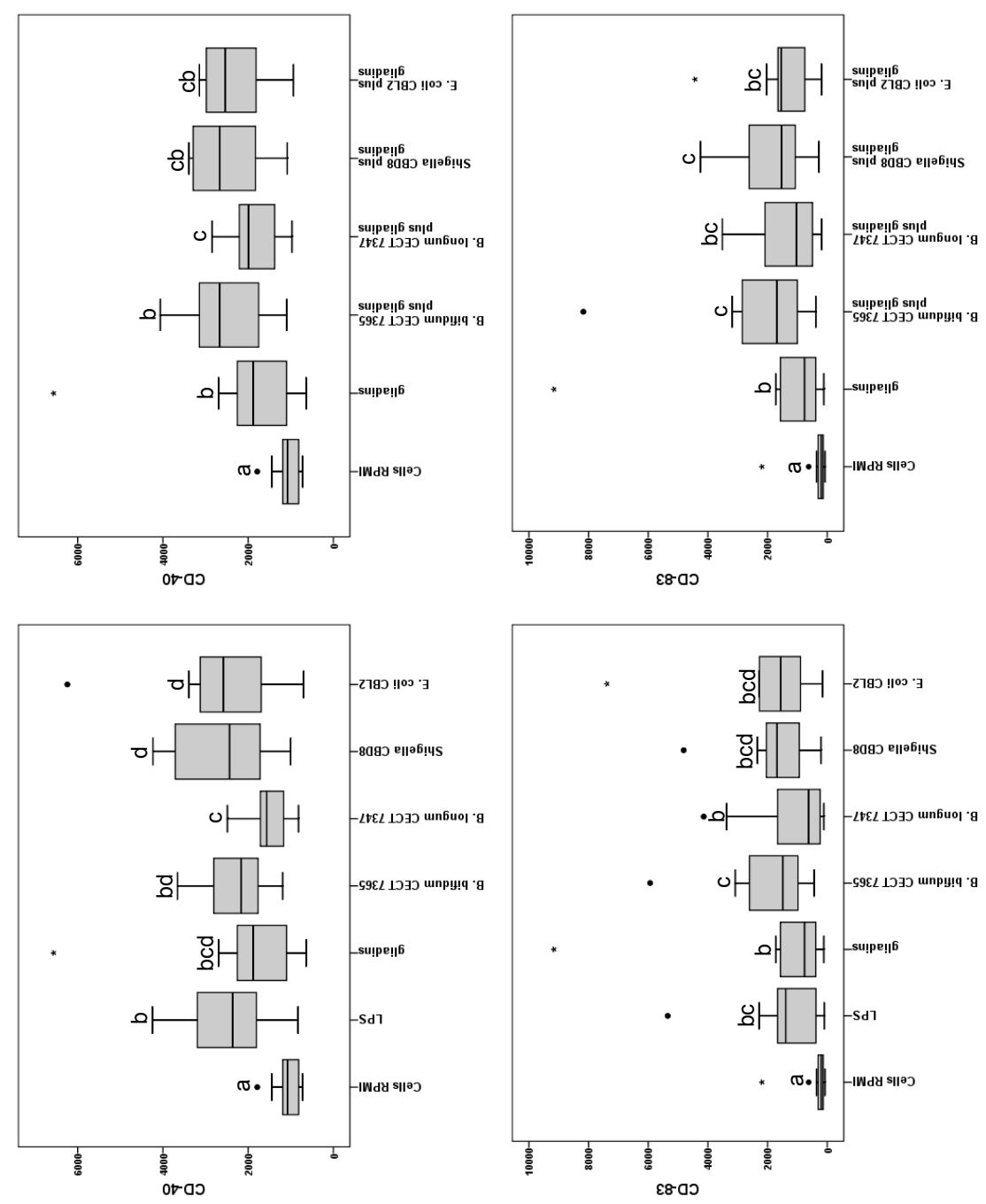

ב⿱艹 
Cytokine production and surface molecule expression by MDDCs co-cultured with Caco-2 cells stimulated with intestinal bacteria and gliadin

Cytokine production by MDDCs in co-culture with Caco-2 cells, after stimulation of Caco-2 cells with bacterial cell suspensions was evaluated (Supplementary Table 1).The Gram-negative bacteria Shigella CBD8 and E. coli CBL2 induced higher IFN- $\gamma$ and TNF- $a$ secretion by MDDCs than $B$. bifidum CECT $7365 \quad(P=0.010-0.035)$. Shigella CBD8 also induced higher IFN $-\gamma$ secretion $(P=0.010)$ and $E$. coli CBL2 higher TNF- $a$ secretion $(P=0.088)$ by MDDCs than $B$. longum CECT 7347 although in the last case statistical significance was not reached.

Cytokine production by MDDCs in co-culture with Caco-2 cells, after stimulation of Caco-2 cells with bacterial cell suspensions combined with gliadins, was also analyzed, but no differences were detected compared to cytokine production induced by each bacterial strain alone (Supplementary Table 2). No statistically significant differences were detected for IL-21, IL-15 and IL-12 production possibly due to the low concentrations detected.

For surface marker expression in MDDCs co-cultured with Caco-2 cells, significant effects were only detected when Shigella CBD8 was used to stimulated Caco-2 cells, which increased CD-83 expression by MDDCs compared to nonstimulated cells $(P=0.029)$, gliadins $(P=0.029)$ and $B$. longum CECT $7347(P=0.029)$. No differences were detected among different stimuli or between each stimulus alone or the stimulus plus gliadins (data not shown).

TJ protein mRNA expression in cultures of Caco-2 cells and MDDC analyzed by RT-PCR

The effects of intestinal bacteria and gliadins on $\mathrm{TJ}$ protein expression in a differentiated monolayer of Caco2 cells were analyzed after $24 \mathrm{~h}$ of stimulation. In these conditions, the expression of ZO-1 and occludin genes differed significantly among different stimuli (Table 2). B. longum CECT 7347 alone significantly up-regulated ZO-1 expression compared with non-stimulated cells $(P=0.005)$, LPS $(P=0.009)$ and gliadins $(P=0.009)$, whereas LPS and gliadins significantly downregulated ZO-1 expression compared to controls $(P=0.005)$. Moreover, $B$. longum CECT 7347 up-regulated ZO-1 expression in comparison with B. bifidum CECT 7365 $(P=0.028)$. B. longum CECT 7347 plus gliadins also increased ZO-1 expression in comparison to gliadins alone $(P=0.009)$ and $B$. longum CECT 7347 alone $(P=0.047)$. Occludin expression followed a slightly different pattern, since gliadins did not significantly affect the expression. However, the other stimuli, including $B$. bifidum CECT 
Table 2: ZO-1 and occludin mRNA expression in differentiated monolayer of Caco-2 cells after 24 $\mathrm{h}$ stimulation analyzed by RT-PCR.

\begin{tabular}{lcccc}
\hline \multicolumn{1}{c}{ Stimuli } & ZO-1 & (Min-Max) & Occludin & (Min-Max) \\
\hline Non-stimulated cells (control) & 1.00 & $(1.0-1.0)$ & 1.00 & $(1.0-1.0)$ \\
B. bifidum CECT 7365 & 0.99 & $(0.40-1.14)$ & 0.63 & $(0.5-0.8)$ \\
B. bifidum CECT 7365 plus gliadins & 0.81 & $(0.17-0.95)$ & 0.39 & $(0.38-0.40)$ \\
B. longum CECT 7347 & 1.18 & $(1.03-2.57)$ & 0.66 & $(0.64-0.69)$ \\
B. longum CECT 7347 plus gliadins & 1.68 & $(1.48-3.81)$ & 0.89 & $(0.70-1.09)$ \\
E. coli CBL2 & 1.01 & $(0.28-1.27)$ & 0.56 & $(0.44-0.71)$ \\
E. coli CBL2 plus gliadins & 1.70 & $(0.17-1.79)$ & 0.57 & $(0.41-0.80)$ \\
Shigella CBD8 & 1.81 & $(0.76-1.98)$ & 0.91 & $(0.89-0.92)$ \\
Shigella CBD8 plus gliadins & 1.36 & $(0.46-1.46)$ & 0.86 & $(0.84-0.89)$ \\
LPS & 0.76 & $(0.12-0.89)$ & 1.35 & $(1.29-1.42)$ \\
Gliadins & 0.84 & $(0.09-0.99)$ & 1.02 & $(0.98-1.06)$ \\
\hline
\end{tabular}

Data are expressed as median with maximum and minimum of $\Delta \Delta \mathrm{Ct}$ values.

7365, E. coli CBL2, Shigella CBD8 and $B$. longum CECT 7347, slightly down-regulated occludin expression $(P=0.014-21)$ with the exception of LPS, which up-regulated it $(P=0.014)$. On comparing different bacterial stimuli, Shigella CBD8 decreased occludin gene expression to a lower extent than B. bifidum CECT 7365, B. longum CECT 7347 and E. coli CBL2 $(P=0.021)$. When combined with gliadins, B. bifidum CECT 7365 and Shigella CBD8 decreased occludin expression to a significantly greater extent than the corresponding strains alone $(P=0.021)$, whereas $B$. longum CECT 7347 significantly increased it compared to the strain alone $(P=0.021)$.

When gene expression of $\mathrm{TJ}$ proteins was analyzed in MDDCs co-cultured with Caco-2 cells, differences were detected for ZO-1 and occludin expression among different stimuli (Table 3), but not when MDDCs were cultured alone. In MDDCs co-cultured with Caco-2 cells, ZO-1 gene expression was down-regulated by LPS $(P<0.001)$ and gliadins $(P=0.017)$ in comparison with nonstimulated cells, while the effects of the bacterial strain tested were not significant due to their large variability. When the bacterial cell suspensions were combined with gliadins, differences were detected for Shigella CBD8 plus gliadins, which decreased ZO-1 expression in MDDCs as compared with Shigella CBD8 alone $(P=0.043)$ or non-stimulated cells $(P<0.001)$ or B. bifidum CECT $7365(P=0.010)$. Furthermore, B. bifidum CECT 7365 plus gliadins upregulated ZO-1 expression compared to gliadins alone 
Table 3: ZO-1 and occludin mRNA expression in MDDCs co-cultured with stimulated Caco-2 cells analyzed by RT-PCR.

\begin{tabular}{lclcc}
\hline \multicolumn{1}{c}{ Stimuli } & ZO-1 & (Min-Max) & Occludin & (Min-Max) \\
\hline Non-stimulated cells (control) & 1.00 & $(1.0-1.0)$ & 1.00 & $(1.0-1.0)$ \\
B. bifidum CECT 7365 & 1.41 & $(0.15-3.45)$ & 1.26 & $(0.91-1.42)$ \\
B. bifidum CECT 7365 plus gliadins & 4.43 & $(0.53-11.08)$ & 1.20 & $(1.20-1.21)$ \\
B. longum CECT 7347 & 0.72 & $(0.16-5.54)$ & 0.77 & $(0.42-1.16)$ \\
B. longum CECT 7347 plus gliadins & 3.26 & $(0.21-7.81)$ & 2.20 & $(1.91-2.57)$ \\
E. coli CBL2 & 1.20 & $(0.22-4.57)$ & 1.07 & $(1.04-1.11)$ \\
E. coli CBL2 plus gliadins & 1.51 & $(0.43-3.27)$ & 1.68 & $(1.58-1.77)$ \\
Shigella CBD8 & 0.82 & $(0.20-2.25)$ & 1.28 & $(1.11-1.36)$ \\
Shigella CBD8 plus gliadins & 0.48 & $(0.11-0.81)$ & 1.02 & $(0.99-1.06)$ \\
LPS & 0.0027 & $(0.0027-0.59)$ & 2.47 & $(2.42-2.52)$ \\
Gliadins & 0.58 & $(0.11-1.03)$ & 1.18 & $(1.13-1.23)$ \\
\hline
\end{tabular}

Data are expressed as mean and standard deviation of $\Delta \Delta \mathrm{Ct}$ values.

$(P=0.050)$. In relation to occludin gene expression in MDDCs cocultured with Caco-2 cells, the effects of gliadin alone were not significant, however LPS enhanced occludin expression in comparison with cells alone $(P=0.050)$. Moreover, $B$. longum CECT 7347 plus gliadins enhanced occludin expression in comparison to $B$. longum CECT 7347 alone $(P=0.010)$.

\section{DISCUSSION}

This is the first study to provide evidence for the differential influence of intestinal bacteria and their interactions with gliadins on MDDCs morphology and dynamic attachment and spreading. These data may reflect the phenotypic changes DCs undergo, upon stimulation, associated with their maturation process and conversion from a tissue resident, antigen-capturing cell to a highly migratory antigenpresenting cell $(32,33)$. Extensive changes in morphology, cytoskeletal organization and cell adhesion are considered indexes of the maturation and transition process that may ultimately influence T-cell activation (33). In particular, podosomes are sites of active matrix degradation, which promote cell migration and invasion, and their presence is peculiar to immature DCs, whereas mature DCs are loosely adherent and not forming podosomes on fibronectin but characteristic actinrich extensions (dendrites) that maximize the contact area with T-cells (33). In our study, Shigella CBD8, E. coli CBL2, LPS and gliadins induced major changes in MDDC morphology, which could reflect a mature phenotype, whereas $B$. 
bifidum CECT 7365 and B. longum CECT 7347 did not induce evident morphological changes. These results are in agreement with those by Chladkova et al. (15) who described that gliadin is able to induce the loss of podosomes in a dose-dependent manner and that gliadin fragments induce cytoskeletal remodeling and mediate the morphological transition from immature DC to mature DC. These morphological data are in agreement with dynamic adhesion and spreading assays. When DCs are immature they are highly adhesive and possess podosomes, then on undergoing maturation they start to change their morphology, lose podosomes and acquire dendrites. We observed that Shigella CBD8, with and without gliadins, induced faster and more remarkable changes in adhesion and spreading in MDDCs than the other stimuli. E. coli CBL2 also induced changes while the bifidobacterial strains, particularly B. bifidum CECT 7365 , had no significant effect on the cells and even reduced the effect of gliadins resembling the situation of nonstimulated cells (data not shown). The attachment and spreading experiments show the interaction of MDDCs with fibronectin, which composes ECM components and interacts specifically with the cells through specialized cell-surface receptors called integrins. The latter recognize and bind to specific motifs within the ECM proteins, thereby mediating the ability of cells to specifically adhere to and interact with the appropriate matrix protein (31). Integrins also initiate an intracellular signaling cascade that directs cellular processes such as cell survival, proliferation, differentiation and migration $(31,34)$.

Overall, the differential effects of the intestinal bacteria tested on MDDCs morphology, adhesion and spreading suggest that enterobacteria, in particular, or their cell-wall components could contribute to inducing a full phenotypic and functional DC maturation process and thus enhance antigen presentation and stimulation of specific T-cell responses.

Subsequently, we also evaluated the effects of different intestinal bacteria on direct markers of MDDC immune function, such as cytokine production and surface molecule expression, as well as their ability to modify the response to gliadin. The two enterobacteria and, especially, Shigella CBD8 that represent a real pathogen triggered a stronger Th1type inflammatory response, with particularly high IFN- $\gamma$, TNF- $a$ and IL-12 secretion compared to the effects of the two bifidobacterial strains tested. Similarly, E. coli CBL2 also induced greater IFN- $\gamma$ and IL-12 secretion than the two bifidobacterial strains tested. These effects on the cytokine profile followed a similar trend to those detected in PBMCs in our previous study (20), but were more pronounced. In addition, this study shows that gliadin stimulation 
induced higher IFN- $\gamma$ secretion than B. bifidum CECT 7365 , which was not evident in previous studies with PBMCs (20). Moreover, B. longum CECT 7347 plus gliadins reduced the levels of IFN- $\gamma$ production induced by gliadins alone and also induced higher secretion of IL-10 than when the bacterium was used as the sole stimulus. This would suggest its potential role in the regulation of the aberrant immunological response induced by wheat gluten proteins. In relation to MDDC surface molecule expression, the differences between enterobacteria and bifidobacteria were not as remarkable as those detected in PBMCs (20). However, B. longum CECT 7347 clearly induced lower expression of most of the activation markers when compared with Shigella CBD8, E. coli CBL2 and B. bifidum CECT 7365 in the presence or absence of gliadins.

Our study also examined the role of the epithelial cell layer in the response of MDDCs to different stimuli. Similar results were observed when MDDCs were co-cultured with differentiated Caco-2 cells and stimulated with gliadin and different bacterial strains. Unlike bifidobacteria, enterobacteria induced higher production of pro-inflammatory cytokines, with predominant increases in IFN- $\gamma$ and TNF- $a$, which could contribute to the intestinal inflammatory milieu characteristic of CD patients. Accordingly, stool samples of CD patients, representing an unbalanced microbiota, were also shown to induce a pro-inflammatory cytokine pattern characterized by high levels of IFN- $\gamma$ and TNF- $a$ production by PBMCs. However, this imbalance could be reversed by the two bifidobacterial strains tested in this study (35), suggesting that intestinal bacteria could influence the polarization of the immunological responses in the presence of factors influencing $\mathrm{CD}$, including the luminal bacterial load and wheat-gluten-derived peptides. The effects of different bacterial strains and gliadins on expression of TJ-related proteins in Caco-2 cells were also studied as $\mathrm{CD}$ has also been associated with increases in intestinal permeability and changes in expression of $\mathrm{TJ}$ related proteins $(36,37)$. In this study, gliadin and LPS were shown to reduce ZO-1 gene expression in Caco-2 cells, while $B$. longum CECT 7347 increased ZO-1 expression alone and in combination with gliadins, reversing this adverse effect. The effects of the different bacterial strains on occludin expression followed opposite trends, but their meaning in the context of $\mathrm{CD}$ is unclear since gliadins did not modify occluding expression. Previous in vitro studies, using monolayer Caco-2 cell cultures and three-dimensional Lovo cell line culture, indicated that gliadin directly damages $\mathrm{TJ}$, for example decreasing expression of ZO-1 and occluding proteins, thereby contributing to gut barrier disruption 
(37, 39). In patients with active coeliac disease, both ZO-1 protein levels and mRNA were reduced and F-actin organization was disrupted (40). Similarly, Drago et al. (38) reported significant lower expression of both ZO-1 and occluding genes in the intestinal tissues obtained from $\mathrm{CD}$ patients, compared to non-CD controls, which represent the effect of chronic exposure to gluten.

DCs expressing TJ proteins are reported to open the TJ between epithelial cells and directly take up microorganisms or other antigens, thus contributing to antigen translocation, while preserving integrity of the epithelial barrier $(11,41)$. Thus the effects of different bacterial strains and gliadins on the expression of $\mathrm{TJ}$ related proteins in MDDCs were also evaluated in our study. Differences in TJ protein gene expression on MDDCs among different stimuli were only detected when these cells were co-cultured with Caco-2 cells. These findings suggest that the interactions with Caco-2 cells play an important role in MDDC recognition of different stimuli, which may lead to different TJ protein expression during transepithelial exchanges. In this context, previous studies demonstrated that particle uptake by MDDCs was also higher in co-cultures with epithelial cells (41). LPS and gliadins reduced ZO-1 expression in agreement with the effects on Caco-2 cells. However, B. bifidum CECT 7365 plus gliadins upregulated ZO-1 expression compared to gliadins alone. In relation to occludin, LPS increased the expression of this protein gene while gliadins and most of the bacteria did not exert significant effects. Only B. longum CECT 7347 combined with gliadin increased occludin expression compared with the strain alone. Bacterial components, such as LPS, are reported to trigger the reorganization of $\mathrm{TJ}$ proteins via up-regulation of ZO-1 and slight down-regulation of occludin, allowing DCs to detach from junctions with epithelial cells and migrate to draining lymph nodes (11). By contrast, in our study the effects of LPS on ZO-1 and occludin expression and those of the enterobacteria, which represent an LPS stimulus, on occludin expression followed the opposite trend. These differences could be explained by differences in mRNA expression of these genes at different stages of DCs maturation and exposure time as indicated previously (11). In our study, the effects of $B$. longum CECT 7347 on ZO-1 expression were opposite to those of LPS. This would suggest that this bifidobacterial strain could play a positive role in the regulation of $\mathrm{TJ}$ related protein expression; however, further investigations are required to provide direct evidence of the physiological significance of the effects detected in $\mathrm{TJ}$ protein gene expression.

In conclusion, this study confirms that enterobacteria could exert pathogenic effects similar to those 
exerted by gliadins, contributing to phenotypic DC maturation. This is reflected in morphological changes and increased attachment/spreading ability, and the induction of high inflammatory cytokine production, particularly of IFN- $\gamma$. In contrast, $B$. bifidum CECT 7365 and B. longum CECT 7347 did not cause gliadininduced morphological changes, and induced adhesion and spreading ability of MDDCs and inflammatory cytokine production to a lesser extent. In particular, $B$. longum CECT 7347 reduced IFN- $\gamma$ production induced by gliadins and increased IL-10 secretion when both stimuli were combined and also reversed the gliadin-reduced ZO-1 expression in Caco-2 cells. Altogether this could ultimately contribute to ameliorating the response to gluten peptides in the context of CD. Based on these results, we suggest that specific components of the gut microbiota may influence phenotypic and functional maturation of DCs differently and their interactions with epithelial cells, and could ultimately define the role of DCs in T-cell activation and disease progression.

\section{Aknowledgments}

This work was supported by grants 2006 CZ0030 and 2008CZ0023 from CSIC (Spain) and AGL2011-25169 and Consolider Fun-C-Food CSD2007-00063 from the Spanish Ministry of Science and Innovation and 200570F0091/92/93 from CSIC. The scholarship to G. De Palma from JAE-CSIC
(Spain) is fully acknowledged. This work was also supported by grants AV CR-CSIC. and IAA 500200801 of the Academy of Sciences, 310/07/0414, 310/08/H077, 310/09/1640 and of the Grant Agency of the Czech Republic, Project 2B06155 of the Ministry of Education, and Institutional Research Concept RVO: 61388971.

\section{REFERENCES}

1. Di Sabatino A, Corazza G R (2009) Coeliac disease. Lancet 373, 1480-1493.

2. Dubois PC, van Heel DA (2008) Translational mini-review series on the immunogenetics of gut disease: immunogenetics of coeliac disease. Clin Exp Immunol 153, 162-173.

3. Stepniak D, Koning F (2006) Celiac disease-sandwiched between innate and adaptive immunity. Hum. Immunol 67, 460-468.

4. Nilsen EM, Jahnsen FL, Lundin, KE et al. (1998) Gluten induces an intestinal cytokine response strongly dominated by interferon gamma in patients with celiac disease. Gastroenterology 115, 551-563.

5. Monteleone I, Sarra M, Del Vecchio BG et al. (2010) Characterization of IL-17Aproducing cells in Celiac disease mucosa. $J$. Immunol. 184, 2211-2218.

6. Fina D, Sarra M, Caruso R et al. (2008) Interleukin 21 contributes to the mucosal $\mathrm{T}$ helper cell type 1 response in coeliac disease. Gut 57, 887-892.

7. Fernández S, Molina IJ, Romero $\mathrm{P}$ et al. (2011) Characterization of gliadin-specific Th17 cells from the mucosa of celiac disease patients. Am. J. Gastroenterol. 106, 528-538.

8. Green PH, Cellier C (2007) Celiac disease. N Engl J Med 357, 1731-1743.

9. Banchereau J, Briere F, Caux C et al. (2000) Immunobiology of dendritic cells. Ann. Rev Immunol 18, 767-811.

10. Coombes JL, Powrie F (2008) Dendritic cells in intestinal immune regulation. Nat Rev Immunol 8, 435-446.

11. Rescigno M, Urbano M, Valzasina, B et al. (2001) Dendritic cells express tight junction proteins and penetrate gut epithelial monolayers to sample bacteria. Nat Immunol 2, 361-367.

12. Raki M, Tollefsen S, Molberg O et al. (2006) A unique dendritic cell subset accumulates in the celiac lesion and efficiently activates 
gluten-reactive T cells. Gastroenterology 131, 428-438.

13. Beitnes AC, Raki M, Brottveit M etal. (2012) Rapid Accumulation of CD14CD11c Dendritic Cells in Gut Mucosa of Celiac Disease after in vivo Gluten Challenge. PLoS One 7, e33556.

14. Palova-Jelinkova L, Rozkova D, Pecharova et al. (2005) Gliadin fragments induce phenotypic and functional maturation of human dendritic cells. J Immunol 175, 70387045 .

15. Chladkova B, Kamanova J, Palova-Jelinkova L et al. (2010) Gliadin fragments promote migration of dendritic cells. J Cell Mol Med 15, 938-948.

16. Collado MC, Donat E, Ribes-Koninckx C et al. (2008) Imbalances in faecal and duodenal Bifidobacterium species composition in active and non-active coeliac disease. $B M C$ Microbiol 8, 232.

17. Nadal I, Donat E, Ribes-Koninckx C et al. (2007) Imbalance in the composition of the duodenal microbiota of children with coeliac disease. J Med Microbiol 56, 1669-1674.

18. Collado MC, Donat E, Ribes-Koninckx C et al. (2009) Specific duodenal and faecal bacterial groups associated with paediatric coeliac disease. J Clin Pathol 62, 264-269.

19. Ou G, Hedberg M, Horstedt P et al. (2009) Proximal small intestinal microbiota and identification of rod-shaped bacteria associated with childhood celiac disease. Am J Gastroenterol 104, 3058-3067.

20. De Palma G, Cinova J, Stepankova R et al. (2009) Pivotal Advance: Bifidobacteria and gram-negative bacteria differentially influence immune responses in the proinflammatory milieu of celiac disease. $J$ Leukoc Biol 87, 765-78.

21. Cinova J, De Palma G, Stepankova R et al. (2011) Role of intestinal bacteria in gliadininduced changes in intestinal mucosa: study in germ-free rats. PLoS One 6, e16169.

22. Cinova J, Palova-Jelinkova L, Smythies LE et al. (2007) Gliadin peptides activate blood monocytes from patients with celiac disease. J Clin Immunol 27, 201-209.

23. Izquierdo $E$, Medina $M$, Ennahar $S$ et al. (2008) Resistance to simulated gastrointestinal conditions and adhesion to mucus as probiotic criteria for Bifidobacterium longum strains. Curr Microbiol 56, 613-618.

24. Medina M, Izquierdo E, Ennahar $S$ et al. (2007) Differential immunomodulatory properties of Bifidobacterium longum strains: relevance to probiotic selection and clinical applications. Clin Exp Immunol 150, 531538.

25. Sanchez E, Nadal I, Donat E et al. (2008) Reduced diversity and increased virulencegene carriage in intestinal enterobacteria of coeliac children. BMC. Gastroenterol 8, 50.

26. Laparra JM, Sanz Y (2010) Bifidobacteria inhibit the inflammatory response induced by gliadins in intestinal epithelial cells via modifications of toxic peptide generation during digestion. J Cell Biochem 109, 801807.

27. de Mattos AM, Meyer MM, Norman DJ et al. (1997) Interleukin-12 p40 m-RNA expression in human kidney allograft biopsies. Transpl Immunol 5, 199-203.

28. Linder S, Aepfelbacher M (2003) Podosomes: adhesion hot-spots of invasive cells. Trends Cell Biol 13, 376-385.

29. Burns S, Hardy SJ, Buddle J et al. (2004) Maturation of DC is associated with changes in motile characteristics and adherence. Cell Moti. Cytoskeleton 57, 118-132.

30. Alvarez D, Vollmann EH, von Andrian UH (2008) Mechanisms and consequences of dendritic cell migration. Immunity 29, 325342.

31. Atienza JM, Zhu J, Wang X et al. (2005) Dynamic monitoring of cell adhesion and spreading on microelectronic sensor arrays. $J$ Biomol Screen 10, 795-805.

32. Rescigno M, Di Sabatino A (2009) Dendritic cells in intestinal homeostasis and disease. $J$ Clin Inves. 119, 2441-2450.

33. van Helden SF, Krooshoop DJ, Broers KC et al. (2006) A critical role for prostaglandin E2 in podosome dissolution and induction of high-speed migration during dendritic cell maturation. J Immunol 177, 1567-1574.

34. Margadant C, Monsuur HN, Norman JC et al (2011) Mechanisms of integrin activation and trafficking. Curr Opin Cell Biol 23, 607614.

35. Medina M, De Palma G, Ribes-Koninckx C et al. (2008) Bifidobacterium strains suppress in vitro the pro-inflammatory milieu triggered by the large intestinal microbiota of coeliac patients. J Inflamm (Lond) 5, 19.

36. Visser J, Rozing J, Sapone A et al. (2009) Tight junctions, intestinal permeability, and autoimmunity: celiac disease and type 1 diabetes paradigms. Ann N Y Acad Sci 1165, 195-205.

37. Drago S, El Asmar R, Di PM et al. (2006) Gliadin, zonulin and gut permeability: 
Effects on celiac and non-celiac intestinal mucosa and intestinal cell lines. Scand J Gastroenterol 41, 408-419.

38. Sander GR, Cummins AG, Henshall T et al. (2005) Rapid disruption of intestinal barrier function by gliadin involves altered expression of apical junctional proteins. FEBS Lett 579, 4851-4855.

39. Elli L, Roncoroni L, Doneda L et al. (2011) Imaging analysis of the gliadin direct effect on tight junctions in an in vitro threedimensional Lovo cell line culture system. Toxicol In Vitro 25, 45-50.

40. Pizzuti D, Bortolami M, Mazzon E et al. (2004) Transcriptional down regulation of tight junction protein ZO-1 in active coeliac disease is reversed after a gluten-free diet. Dig Liver Dis 36, 337-341.

41. Blank F, Wehrli M, Lehmann A et al. (2011) Macrophages and dendritic cells express tight junction proteins and exchange particles in an in vitro model of the human airway wall. Immunobiology 216, 86-95. 


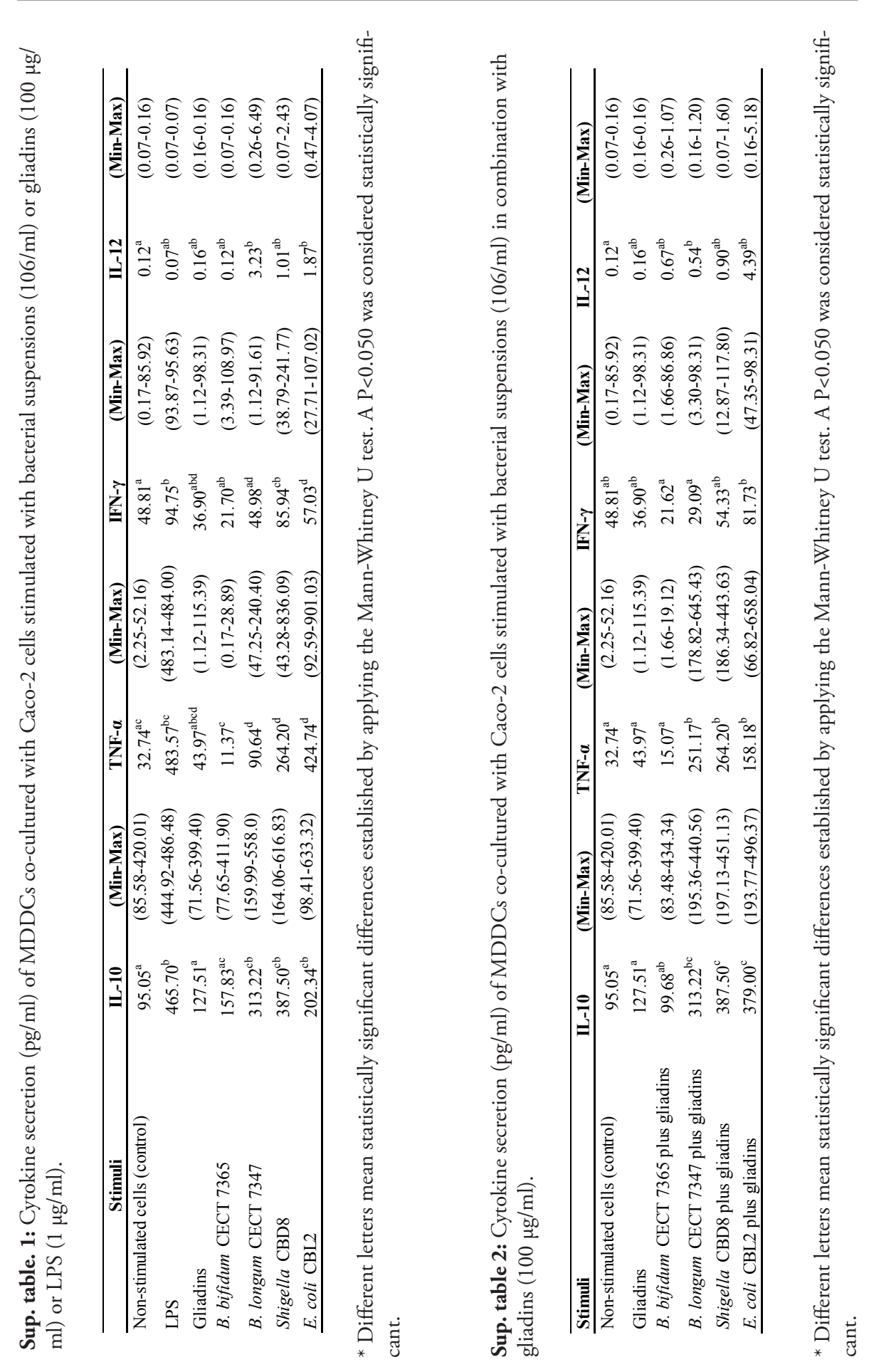




\section{Influence of Bifidobacterium longum CECT 7347 and gliadin peptides on intestinal epithelial cell proteome}

Marta Olivares, Moisés Laparra, and Yolanda Sanz

J Agric Food Chem (2011) 59, 7666-7671

Microbial Ecology and Nutrition Research Group, Institute of Agrochemistry and Food Technology, National Research Council (IATA-CSIC), 


\begin{abstract}
Celiac disease is an enteropathy caused by an abnormal immune response to cereal gluten proteins (gliadin). To unravel the possible role of the interactions between gliadin peptides and specific intestinal bacteria, the response of intestinal epithelial (Caco-2) cells to gliadin subjected to gastrointestinal digestion in the presence or absence of Bifidobacterium longum CECT 7347 has been studied. Changes in the proteome of Caco2 cells were determined by 2DE and MALDI-TOF. Gliadins digested without $B$. longum altered the expression of a higher number of proteins than in the presence of the bacterium (21 versus 9) and these proteins were involved in disorganization of cell cytoskeleton, inflammation and apoptosis. Gliadins digested in the presence of the bacterium influenced the production of proteins involved in calcium homeostasis and cell survival and function. Therefore, B. longum CECT 7347 might ameliorate gliadin toxicity and modify the responses of intestinal epithelial cells to the gliadin challenge.
\end{abstract}

Keywords: Bifidobacterium longum, celiac disease, Caco-2 cells, probiotic, proteome

\section{INTRODUCTION}

Cereal gluten proteins (gliadin $\alpha, \beta$, $\gamma$ and $\varpi)$ are the main environmental factors causative of celiac disease (CD) pathogenesis. The incomplete hydrolysis of gliadin by human enzymes during gastrointestinal digestion leads to the generation of peptides able to trigger cytotoxic and inflammatory signals in intestinal epithelial cells of CD patients (1). Clinical manifestations of the disease often include intestinal symptoms and nutrient malabsorption associated with severe mucosal damage (2). Currently, the only available therapy for CD patients is the adherence to a strict life-long gluten-free diet. However, compliance with this dietary recommendation is complex and other alternative or adjuvant strategies are needed (3).

Alterations in the composition of the gut microbiota of $\mathrm{CD}$ patients are characterized by decreased Bifidobacterium numbers $(4,5)$. The association of imbalances in the intestinal microbiota and the positive reported roles that bifidobacteria plays on intestinal health has led to propose the use of probiotics as part of additional and alternative nutritional strategies for improving 
the quality of life of $\mathrm{CD}$ patients. Certain strains of the Bifidobacterium genus effectively reduced in vitro the toxicity and inflammatory potential of gliadin-derived peptides (6). The positive effect of bifidobacteria was attributed to their proteolytic capacity on gliadin peptides; however, the effects produced by different bifidobacteria seemed to be strain-dependant demonstrating the most positive effect produced by $B$. longum CECT 7347 strain, which motivated the present study.

Gliadin-derived peptides are thought to stimulate enterocytes $(7,8)$ and macrophages (9) via specific surface receptors such as the chemokine CXCR3, a 7-transmembrane G-protein, present in the brush border membrane, causing the upregulation of pro-inflammatory cytokine expression (10, 11). These effects have been linked to the activation of the nuclear transcription factor kappa-B (NF$\kappa \mathrm{B})$ pathway in the small intestinal mucosa of CD patients (12). After sensing an inflammatory stimulus, the inhibitor I $\kappa \mathrm{B}$ is phosphorylated triggering its degradation, thereby allowing the translocation of NF$\kappa \mathrm{B}$ to the nucleus where it induces the expression of a variety of genes involved in inflammation, immune regulation, and cell survival and proliferation (13). Furthermore, alterations in the integrity and function of the intestinal barrier have also been associated to gliadin toxicity (14). Gliadin-derived peptides can mediate the disorganization of tight junction-related proteins leading to increased intestinal permeability (15), and expression (mRNA) of ionic channels and the chemokine CXCR3 receptor $(6,7)$. However, there is limited knowledge of the possible role of the interplay between gliadin peptides and intestinal bacteria in the activation of pathogenic or protective responses in the intestine.

The objective of this study was to evaluate the changes in the proteome of Caco- 2 cells, widely used as human intestinal model, exposed to gliadin digested in vitro, in the presence or absence of B. longum CECT 7347 , and in response to the bifidobacteria alone. The ultimate goal of the study was to gain a better understanding of early alterations induced by gliadin in enterocytes, and their possible modulation by components of the intestinal microbiota.

\section{MATERIAL AND METHODS}

\section{Bacterial cultures}

Bifidobacterium longum CECT 7347 was isolated from faeces of healthy infants as described elsewhere (15). The bacterial cultures were grown in Man-Rogosa-Sharpe broth and agar (Scharlau, Barcelona, Spain) supplemented with $0.05 \%(\mathrm{w} / \mathrm{v})$ cysteine (MRSC) (Sigma, St. Louis, $\mathrm{MO}$ ), and incubated at $37^{\circ} \mathrm{C}$ under anaerobic conditions (AnaeroGen, Oxoid, Basingstoke, UK) for $24 \mathrm{~h}$. 
The studies employed bacterial cell suspensions with absorbance of 0.5 $(\lambda, 600 \mathrm{~nm})$ corresponding to $10^{8}$ colony forming units $(\mathrm{CFU}) / \mathrm{mL}$.

\section{Cell culture conditions}

The human colon carcinoma (Caco2) cell-line was obtained from the American Type Culture Collection (Rockville, MD, USA) at passage 17, and used in experiments at passages 33-42. Caco-2 cells were grown in DMEM (AQ-Media, Sigma, USA) containing $4.5 \mathrm{~g}$ $\mathrm{L}^{-1}$ glucose, and supplemented with $25 \mathrm{mM}$ 4-(2-hydroxyethyl)1-piperazineethanesulfonic acid (HEPES) buffer (Biowhittaker, Schiedam, Holland), 10\% (v/v) fetal bovine serum (Sigma), 1\% (v/v) nonessential amino acids (Biowhittaker), $1 \% \quad(\mathrm{v} / \mathrm{v}) \quad$ L-glutamine (Sigma) and $1 \%(\mathrm{v} / \mathrm{v})$ antibiotic solution (penicillin, streptomycin and fungizone) (Sigma). Cells were maintained at $37{ }^{\circ} \mathrm{C}$ in $5 \% \mathrm{CO}_{2} /$ 95\% relative humidity and culture medium was changed every 2 days (6).

For experimental studies, Caco- 2 cells were seeded at densities of 50,000 cells $/ \mathrm{cm}^{2}$ onto 6-well plates (Costar, Corning, USA). Cell cultures were grown with DMEM, and culture medium was changed every 2 days. Experiments were performed 5 days post seeding. Cell cultures exposed to DMEM were used as controls.

\section{In vitro digestion of gliadin}

The gastrointestinal digestion process was simulated as previously described (16), using porcine pepsin (P7000, Sigma) (800-2500 units/mg protein), pancreatin (P1750, Sigma) (activity $4 \times \mathrm{USP}$ specifications) and bile (B3883, Sigma). Three $\mathrm{mL}$ of a saline solution $(140 \mathrm{mM}$ $\mathrm{NaCl}, 5 \mathrm{mM} \mathrm{KCl}$ adjusted to $\mathrm{pH}$ 3) was added to aliquots $(150 \mathrm{mg})$ of a commercially available gliadin extract (G3375, Sigma). The mixture was immersed in a water bath $(60$ $\left.{ }^{\circ} \mathrm{C}\right)$ for 30 minutes with gentle agitation. Once the samples were at room temperature, gastric and intestinal digestions were conducted on a rocking platform shaker placed in an incubator $\left(37^{\circ} \mathrm{C} / 5 \%\right.$ $\mathrm{CO}_{2} / 95 \%$ relative humidity). After the gastric digestion (pepsin in 0.1 $\mathrm{M} \mathrm{HCl} / \mathrm{pH} 3 / 1 \mathrm{~h}$ ), the intestinal digestion (pancreatin-bile in 0.1 $\mathrm{M} \mathrm{NaHCO} / \mathrm{pH}$ 6.8-7.0/2 h) was carried out in the upper chamber of a two-chamber system in 6-well plates formed by fitting the bottom of a Transwell insert ring (Costar) with a 15,000 molecular mass cutoff dialysis membrane (Spectra/Por 2.1, Spectrum Medical, Gardena, CA, USA). Aliquots $(1.5 \mathrm{~mL})$ of the gastro-intestinal digests, inoculated or not with bacterial cell suspensions $\left(10^{8} \mathrm{CFU} / \mathrm{mL}\right)$, were loaded into the upper chambers and $1 \mathrm{~mL}$ of saline solution ( $\mathrm{pH} \mathrm{7)}$ was added to the bottom chamber. Afterwards, the inserts were removed and total protein content in the dialysates was quantified using a Lowry method based on a commercial kit (TP0200, 
Sigma).

\section{Toxicity experiments}

Caco-2 cell viability in cultures exposed $(6 \mathrm{~h})$ to digested gliadin $(0.25 \mathrm{mg} / \mathrm{mL})$, inoculated or not with B. longum CECT 7347, were determined by the neutral red (NR) (3-amino-7-dimethylamino2-methylphenazine hydrochloride) (Sigma) uptake assay (6). The culture medium was removed and kept to determine cytokines as described below. Cells were washed twice with phosphate buffer saline (PBS) at $\mathrm{pH}$ 7.2 (Sigma) and NR uptake was measured using a commercial kit (No. 7H092, Sigma) at $540 \mathrm{~nm}$ with background subtraction at $690 \mathrm{~nm}$. Control cells exposed to DMEM were analyzed in every assay.

\section{Analysis of cytokines}

Tumor necrosis factor (TNF)- $\alpha$ (eBioscience Inc, San Diego, CA, USA), interleukin (IL)-1 $\beta$ (eBioscience) and IL-10 (eBioscience) were determined in the supernatant from cell cultures by ELISAs according to the manufacturers' instructions. The results of the ELISA assays are expressed as picograms per $\mathrm{mL}(\mathrm{pg} / \mathrm{mL})$.

\section{Protein Extraction and 2-DE separation}

Caco- 2 cells were exposed for 6 hours to digested gliadins $(0.25 \mathrm{~g} / \mathrm{mL})$, inoculated or not with $B$. longum CECT 7347, or to the bifidobacteria $\left(10^{8} \mathrm{CFU} / \mathrm{mL}\right)$. The culture supernatant was removed and kept to determine cytokines as described below, and cells were washed twice with PBS for proteome analyses $(\mathrm{pH}$ 7.2) (Sigma).

Protein extraction was performed as described elsewhere (17) by pipetting with lysis buffer [7 M urea (GE Healthcare, Princeton, USA), $2 \mathrm{M}$ thiourea (GE Healthcare), Nonidet p-40 (USB Corporation, Queveland, USA) $(1 \% \quad \mathrm{v} / \mathrm{v})$, and protease inhibitors (Roche, Complete 04693 $116001)]$. After centrifugation at 4 ${ }^{\circ} \mathrm{C}$ and $11,000 \mathrm{~g}$ for $10 \mathrm{~min}$, total protein content was determined as previously described. Aliquots (200 $\mu \mathrm{g}$ of protein $/ 2 \mu \mathrm{L}$ ) were mixed with rehydration solution $(340 \mu \mathrm{L})[7 \mathrm{M}$ urea, $2 \mathrm{M}$ thiourea, DTT (Fluka, Arjeplog, Sweden) (0.2\%, v/v), Nonidet p-40 (1\%, v/v), Pharmalyte 3-10 (GE Healthcare) (1\%, v/v) and bromophenol blue] and loaded in the dry polyacrylamide gel strips with an immobilized $\mathrm{pH}$ gradient (IPG) (GE Healthcare, Immobiline $\mathrm{IM}^{\mathrm{TM}}$ DryStrip pH 3-10 NL, $18 \mathrm{~cm}$ ). The IPG strips were covered with mineral oil (GE Healthcare) and kept at room temperature overnight. Protein separation according to the isoelectric point $(\mathrm{p} I)$ was conducted with an Ettan IPG-Phor II cuvette and the program was visualized through Ettan control software 1.0. Isoelectric focusing (IEF) was carried out under the following conditions: step 1, increase from 0 to $500 \mathrm{~V}$ in $5 \mathrm{~h}$; step 2, $500 \mathrm{~V}$ for $5 \mathrm{~h}$; step 3, increase from 500 to $3,500 \mathrm{~V}$ in 
9.5 h; and step 4, 3,500 V for $4 \mathrm{~h}$. Focused IPG strips were equilibrated with equilibration buffer $[50 \mathrm{mM}$ Tris-HCl (pH 8.8) (Sigma), SDS $(2 \%, \mathrm{v} / \mathrm{v}), 6 \mathrm{M}$ urea, glycerol $(30 \%$, $\mathrm{v} / \mathrm{v})$, dithiothreitol (DTT) $(1 \%, \mathrm{v} / \mathrm{v})$ and iodoacetamide (IAA) (Sigma) $(2.5 \%, w / v)]$. The second dimension was run (Ettan Dalt Six cuvette) in pairs side by side. The strips were sealed with an agarose solution $0.5 \%$ $(\mathrm{w} / \mathrm{v})$ and run overnight at a constant voltage in a polyacrylamide gel (BioRad, California, USA) (acrylamidebisacrylamide, $\quad 12.5 \%-0.27 \%, \quad 2.2$ C). The analyses were performed in triplicate for each treatment.

\section{Tryptic digestion and analysis of protein spots}

Two dimensional (2-D) gels of independent triplicates of each treatment were revealed by silver staining as described elsewhere (18). The stained gel was digitally scanned and spot detection, quantification and analysis were managed using PDQuest software (Bio-Rad). 2-D gel data were normalized by dividing each spot quantity by the total of all of the valid spots in the 2-D gel image to obtain a normalized spot quantity value. For each matched spot, the mean of the values from three 2-D gels was calculated. The differences in protein expression between controls and treated groups were considered statistically significant at $P<0.05$ applying the Student's $t$ test. Gel spots were excised from the gels using biopsy punches. Proteins selected for analysis were in-gel reduced, alkylated, and digested with trypsin (Promega, Madison, WI). Briefly, spots were washed twice with water, shrunk for $15 \mathrm{~min}$ with acetonitrile $(\mathrm{ACN}) 50 \%(\mathrm{v} / \mathrm{v})$, and dried in a vacuum centrifuge for $30 \mathrm{~min}$. After reduction with $10 \mathrm{mM}$ DTT in 25 $\mathrm{mM} \mathrm{NH} \mathrm{HCO}_{3}$ for $30 \mathrm{~min}$ at 55 ${ }^{\circ} \mathrm{C}$, the samples were alkylated with $55 \mathrm{mM}$ IAA in $25 \mathrm{mM} \mathrm{NH}_{4} \mathrm{HCO}_{3}$ in $\mathrm{ACN} 50 \%(\mathrm{v} / \mathrm{v})$ for $20 \mathrm{~min}$. Then, samples were dehydrated with ACN $100 \%$ for $5 \mathrm{~min}$ and digested with $12.5 \mathrm{ng} / \mathrm{mL}$ sequencing grade trypsin (Promega) in $25 \mathrm{mM} \mathrm{NH}_{4} \mathrm{HCO}_{3}$ $(\mathrm{pH} 8.5)$ for at least $16 \mathrm{~h}$ at $37^{\circ} \mathrm{C}$.

\section{Identification of peptides and database search}

Peptide analyses were performed using an Applied Biosystems 4700 Proteomics Analyzer mass spectrometer (Applied Biosystems, Framingham, MA) equipped with a $355 \mathrm{~nm}$ pulsed nitrogen laser and operated in reflectron positive ion mode as previously reported (19). Briefly, the digested samples were mixed with a $5 \mathrm{mg} / \mathrm{mL} \alpha$-Cyano4-hydroxycinnamic acid (CHCA) matrix solution and dissolved in ACN 50\% (v/v) with formic acid $0.1 \%(\mathrm{v} / \mathrm{v})$. The indicated collision cell pressure was increased from $4.0 \times 10^{-8} \mathrm{mbar}$ (no collision gas) to $6.6 \times 10^{-7}$ mbar. At a resolution above 10,000 in MS mode, the monoisotopic peptide signals could be accurately mass measured $(<50$ $\mathrm{ppm})$. The mass spectrometry (MS) 
and MS/MS spectrum data of tryptic peptides were obtained from MALDI-TOF MS in the reflector mode and used to search for protein candidates in SwissProt and/or National Center for Biotechnology Information (NCBI) databases using MASCOT v 2.3. Only those spots that were found in all the independent replicates were considered for further protein fingerprinting and database interrogation. We determined that a protein was correctly identified if the search results satisfied the following criteria: (i) protein is from the correct species (Homo sapiens); (ii) peptide mass tolerance of $50 \mathrm{ppm}$; (iii) MS/ MS ion mass tolerance of $0.25 \mathrm{Da}$; (iv) allow up to one missed cleavage; (v) variable modifications considered were Cys as $S$-carbamidomethyl derivative and Met in oxidized form.

\section{Statistical analysis}

One-way analysis of variance (ANOVA) and the tukey post test were applied. Statistical significance was established at $<0.05$ for all comparisons. SPSS v.15 software (SPSS Inc., Chigado, USA) was used for the statistical analysis.

\section{RESULTS AND DISCUSSION}

A recent proteomic approach demonstrated that Caco-2 cells, although they have a tumoral origin, express proteins that are characteristic of human intestinal epithelium at comparable levels to small intestinal scrapings supporting their use to mimic the small intestine (20). Representative 2-D gels of Caco2 cell proteomes after the different treatment are shown in Figure 1. The proteome of cell cultures exhibited different protein expression patterns (Table 1).

In Caco-2 cultures exposed to gliadin digested without $B$. longum CECT 7347 the spots that were up-regulated included proteins that participate in the cellular signalling of gliadin (G12); proteins of the actin filaments and cycle progression (G13), proteins of the outer nuclear membrane that are linked to intermediate filaments (G9) and proteins associated with microtubules (G6 and G5); proteins that regulate apoptosis via apoptotic protease activating factor 1 (APAF-1) and stress-induced apoptosis (G20); and proteins that participate in the cross-talk between intestinal and immune cells (G15 and G17).

The up-regulation detected in regulator G-protein signalling 5 (G12) could reflect the cellular response to counteract the cytotoxic effect of gliadin through their interaction with the CXCR3, a 7-transmembrane G-protein coupled receptor (7). This result is concordant with the significant inhibition of $\mathrm{NF}-\kappa \mathrm{B}$ activation mediated by both G-protein coupled receptor kinase-2 and -5 reported in other studies (21). It has been also reported that gliadin induced deterioration of actin cytoskeleton and function of intestinal proteins in Caco-2 cells 

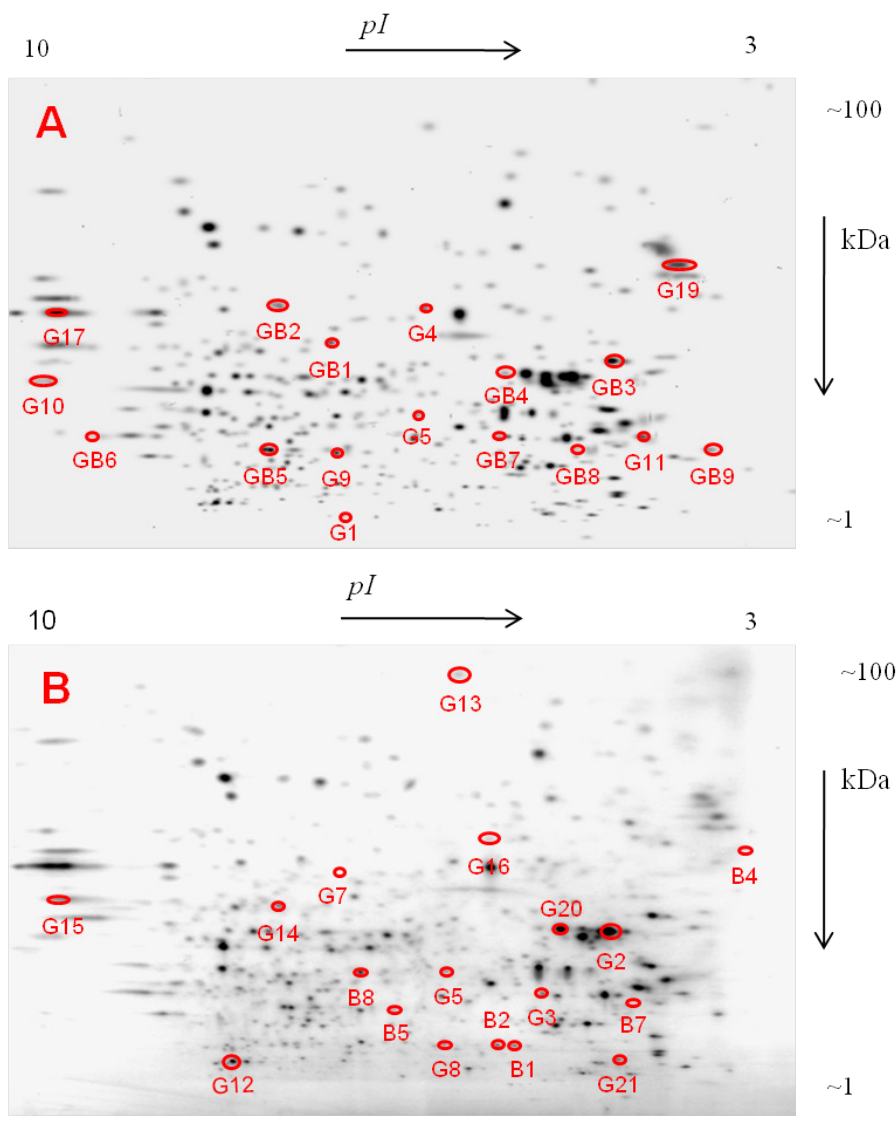

Figure 1: 2-D gel images of the proteins extracted from the Caco-2 cells exposed to gliadin (A) and gliadin inoculated with B. longum CECT 7347 (B). The first dimension was run on an inmobilized $\mathrm{pH}$ gradient (3-10) and the second dimension resolved in a SDS-PAGE $18 \mathrm{~cm}$ gel. Proteins were visualized by silver staining. Images show one representative gel of three independent samples. Arrows refer to spots that have been identified by MALDI-TOF MS. The name of the spots corresponds to the nomenclature used in Table 1.

(22). The up-regulation of proteins such as Sorting nexin-20 (G15) in response to the gliadin challenge could be related to the activation of interactions between intestinal epithelial cells and immune cells. This protein cycles P-selectin glycoprotein ligand 1 (PSLG1) into endosomes, via high affinity calciumdependent interactions with E-, Pand L-selectins (23). Enterocytes, which express human leukocyte antigen (HLA)-DR proteins, are capable of processing transcytosing 
Table 1. List of identified protein spots of Caco-2 cultures exposed to digested gliadin, inoculated (GB) or not (G) with B. longum CECT 7347, and to B. longum CECT $7347\left(10^{8} \mathrm{CFU} / \mathrm{mL}\right)$ alone (B) showing differential production compared to control cultures.

\begin{tabular}{|c|c|c|c|c|c|}
\hline & Protein identified $(\mathrm{Mr} / \mathrm{PI})^{a}$ & $\begin{array}{l}\text { Accession } \\
\text { number }^{b}\end{array}$ & $\begin{array}{c}\text { Score/ } \\
\text { peptides } \\
\text { matched }\end{array}$ & $\begin{array}{c}\text { (\%) } \\
\text { Seq } \\
\text { Cover }\end{array}$ & $\begin{array}{c}\text { Express } \\
\text { ion to } \\
\text { control }^{c}\end{array}$ \\
\hline G1 & AN1-type zinc finger protein $3(26023 / 7.42)$ & Q9H8U3 & $28 / 2$ & 14 & 7.72 \\
\hline G2 & Coiled-coil domain-containing protein $29(32003 / 6.41)$ & Q4UJ79 & $41 / 3$ & 12 & 0.01 \\
\hline G3 & DNA topoisomerase 3-alpha $(114239 / 8.69)$ & Q13472 & $57 / 9$ & 8 & 48.69 \\
\hline G4 & Keratin, type I cytoskeletal 17 (48361 /4.97) & Q04695 & $72 / 8$ & 19 & 0.06 \\
\hline G5 & Kinetochore protein Spc25 (26194 /7.71) & Q9HBM1 & $47 / 4$ & 15 & 5.73 \\
\hline G6 & Microtubule-actin cross-linking factor $1(623626 / 5.27)$ & Q9UPN3 & $52 / 8$ & 1 & 1.31 \\
\hline G7 & Myosin-Vc (203978 /7.69) & Q9NQX4 & $51 / 7$ & 4 & 19.81 \\
\hline G8 & NEDD4-binding protein $3(60889 / 8.33)$ & O15049 & $50 / 6$ & 12 & 1.91 \\
\hline G9 & Nesprin-3 (112774 /5.88) & Q6ZMZ3 & $61 / 9$ & 12 & 1.25 \\
\hline G10 & $\begin{array}{l}\text { Probable global transcription activator SNF2L1 } \\
(123211 / 8.26)\end{array}$ & P28370 & $43 / 7$ & 5 & 22.40 \\
\hline G11 & Protein SSX5 (21647/9.35) & O60225 & $37 / 2$ & 14 & 0.66 \\
\hline G12 & Regulator of G-protein signalling 5 (21104 /6.85) & O15539 & $27 / 3$ & 8 & 1.50 \\
\hline G13 & RhoGEF and PH domain-containing prot $1(107691 / 6.14)$ & P98174 & $36 / 3$ & 4 & 5.80 \\
\hline G14 & Secretagogin $(32190 / 5.25)$ & O76038 & $47 / 4$ & 17 & 1.65 \\
\hline G15 & Sorting nexin-20 (36668 /8.94) & Q7Z614 & $27 / 2$ & 8 & 3.60 \\
\hline G16 & Tetratricopeptide repeat protein $38(53267 / 5.61)$ & Q5R3I4 & $44 / 3$ & 7 & 2.20 \\
\hline G17 & T-cell receptor $\alpha$ chain V region CTL-L17(15545/8.54) & P04437 & $41 / 3$ & 14 & 4.71 \\
\hline G18 & Ubiquitin-protein ligase E3A (101593/5.12) & Q05086 & $42 / 4$ & 5 & 0.31 \\
\hline G19 & $\begin{array}{l}\text { UV excision repair protein RAD23 homolog A } \\
(39642 / 4.56)\end{array}$ & P54725 & $57 / 7$ & 17 & 0.24 \\
\hline G20 & Uveal autoantigen with coiled-coil domains $(163545 / 6.60)$ & Q9BZF9 & $33 / 5$ & 3 & 3.90 \\
\hline G21 & $\begin{array}{l}\text { V-set and transmembrane domain-containing prot } 1 \\
(26405 / 4.98)\end{array}$ & Q6UX27 & $27 / 2$ & 17 & 0.57 \\
\hline B1 & Cell death activator CIDE-A (24899/9.34) & O60543 & $41 / 3$ & 21 & 1.67 \\
\hline B2 & Docking protein $6(38692$ / 8.72) & Q6PKX4 & $31 / 3$ & 10 & 1.41 \\
\hline B3 & Elongation factor $2(96246 / 6.41)$ & P13639 & $31 / 3$ & 3 & 75.70 \\
\hline B4 & Leucine-rich repeat-containing prot $45(76475 / 5.95)$ & Q96CN5 & $50 / 6$ & 10 & 0.08 \\
\hline B5 & $\begin{array}{l}\text { SH3 domain-binding glutamic acid-rich-like protein } 2 \\
(12375 / 6.29)\end{array}$ & Q9UJC5 & $21 / 1$ & 16 & 3.26 \\
\hline B6 & Spectrin alpha chain $(280884 / 4.96)$ & P02549 & $42 / 5$ & 2 & 0.09 \\
\hline B7 & U6 snRNA-associated Sm-like protein LSm4 (15511/10.02) & Q9Y4Z0 & $38 / 3$ & 17 & 2.68 \\
\hline B8 & Zinc finger protein $540(79325 / 9.58)$ & Q8NDQ6 & $54 / 4$ & 5 & 0.72 \\
\hline GB1 & Dynein heavy chain 10 , axonemal (517677 /5.64) & Q8IVF4 & $50 / 10$ & 3 & 1.38 \\
\hline GB2 & EF-hand domain-containing (24092 /8.95) & A8MZ26 & $44 / 3$ & 14 & 3.68 \\
\hline GB3 & EF-hand domain-containing $(67022 / 9.51)$ & Q6NXPO & $41 / 4$ & 8 & 1.68 \\
\hline GB4 & Golgin subfamily A member $4(261892 / 5.33)$ & Q13439 & $85 / 17$ & 8 & 0.61 \\
\hline GB5 & Myosin-4 (223844 /5.67) & Q9Y623 & $50 / 8$ & 6 & 0.33 \\
\hline GB6 & RWD domain-containing protein 4A (21238 /5.24) & Q6NW29 & $36 / 2$ & 14 & 23.27 \\
\hline GB7 & Signal recognition particle $54 \mathrm{kDa}$ protein $(55953 / 8.87)$ & P61011 & $51 / 4$ & 10 & 229.80 \\
\hline GB8 & Trafficking protein particle sub $26(18199 / 8.88)$ & Q86SZ2 & $29 / 2$ & 13 & 4.39 \\
\hline GB9 & Zinc finger protein 64 homolog $(74565 / 8.80)$ & Q9NTW7 & $46 / 5$ & 9 & 472.01 \\
\hline
\end{tabular}

${ }^{a}$ Theoretical molecular mass $(\mathrm{Mr}, \mathrm{Da})$ and theoretical $p I$ of the corresponding protein based on the SwissProt database. ${ }^{b}$ SwissProt accession number. ${ }^{c}$ The relative expression to controls was determined by comparing the mean value of each spot to that of the corresponding spots of control cultures and expressed as a ratio. Significant differences in protein expression were calculated from triplicate analyses applying the Student's $t$ test $(\mathrm{p}<0.05)$. 
and presenting food antigens to T-lymphocytes of the lamina propria (24). PSGL1 is critical to initial leukocyte capture (25), and could mediate the interactions between enterocytes and T-lymphocytes in response to gliadin. Gliadin exposure also caused up-regulation of the T-cell receptor alpha chain $\mathrm{V}$ region CTL-L17 (G17) in Caco-2 cells. Accordingly, the presence of $\beta / \alpha$ T-cell receptors has been identified in large vacuoles and Golgi complexes of enterocytes from patients with active CD, but not in those from patients on a gluten-free diet (26).

The exposure of Caco-2 cells to digested gliadin also caused the down-regulation of proteins involved in structural functions such as forming stiff bundles of fibres (G2); in DNA-dependent transcription (G11); in post-replication repair functions (G19); in protein synthesis and epithelial cell growth through binding to the adapter protein stratifin and stimulation of the protein kinase $\mathrm{B} /$ mammalian target of rapamycin (Akt/mTOR) pathway (G4); and in the cell cycle (G18).

Cytoskeletal (CK) proteins are major structural proteins in eukaryotic cells, which are usually over-expressed in colon carcinoma (27) and gastric cancer cells (28). However, some CK proteins (CK-18 and -19) are down-regulated during apoptosis (29). Apoptosis has been proposed as a major event underlying villous atrophy in CD (30). In the present study, the down-regulation of gliadin-mediated Keratin type I cytoskeletal 17 (G4) in Caco-2 cells would suggest a pro-apoptotic effect of gliadin. This suggestion is also supported by the up-regulation of Uveal autoantigen with coiled-coil domains (G20), which promotes apoptosis by causing the upregulation of apoptosome, the downregulation of lectin galactosidebinding soluble 3 (LGALS3) and the inactivation of NF-KB. However, different in vitro studies have reported conflicting results regarding gliadin-induced apoptosis in intestinal cells $(6,31)$. These studies suggest the likely existence of a threshold for gliadin to cause toxicity. Wheat gliadin $(0.5-1.5 \mathrm{mg} /$ $\mathrm{mL}$ for $48 \mathrm{~h}$ ) induced apoptosis of not confluent intestinal cells (Caco2) by a receptor-mediated (Fas-Fas ligand) pathway (31) similarly to the results reported in the present study. In contrast, in confluent Caco2 cultures (5 days post-seeding) exposed to digested gliadin (0.25 $\mathrm{mg} / \mathrm{mL}$ for $15 \mathrm{~h}$ ), apoptosis was not detected (6). All the aforementioned changes detected in the proteome of Caco-2 cells after gliadin exposure were associated to an inflammatory response, as reflected by increased TNF- $\alpha$ production (Figure 2); however, the exposure to digests of gliadin did not cause statistically significant $\quad(P>0.05) \quad$ differences in IL-1 $\beta$ and IL-10 production, although the results showed a similar trend.

In cell cultures exposed to digested 


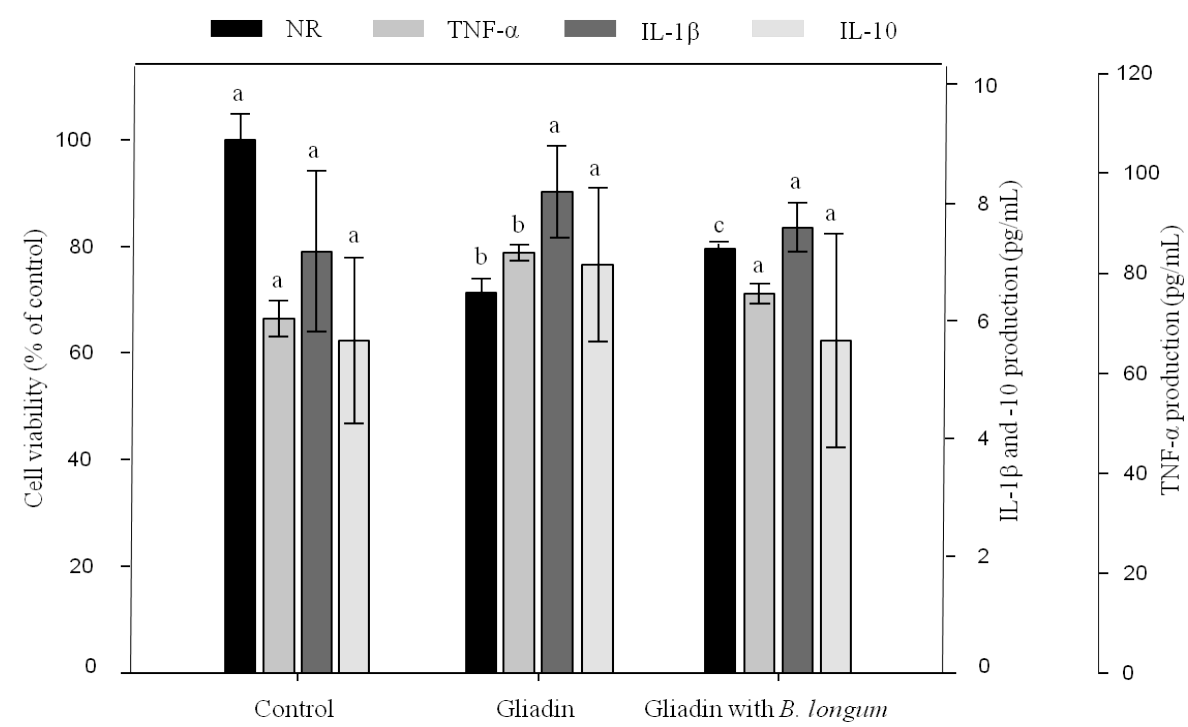

Figure 2. Effect of digested gliadin, inoculated or not with B. longum CECT 7347, on cell viability (Neutral red, NR uptake) and production $(\mathrm{pg} / \mathrm{mL})$ of tumor necrosis alpha (TNF- $\alpha$ ), interleukin (IL)-1 $\beta$, and IL-10. Different superscript letters indicate significant $(P<0.05)$ differences for each treatment.

gliadin inoculated with $B$. longum CECT 7347, changes were detected in nine proteins (Table $\mathbf{1}$ ). The seven up-regulated proteins might participate in vesicular transport (GB8); in calcium homeostasis (GB2); in DNA binding (GB9); and in ubiquitination in the case of proteins associated with ubiquitinprotein ligase activity (GB6). Ubiquitination is not only important in cellular homeostasis, but also in human disease, ensuring controlled degradation of proteins. Even if the up-regulation of proteins involved in this pathway was able to induce ubiquitination and degradation of the $(\mathrm{I} \kappa \mathrm{B} \alpha)$ inhibitor and activate inflammation via the NFKB pathway, the exposure of Caco- 2 cells to gliadin digested with the bifidobacteria was not associated with an inflammatory response (Figure 2). Previous data also demonstrate that NF- $\mathrm{KB}$ is not activated in intestinal cells exposed to digests of gliadin inoculated with B. longum CECT 7347 (6). These results could be explained, at least in part, by the fact that ubiquitin ligases become highly specific by post-translational modification of the substrate proteins, and targets of the ubiquitin ligase also include many other types of proteins, such as cell cycle regulatory proteins and proteins unable to fold properly at 
the endoplasmic reticulum.

EF-hand domain-containing proteins (GB2), which participate in calcium homeostasis, were also up-regulated under the effects of gliadin digested in the presence of the bifidobacteria. This response could result from the activation of molecular systems controlling cytoplasmic $\mathrm{Ca}^{+2}$ levels into cells, which could contribute to stabilizing cytoskeletal alterations caused by gliadin in intestinal cells. It has been reported that gliadin-like peptides binding to CXCR3 receptor induced the over-expression of the glutamate receptor (7) coupled to ion channels controlling $\mathrm{Ca}^{+2}$ influx into cells (32) playing a critical role in the cellular resistance to apoptosis (33). This might suggest that $B$. longum CECT 7347 could reduce gliadin-induced toxicity to intestinal epithelial cells by regulating $\mathrm{Ca}^{+2}$ homeostasis. This hypothesis could explain the increased viabilities of Caco- 2 cells exposed to gliadin digested in the presence of B. longum CECT 7347 compared to those not inoculated with the bacterium (Figure 2).

It has been suggested that Bifidobacterium strains play an important role in health by influencing the host's intestinal barrier functions and the epithelial and immune cell response $(s)(15,34)$. To test this hypothesis, the influence of B. longum CECT 7347 alone on Caco-2 cell proteome was also evaluated. B. longum CECT 7347 exposure induced significant changes in eight proteins, five of which were up-regulated and three were downregulated (Table 1). B. longum CECT 7347 induced proteins involved in ribosomal translation (B3 and $\mathrm{B} 7$ ); in cell proliferation (B1); and in bacterial recognition (B4). The upregulation of proteins involved in ribosomal translation in the presence of B. longum CECT 7347 could contribute to the adequate synthesis of proteins in intestinal epithelial cells and thus their rapid turnover. Up-regulation of protein leucine-rich repeat-containing protein 45 (B4) could be involved in the bacterial recognition by Toll-like receptors as part of their leucine-rich domains (35).

The exposure of Caco-2 cells to B. longum CECT 7347 also led the down-regulation of the $\mathrm{SH} 3$ domain-binding glutamic acidrich-like protein 2 (B5), zinc finger protein 540 (B8) and spectrin alpha chain (SPTA) (B6). The SPTA is a membrane protein that plays a role in signal transduction, regulating voltage-dependent anion channels (36), which could contribute to gut physiology by modulating electrolyte transport processes through the apical side of enterocytes.

The results from the present study reveal marked changes in the proteome of intestinal epithelial cells in response to their interaction with gliadin-derived peptides. Caco-2 cell cultures exposed to gliadin digested in the absence of B. longum CECT 7347 showed 
alterations of key proteins involved in CK integrity, cell apoptosis and interactions with immune cells, and significant increases in TNF- $\alpha$ production. In contrast, when gliadin was digested in the presence of B. longum CECT 7347 their effect on the proteome was ameliorated, inducing alterations in a lower number of proteins. These proteins were involved in controlling ionic homeostasis, CK integrity and signal transduction. Altogether, the results suggest that B. longum CECT 7347 reduces the toxic and inflammatory effects of gliadin-derived peptides, and could contribute to improving the survival and physiological function of intestinal epithelial cells. The significance of these proteomic changes in vivo deserves further investigation.

\section{Acknowledgements}

This work was supported by grants AGL200801440/ALI and Consolider Fun-C-Food CSD2007-00063 from the Spanish Ministry of Science and Innovation (MICINN, Spain) and PIF08-010-4 form CSIC. J. M. Laparra has a postdoctoral contract of the programme "Juan de la Cierva" (MICINN, Spain). M. Olivares has a contract supported by grant CEN-20091006 (MICINN, Spain).

\section{REFERENCES}

1. Shan L, Qiao SW, Arent-Hansen $\mathrm{H}$ et al. (2005) Identification and analysis of multivalent proteolytically resistant peptides from gluten: implications for celiac sprue. J Proteome Res 4,
1732-1741.

2. Wieser H, Koehler P (2008) The biochemical basis of celiac disease. Cereal Chem 85, 1-13.

3. Sollid LM, Khosla C (2005) Future therapeutic options for celiac disease. Nat Clin Pract Gastroenterol Hepatol 2, 140-147.

4. Nadal I, Donat E, Ribes-Koninckx C et al. (2007) Imbalance in the composition of the duodenal microbiota of children with coeliac disease. J Med Microbiol 56, 1669-1674.

5. Sanz Y, Sánchez E, Marzotto M et al. (2007) Differences in faecal bacterial communities in coeliac and healthy children as detected by PCR and denaturing gradient gel electrophoresis. FEMS Immunol Med Microbiol 51, 562-568.

6. Laparra JM, Sanz Y (2010). Bifidobacteria inhibit the inflammatory response induced by gliadins in intestinal epithelial cells via modification of toxic peptide generation during digestion. J Cell Biochem 109, 801-807.

7. Lammers $\mathrm{KM}, \mathrm{Lu} \mathrm{R}$, Brownley $\mathrm{J}$ et al. (2008) Gliadin induces an increase in intestinal permeability and zoulin release by binding to the chemokine receptor CXCR3. Gastroenterology 135, 194-204.

8. Laparra JM, Sanz Y. (2010) Gliadins induce TNF-alpha production through cAMP-dependent protein kinase $\mathrm{A}$ activation in intestinal cells (Caco-2). J Physiol Biochem 66, 153-159.

9. Thomas KE, Sapone A, Fasano A et al. (2006) Gliadin stimulation of murine macrophage inflammatory gene expression and intestinal permeability are MyD88-dependent: role of the innate immune response in Celiac Disease. $J$ Immunol 176, 2512-2521.

10. Nilsen EM, Jahnsen FL, Lundin KE et al. (1998) Gluten induces an intestinal cytokine response strongly dominated by interferon gamma in patients with celiac disease. Gastroenterology $115,551-563$.

11. Beckett CG, Dell'Olio D, Shidrawi RG et al. (1999) Gluten-induced nitric oxide and proinflammatory cytokine release by cultured coeliac small intestinal biopsies. Eur. J. Gastroenterol Hepatol 11, 529-535.

12. Maiuri MC, De Stefano D, Mele G et al. (2003) Nuclear factor kappa B is activated in small intestinal mucosa of celiac patients. J Mol Med 81, 373-379.

13. Viatour P, Merville MP, Bours V et al. (2005)

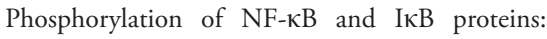
implications in cancer and inflammation. Trends Biochem Sci 30, 43-52.

14. Clemente MG, De Virgiliis S, Kang JS et al. (2003) Early effects of gliadin on enterocyte intracellular signalling involved in intestinal barrier 
function. Gut 52, 218-223.

15. Medina M, De Palma G, Ribes-Koninckx C et al. (2008) Bifidobacterium strains suppress in vitro the pro-inflammatory milieu triggered by the large intestinal microbiota of coeliac patients. J Inflamm (Lond) 3, 5-19.

16. Laparra JM, Glahn RP, Miller DD (2009) Assessing potential effects of inulin and probiotic bacteria on $\mathrm{Fe}$ availability from common beans (Phaseolus vulgaris L.) to Caco-2 cells. J Food Sci 74, 40-46.

17. Marvin-Guy L, Lopes LV, Affolter $M$ et al. (2005) Proteomics of the rat gut: analysis of the myenteric plexus-longitudinal muscle preparation. Proteomics 5, 2561-2569.

18. Yan JX, Wait R, Berkelman T et al. (2000) A modified silver staining protocol for visualization of proteins compatible with matrix-assisted laser desorption/ionization and electrospray ionizationmass spectrometry. Electrophoresis, 21, 3666-3672.

19. Lin WY, Hsu WY, Hish CH et al. (2007) Proteome changes in Caco-2 cells treated with Monascus-Fermented red mold rice extract. J Agric Food Chem 55, 8987-8994.

20. Lenaerts K, Bouwman FG, Lamers WH et al. (2007) Comparative proteomic analysis of cell lines and scrapings of the human intestinal epithelium. BMC Genomics 3, 80-91.

21. Patial S, Luo J, Porter KJ et al. (2009) G-protein coupled-receptor kinases mediate TNF $\alpha$-induced $\mathrm{NF \kappa B}$ signaling via direct interaction with and phosphorylation of $\mathrm{I} \kappa \mathrm{B} \alpha$. Biochem $J$ 425, 169178.

22. Reinke Y, Zimmer KP, Naim HY (2009) Toxic peptides in Frazer's fraction interact with the actin cytoskeleton and affect the targeting and function of intestinal proteins. Exp Cell Res 315, 3442-3452. 23. Rodgers SD, Camphausen RT, Hammer DA (2001) Tyrosine sulfation enhances but is not required for PSGL-1 rolling adhesion on P-selectin. Biophys J 81, 2001-2009.

24. Zimmer KP, Poremba C, Weber P et al. (1995) Translocation of gliadin into HLA-DR antigen containing lysosomes in coeliac disease enterocytes. Gut 36, 703-709.

25. Bernimoulin MP, Zeng XL, Abbal C et al. (2003) Molecular basis of leukocyte rolling on PSGL-1. Predominant role of core-2 O-glycans and of tyrosine sulfate residue 51. J Biol Chem 278, 37-47.

26. Zimmer KP, Naim H, Weber P et al. (1998) Targeting of gliadin peptides, CD8, $\alpha / \beta / \mathrm{TCR}$, and $\gamma / \delta$-TCR to Golgi complexes and vacuoles within celiac disease enterocytes. FASEB J 12, 1349-1357. 27. Pantel K, Schlimok G, Braun S et al. (1993) Differential expression of proliferation-associated molecules in individual micrometastatic carcinoma cells. J Natl Cancer Inst 85, 1419-1424.

28. Kim H, Page GP, Barnes S (2004) Proteomics and mass spectrometry in nutrition research. Nutrition 20, 155-165.

29. Svasti J. Srisomsap C, Subhasitanont P et al. (2005). Proteomic profiling of cholangiocarcinoma cell line treated with pomiferin from Derris malaccensis. Proteomics 5, 4504-4509.

30. Moss SF, Attia L, Scholes JV et al. (1996) Increased small intestinal apoptosis in celiac disease. Gut 39, 811-817.

31. Giovannini C, Sánchez M, Straface E et al (2000) Induction of apoptosis in Caco-2 cells by wheat gliadin peptides. Toxicology 145, 63-71.

32. Mayer M (2004). Structure and function of glutamate receptors. Ann NY Acad Sci 1038, 125 130.

33. Vanoverberghe K, Vanden Abeele F, Mariot $\mathrm{P}$ et al. (2004) $\mathrm{Ca}^{2+}$ homeostasis and apoptotic resistance of neuroendocrine-differentiated prostate cancer cells. Cell Death Differ 11, 321330.

34. Young SL, Simon MA, Baird MA et al. (2004) Bifidobacterial species differentially affect expression of cell surface markers and cytokines of dendritic cells harvested from cord blood. Clin Diagn Lab Immunol 11, 686-690.

35. Akira S, Takeda K (2004) Toll-like receptor signalling. Nat. Rev. Immunol. 4, 499-511.

36. Vanderpool C, Yan F, Polk DB (2008) Mechanisms of probiotic action: Implications for therapeutic applications in inflammatory bowel diseases. Inflamm Bowel Dis 14, 1585-1596.

37. Bennett V, Baines AJ (2001) Spectrin and Ankyrin-Based Pathways: Metazoan Inventions for Integrating Cells Into Tissues. Physiol Rev 81, 1353-1392. 


\section{Chapter 2}

- Bifidobacterium longum CECT 7347 modulates immune responses in a gliadin-induced enteropathy animal model 


\section{Bifidobacterium longum CECT 7347 modulates immune responses in a gliadin-induced enteropathy animal model}

Laparra JM, Olivares M, Gallina O, Sanz, Y.

PLoS One (2012) 7e30744

Microbial Ecology and Nutrition Research Group, Institute of Agrochemistry and Food Technology, National Research Council (IATA-CSIC), Valencia, Spain 


\section{ABSTRACT}

Coeliac disease $(\mathrm{CD})$ is an autoimmune disorder triggered by gluten proteins (gliadin) that involves innate and adaptive immunity. In this study, we hypothesise that the administration of Bifidobacterium longum CECT 7347, previously selected for reducing giadin immunotoxic effects in vitro, could exert protective effects in an animal model of gliadininduced enteropathy. The effects of this bacterium were evaluated in newborn rats fed gliadin alone or sensitised with interferon (IFN)- $\gamma$ and fed gliadin. Jejunal tissue sections were collected for histological, NFKB mRNA expression and cytokine production analyses. Leukocyte populations and T-cell subsets were analysed in peripheral blood samples. The possible translocation of the bacterium to different organs was determined by plate counting and the composition of the colonic microbiota was quantified by real-time PCR. Feeding gliadin alone reduced enterocyte height and peripheral CD4+ cells, but increased CD4+/Foxp3+ T and CD8+ cells, while the simultaneous administration of B. longum CECT 7347 exerted opposite effects. Animals sensitised with IFN- $\gamma$ and fed gliadin showed high cellular infiltration, reduced villi width and enterocyte height. Sensitised animals also exhibited increased NFKB mRNA expression and TNF- $\alpha$ production in tissue sections. $B$. longum CECT 7347 administration increased NFKB expression and IL-10, but reduced TNF- $\alpha$, production in the enteropathy model. In sensitised gliadin-fed animals, CD4+, CD4+/Foxp3+ and CD8+ T cells increased, whereas the administration of $B$. longum CECT 7347 reduced CD4+ and CD4+/Foxp3+ cell populations and increased CD8+ T cell populations. The bifidobacterial strain administered represented between $75-95 \%$ of the total bifidobacteria isolated from all treated groups, and translocation to organs was not detected. These findings indicate that $B$. longum attenuates the production of inflammatory cytokines and the CD4+ T-cell mediated immune response in an animal model of gliadininduced enteropathy.

Keywords: Coeliac disease, Bifidobacterium, gliadin, weaning rats, enteropathy. 


\section{INTRODUCTION}

Coeliac disease (CD) is an autoimmune enteropathy triggered by cereal gluten proteins (gliadin) in genetically predisposed individuals (1). In CD patients, peptides resulting from incomplete protein hydrolysis by digestive enzymes cause a deregulated immune response and inflammation. The degree of intestinal inflammation can vary from intraepithelial lymphocytosis to severe infiltration of mononuclear cells in the lamina propria, causing villous atrophy and crypt cell hyperplasia in the small intestine (2). Several attempts have been made to develop animal models that reproduce $\mathrm{CD}$ pathogenesis, including the immune response, the mucosal lesions and the symptoms (3-5). The intragastric administration of gliadin to inbred rats after weaning (4) or to immunocompetent mice at 10 days of age failed to reproduce the damage of the intestinal mucosa (6). Human leukocyte antigen (HLA)-DQ8/HCD4 or single HLADQ8 transgenic mice sensitised with gluten developed an immune response to gliadin that involved both the adaptive and innate immune system $(7,8)$ and dependent changes in gut neuromuscular and epithelial secretory function (8), but did not develop a gluten-dependent enteropathy. Nevertheless, repeated oral administration of gliadin to rats, previously sensitised with interferon gamma (IFN- $\gamma$ ) immediately after birth, caused mucosal lesions characterised by shortening of jejunal villi, crypt hyperplasia, and increased cellular infiltration, including CD8 $\alpha \beta+$ and CD4+ T lymphocytes (9). Activation of CD4+ T-helper 1 (Th1) cells that produce IFN- $\gamma$ and intraepithelial CD8+ lymphocytes are responsible for the cytotoxic effects on intestinal epithelium, which in turn could increase passage of gliadin antigens to the lamina propria and further activate the CD4+ Th1 cell response $(10,11)$. Thus, this model reproduces a CD4+ $\mathrm{T}$ cell mediated enteropathy, defined as hyperplasic-infiltrative (type II), similar to that described in CD patients (9). Undoubtedly, further refinement of the available animal model of CD is desirable, but it is considered appropriate to initially explore pathogenic mechanism and potential pharmaceutical or nutritional interventions (9). The production of $\mathrm{T}$ cells with regulatory activity (Tregs) constitutes one of immunosuppressive mechanisms that contribute to intestinal tolerance and prevention of autoimmunity. In particular, natural self-antigenreactive $\mathrm{CD} 4+\mathrm{CD} 25+$ cells acquired Foxp3 expression, a key marker of the development of regulatory activity, in the thymus and then enter peripheral tissues, where they can suppress the activation of other self-reactive $\mathrm{T}$ cells contributing to immune tolerance. These Tregs (CD4+CD25+Foxp3+) are particularly increased in the mucosa 
and peripheral blood of active $\mathrm{CD}$ patients as a consequence of the activation of a regulatory response to counteract the inflammation caused by gluten $(12,13)$, but their role in animal models of CD has not been studied so far.

In recent years, innate immunity and early interactions of gliadin-derived peptides with intestinal epithelial cells have also been considered critical in the development of the disease. Some gluten peptides can mediate an innate-immune response that involves induction of interleukine (IL)-15 production by epithelial and dendritic cells. IL-15 induces up-regulation of the nonMHC class I receptor NKG2D on intraepithelial lymphocytes (IELs), and its ligand MICA on epithelial cells, that interact and activate cytolytic function on enterocytes (14). The activation of the NFKB pathway in intestinal epithelial cells also mediates the production of other inflammatory cytokines, such as the tumour necrosis factor (TNF)- $\alpha$, which facilitates the interaction of IELs and intestinal epithelial cells promoting tissue inflammation (15). In germ-free rat pups, colonisation by the whole microbiota has similar effects as administration of gliadin on IEL subpopulations, suggesting that both factors activate common immunological responses that may influence CD development (4). Human studies also report that CD is characterised by imbalances in the composition of the microbiota and, particularly, reduced numbers of total bifidobacteria and B. longum (16). In vitro studies have demonstrated that the presence of $B$. longum CECT 7347 during the intestinal digestion of gliadin leads to the generation of different peptide sequences and reduces their toxic and inflammatory effects on intestinal epithelial cells (17). In addition, B. longum CECT 7347 has been shown in vitro to counteract the inflammatory response induced by the altered faecal microbiota of CD patients in peripheral blood mononuclear cells (18). Yet, the possible in vivo effects of this bifidobacterial strain on CD have not been evaluated.

In the light of the evidence available, in this study we hypothesise that the administration of $B$. longum CECT 7347, with immunoregulatory properties and ability to attenuate in vitro gliadin toxicity on epithelial cells, could exert protective effects in a model of gliadin-induced enteropathy in weaning rats.

\section{MATERIAL AND METHODS}

Bacterial strain and culture
conditions
Bifidobacterium longum CECT 7347 was isolated from faeces of healthy infants as described elsewhere (18). The bacterial cultures were grown in Man-Rogosa-Sharpe agar and broth (Scharlau, Barcelona, Spain) supplemented with $0.05 \% \quad(\mathrm{w} / \mathrm{v})$ cysteine (MRS-C; Sigma-Aldrich, St. 
Louis, USA), and kept at $37{ }^{\circ} \mathrm{C}$ in anaerobic conditions (AnaeroGen, Oxoid, Basingstoke, UK) for $24 \mathrm{~h}$. For animal studies, a pure culture of the strain was grown overnight and used to inoculate fresh MRS-C broth for $22 \mathrm{~h}$. Cells were harvested by centrifugation $(6,000 \mathrm{xg}$ for $15 \mathrm{~min})$ at stationary growth phase, washed twice in phosphate buffered saline (PBS, $130 \mathrm{mM}$ sodium chloride and $10 \mathrm{mM}$ sodium phosphate, $\mathrm{pH}$ 7.4), and re-suspended in $10 \%(\mathrm{w} / \mathrm{v})$ hypoallergenic milk-based formula (Nutramigen $^{\oplus}$, Mead Johnson B.V., Nijmegen, Netherlands). Aliquots of these cell suspensions were frozen in liquid nitrogen and stored at -80 ${ }^{\circ} \mathrm{C}$ until used. The number of live cells after freezing and thawing was determined by plate counting on MRS-C agar after 48 h of incubation, and were expressed as colony-forming units (CFU) per mL. More than 90\% of cells were alive upon thawing and no significant differences were found during storage time ( 4 months). One fresh aliquot was thawed for every new experiment to avoid variability in bacterial cell viability between experiments.

\section{Animals and experimental design}

Animal experiments were carried out in strict accordance with the recommendations in the Guide for the Care and Use of Laboratory Animals of University of Valencia (SCSIE, University of Valencia, Spain) and the protocol was approved by its Ethic Committee.
Experimental animals were female, weaning Wistar rats, provided by the SCSIE. The adult females were date-mated, and fed ad libitum with a standard diet (Harlan Bioproducts, Indianapolis, USA). Shortly after spontaneous birth, animals were randomly distributed into seven different groups ( $\mathrm{n}=6$ per group): 1) artificially reared (AR) with the hypoallergenic milk-based formula; 2) $A R$ and fed B. longum CECT 7347; 3) AR and fed gliadin-derived peptides (GP); 4) AR and fed GP and $B$. longum CECT $7347 ; 5$ ) AR sensitised with $1,000 \mathrm{U}$ IFN- $\gamma$ administered intraperitoneally immediately after birth; 6) AR sensitised with IFN- $\gamma$ and fed GP; 6) AR sensitised with IFN- $\gamma$ and fed GP and B. longum CECT 7347.

Newborn animals were hand-fed $(100 \mu \mathrm{L})$ using a micropipette every 4 hours (4-5 times a day) until the age of 10 days. They were fed with the hypoallergenic milk-based formula for newborns, composed of: $19 \mathrm{~g}$ proteins; $34 \mathrm{~g}$ fats; $75 \mathrm{~g}$ carbohydrates; $680 \mathrm{Kcal} ; 260 \mathrm{mOsm}$ per L. The bacterium was administered at a concentration of $6.0 \times 10^{7}-8.2 \times 10^{8}$ CFU/day, as determined by plate counting on MRS-C agar, in a single dose during the 10 days. To obtain the GP, a commercially available extract of gliadin (Sigma-Aldrich, St. Louis, USA) was submitted to in vitro digestion and then dialysed using a $15 \mathrm{kDa}$ cut-off membrane (17). Weaning rats were fed $50 \mu \mathrm{g}$ gliadin/day in a single dose during 
the 10 days and finally they received a provocative dose of gliadin $100 \mu \mathrm{g}$ $\sim 2$ hours before sacrifice.

Changes in body weight were monitored every two days. After treatment, rats were anaesthetised (isofluran) and killed by exsanguination. Whole blood samples were preserved in EDTAtreated tubes to prevent coagulation (at room temperature) for leukocyte analyses. Sections $(1 \mathrm{~cm})$ of the proximal jejunum were immersed in RNA later buffer (Qiagen, USA) or Krebs's buffer and kept at $-80^{\circ} \mathrm{C}$ for gene expression and cytokine analyses. Liver, spleen and colon content samples were also collected in PBS and immediately used for microbiological analyses by plate culturing.

\section{Histologic and morphometric evaluation}

Jejunal tissue sections $(1 \mathrm{~cm})$ were fixed in formaldehyde $10 \%$ and then sections of $5 \mu \mathrm{m}$ were stained with haematoxylin-eosin. The samples were analysed with a Nikon Eclipse 90i microscope equipped with a Nikon DS-5Mc digital camera. Photos were analysed with the Nis Elements software (Nikon Instruments Inc., Melville, USA). The parameters analysed included villi width and length and number of infiltrated cells in the lamina propria because their changes characterized the histologic lesions of this enteropathy, and the number and height of enterocytes that provide an indication of the disorganization of the cellular epithelial layer.

\section{Leukocyte counts}

The morphological identification of immune cells was conducted by the May-Grünwald Giemsa's staining procedure. Aliquots $(25 \mu \mathrm{L})$ of blood samples were extended on glass slides and were allowed to air-dry. The samples were covered with MayGrünwald's solution (Sigma-Aldrich, St. Louis, USA) for 3 minutes, and afterwards an equal volume of PBS was added and incubated for 3 additional minutes. The preparations were gently rinsed with $\mathrm{PBS}$, and then covered with a dilution $(1: 20, \mathrm{v} / \mathrm{v})$ of the Giemsa stain-modified solution in PBS for 12 minutes. Finally, the samples were washed, air-dried and analysed using an Olympus BX51 microscope (Madrid, Spain).

\section{Lymphocyte phenotyping}

Aliquots $(100 \mu \mathrm{L})$ of peripheral blood were mixed with the following fluorochrome-conjugated antibodies: Anti-rat CD 45, CD4, CD8 and Foxp3 (eBiosciences, Hattfield, UK). Then samples were prepared for flow cytometry analysis with the Immunoprep kit (Beckman Coulter, USA) according to the manufacturer's instructions, and further analysed on a Modular Flow Cytometer Cell Sorter (MoFlo Sorter, Dakocytomation, USA). 
Real-time reverse transcriptionpolymerase chain reaction (RTqPCR)

Total RNA was extracted from tissue samples with the RNeasy mini kit (Qiagen) according to the manufacturer's instructions. One microgram of total RNA was converted to double-stranded cDNA using AMV Reverse Transcriptase (Promega, Madison, USA). PCR was performed with primers designed for the following Rattus norvegicus genes: NFкB (forward 5'- CTT CTC GGA GTC CCT CAC TG-3', reverse 5'CCA ATA GCA GCT GGA AAA GC-3') and $\beta$-actin (forward 5'CTC TTC CAG CCT TCC TTC CT-3'; reverse 5'- TAG AGC CAC CAA TCC ACA CA-3'), the latter used as a housekeeping gene. The PCR mix (20 $\mu \mathrm{L}$ reaction volume) consisted of $7.5 \mu \mathrm{L}$ SYBR Green I master mix, $1.3 \mu \mathrm{mol} / \mathrm{L}$ primers, and $2.5 \mu \mathrm{L}$ cDNA. PCR reactions were performed in triplicate in a LightCycler 480 (Roche) system with the following conditions: 1 cycle at $95^{\circ} \mathrm{C}$ for $5 \mathrm{~min}, 35$ cycles at $60{ }^{\circ} \mathrm{C}$ for $20 \mathrm{~s}$ and $72{ }^{\circ} \mathrm{C}$ for 45 s. The relative mRNA expression of the tested gene relative to $\beta$-actin expression was calculated using the $2^{-\Delta \Delta C_{\mathrm{P}}}$ method (19). Samples of each animal tissue were measured in duplicate and gene expression was expressed as fold-change.

\section{Cytokine protein assay}

Jejunal tissue sections $\left(\begin{array}{ll}1 & \mathrm{~cm}\end{array}\right)$ were kept in Krebs's buffer (1 $\mathrm{ml}$ ) supplemented with protease inhibitors (Roche) until analysis. Tumour necrosis factor- $\alpha$ (TNF- $\alpha$ ) (Diaclone, Besançon, France), and interleukine (IL)-10 (Abcam, Cambridge, UK) were determined by ELISAs according to the manufacturer's instructions. Prior to cytokine determination, tissue samples were homogenised in cell lysis buffer using a TissueRuptor (Qiagen). Then, samples were centrifuged (1000 xg, $15 \mathrm{~min}$ ) to get clear supernatants for cytokine determination. The results of the ELISA assay are expressed as picograms per gram of tissue ( $\mathrm{pg} / \mathrm{g})$.

\section{Microbiological analyses}

Aliquots $(50 \mathrm{mg})$ of different biologic samples (colon content, mesenteric lymph nodes (MLN), spleen and liver) were diluted (1/9) in PBS and decimal dilutions were plated on MRS-C agar supplemented with mupirocin $(80 \mathrm{mg} / \mathrm{L})$ (SigmaAldrich) and acetic acid ( $1 \mathrm{ml} / \mathrm{L})$ to increase the selectivity of the medium for bifidobacteria. Counts were performed on the highest dilution plates and were expressed as colony forming units (CFU) per gram of faeces. Isolated colonies (810) from colon samples were also checked by RAPD PCR analysis to confirm whether the DNA profile of the isolates corresponded with the DNA profile of a pure culture of the administered strain $B$. longum CECT 7347. The random primer 1254 (5'CCG CAG CCA A-3') was used for 
RAPID-PCR analysis as previously described (20). The RAPD-PCR products were visualised on a $1.5 \%$ w/v agarose gel after staining with ethidium bromide.

The composition of the microbiota was also analysed by real-time PCR. Samples of colon content were collected, diluted 1/9 in PBS and homogenised thoroughly by agitation in a vortex. Aliquots were used for DNA extraction using the QIAamp DNA stool Mini kit (Qiagen, Hilden, Germany) following the manufacturer's instructions. Genus-, group- and species-specific primers were used as described previously to quantify the different bacterial groups of the intestinal microbiota $(21,22)$. Briefly, PCR reactions were performed in triplicate in a LightCycler 480 (Roche). Each reaction mixture $(15 \mu \mathrm{l})$ consisted of $7.5 \mu \mathrm{l}$ of SYBR Green PCR Master Mix (Roche), $3.5 \mu \mathrm{l}$ of sterile water, $0.75 \mu$ of each of the specific primers at a concentration of $10 \mu \mathrm{M}$, and $2.5 \mu \mathrm{l}$ of template DNA. 16 rRNA gene copy numbers of each bacterial group or species were calculated by comparing the $\mathrm{C}_{\mathrm{t}}$ values obtained with those from a standard curve (23). Standard curves were generated from serial dilutions of a known copy number of the target gene cloned into a plasmid vector. For each reference strain the 16S rRNA gene was cloned into a pGEM-T Easy Vector System (Promega). An E. coli strain was transformed with the recombinant plasmids and plasmid
DNA was extracted from E. coli by the miniprep method (24). Six non-zero standard concentrations were used to construct the standard curves for each reference strain representing a species or a group and the plasmid DNA concentrations ranged from $10^{4}$ to $10^{10}$ copies of DNA per reaction. Standard curves were constructed by plotting the $\mathrm{C}_{t}$ values against the logarithm of their initial template copy number. DNA concentration was measured using a NanoDrop ${ }^{\circ}$ and the corresponding copy number was calculated (25). The following reference strains were used as standards: Bifidobacterium longum subsp. longum CECT 4503, Bacteroides fragilis DSMZ 2451; Clostridium coccoides DSMZ 933; C. leptum DSMZ 935; Lactobacillus casei ATCC 393; and E. coli CECT 4558.

\section{Statistical analyses}

Statistical analyses were performed using SPSS v. 15 software (SPSS Inc., Chicago, IL, USA). For normally distributed data ANOVA and the Student $t$ test were applied and, for non-normally distributed data, the Mann-Whitney $U$ test was used. Statistical significance was established at $P<0.05$ for all comparisons. 


\section{RESULTS}

\section{Body weight and morphometric analyses of jejunal sections}

Significant $\quad(P>0.05) \quad$ differences in body weight were not detected among the different experimental animal groups (data not shown). The animals sensitised with IFN- $\gamma$ and fed gliadin were the only ones that presented signs of diarrhoea. The animal group that was diagnosed with diarrhoea had faecal sports around the anal area and the colon contents recovered after the sacrifice had watery consistency. Morphometric analyses of jejunal tissue sections revealed that animals fed with gliadin alone did not exhibit significant alterations compared to controls, except for decreased $(P=0.014)$ enterocyte height (Table 1), but this alteration was restored by simultaneous administration of B. longum CECT 7347. In animals sensitised with IFN- $\gamma$ and fed gliadin, there was a significant decrease in villi width $(P=0.048)$ and enterocyte height $(P=0.033)$ and an increase in enterocyte numbers $(P=0.001)$ in the apical part of jejunal sections and also higher $(P=0.001)$ infiltration of cells in the lamina propria compared to the controls (Figure 1). However, these changes were not observed in animals only sensitized with IFN- $\gamma$ but not fed gliadin. B. longum CECT 7347 administration increased villi width $(P=0.004)$ and enterocyte height $(P=0.005)$, partially restoring the alterations detected in animals sensitised with IFN- $\gamma$ and fed gliadin but did not decrease the cellular infiltration observed in the IFN/ gliadin group. Feeding of $B$. longum CECT 7347 alone or together with gliadin increased $(P=0.016$ and $P=0.020$, respectively) villi length when compared to control animals.

\section{NFkB mRNA expression analysis}

Gliadin feeding significantly $(P=0.013)$ reduced NFKB mRNA expression, while the simultaneous administration of $B$. longum CECT 7347 restored its levels, reaching similar values as those of controls (Figure 2). In animals sensitised with IFN- $\gamma$ and fed gliadin, NFKB expression was markedly increased $(P<0.001)$ and the simultaneous administration of $B$. longum CECT 7347 produced even higher NFKB $(P=0.045)$ gene expression. Feeding of $B$. longum CECT 7347 alone to weaning animals did not alter the basal expression of this inflammatory marker indicating that the intestinal inflammatory milieu and the simultaneous presence of other stimuli modify the immune effects of this bacterial strain. Sensitisation with IFN- $\gamma$ immediately after birth did not exert a significant effect in comparison with controls.

\section{Cytokine production}

The cytokine concentrations in jejunal tissue sections from different experimental animal groups quantified by ELISA are shown in Figure 3. In tissue samples from 


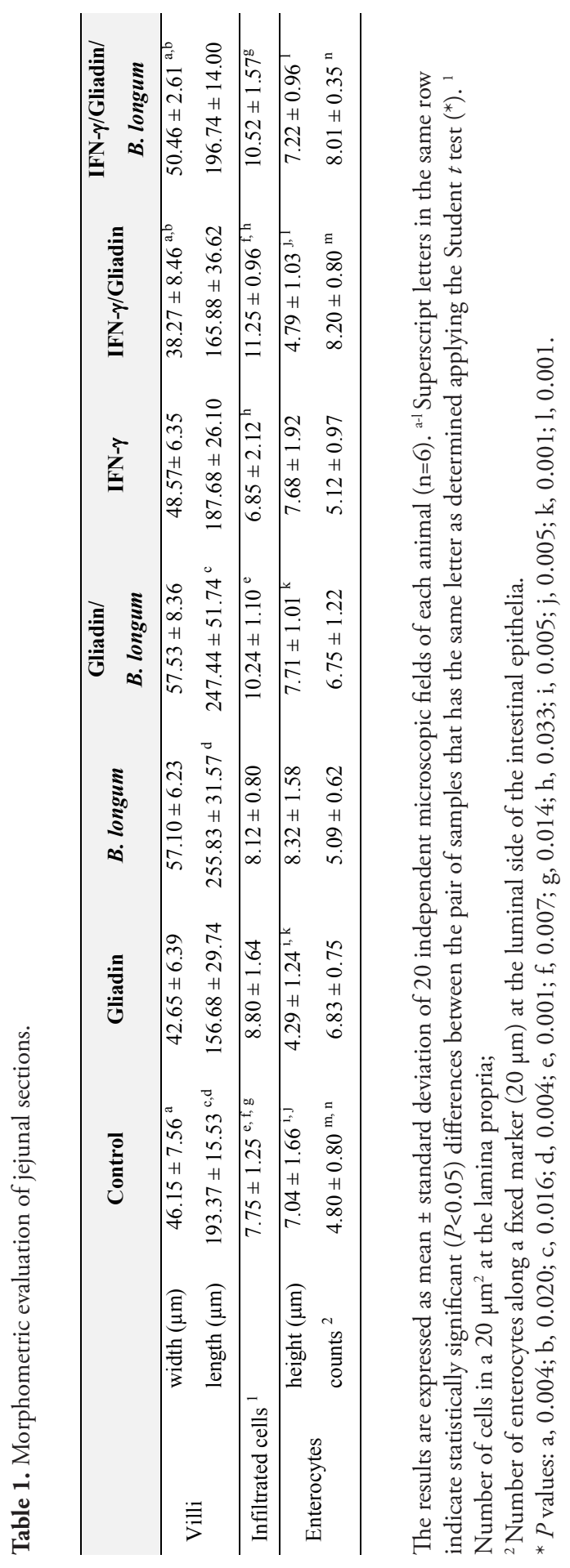




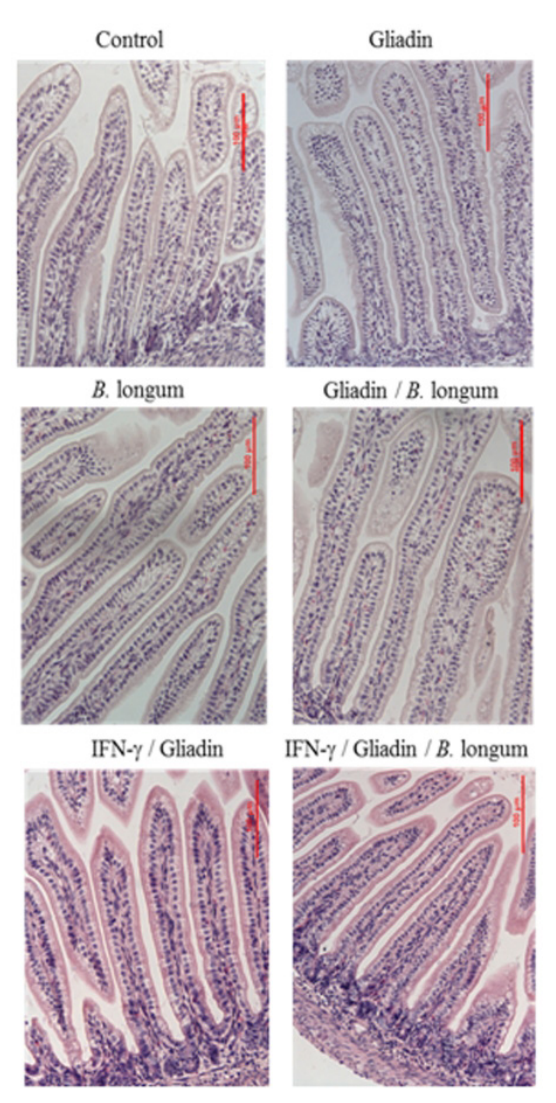

Figure 1. Histology of jejunal tissue sections of different experimental rat groups, stained with hematoxylin-eosin showing the different degree of cellular infiltration in the lamina propria of animals sensitized or not with IFN $-\gamma$ and fed gliadins and B. longum CECT 7347.

animals fed either gliadin or $B$. longum CECT 7347 the concentration of the inflammatory cytokine TNF- $\alpha$ was not increased, but that of the anti-inflammatory cytokine IL-10 $(P=0.003, P=0.006$, respectively) did increase in comparison with controls. The simultaneous administration of both gliadin and B. longum CECT
7347 caused a significant increase in TNF- $\alpha$ and IL-10 production, in comparison with the control ( $P=0.012$ and $P=0.028$, respectively) and with the administration of either gliadin $(P<0.001$ and $P=0.017$, respectively) or $B$. longum CECT $7347 \quad(P=0.029$ and $P=0.001$, respectively) alone. In animals sensitised with IFN- $\gamma$ and fed gliadin, TNF- $\alpha$ concentrations were significantly $\quad(P=0.007) \quad$ increased and, to a lesser extent, also those of IL-10 $(P=0.008)$ in comparison with control animals. This effect could be only attributed to the administration of gliadin because animals sensitized with IFN- $\gamma$ but not fed with gliadins did not exhibit significant increases in cytokine production. The administration of $B$. longum CECT 7347 to the enteropathy model significantly reduced TNF- $\alpha \quad(P=0.003)$ and increased IL-10 $\quad(P<0.001) \quad$ production, indicating its ability to counteract the inflammatory response in the intestinal mucosa.

\section{Leukocyte count and lymphocyte phenotyping}

The alterations in peripheral leukocyte populations in different animal groups are shown in Table 2. Gliadin administration did not cause significant alterations in the lymphocyte population compared to controls, except for an increase in eosinophils $(P=0.048)$. This alteration was restored by simultaneous administration of $B$. 


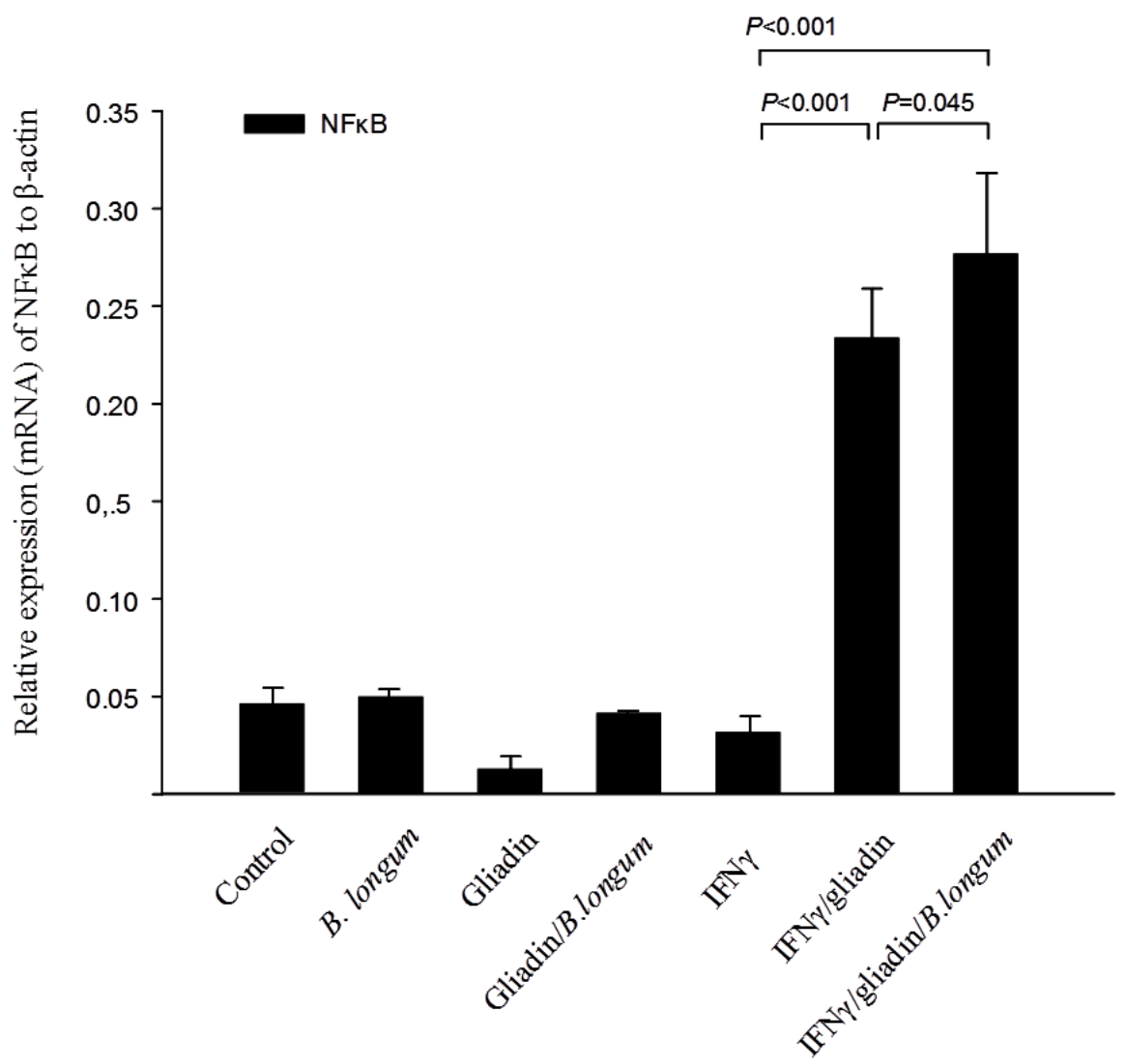

Figure 2. Expression (mRNA) of nuclear factor kappa B (NFKB) in jejunal sections of rats after different treatments. The results are expressed as mean \pm standard deviation $(\mathrm{n}=6) .{ }^{*}$ Indicates statistically significant $(P<0.05)$ differences relative to the controls; bars indicate significant differences between the specific pair comparisons as determined by applying the Student $t$ test.

longum CECT $7347 \quad(P=0.048)$. Sensitization of animals with IFN- $\gamma$ did not cause significant changes in leukocyte population, but feeding gliadins to animals sensitised with IFN- $\gamma$ decreased lymphocyte populations significantly $(P=0.028)$ in comparison to non-sensitised animals that had been fed gliadin. In contrast, monocyte populations significantly increased in sensitized and gliadin-fed animals $(P=0.039)$ and also in those simultaneously fed B. longum CECT $7347 \quad(P=0.005)$ in comparison to controls. The administration of the bifidobacterial strain alone did not significantly modify the leukocyte populations in comparison to controls.

In rats, leukocyte counts have been 


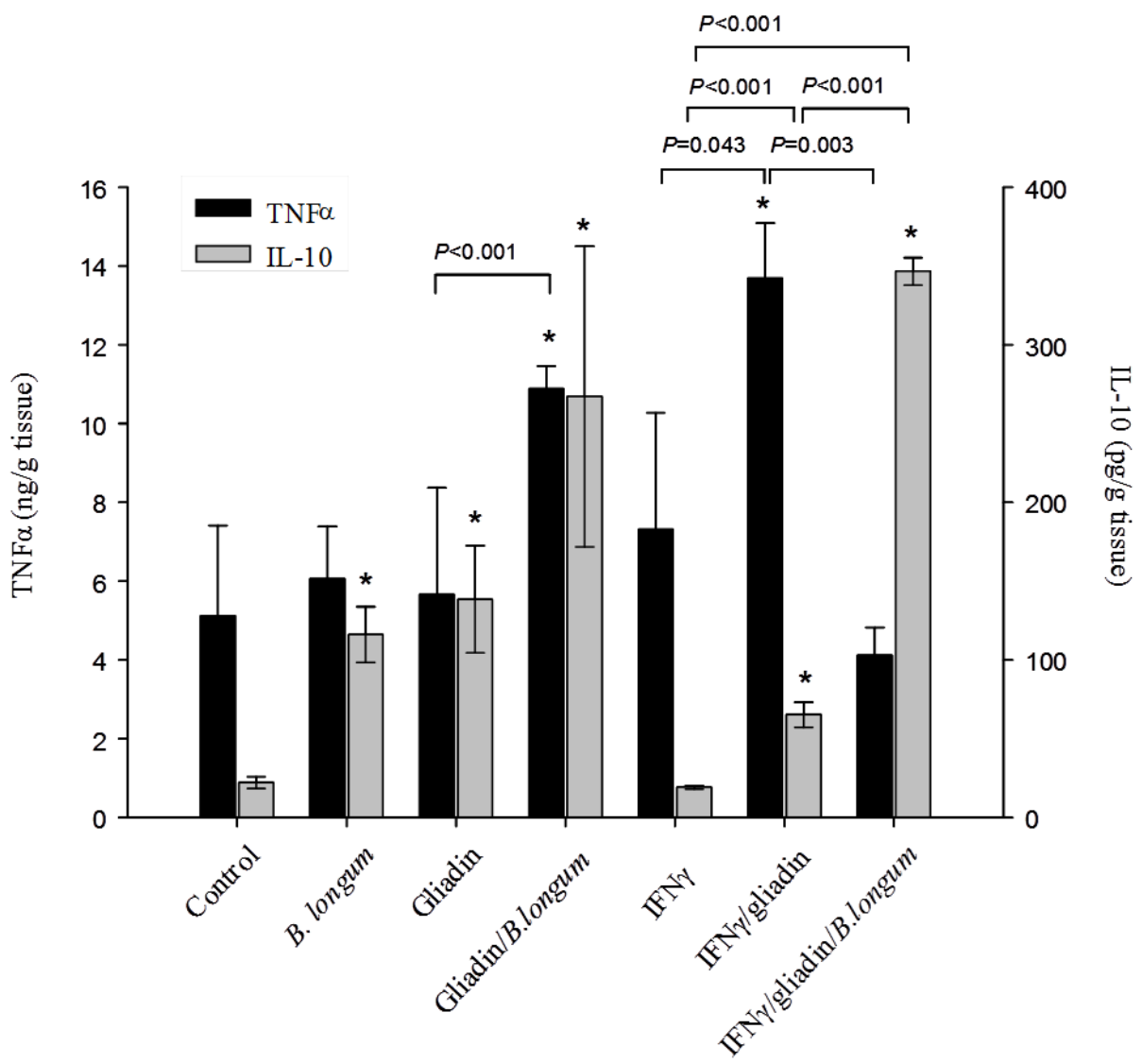

Figure 3. Tumour necrosis factor (TNF)- $\alpha$ and interleukine (IL)-10 production in jejunal tissue sections of rats after different treatments. The results are expressed as mean \pm standard deviation $(\mathrm{n}=6) .{ }^{*}$ Indicates statistically significant $(P<0.05)$ differences compared to the controls; bars indicate significant differences between the specific pair comparisons as determined by applying the Student $t$ test.

reported to be highly variable in the range 6000-18000 leukocytes/ $\mu \mathrm{l}(26)$, which is in agreement with the values found in our experimental animal groups. The lymphocyte population was identified with the lymphocyte marker CD45 and further T-cell phenotyping analyses were done within this population (Figure 4). Feeding gliadin significantly reduced CD4+ lymphocyte numbers $(P=0.003)$ compared to controls, whereas Foxp3+ $\mathrm{T}$ cell numbers increased $(P<0.001)$. The administration of $B$. longum CECT 7347 together with gliadin exerted the opposite effects in all T-lymphocyte subpopulations, increasing CD4+ cells $(P=0.010)$ and reducing $\mathrm{CD} 8+(P=0.008)$ and 


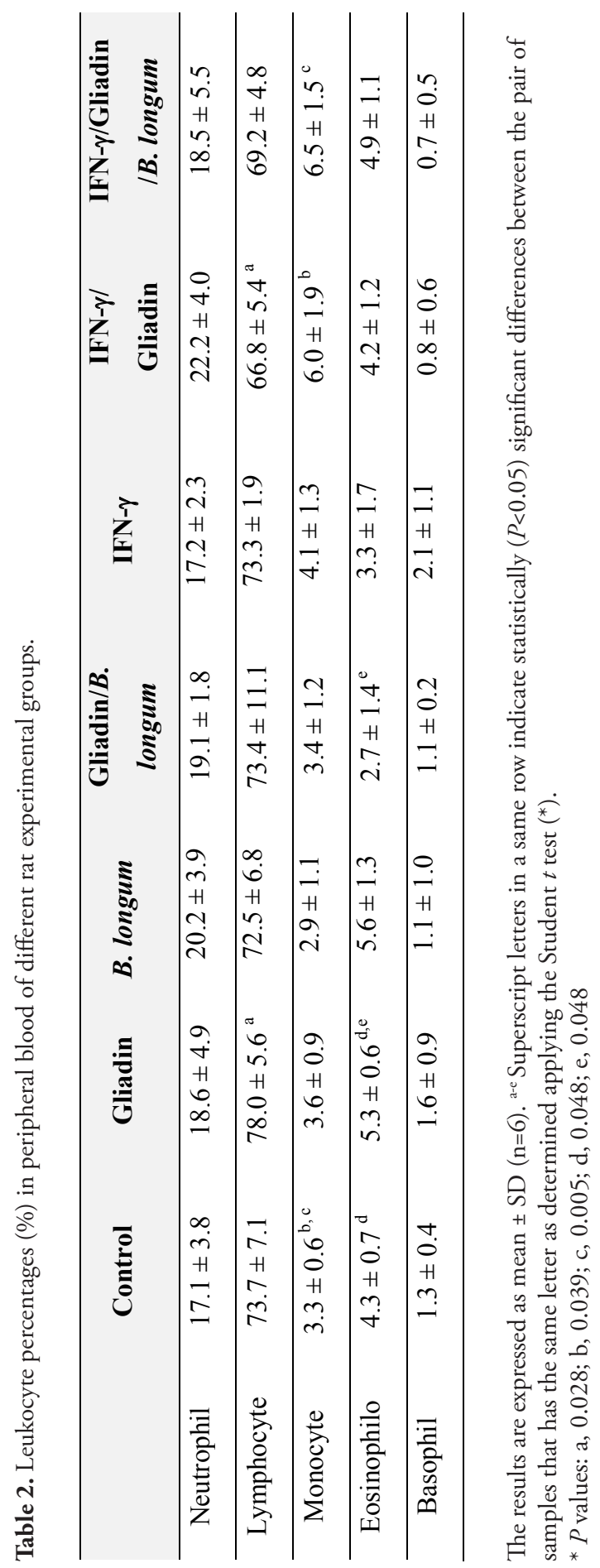




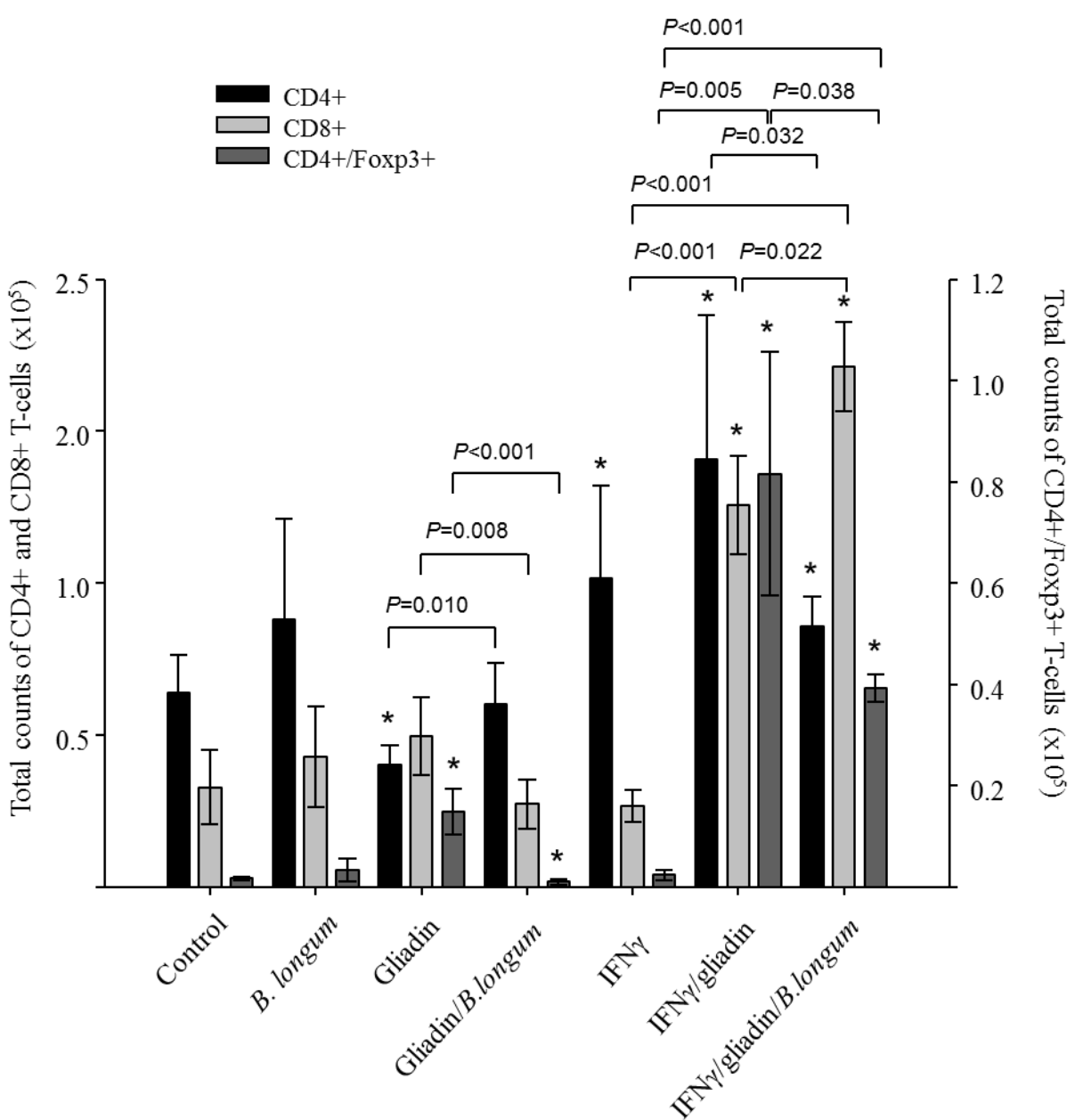

Figure 4. Phenotyping of lymphocyte populations in peripheral blood of rats after different treatments. The results are expressed as mean \pm standard deviation $(\mathrm{n}=6) .{ }^{*}$ Indicates statistically significant $(P<0.05)$ differences relative to the controls; bars indicate significant differences between the specific pair comparisons as determined by applying the Student $t$ test.

Foxp3+ T cells $(P<0.001)$. Animals sensitized with IFN- $\gamma$ exhibited significantly $(P=0.041)$ increased CD4+ cells, but not those of CD8+ and CD4+Foxp3 cells. In addition, in animals sensitised with IFN- $\gamma$ and fed gliadin, there was a much more marked increase in all T-lymphocyte subpopulations compared to controls. In this model, the administration of $B$. longum CECT 7347 significantly reduced CD4+ $(P=0.032)$ and Foxp $3+\mathrm{T}(P=0.038)$ cell populations, but increased those of CD8+ cells $(P=0.022)$. The administration of $B$. longum CECT 
7347 alone did not significantly affect any of the $\mathrm{T}$ cell lymphocyte populations analysed.

\section{Bacterial translocation and microbiota composition}

Translocation of Bifidobacterium spp. to liver, spleen and MLN was not detected by plate counting in any of the treated animal groups. RAPD analyses of colonies isolated from selective media for bifidobacteria present in colon samples indicated that the strain administered represented between $75-95 \%$ of the total bifidobacteria. The quantitative analyses of specific bacterial groups by real time-PCR also indicated that the administration of the bifidobacterial strain contributed to an increase in the total gene copies of this bacterial group by at least one logarithmic unit (Table 3). Neither feeding gliadin alone nor sensitization with IFN- $\gamma$ alone significantly modified the composition of the microbiota in comparison with controls. In animals sensitised with IFN- $\gamma$ and fed gliadin, significantly higher gene copy numbers of the Bacteroides fragilis group were detected in comparison with controls $(P=0.030)$ and with rats fed gliadin $(P=0.020)$ gliadin plus $B$. longum CECT 7347 $(P=0.049)$ and in those sensitized with IFN- $\gamma \quad(P=0.025)$. The administration of $B$. longum CECT 7347 did not restore microbiota alterations in the enteropathy model and only contributed to increasing total Bifidobacterium gene copy numbers.

\section{DISCUSSION}

This study reports for the first time the effects of feeding a bifidobacterial strain (B. longum CECT 7347) at an early postnatal period on the intestinal mucosal architecture and markers of innate and adaptive immunity in an experimental animal model of gliadin-induced enteropathy.

In previous studies, gliadin administration to inbred rats after weaning (4) or adult mice (6) failed to reproduce the enteropathy, probably due to immunocompetence of the experimental animals and lack of gliadin access beyond the epithelial cell layer. Moreover, feeding gliadin even during the early neonatal period was insufficient to cause mucosal damage and significant alterations in epithelium architecture in agreement with our study $(4,27)$. Sensitisation of animals with IFN- $\gamma$ appeared to be necessary to cause mucosal damage and immunologic changes resembling those observed in human CD (9). IFN- $\gamma$ administration to weaning animals increases macromolecular transport across Peyer's patches (28), and macrophage priming (29) that favours the full establishment of a jejunal mucosal reaction and the instauration of the enteropathy (9). However sensitisation with IFN- $\gamma$ alone did not caused histological alterations in our 


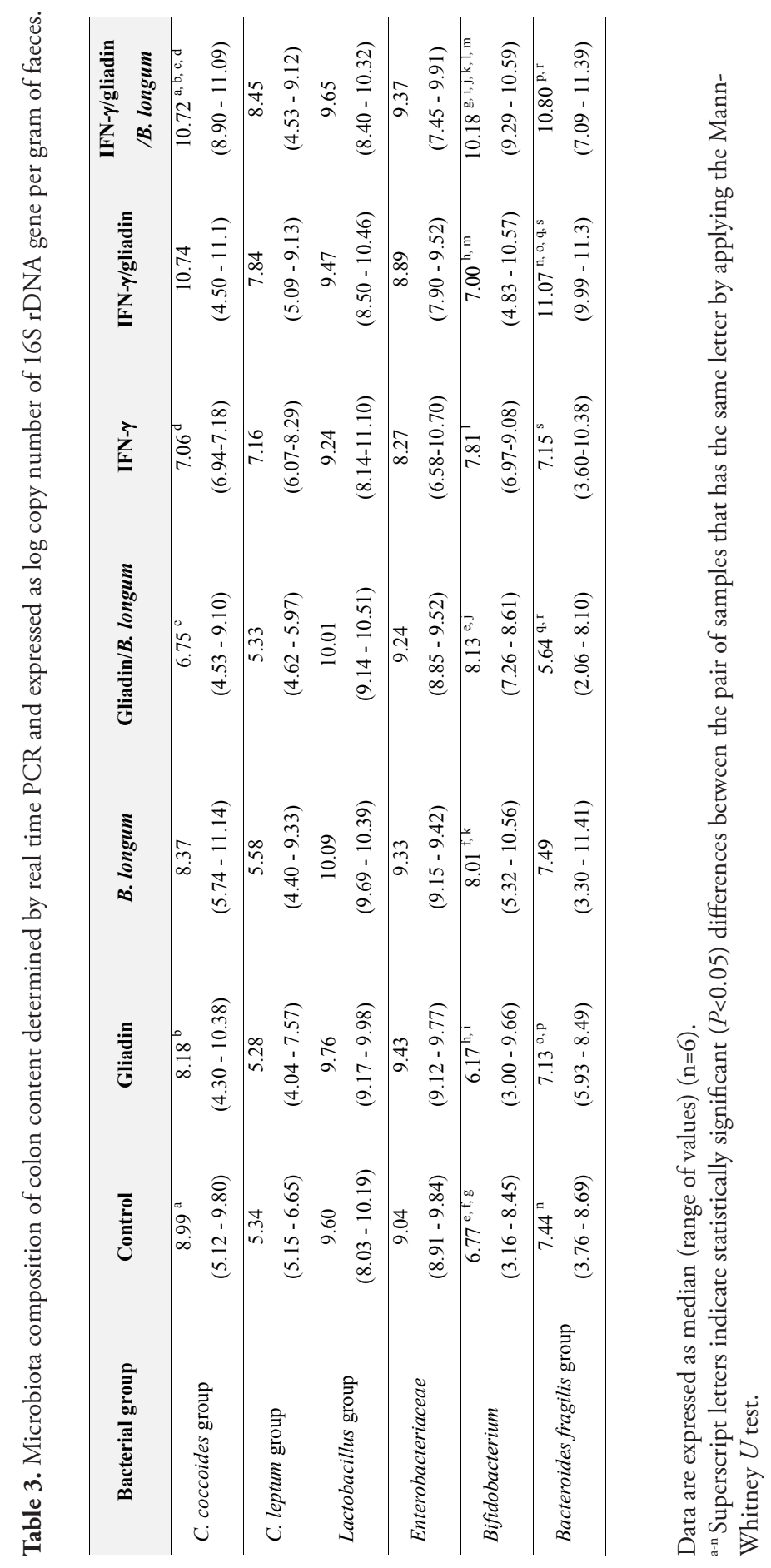


study, in accordance with previous reports (9). Thus, the animal model used in the present study approaches an intermediate state between proliferative and destructive phases of CD that ultimately lead to complete villous atrophy and disruption of intestinal epithelium integrity, which are major characteristics of fully developed CD $(2,30)$. B. longum CECT 7347 administration to gliadin-fed animals sensitised with IFN- $\gamma$, partially reduced some of the alterations in jejunal architecture caused by the triggers of the disease, which could theoretically contribute to improving the gut barrier function and preventing gliadin translocation to the submucosa. Similarly, administration of Lactobacillus casei ATCC 9595 restored the intestinal damage caused by gliadins in HLADQ8 transgenic mice treated with indomethacin (27).

In $\mathrm{CD}$ patients, gliadin acts as potent inducer of inflammatory gene expression and cytokine production, including TNF- $\alpha$ and NFKB (3133). In this study, NFKB expression (mRNA) was increased in animals sensitised with IFN- $\gamma$ and fed gliadin, in agreement with the NFKB activation found in the intestinal mucosa of CD patients (32). NFKB activation has been identified as the mechanism by which gliadin mediates TNF $\alpha$ production in enterocytes (17) and human monocytes (33). Accordingly, TNF- $\alpha$ production was also significantly increased in animals sensitised with IFN- $\gamma$ and fed gliadin.
However, the administration of gliadin alone neither induced NFKB expression nor TNF- $\alpha$ production in comparison with controls. It is possible that gliadin administered alone stimulates a regulatory response reflected in the down-regulation of NFкB mRNA expression and the increased IL-10 production leading to tolerance in these animals, which are not genetically predisposed to the disease. In fact, previous authors also demonstrated that IFN- $\gamma$ administered intraperitoneally was necessary to induce the disease together with oral administration of gliadin (9). In contrast, the simultaneous administration of B. longum CECT 7347 and gliadin increased NFкB mRNA expression and cytokine production in comparison with the group only fed gliadin. This could be due to additional interactions of bacterial components with Tolllike receptors (TLRs) that uponligand binding can also activate the NFKB pathway and cytokine production. Therefore, the results indicate that this bacterial strain caused certain immune activation in the simultaneous presence of gliadin; however, these effects were not significant in comparison with the control group except for cytokine production and were not translated in other pathologic signs. Notably, the administration of $B$. longum CECT 7347 to animals sensitised with IFN- $\gamma$ and fed gliadin reduced TNF- $\alpha$ production and increased IL- 
10 production and NFKB expression, triggering an anti-inflammatory and regulatory response. Interestingly, the two treatments IFN- $\gamma$ sensitization plus gliadin feeding and IFN- $\gamma$ sensitization plus gliadin and $B$. longum feeding activated NFкB mRNA expression, but the final effect on cytokine production markedly differed. The effects on these inflammatory markers on our enteropathy model are in agreement with the inflammatory role of gliadins in CD patients and enterocytes previously reported $(15,32)$. However, an increased in NFKB mRNA expression does not always lead to an inflammatory response because this pathway is regulated at different stages and by diverse mechanisms controlling, for instance, the ubiquitination of the inhibitor I $\mathrm{B}$, which promotes the translocation of the heterodimer $\mathrm{p} 50 / \mathrm{p} 65$ to the nucleus and the final induction of inflammatory cytokines such as TNF- $\alpha$ (34). In this context, it has been reported that some commensal bacterial can induce transient activation or inhibition of the NFKB signalling pathway at different steps that contribute to attenuating and regulating the pro-inflammatory responses. For example, B. thetaiotaomicron acts downstream NFKB activation by promoting nuclear export of NFKB subunit relA in complex PPAR- $\gamma$ (35), while other commensal bacterial block NFKB at more proximal steps, inhibiting ubiquitination and proteolytic inactivation of the

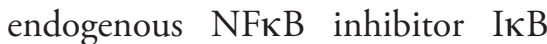
(36). Therefore, it is possible that the $B$. longum strain used in this study only causes a transient activation of NFKB mRNA expression without enhancing the final production of inflammatory mediators such as TNF- $\alpha$ in the enteropathy animal model.

In addition, our results evidence significant differences between the immunomodulatory properties of B. longum CECT 7347 and $L$. casei ATCC 9595, since this latter strain was unable to rescue IL-10 production in the enteropathy model of HLA-DQ8 transgenic mice (27). IL-10 production was also stimulated by the administration of $B$. longum CECT 7347 in control animals but not that of TNF- $\alpha$, which is an additional indication of the antiinflammatory properties of this strain also in the absence of other stimuli such as gliadin or an inflammatory condition. IL-10 seems to be indispensable for the induction of oral tolerance to dietary antigens, the inhibition of chemokine production and the antigen-presenting capacity of monocytes and macrophages, and induction of the production of soluble antagonists of proinflammatory cytokines such as IL-1 and TNF $\alpha$ (37).

Leukocyte counts and phenotyping analyses of T-cell subsets in peripheral blood support that IFN- $\gamma$ sensitisation of weaning animals is effective in stimulating a 
$\mathrm{T}$ cell-mediated response to orally administered gliadin antigens, partially mimicking the effect in humans. Monocyte numbers were significantly increased in animals sensitised with IFN- $\gamma$ and fed gliadin, which suggests a response to inflammatory signals that could not be significantly reduced by $B$. longum CECT 7347. The data from lymphocyte phenotyping indicated that gliadin alone reduces $\mathrm{CD} 4+\mathrm{T}$ cells and increases CD4+/Foxp3+ $\mathrm{T}$ cells, suggesting a regulatory response in agreement with previous data. Although these changes were reversed by B. longum CECT 7347 administration, indicating that the bacterium can induce certain immune activation in an opposite direction, these effects were not significant in comparison with controls. Our study also demonstrates that IFN- $\gamma$ sensitisation, prior to gliadin administration, was necessary to induce an enteropathy mediated by $\mathrm{CD} 4+\mathrm{T}$ cells, while IFN- $\gamma$ sensitisation alone did not cause significant changes in lymphocyte subpopulations. In the enteropathy model, the changes in $\mathrm{CD} 4+$ were also accompanied by an increase in CD4+/Foxp3+ (Tregs) cells, which suggests the development of a counterregulatory response, as previously reported $(7,11)$. The increased Treg cell numbers is concordant with the increased percentages of circulating regulatory $\mathrm{CD} 4+\mathrm{CD} 25+$ Foxp3+ $\mathrm{T}$ cells found in untreated, compared to treated (gluten-free diet) $\mathrm{CD}$ patients $(12,13)$. In this study, feeding of B. longum CECT 7347 significantly decreased $\mathrm{CD} 4+$ and CD4+/Foxp3 Tregs cells in animals sensitised with IFN- $\gamma$, indicating its ability to counteract the Th1-type inflammatory response triggered by gliadin. However, a recent study has demonstrated that $L$. casei ATCC 9595 administration was unable to significantly modulate CD25+T cell populations in HLA-DQ8 transgenic mice that had been fed gliadins (27). B. longum CECT 7347 also induced CD8+ T cells in this model of enteropathy in agreement with the microbiota-mediated increase in $\mathrm{CD} 8+$ lymphocytes previously reported (4); the role of which in this disease remains to be determined.

Microbiota composition of animals sensitised with IFN- $\gamma$ and fed gliadins showed increased gene copy numbers of the Bacteroides fragilis group in comparison with control animals; these differences were not associated with gliadin intake and, therefore, could be due to the induced alterations in intestinal epithelium architecture and the underlying inflammation in the enteropathy model (30, 31). This alteration resembles that found in paediatric CD patients that showed increased bacteroides numbers in faeces and duodenal biopsies, but not solely associated with the inflammatory phase of the disease $(38,39)$. Bifidobacteria and lactobacilli numbers were not related to gliadin intake or the 
induced inflammation, in contrast to human data $(38,39)$. As expected, administration of $B$. longum CECT 7347 led to increased gene copy numbers of total bifidobacteria in the colon, which could be responsible for the biological effects detected on the mucosa and inflammatory markers under gliadin or IFN- $\gamma$ and gliadin administration. Studies in vitro and in situ have reported positive effects of different Bifidobacterium strains in the context of $\mathrm{CD}$, including the reduction of gliadin toxicity (17, 40) and inflammatory potential of gliadin peptides on intestinal cells (17). This study has demonstrated the protective effects of $B$. longum CECT 7347 against the aberrant gliadin response in vivo, by reducing inflammatory cytokine production and increasing regulatory cytokine production (IL-10) in the jejunal mucosa, and reduced activation of CD4+ T cells. However, the limitations of the animal model used to flly reproduce the fundamental features of the disease makes necessary to consider the results reposted with caution and, undoubtedly, studies in humans will be necessary to really prove beneficial effects of this bacterium on the disease.

\section{REFERENCES}

1. Wieser H, Koehler P (2008) The biochemical basis of celiac disease. Cereal Chem 85, 1-13.

2. Schuppan D, Junker Y, Barisani D (2009) Celiac Disease: From pathogenesis to novel therapies. Gastroenterology 137, 1912-1933.
3. Troncone R, Ferguson A (1991) Animal model of gluten induced enteropathy in mice. Gut 32, 871-875.

4. Stěpanková R, Tlaskalová $H$, Šinkora J et al. (1996) Changes in jejunal mucosa after longterm feeding of germfree rats with gluten. Scand J Gastroenterol 31, 551-557.

5. Kozakova H, Stěpanková R, Tučková L et al. (2000) Humoral and Cellular immune responses in gluten-treated suckling or hand fed rats. Physiol Res 49, 665-672.

6. Tlaskalová-Hogenová H, Stěpánková R, Farré $M$ et al. (1997) Autoimmune reactions induced by gliadin feeding in germ-free AVN rats and athymic nude mice. Animal models for celiac disease. Ann NY Acad Sci 815, 503-505.

7. Black KE, Murray JA, David CS (2002) HLADQ determines the response to exogenous wheat proteins: a model of gluten sensitivity in transgenic knockout mice. J Immunol 169, 5595-5600.

8. Verdu EF, Huang X, Natividad J et al. (2008) Gliadin dependent neuromuscular and epithelial secretory responses in gluten-sensitive HLA-DQ8 transgenic mice. Am J Physiol Gastrointest Liver Physiol 294, G217-G225.

9. Stepánková R, Kofronová O, Tucková L et al. (2003) Experimentally induced gluten enteropathy and protective effect of epidermal growth factor in artificially fed neonatal rats. J Pediatr Gastroenterol Nutr 36, 96-104.

10. Westendorf AM, Fleissner D, Deppenmeier $S$ et al. (2006) Autoimmune-mediated intestinal inflammation-impact and regulation of antigenspecific CD8+ T cells. Gastroenterology 131, 510524.

11. D’arienzo R, Stefanile R, Maurano F et al. (2009). A deregulated immune response to gliadin causes a decreased villus height in DQ8 transgenic mice. Eur J Immunol 39, 3552-3561.

12. Kivling A, Nilsson L, Fälth-Magnusson K et al. (2008) Diverse Foxp3 expression in Children with Type I Diabetes and Celiac Disease. Ann NY Acad Sci 1150, 273-277.

13. Frisullo G, Nociti V, Iorio R et al. (2009) Increased CD4+CD25+Foxp3+ $\mathrm{T}$ cells in peripheral blood of celiac disease patients: correlation with dietary treatment. Hum Immunol 70, 430-435.

14. Terrazzano G, Sica M, Gianfrani C et al. (2007) Gliadin regulates the NK-dendritic cell cross-talk by HLA-E surface stabilization. J Immunol 179, 372-381.

15. Hoffman RA (2000) Intraepithelial lymphocytes coinduce nitric oxide synthase in 
intestinal epithelial cells. Am J Physiol: Gastointest Liver Physiol 278, G886-G894.

16. Collado MC, Donat E, Ribes-Koninckx C et al. (2009) Specific duodenal and faecal bacterial groups associated with paediatric coeliac disease. $J$ Clin Pathol 62, 264-269.

17. Laparra JM, Sanz Y (2010) Bifidobacteria inhibit the inflammatory response induced by gliadin in intestinal epithelial cells via modification of toxic peptide generation during digestion. J Cell Biochem 109, 801-807.

18. Medina M, De Palma G, Ribes-Koninckx C et al. (2008) Bifidobacterium strains suppress in vitro the pro-inflammatory milieu triggered by the large intestinal microbiota of coeliac patients. J Inflamm (Lond) 5, 19.

19. Livak KJ, Schmittgen TD (2001) Amalysis of Relative Gene Expression Data Using Real-Time Quantitative PCR and the $2^{-\Delta \Delta C}$ Tethod. Methods 25, 402-408.

20. Akopyanz N, Bukanov NO, Westblom TU et al. (1992). DNA diversity among clinical isolates of Helicobacter pylori detected by PCR-based RAPD fingerprinting). Nucleic Acids Res 20, 5137-5142. 21. Matsuki T, Watanabe K, Fujimoto J et al. (2002) Development of 16S rRNA-gene-targeted group-specific primers for the detection and identification of predominant bacteria in human feces. Appl Environ Microbiol 68, 5445-5451.

22. Malinen E, Kassinen A, Rinttilä T et al. (2003) Comparison of real-time PCR with SYBR Green I or 5'-nuclease assays and dot-blot hybridization with rDNA-targeted oligonucleotide probes in quantification of selected faecal bacteria. Microbiology 149, 269-277.

23. Yu Y, Lee C, Kim J, Hwang S (2005) Group-specific primer and probe sets to detect methanogenic communities using quantitative real-time polymerase chain reaction. Biotechnol Bioeng 89, 670-679.

24. Birnboim HC, Doly J (1979) A rapid alkaline extraction procedure for screening recombinant plasmid DNA. Nucleic Acids Res 7, 1513-1523.

25. Whelan JA, Russell NB, Whelan MA (2003) A method for the absolute quantification of cDNA using real-time PCR. J Immunol Methods 278, 261269.

26. Ringler, Dabich. The Laboratory Rat, Vol I, ISBN 0-12-074901.

27. D'Arienzo R, Stefanile R, Maurano F et al. (2011) Immunomodulatory effects of Lactobacillus casei administration in a mouse model of gliadinsensitive enteropathy. Scand J Immunol 74, 334341.

28. Sütas Y, Aution S, Rantala I et al. (1997) IFN gamma enhances macromolecular transport across
Peyer's patches in suckling rats: Implications for natural immune responses to dietary antigens early in life. J Pediatr Gastroenterol Nutr 24, 162-169. 29. Williams JG, Jurkovich GJ, Hahnel GB et al. (1992) Macrophage priming by interferon $\gamma$ : a selective process with potencially harmful effects. J Leukoc Biol 52, 579-584.

30. Clemente MG, De Virgilis S, Kang JS et al. (2003) Early effects of gliadin on enterocyte intracellular signaling involved in intestinal barrier function. Gut 52, 218-223.

31. Thomas K, Sapone A, Fasano A et al. (2006) Gliadin stimulation of murine macrophage inflammatory gene expression and intestinal permeability are MyD88-dependent: Role of the innate immune response in celiac disease. $J$ Immunol 176, 2512-2521.

32. Maiuri MC, De Stefano D, Mele et al. (2003) Nuclear factor $\kappa \mathrm{B}$ is activated in small intestinal mucosa of celiac patients. J Mol Med 81, 373-379. 33. Jelínková L, Tuckova L, Cinová J et al. (2004) Gliadin stimulates human monocytes to production of IL-8 and TNF $\alpha$ through a mechanism involving NFкB. FEBS Letters 571, 81-85.

34. Viatour P, Merville MP, Bours V et al. (2005) Phosphorylation of $\mathrm{NFkB}$ and $\mathrm{IkB}$ proteins: implications in cancer and inflammation. Trends Biochem Sci 30, 43-52.

35. Kelly D, Campbell JI, Jing TP et al. (2004) commensal anaerobic gut bacteria attenuate inflammation by regulating nuclear-cytoplasmic shuttling of PPAR-gamma and RelA. Nat Immunol 5, 104-112.

36. Neish AS, Gewirtz AT, Zang H et al. (2000) Prokaryotic regulation of epithelial responses by inhibition of IkappaB-alpha ubiquitination. Science 289, 1560-1563.

37. Izcue A, Coombes JL, Powrie F (2009) Regulatory Lymphocytes and Intestinal Inflammation. Annu Rev Immunol 27, 313-338.

38. Nadal I, Donat E, Ribes-Koninckx C et al. (2007) Imbalance in the composition of the duodenal microbiota of children with celiac disease. J Med Microbiol 56, 1669-1674.

39. Collado MC, Donat E, Ribes-Koninckx C et al. (2008) Imbalances in faecal and duodenal Bifidobacterium species composition in active and non-active coeliac disease. BMC Microbiol 8, 232. 40. De Palma G, Cinova J, Stepankova R et al. (2010) Pivotal Advance: Bifidobacteria and Gramnegative bacteria differentially influence immune responses in the proinflammatory milieu of celiac disease. J Leukoc Biol 87, 765-778. 


\section{Chapter 3}

- Human-milk composition differs in healthy mothers and mothers with celiac disease

- The HLA-DQ2 genotype selects for early intestinal microbiota composition in infants at high risk of developing celiac disease 


\section{Human-milk composition differs in healthy mothers and mothers with celiac diseas}

Marta Olivares ${ }^{1}$, Simone Albrecht ${ }^{2}$, Giada De Palma ${ }^{1}$, María Desamparados Ferrer $^{1,}$ Gemma Castillejo ${ }^{3}$, Henk A. Schols ${ }^{2}$, Yolanda Sanz ${ }^{1}$

Eur J Nutr (2014) 54, 119-128

${ }^{1}$ Microbial Ecology, Nutrition \& Health Research Group. Institute of Agrochemistry and Food Technology. National Research Council (IATA-CSIC). Valencia, Spain. ${ }^{2}$ Laboratory of Food Chemistry. Wageningen University. Wageningen, The Netherlands. ${ }^{3}$ Paediatric Gastroenterology Unit, Hospital Universitari Sant Joan de Reus, Universitat Rovira i Virgili. Tarragona, Spain. 


\section{ABSTRACT}

To investigate whether breast-milk composition and microbiota differ in healthy mothers and mothers with celiac disease (CD) to ultimately contribute to identify additional factors determining CD risk. Breastmilk samples from healthy mothers $(\mathrm{n}=12)$ and mothers with $\mathrm{CD}$ $(n=12)$ were collected. Cytokines and secretory immunoglobulin A $(\operatorname{sg} \mathrm{A})$ were analysed by bead-arrays and flow cytometry and human milk oligosaccharides (HMOs) were assessed by capillary electrophoresis with laser-induced fluorescence (CE-LIF) detection. Breast milk microbiota composition was analysed by conventional and quantitative real-time PCR. Breast-milk from CD mothers showed significantly lower levels of interleukin (IL) $12 \mathrm{p} 70(P<0.042)$, transforming growth factor (TGF)- $\beta 1$ $(P<0.018)$ and sIgA $(P<0.003)$ and almost significantly lower levels of interferon (IFN) $-\gamma(P<0.058)$. Six mothers in each group belonged to the secretor $\operatorname{Le}(\mathrm{a}-\mathrm{b}+)$ type, one to the secretor $\mathrm{Le}(\mathrm{a}-\mathrm{b}-)$ type and five to the non-secretor Le $(\mathrm{a}+\mathrm{b}-)$ type. CD mothers of non-secretor Le $(\mathrm{a}+\mathrm{b}-)$ type showed increased Lacto-N-tetraose content $(P<0.042)$ compared with healthy mothers. $\mathrm{CD}$ mothers' milk showed reduced gene copy numbers of Bifidobacterium spp. $(P<0.026)$ and $B$. fragillis group $(P<$ $0.044)$. CD mothers' breast milk is characterized by a reduced abundance of immunoprotective compounds (TGF- $\beta 1$ and sIgA) and bifidobacteria. The reduction of these components could theoretically diminish the protective effects of breast-feeding on the child's future risk of developing CD.

Keywords: Celiac disease, human-milk, immunity, microbiota. 


\section{INTRODUCTION}

Celiac disease (CD) is an autoimmune disorder for which the main genetic determinant (human leukocyte antigen (HLA)-DQ2/8) and environmental trigger (gluten) are known, although they do not fully explain CD onset. Perinatal and early postnatal environmental factors, influencing immune development and gut ecosystem of young children, have also been associated with CD susceptibility (1). Longer breast-feeding and, specially, breast-feeding at the time of gluten introduction seems to reduce the risk of developing $\mathrm{CD}$ or at least delay its onset in most casecontrol observational retrospective studies included in the meta-analysis by Akobeng et al. (2). A more recent cross-sectional study performed in two birth cohorts, one born in the so-called "Swedish CD epidemic" (1993) and another born after the epidemic (1997) indicates that reduced $\mathrm{CD}$ prevalence (clinically and screening-detected cases) in the second cohort at 12 years of age were related to changes in early feeding practices. These practices included the gradual introduction of glutencontaining foods from 4 months of age simultaneous to breastfeeding (3). However, no protective effect of breast-feeding on CD risk or CD autoimmunity was observed in other prospective studies $(4,5)$. Duration of breast-feeding could be associated with reduced or delayed gluten exposure, which could contribute to the protective effect of breast milk against CD development. It is also biologically plausible that breast-milk components (immune mediators, human milk oligosaccharides, etc.) promote oral tolerance to dietary antigens by modulating immune development and function, and infant's gut microbiota composition $(1,6)$.

The colonization of the new-born intestine by an adequate consortium of bacteria may contribute to proper development of the host's immune functions and, conversely, imbalances in micobiota can increase susceptibility to immune-mediated disorders in early and later life. Animal studies have provided direct evidence of the role gut microbial colonization plays in immune developmental processes and the orchestration of appropriate or aberrant immune responses (7). Human observational studies have also reported imbalances in gut microbiota composition that precede the development of specific immune-mediated diseases later in life, thus suggesting causation (8). Although colonization seems to be host-specific, breastfeeding is one of the main environmental factors influencing microbiota composition early in life $(9,10)$. These effects are thought to be primarily mediated by the presence of oligosaccharides, which are minimally hydrolysed by human enzymes and reach the large intestine, constituting the main substrate for the infants' gut 
microbiota and, particularly, for bifidobacteria (6). In recent years, breast milk has also been considered as a possible source of the bacteria colonizing the infant's gut $(10,11)$. The demonstration that lactic acid bacteria isolated from breast skin and milk are different, demonstrate their different origin and suggest an endogenous route for breast milk colonization (12). Comparisons between bacterial strains present in mother-infant pair samples also suggest possible bacterial transference from the mother's milk to the infant's gut (10). The mechanism involved in colonization of human milk remains unclear but research reports that dendritic cells are able to capture bacteria from the intestinal lumen via the opening of the tight junctions between epithelial cells, subsequently reaching the mammary gland by the dendritic cells $\mathrm{CD} 18^{+}(13)$.

Human milk is also known to provide many bioactive substances involved not only in immune passive protection, but also in modulation of the neonate immunological development (14). A complex network of chemoattractants and cytokines in human milk are thought to play a role in compensating for the developmental delay of the neonate immune system, and in preventing the development of immune-mediated diseases (15). Human-milk cytokine and secretory immunoglobulin A (sIgA) content have been shown to differ depending on various factors, including the mother's immune status and dietary content of fatty acids, with potential consequences on infant health (16). The intake of probiotic bacteria has also been related to changes in breast milk composition, including differences in cytokine content (17). Yet the origin of immunoactive components in breast milk and its possible relationship with the breastmilk microbiota composition remain unknown.

The primary objective of the present study was to establish possible relationships between microbiota composition, human milk oligosaccharides (HMO) and immune markers (cytokines and sIgA) in breast milk from healthy mothers and mothers with CD. A wider goal of this research is to gain a greater understanding of how early postnatal environmental factors, and their interaction with host-intrinsic factors, could influence the risk of developing CD.

\section{MATERIAL AND METHODS}

\section{Collection and processing of samples}

Breast-milk samples were collected one month after delivery from 12 healthy mothers and 12 mothers with $C D$ under a gluten-free diet (GFD) for more than 2 years and without disease symptoms. CD was diagnosed according to criteria set by the European Society for Pediatric Gastroenterology, Hepathology 
and Nutrition (ESPGHAN) (18).

Mothers enrolled in the study were instructed to collect the milk sample in aseptic conditions by manual expression into sterile tubes using sterile gloves at early feed. Samples were immediately stored at -20 ${ }^{\circ} \mathrm{C}$. Five $\mathrm{mL}$ of breast milk were centrifuged $(10,000 \mathrm{xg}, 10 \mathrm{~min})$ and the fatty layer was discarded. We collected the supernatant to determine immune markers and the pellet for bacterial DNA extraction, as described below.

\section{Ethical standards}

This study was conducted according to the guidelines laid down in the Declaration of Helsinki and all procedures involving human subjects/patients were approved by the Committee on Ethical Practice at the Hospital Universitari Sant Joan (Tarragona, Spain). All the mothers participating in the study gave written informed consent.

\section{Cytokine and sIgA quantification}

Supernatant concentration of interleukin (IL)-12p70, IL-10, IL-13, interferon (IFN) $-\gamma$, tumor necrosis factor (TNF)- $\alpha$ and transforming growth factor (TGF)- $\beta 1$ in breast milk were quantified using the Multiple Analyte Detection FlowCytomixTM inflammation panel following the manufacturer's instructions (eBioscience, San Diego, USA). Samples and standard curves were analyzed on a FACS-Canto II Deckton Dickinson cytometer (BD
Bioscience). Data were processed using the FlowCytomixPro software (eBioscience). Threshold sensitivities for each cytokine were: $1.5 \mathrm{pg} / \mathrm{mL}$ for IL-12p70, $1.6 \mathrm{pg} / \mathrm{mL}$ for IFN- $\gamma$, $1.9 \mathrm{pg} / \mathrm{mL}$ for IL-10, $4.5 \mathrm{pg} / \mathrm{mL}$ for IL-13, $3.2 \mathrm{pg} / \mathrm{mL}$ for TNF-a and $10.0 \mathrm{pg} / \mathrm{mL}$ for TGF- $\beta 1$. The sIgA content was quantified in milk supernatants using a commercial ELISA kit following the manufacturer's instructions (Bethyl, Montgomery, USA).

\section{Bacterial DNA isolation and real- time PCR for microbiota analysis} DNA from breast milk was extracted using the QIAamp DNA Blood Mini Kit (Qiagen, Hilden, Germany) following the manufacturer's instructions. Real time PCR analyses were carried out to quantified the content of different bacterial groups using specific primers as previously described $(19,20)$. PCR amplifications were performed in a LightCycler 480 Real-Time PCR System (Roche, Mannhein, Germany) in a multiwell-plate with $15 \mu \mathrm{L}$ of reaction mixture that consisted of $7.5 \mu \mathrm{L}$ SYBR Green PCR Master Mix (Roche), $3.5 \mu \mathrm{L}$ DNase free water, $0.75 \mu \mathrm{L}$ of each specific primer $(10 \mathrm{mM})$ and $2.5 \mu \mathrm{L}$ of the DNA sample. 16S rRNA gene copy numbers of each bacterial group were calculated by comparing the cycle threshold $(\mathrm{Ct})$ values obtained with those from a standard curve. Standard curves were generated from serial dilutions of a known copy 
number of the target gene cloned into a plasmid vector. For each reference strain the 16S rRNA gene was cloned into a pGEM-T Easy Vector System (Promega, Madison, USA). Standard curves were constructed by plotting the $\mathrm{Ct}$ values against the logarithm of their initial template copy number using LightCycler ${ }^{\circledast} 480$ Software, Version 1.5.

To study the prevalence of different Bifidobacterium species (B. bifidum, $B$. breve, $B$. catenolatum, $B$. longum and $B$. infantis) we used specific primers as described by Matsuki et al. (21). PCR products were separated in a $2 \%(\mathrm{w} / \mathrm{v})$ agarose gel stained with ethidium bromide and we recorded the presence or absence of the amplicon according to molecular mass.

\section{Human milk oligosaccharide extraction from breast-milk samples}

Carbohydrates were extracted from one aliquot $(1 \mathrm{~mL})$ of breast milk following Stahl et al. (22). The procedure included pasteurization $\left(30 \mathrm{~min}, 70{ }^{\circ} \mathrm{C}\right)$, defatting at $4{ }^{\circ} \mathrm{C}$ and protein precipitation by adding double the amount (v/v) of cold ethanol. The carbohydrates extracted from milk were purified by solid phase extraction on graphitized carbon column cartridges (150 mg bed weight, $4 \mathrm{~mL}$ tube size; Alltech, Deerfield, Il) as described previously $(23,24)$. In short, the cartridges were washed with 80/20 (v/v) acetonitrile $(\mathrm{ACN}) /$ water containing $\quad 0.1 \%$ (v/v) trifluoroacetic acid (TFA) and later with millipore water. After loading the sample extract onto the cartridge, monomers and lactose were largely removed by elution with an aqueous 5\% (v/v) ACN solution. The remaining carbohydrates on the cartridge were eluted with 40/60 (v/v) ACN/water containing 0.05\% (v/v) TFA. The solution was dried under a stream of air and the dried sample was then rehydrated with millipore water.

\section{Human milk oligosaccharide determination by capillary electrophoresis-laser-induced fluorescence (CE-LIF)}

For CE-LIF analysis, the carbohydrates present in the breast milk samples were derivatized with the fluorescent 9-aminopyrene1,4,6-trisulfonate (APTS) overnight at room temperature as reported elsewhere (25). Five nanomole xylose was added as internal standard and mobility marker. CE-LIF was performed on a ProteomeLab PA 800 characterization system (Beckman Coulter, Fullerton, CA), equipped with a laser induced fluorescence detector (LIF) (excitation: 488 $\mathrm{nm}$, emission: $520 \mathrm{~nm}$ ) (Beckman Coulter) and a polyvinyl alcoholcoated capillary $(50 \mu \mathrm{m}$ x $50.2 \mathrm{~cm}$ (Beckman Coulter), detector after $40 \mathrm{~cm}$ ), kept at $25^{\circ} \mathrm{C}$. Samples were loaded hydrodynamically (4 $s$ at $0.5 \mathrm{psi}$, representing approx. $14 \mathrm{~nL}$ sample solution) into the capillary. Separation was performed 
in the reversed polarity mode $(30$ $\mathrm{kV}, 20 \mathrm{~min}$ ) in the $25 \mathrm{mM}$ acetate buffer containing $0.4 \%$ polyethylene oxide provided in the ProteomeLab Carbohydrate Labeling and Analysis Kit (Beckman Coulter). Due to the low $\mathrm{pK}_{\mathrm{a}}$ of the sialic acid, residues $\left(\mathrm{pK}_{\mathrm{a}}^{\mathrm{a}}\right.$ 2.6) the separation buffer was adjusted to $\mathrm{pH} 2.4$ by adding $1.2 \% \quad(\mathrm{v} / \mathrm{v})$ formic acid. Peaks were integrated manually using Chromeleon software 6.8 (Dionex, Sunnyvale, CA). The HMOs quantified are schematically represented in Table 2.

\section{Statistical analysis}

Data distribution was analysed using Shapiro-Wilk W test (SPSS Statistic $19 \mathrm{v}$ software). Normal distribution was found for cytokines, sIgA and HMO data and the t-test was applied to compare the means of the values of the two groups of mothers. Microbiota data did not show a normal distribution and, therefore, the non-parametric Mann-Whitney $U$ test was applied to compare the medians of the values of the two groups of mothers. Categorical variables (presence or absence) for prevalence of Bifidobacterium spp. were analyzed using the Fisher test. Correlations between parameters were determined applying the Pearson coefficient. In all cases, statistically significant differences were established at $P$ value $<0.05$.

\section{RESULTS}

\section{Demographic and clinical characteristics}

The demographic and clinical characteristics of the mothers and their infants are summarized in Table 1. No significant differences were detected in maternal age, duration of gestation and mode of delivery. All infants were born at term and their birth weight, length and sex distribution were not significantly different between groups. Therefore, the study groups and their milk samples were comparable.

\section{Immune parameters in breast milk from mothers with $C D$ and healthy mothers}

The cytokines and sIgA content in the supernatants of breast milk from 12 healthy mothers and 12 mothers with CD were analyzed (Figure 1). The quantifications were positive (above the detection threshold) in $66.7 \%$ of cases for IL-13 and TNF- $a$, and in $37.5 \%$ for TGF- $\beta 1$. The other cytokine quantifications were positive in at least $75 \%$ of the samples (data not shown). No differences in cytokine prevalence were observed between groups (data not shown). Overall, mothers with CD had lower cytokine content in breast milk compared with healthy mothers, being statistically significant for IL-12(p70), TGF- $\beta 1$ and sIgA levels $(P=0.042,0.018$, 0.003 , respectively) and of borderline significance for IFN- $\gamma(P=0.058)$. 
Table 1: Clinical and demographic characteristics of healthy mothers and mothers with celiac disease $(\mathrm{CD})$ and their infants.

\begin{tabular}{|c|c|c|c|c|c|c|}
\hline & \multirow[t]{2}{*}{ Characteristics $^{\mathrm{a}}$} & \multicolumn{2}{|c|}{$\begin{array}{l}\text { Healthy mothers } \\
\quad(n=12)\end{array}$} & \multicolumn{2}{|c|}{$\begin{array}{l}\text { Mothers with } \\
\text { CD }(n=12)\end{array}$} & \multirow[t]{2}{*}{$P$-value } \\
\hline & & Mean & SE & Mean & SE & \\
\hline \multirow[t]{3}{*}{ Mothers } & Age & 33.2 & 1.3 & 34.5 & 3.6 & 0.570 \\
\hline & Weeks of gestation & 39.1 & 1.6 & 38.9 & 2.4 & 0.986 \\
\hline & $\begin{array}{l}\text { Mode of delivery } \\
\text { Vaginal } \\
\text { Caesarean }\end{array}$ & \multicolumn{2}{|c|}{$\begin{array}{c}10(83.3) \\
2(16.7)\end{array}$} & \multicolumn{2}{|c|}{$\begin{array}{c}10(83.3) \\
2(16.7)\end{array}$} & 0.704 \\
\hline \multirow[t]{3}{*}{ Infants } & Birth weight (g) & 3650 & 923 & 3590 & 1044 & 0.704 \\
\hline & Birth length (cm) & 48 & 4 & 49 & 4 & 0.751 \\
\hline & $\begin{array}{l}\text { Sex } \\
\text { Male } \\
\text { Female }\end{array}$ & \multicolumn{2}{|c|}{$\begin{array}{l}5(41.7) \\
7(58.3)\end{array}$} & \multicolumn{2}{|c|}{$\begin{array}{l}4(33.3) \\
8(66.7)\end{array}$} & 0.500 \\
\hline
\end{tabular}

${ }^{a}$ Data of continuous variables are expressed as mean and standard error (SE) (in brackets) and data of categorical variables are expressed as absolute numbers and percentage (in brackets). Statistically significant differences were established at two-tailed $P<0.05$ using the t-test for continuous variables and using the Fisher test for categorical variables.

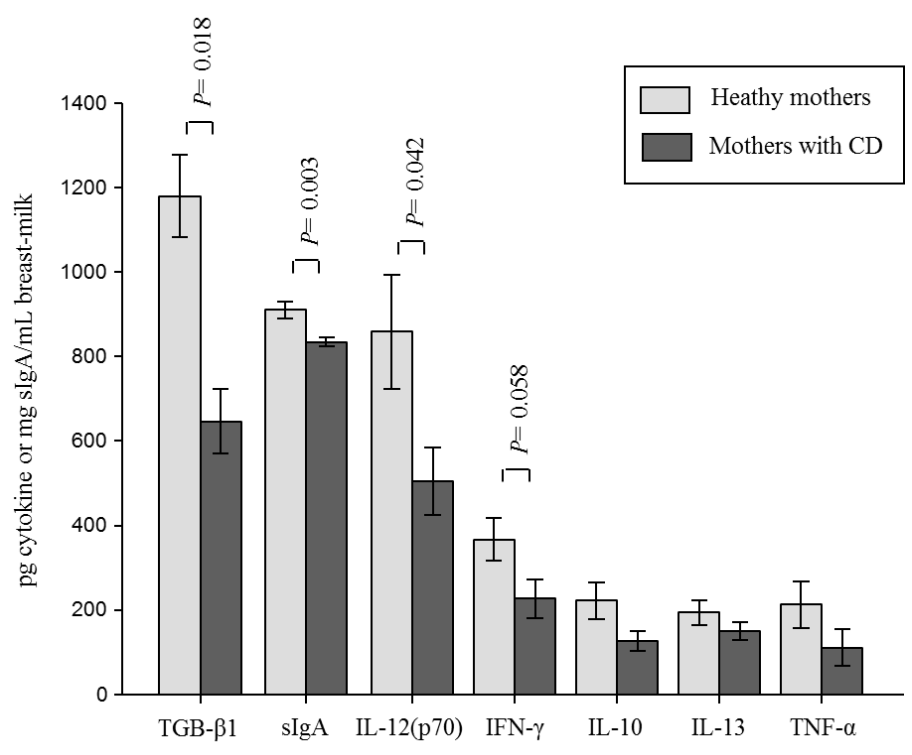

Figure 1. Cytokine and secretory $\operatorname{IgA}(\operatorname{sg} A)$ in breast-milk of healthy mothers and mothers with celiac disease (CD). Values are expressed as means and standard error of means. Statistically significant differences were establish at two-tailed $P<0.050$ using the t-test. 
No differences were detected for IL10 ( $P=0.094), \mathrm{IL}-13(P=0.228)$ and TNF-a $(P=0.173)$ between healthy mothers and mothers with CD.

\section{Oligosaccharide concentrations in breast milk from healthy mothers and mothers with $C D$}

Healthy mothers and mothers with CD were separated according to their Lewis and secretor profile as:
Le(a-b+)-secretor, Le(a+b-)-nonsecretor, Le(a-b-)-secretor and Le(ab-)-non-secretor, which depends on fucosyltransferase expression influencing the composition of fucosylated HMOs (26). In both groups, six mothers belonged to the $\operatorname{Le}(a-b+)$-secretor profile, five to the $\operatorname{Le}(\mathrm{a}+\mathrm{b}-)$-non-secretor, one to Le(a-b-)-secretor type and none to the Le(a-b-)-non-secretor. Table 2

Table 2. Human milk oligosaccharides $(\mathrm{HMO})^{\mathrm{a}}$ analyzed in the present study.

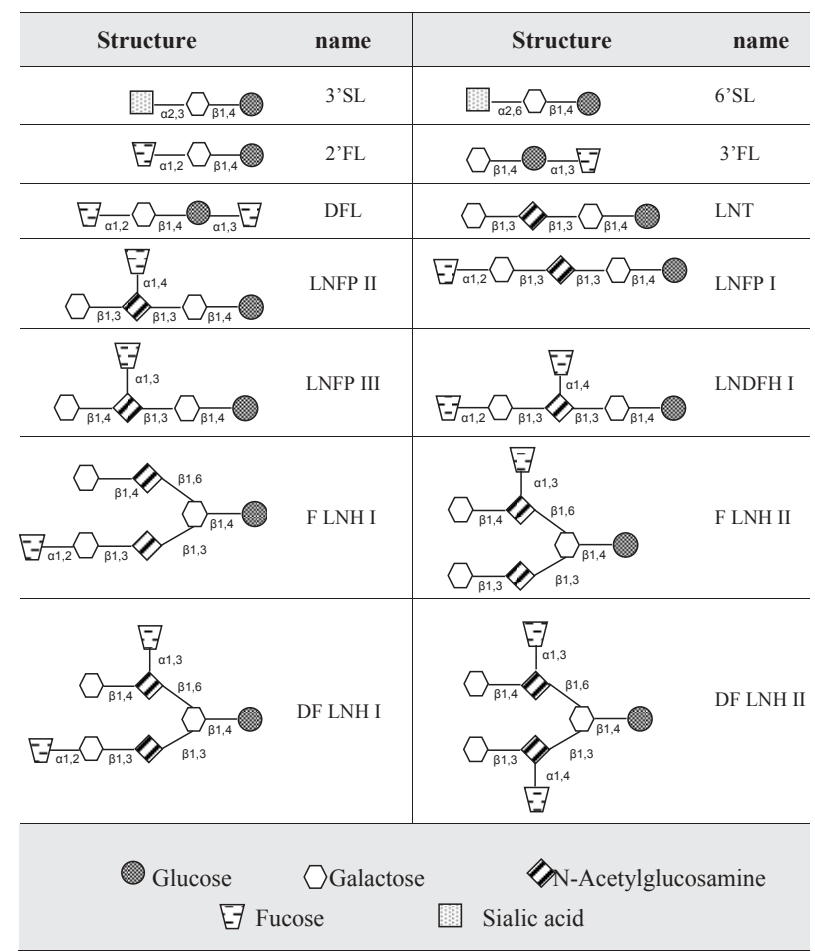

${ }^{a}$ Schematic representation of the molecular structure of the human milk oligosaccharides (HMOs) analysed in the present study by capillary electrophoresis-laser-induced fluorescence (CE-FIL). The analyses included two structures of sialyllactoses (SL) 3'SL and 6'SL; two fucosyllactoses (FL) 2'FL and 3'FL; difucosyllactose (DFL); lacto-N-tetraose (LNT); three lacto-N-fucopentaoses (LNFP) LNFP I, LNFP II, LNFP III; one lacto-N-difucosylhexaose (LNDFH) LNDFH I; two fucosyllacto-N-hexaose (F LNH) F LNH I and F LNH II; and two difucosyllacto-N-hexaose (DF LNH) DF LNH I and DF LNH II. 
summarizes HMO quantification. HMO contents were compared between healthy mothers and mothers with $\mathrm{CD}$ of the same secretor status (Table 3). In milk of the $\mathrm{Le}(\mathrm{a}+\mathrm{b}-)$-non-secretor type, higher LNT and LNFPII contents were detected for mothers with CD compared with healthy ones, but only differences in LNT content differed significantly $(P=0.042$ and 0.075 , respectively). No differences were detected in HMO content between the two groups of mothers with the Le(a-b+)-secretor type.

\section{Breast-milk microbiota}

Breast-milk microbiota composition of healthy mothers and mothers with $\mathrm{CD}$ is shown in Table 4. Mothers with CD showed a statistically significant reduction in the gene copy numbers of Bifidobacterium spp. $(P=0.026)$ and $B$. fragillis group $(P=0.044)$ compared with healthy mothers. Of the Bifidobacterium species analyzed only B. bifidum and B. breve were detected but their levels were too low for quantification by real-time PCR. No statistically significant differences were detected in the prevalence of these two species, although, as expected, they tended to be more prevalent in healthy mothers' than in CD mothers' breast milk (Table 5).

\section{DISCUSSION}

Here we have demonstrated that breast milk from mothers with $\mathrm{CD}$ and from healthy mothers differs in immune parameters and, albeit to a lower extent, in microbiota and HMO composition. This sheds new light on how breast-feeding may affect the risk of offspring of developing $\mathrm{CD}$, and help explain the controversy across diverse epidemiological studies. Several epidemiological studies have reported that breast feeding provides benefits to the infant's health and may protect against $\mathrm{CD}$, particularly if kept up when gluten is introduced into the diet $(2,3)$, whereas other studies have not found this association (4, 5). There is also debate as to whether breast-feeding only delays $\mathrm{CD}$ onset or actually provides permanent protection, as seems to be the case in the longer study by Ivarsson et al. (3). Our case-control study showed TGF- $\beta 1$ concentration was significantly lower in mothers with CD than in healthy mothers, which may influence the development of the newborn's immune response. TGF- $\beta$ is an important family of growth factors involved in developing oral tolerance and regulating most mechanisms triggered by antigen feeding, as well as in maintaining intestinal immune homeostasis (27). CD patients' pathologic immune response to gluten proteins is characterized by the uncontrolled production of IFN- $\gamma$ by intraepithelial T-cells, which is not sufficiently counteracted by TGF- $\beta 1$ production, possibly due partly to the inhibitory effect of IL-15 over 


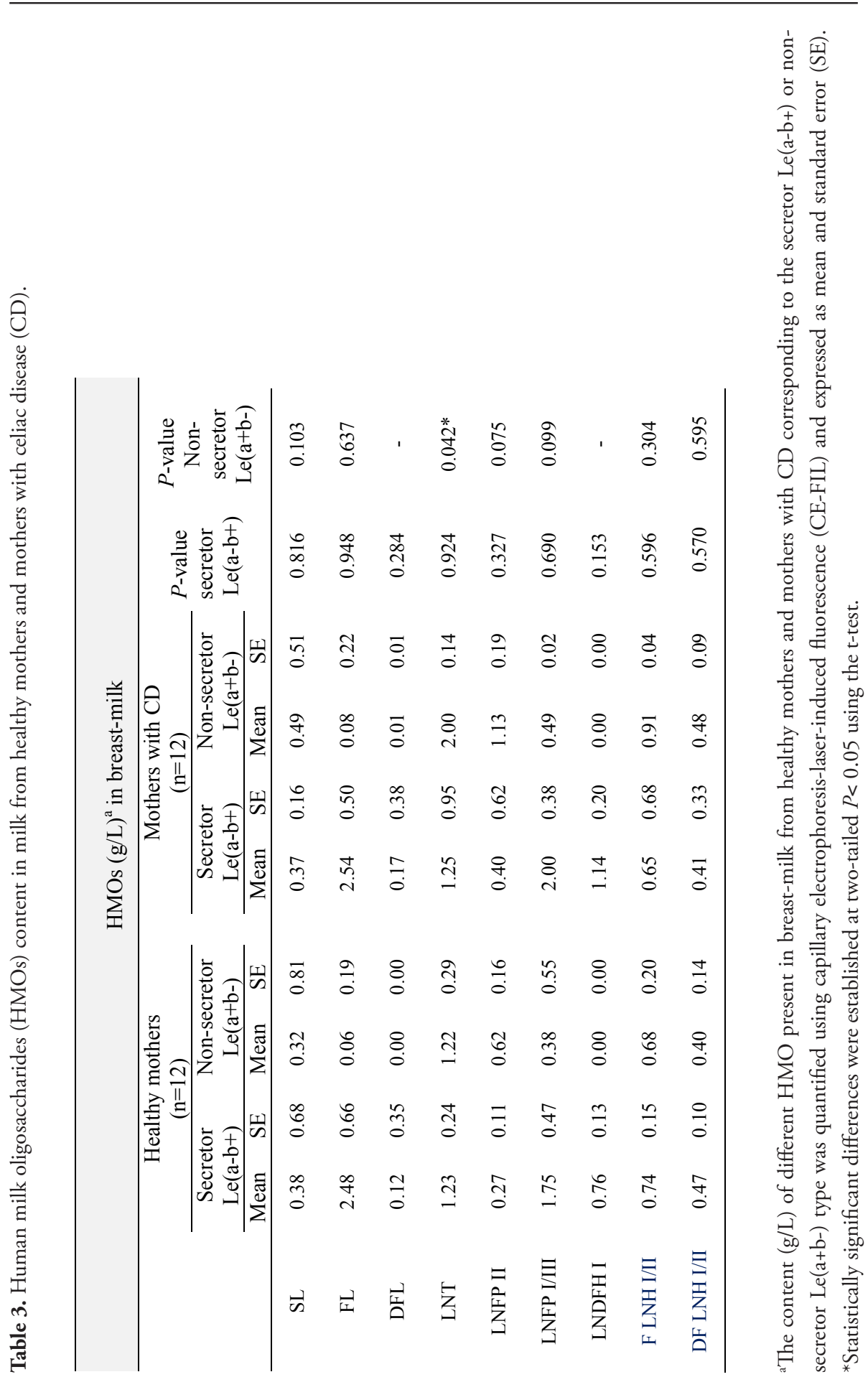


Table 4. Breast-milk microbiota composition in healthy mothers and mothers with celiac disease (CD).

\begin{tabular}{lccc}
\hline Bacterial groups & \multicolumn{2}{c}{${ }^{\mathrm{a}}$ Gene copy numbers/mL of breast-milk } \\
& $\begin{array}{c}\text { Healthy mothers } \\
(\mathrm{n}=12)\end{array}$ & $\begin{array}{c}\text { Mothers with CD } \\
(\mathrm{n}=12)\end{array}$ & $P$-value \\
\hline Bifidobacterium spp. & 2.48 & 2.36 & $0.026^{*}$ \\
B. fragillis group & $(2.37-2.78)$ & $(2.29-2.57)$ & \\
& 2.04 & 1.96 & $0.044^{*}$ \\
Enterobacteriaceae & $(1.89-2.16)$ & $(1.90-2.03)$ & \\
& 3.25 & 3.29 & 0.883 \\
Lactobacillus group & $(3.14-3.38)$ & $(3.12-3.38)$ & \\
& 3.92 & 3,67 & 0.140 \\
C. coccoides group & $(3.16-4.05)$ & $(3.29-3.77)$ & 0.859 \\
Streptococcus group & 3.05 & 3.07 & \\
Enterococcus group & $(2.93-3.43)$ & $(2.96-3.22)$ & 0.160 \\
& 2.76 & 2.99 & \\
& $(2.70-2.95)$ & $(2.77-3.04)$ & 0.093 \\
\hline
\end{tabular}

${ }^{\mathrm{a}}$ Data are expressed as median and $25^{\text {th }}$ and $75^{\text {th }}$ percentiles (in brackets) of log gene copy numbers of each bacterial group. *Statistically significant differences were established at two-tailed $P<0.05$ using the Mann-Whitney $U$ test.

Table 5. Prevalence of Bifidobacterim spp. in breast-milk from healthy mothers and mothers with celiac disease (CD).

\begin{tabular}{lccc}
\hline & \multicolumn{3}{c}{${ }^{\mathrm{a}}$ Prevalence of Bifidobacterium spp. } \\
\hline & $\begin{array}{c}\text { Healthy mothers } \\
(\mathrm{n}=12)\end{array}$ & $\begin{array}{c}\text { Mothers with CD } \\
(\mathrm{n}=12)\end{array}$ & $* P$-value \\
\hline B. bifidum & $10 / 12$ & $7 / 12$ & 0.185 \\
\hline B. breve & $10 / 12$ & $7 / 12$ & 0.185 \\
\hline B. catenulatum & $0 / 12$ & $0 / 12$ & - \\
\hline B. longum & $0 / 12$ & $0 / 12$ & - \\
\hline B. infantis & $0 / 12$ & $0 / 12$ & - \\
\hline
\end{tabular}

${ }^{a}$ Prevalence is expressed as positive cases/total cases. Statistically significant differences were established using the Fisher test at two-tailed $P<0.050$. 
TGF- $\beta 1$ signalling (28). Breast milk constitutes an important source of TGF- $\beta 1$ for the neonate because its expression is absent in the neonatal intestine before day 10 , after which it increases progressively (27). The low TGF- $\beta 1$ levels detected in breastmilk from mother with $C D$ in our study could theoretically limit its protective role in $\mathrm{CD}$ prevention. Some authors have described that allergic mothers presented lower levels of TGF- $\beta 1$ in mature milk (29) or TGF- $\beta 2$ (17); although inconsistent results have also been reported $(30,31)$. In the present study, breast-milk of CD mothers was also characterized by a significant decrease in IL-12p70 and important but no significant reductions in IFN- $\gamma$ and IL-10 compared with healthy mothers. IL-12 is one of the main cytokines involved in Th1type responses, together with IFN- $\gamma$, which is the main cytokine involved in CD. Therefore, an adverse role of reduced Th1-type pro-inflammatory cytokine concentrations in breast milk of mothers with $C D$ could not be inferred, as anticipated for regulatory cytokine reductions. However, similar changes in cytokine levels in breast milk were associated with increased allergy incidence by Tomicic et al. (16). These authors described that reduced concentrations of proinflammatoy $(\mathrm{IFN}-\gamma)$ and regulatory (TGF- $\beta 2$ and IL-10) cytokines and sIgA in breast milk were associated with an increased allergy incidence in the
Swedish population compared to the Estonian population (16). The same trend was reported for allergic mothers' breast milk, where authors interpreted reductions in TGF- $\beta 2$ and IL-10 as a health risk for the infant (32). The latter is a suppressive cytokine, which plays a key role in intestinal tolerance and immune homeostasis. An animal study reports that transgenic mice with IL10 gene disruption spontaneously developed enterocolitis at the time of weaning, which was prevented by parenteral administration of IL-10. The study suggests administration of this cytokine with breast milk could play a crucial role in maintaining gut homeostasis (33). However, other authors concluded that IL10 in breast milk was not required for induction of tolerance and protection from allergic asthma (34). Research has also associated $\mathrm{CD}$ with a significant reduction in sIgA levels. This immunoglobulin is produced by breast secretory cells and is able to survive passage through the gastrointestinal tract (35), where it acts as a first-line of defence by interacting with intestinal antigens and microbes. Thus a reduction in sIgA concentrations supplied by breast milk could reduce the infant's mucosal protection, which may precede gluten intolerance.

Breast-milk of mothers with CD also showed statistically significant reductions in Bifidobacterium spp. and $B$. fragillis gene copy numbers in comparison with healthy mothers' 
milk, although differences in Bifidobacterium at species level were not detected. Previous studies report that reductions in bifidobacteria content in allergic mothers' breast milk are parallel to reduced infant's faecal bifidobacteria (11).

Probiotic interventions support the hypothesis that gut microbiota plays a role in the immunological properties of breast-milk. For instance, administration of Lactobacillus rhamnosus GG was associated with increased TGF- $\beta 2$ concentration in breast-milk (36) while administration of $L$. rhammnosus GG and Bifidobacterium lactis $\mathrm{Bb} 12$ together was associated with increased TNF-a, IL-10, IL-4, and IL-2 concentrations (17). However, neither of these studies investigated whether the administered bacteria were detectable in breast-milk samples. The administration of $L$. rhamnosus GG to mothers during pregnancy and breast-feeding was also associated with a reduction in atopic eczema, compared with mothers taking a placebo, but no direct correlation was detected between increased TGF- $\beta 2$ concentrations and atopic disease or atopy (36). Immunoactive agents present in breast milk can partly come from serum and, therefore, are able to reach the mammary gland via systemic circulation. Probiotics can modify humoral immune mediators via gut stimulation and, therefore, may also influence the composition of immune mediators in breast milk via a similar mechanism (37). Immune mediators may also be partly derived from the mammary gland epithelial cells (38) and produced locally by breast-milk immune cells (39) where a local stimulatory effect of the breast-milk microbiota on these immune cells is likely. In fact, our study supports this hypothesis, showing parallel reductions in both immune mediators and microbial components in breast-milk of mothers with CD.

The presence and abundance of HMOs in breast milk is genetically determined by glycosyltransferase production in the mammary gland. Most of them are common to all women, with the exception of the fucosyltransferases. The expression of (a1,2)-fucosyltransferase (FUT2) and (a1,3/4)-fucosyltransferases (FUT3) responsible for the fucosylation of HMOs and others body glycoproteins (e.g. erythrocytes and mucins), depends on the maternal Secretor- (Se) and Lewis (Le) type, respectively (26). Recently, the expression of FUT2, which participates in $\mathrm{ABH}$ antigen synthesis in mucus and other secretions, has been associated with bifidobacteria diversity and abundance in the human intestinal tract (40). Likewise, the non-secretor phenotype (characterized by the lack of expression of FUT2 gene) has been associated with susceptibly to $\mathrm{CD}$ (41). However, the present study found no differences in the number of cases of the non-secretor 
phenotype between healthy and CD mothers, although such differences may not be appreciable due to the limited population size. However, in $\mathrm{Le}(\mathrm{a}+\mathrm{b}-)-$-non-secretor mothers, LNT content increased in breast milk of mother with CD compared with healthy mothers' milk. This is the first report of the influence of $\mathrm{CD}$ on the presence of HMOs in breast-milk in mothers of a particular secretor status. Mothers secretor status has not been associated with health outcomes in mothers, but with infants' resistance to viral infections (42), which could also constitute risk factors for CD (43).

Bifidobacterium spp. can achieve high cell densities using HMOs as sole carbon source, and bifidobacteria are normally abundant in stools from breast-fed infants, therefore $\mathrm{HMOs}$ appear to act as a prebiotic substrate, helping to shape the microbiota of the infant's intestinal tract (44). Likewise, HMOs may exert a similar effect on the mammary gland, favouring the presence of bifidobacteria in breast milk. Alternatively, bifidobacteria could be transient bacteria and their levels in the mammary gland may depend on their presence in the maternal intestinal microbiota.

The ability of bifidobacteria to consume HMOs is speciesdependent. For example, research reports $B$. longum subsp. longum DJO10A and B. breve ATCC15700 consumed only a portion of a single, nonfucosylated/nonsialylated HMO species (LNnT), while $B$. longum subsp. infantis ATCC15697 consumed oligosaccharides with a low degree of polymerization ( $\leq 7)$ (44). Accordingly, differences in HMO composition would result in differences in Bifidobacterium species composition in human milk but we did not find such differences. Our finding is supported by a previous study that reported differences in infants' microbiota only for $B$. adolescentis and $B$. catenulatum abundances, analysed by denaturing gradient gel electrophoresis (DGGE) in infants fed with milk group 4 (Le(a-b-)-non-secretor) according to classification by Thurl et al. (45), which only represent $1 \%$ of general population (46). This could be explained by the fact that different bacterial species develop different strategies to use HMOs and by the existence of cross-feeding mechanisms among them which overall enable their growth.

The study reported herein has some limitations partly related to its exploratory nature, including a small population size, lack of connexion with clinical outcomes in the offspring and lack of control of mother anthropometric measures and diet, which might also influence the breast milk composition. In particular, it has been recently described that women on a GFD reduce the dietary protein and fibre intakes and increase the fat intake (50), which could also have an impact on breast milk composition. Breastfeeding during the first months 
of life has been associated with a protective effect against asthma (47, 48), atopic dermatitis (49) and CD (2) although not all study results are consistent. Compositional differences between breast milk of mothers with allergic disease and controls have also been reported although their relationships with health outcomes are controversial yet. The results presented here show differences between breast milk composition from healthy mothers and mothers with CD in terms of immune mediators, microbiota and HMOs. It can be speculated that such differences could influence the protective effects of breastfeeding on infant health, and partly explain controversy across studies. Nevertheless, further prospective studies are needed to reveal whether differences in breast-milk composition ultimately influence the risk of offspring of developing CD.

\section{Acknowledgments}

This work was supported by grants AGL2011-25169 and Consolider Fun-CFood CSD2007-00063 from the Spanish Ministry of Economy and Competitiveness (MINECO). The scholarship to M. Olivares from Consejo Superior de Investigaciones Científicas (CSIC) is fully acknowledged.

\section{REFERENCES}

1. Pozo-Rubio T, Olivares M, Nova E et al. (2012) Immune development and intestinal microbiota in coeliac disease. Clin Dev Immunol 2012, 654143.

2. Akobeng AK, Ramanan AV, Buchan I et al. (2006) Effect of breast feeding on risk of coeliac disease: a systematic review and metaanalysis of observational studies. Arch Dis Child 91, 39-43.

3. Ivarsson A, Myléus A, Norström F et al. (2013) Prevalence of childhood coeliac disease and changes in infant feeding. Pediatrics 131, e687-694.

4. Norris JM, Barriga K, Hoffenberg EJ et al. (2005) Risk of coeliac disease autoimmunity and timing of gluten introduction in the diet of infants at increased risk of disease. JAMA 293, 2343-2351.

5. Welander A, Tjernberg AR, Montgomery SM et al. (2010) Infectious disease and risk of later coeliac disease in childhood. Pediatrics 125, e530-536.

6. Garrido D, Barile D, Mills DA (2012)

A molecular Basis for Bifidobacterial Enrichment in the Infant Gastrointestinal Tract. Adv Nutr 3, 415S-421S.

7. El Aidy S, Hooiveld G, Tremaroli V et al. (2013) The gut microbiota and mucosal homeostasis: colonized at birth or at adulthood, does it matter? Gut Microbes 4, 118-124.

8. Madan JC, Salari RC, Saxena D et al. (2012) Gut microbial colonization in premature neonates predicts neonatal sepsis. Arch Dis Child Fetal Neonatal Ed 97, F456462.

9. Rinne M, Kalliomaki M, Arvilommi $\mathrm{H}$ et al. (2005) Effect of probiotics and breastfeeding on the bifidobacterium and lactobacillus/enterococcus microbiota and humoral immune responses. J Pediatr 147, 186-191.

10. Martín R, Jiménez E, Heilig $\mathrm{H}$ et al. (2009) Isolation of Bifodobacteria from Breast 
Milk and Assessment of the Bifidobacterial Population by PCR-Denaturing Gradient Gel Electrophoresis and Quantitative RealTime PCR. Appl Environ Microbiol 75, 965969.

11. Grönlund MM, Gueimonde M, Laitinen K et al. (2007) Maternal breastmilk and intestinal bifidobacteria guide the compositional development of the Bifidobacterium microbiota in infants al risk of allergic disease. Clin Exp Allergy 37, 17641772 .

12. Martín R, Langa $S$, Reviriego $C$ et al. (2003) Human milk is a source of lactic acid bacteria for the infant gut. J Pediatr 143, 754-758.

13. Rescigno M, Rotta G, Valzasina B et al. (2001) Dendritic cells shuttle microbes across gut epithelial monolayers. Immunobiology 204, 572-581.

14. Garofalo R (2010) Cytokines in human milk. J Pediatr 156, S36-40.

15. Peroni DG, Pescollderungg L, Piacentini GL et al. (2010) Immune regulatory cytokines in the milk of lactating women from farming and urban environments. Pediar Allergy Immunol 21, 977-982.

16. Tomicić S, Jonansson G, Voor $\mathrm{T}$ et al. (2010) Breast milk cytokine and IgA composition differ in Estonian and Swedish mothers-relationship to microbial pressure and infant allergy. Pediatr Res 68, 330-334.

17. Hoppu U, Isolauri E, Laakso $\mathrm{P}$ et al. (2011) Probiotics and dietary counselling targeting maternal dietary fat intake modifies breast milk fatty acids and cytokines. Eur J Nutr 51, 211-219.

18. Walker-Smith JA, Guandalini S, Schmitz $\mathrm{J}$ et al. (1990) Revised criteria for diagnosis of coeliac disease. Arch. Dis Child 65, 909-911.

19. Matsuki T, Watanabe K, Fujimoto J et al. (2002) Development of $16 \mathrm{~S}$ rRNAgene-targeted group-specific primers for the detection and identification of predominant bacteria in human feces. Appl Environ Microbiol 68, 5445-5451.

20. Malinen E, Kassinen A, Rinttila $\mathrm{T}$ et al. (2003) Comparison of real-time PCR with SYBR Green I or 5'-nuclease assays and dot-blot hybridization with rDNA-targeted oligonucleotide probes in quantification of selected faecal bacteria. Microbiology 149, 269-277.

21. Matsuki T, Watanabe K, Tanaka R et al. (1999) Distribution of bifidobacterial species in human intestinal microflora examined with $16 \mathrm{~S}$ rRNA-gene-targeted speciesspecific primers. Appl Environ Microbiol 65, 4506-4512.

22. Stahl B, Thurl S, Zeng J et al. (1994) Oligosaccharides from human milk as revealed by matrix-assisted laser desorption/ ionization mass spectrometry. Anal Biochem 223, 218-226.

23. Ninonuevo MR, Park $\mathrm{Y}$, Yin $\mathrm{H}$ et al. (2006) A strategy for annotating the human milk glycome. J Agric Food Chem 54, 7471 7480 .

24. Albrecht S, Schols HA, van den Heuvel EG et al. (2010) CE-LIF-MS in profiling of oligosaccharides in human milk and feces of breast-fed babies. Electrophoresis 31, 12641273.

25. Albrecht $S$, van Muiswinkel GC, Schols HA et al. (2009) Introducing capillary electrophoresis with laser-induced fluorescence detection (CE-LIF) for the characterization of konjac glucomannan oligosaccharides and their in vitro fermentation behavior. J Agric Food Chem 57, 3867-3876.

26. Oriol R, Mollicone R, Cailleau A et al. (1999) Divergent evolution of fucosyltransferase genes from vertebrates, invertebrates, and bacteria. Glycobiology 9, 323-334.

27. Oddy WH, McMahon RJ (2011) Milkderived or recombinant transforming growth factor-beta has effects on immunological outcomes: a review of evidence from animal experimental studies. Clin Exp Allergy 41, 783-793.

28. Benahmed M, Meresse B, Arnulf B et al. (2007) Inhibition of TGF-beta signaling by IL-15: a new role for IL-15 in the loss of immune homeostasis in coeliac disease. Gastroenterology 132, 994-1008.

29. Rigotti E, Piacentini GL, Ress M et al. (2006). Transforming grown factor- 
beta and interleukin-10 in breast milk and development in infants. Clin Exp Allergy 36, 614-618.

30. Böttcher DL, Jenmalm MC, Garofalo RP et al. (2000) Cytokines in breast milk from allergic and nonallergic mothers. Pediatr Res 47, 157-162.

31. Snijder BEP, Damoiseaux JGMC, Penders J et al. (2006) Cytokines and soluble CD14 in breast milk in relation with atopic manifestation in mother and infant (KOALA Study). Clin Exp Allergy 36, 1609-1615.

32. Laiho K, Lampi AM, Hamalainen M et al. (2003) Breast milk fatty acids, eicosanoids, and cytokines in mothers with and without allergic disease. Pediatr Res 53, 642-647.

33. Berg DJ, Davidson N, Nühn R et al. (1996) Enterocolitis and colon cancer in interleukin-10-deficient mice are associated with aberrant cytokine production and CDa+TH1-like responses. J Clin Invest 98, 1010-1020.

34. Verhasselt V, Milcent V, Cazareth J et al. (2008) Breast milk-mediated transfer of an antigen induces tolerance and protection from allergic asthma. Nat Med 14, 170-175.

35. Prentice A, Ewing G, Roberts SB et al. (1987) The nutritional role of breast-milk IgA and lactoferrin. Acta Paediatr Scand 76, 592-598.

36. Rautava S, Kalliomäki M, Isolauri E (2002) Probiotics during pregnancy and breastfeeding might confer immunomodulatory protection against atopic disease in the infant. J Allergy Clin Immunol 109, 119-121. 37. Villena J, Chiba E, Tomosada Y et al. (2012) Orally administered Lactobacillus rhamnosus modulates the respiratory immune response triggered by the viral pathogen-associated molecular pattern poly(I:C). BMC Immunol 13, 53-58.

38. Palkowetz KH, Royer CL, Garofalo R et al. (1994) Production of interleukin-6 and 17 interleukin- 8 by human mammary gland epithelial cells. J Reprod Immunol 26, 57-64.

39. Skansén-Saphir U, Lindfors A, Andersson U (1993) Cytokine production in 20 mononuclear cells of human milk studied at the single-cell level. Pediatr Res 34, 213-216. 40. Wacklin P, Mäkivuokko H, Alakulppi N et al. (2011) Secretor genotype (FUT2 gene) is strongly associated with the composition of Bifidobacteria in the human intestine. PLoS One 6, e20113.

41. Parmar AS, Alakulppi N, PaavolaSakki P et al. (2012) Association study of FUT2 (rs601338) with coeliac disease and inflammatory bowel disease in the Finnish population. Tissue Antigens 80, 488-493.

42. Jiang X, Huang P, Zhong W et al. (2004) Human milk contains elements that block binding of noroviruses to human histo-blood group antigens in saliva. J Infect Dis 190, 1850-1859.

43. Stene LC, Honeyman MC, Hoffenberg EJ et al. (2006) Rotavirus infection frequency and risk of coeliac disease autoimmunity in early childhood: a longitudinal study. Am J Gastroenterol 101, 2333-2340.

44. LoCascio RG, Ninonuevo MR, Freeman SL et al. (2007) Glycoprofiling of bifidobacterial consumption of human milk oligosaccharides demonstrates strain specific, preferential consumption of small chain glycans secreted in early human lactation. $J$ Agric Food Chem 55, 8914-8919.

45. Thurl S, Henker J, Siegel M et al. (1997) Detection of four human milk groups with respect to Lewis blood group dependent oligosaccharides. Glycoconjugate J 14, 795799.

46. Coppa GV, Gabrielli O, Zampini L et al. (2011) Oligosaccharides in 4 different milk groups, Bifidobacteria, and Ruminococcus obeum. J Pediatr Gastroenterol Nutr 53, 8087.

47. Gdalevich M, Mimouni D, Mimouni M (2001) Breast-feeding and the risk of bronchial asthma in childhood: a systematic review with meta-analysis of prospective studies. J Pediatr 139, 261-266.

48. Mimouni Bloch A, Mimouni D, Mimouni M et al. (2002) Does breastfeeding protect against allergic rhinitis during childhood? A meta-analysis of prospective studies. Acta Paediatr 91, 275-279.

49. Gdalevich M, Mimouni D, David M et al. (2001) Breast-feeding and the onset of atopic dermatitis in childhood: a systematic 
review and meta-analysis of prospective studies. J Am Acad Dermatol 45, 520-507. 50. Miranda J, Lasa A, Bustamante MA et al. (2014) Nutricional difference between a gluten-free diet and a diet containing equivalent products with gluten. Plant Foods Hum Nutr DOI 10.1007/s11130-014-04104. 


\title{
The HLA-DQ2 genotype selects for early intestinal microbiota composition in infants at high risk of developing celiac disease
}

\author{
Marta Olivares ${ }^{1}$, Alexander Neef ${ }^{1}$, Gemma Castillejo ${ }^{2}$, Giada De Palma ${ }^{1}$, Vicente \\ Varea $^{3}$, Amalia Capilla ${ }^{4}$, Francesc Palau ${ }^{4}$, Esther Nova ${ }^{5}$, Ascensión Marcos 5 , Isabel \\ Polanco ${ }^{6}$, Carmen Ribes-Koninckx ${ }^{7}$, Luis Ortigosa ${ }^{8}$, Luis Izquierdo ${ }^{1}$, Yolanda \\ Sanz $z^{1}$
}

Gut (2015) 64, 406-417

\footnotetext{
${ }^{1}$ Instituto de Agroquímica y Tecnología de Alimentos, Consejo Superior de Investigaciones Científicas (IATACSIC), Valencia, Spain. ${ }^{2}$ Hospital Universitario Sant Joan de Reus, Tarragona, Spain. ${ }^{3}$ Gastroenterología, Nutrición y Hepatología Pediátrica. Hospital Universitario Sant Joan de Deu and Unidad de Gastroenterología Pediátrica del Institut Dexeus, Barcelona, Spain. ${ }^{4}$ Centro de Investigación Príncipe Felipe (CIPF) and IBVCSIC Associated Unit, CIBER de Enfermedades Raras (CIBERER), Valencia, Spain. ${ }^{5}$ Dept. Metabolismo y Nutrición. ICTAN-CSIC, Madrid. Spain. ' Servicio de Gastroenterología y Nutrición Pediátrica, Hospital Universitario La Paz, Madrid, Spain. ${ }^{7}$ Unidad de Gastroenterología Pediátrica, Hospital Universitario La Fe, Valencia, Spain. ${ }^{8}$ Unidad de Gastroenterología, Hepatología y Nutrición Pediátrica, Hospital Universitario Nuestra Señora de Candelaria, Santa Cruz de Tenerife, Canarias, Spain.
} 


\section{ABSTRACT}

Intestinal dysbiosis has been associated with celiac disease (CD), but whether the alterations are cause or consequence of the disease is unknown. This study investigated whether the HLA-DQ2 genotype is an independent factor influencing the early gut microbiota composition of healthy infants at family risk of $\mathrm{CD}$. As part of a larger prospective study, a subset $(\mathrm{n}=22)$ of exclusively breast-fed and vaginally delivered infants with either high genetic risk (HLA-DQ2 carriers) or low genetic risk (non-HLA-DQ2/8 carriers) of developing CD were selected from a cohort of healthy infants with at least one first-degree relative with CD. Infant fecal microbiota was analyzed by $16 S$ rRNA gene pyrosequencing and real time quantitative PCR. Infants with a high genetic risk had significantly higher proportions of Firmicutes and Proteobacteria and lower proportions of Actinobacteria compared to low risk infants. At genus level, high risk infants had a significant less Bifidobacterium and unclassified Bifidobacteriaceae proportions and more Corynebacterium, Gemella, Clostridium sensu stricto, unclassified Clostridiaceae, unclassified Enterobacteriaceae and Raoultella proportions. Quantitative real time PCR also revealed lower numbers of Bifidobacterium spp. in infants with high genetic risk than in those of low genetic risk. In high risk infants negative correlations were identified between Bifidobacterium spp. and several genera of Proteobacteria (Escherichia/Shigella) and Firmicutes (Clostridium). The genotype of infants at family risk of developing CD, carrying the HLA-DQ2 haplotypes, influences the early gut microbiota composition. This finding suggests that a specific disease-biased host genotype may also select for the first gut colonizers and could contribute to determining disease risk.

Keywords: celiac disease, HLA-DQ genotype, microbiota, pyrosequencing, real-time PCR 


\section{INTRODUCTION}

Celiac disease (CD) is a chronic intestinal inflammatory disorder caused by a deregulated immune response to cereal gluten proteins of wheat, barley and rye in genetically predisposed individuals. The expression of the Human Leukocyte Antigen (HLA) Class II molecules DQ2 and DQ8, coded by the DQA1 and DQB1 genes, is strongly associated with susceptibility to CD. The HLA-DQA1*05:01 and DQB $1{ }^{*} 02: 01$ alleles forming the particular DQ2.5 haplotype confer high susceptibility to CD (1). Susceptibility to CD is increased in those homozygous subjects with this haplotype in $c i s$, or those carrying the DQ2.2 haplotype (HLADQA1*02:01 and DQB1*02:02) in trans with the DQ7.5 haplotype (HLA-DQA1*05:05 and DQB1*03:01). (2). In CD patients, gluten peptides are deaminated by tissue transglutaminase in the lamina propria and recognized by dendritic cells expressing HLA-DQ2/ DQ8 molecules that mediate the typical Th1 response of the disease, producing mainly interferon (IFN)- $\gamma$ (3). Most patients are carriers of the HLA-DQ2/DQ8 genes but these genes are also present in about $40 \%$ of the general population, and only a small percentage (2-5\%) develops CD $(4,5)$. This indicates that the HLA-DQ genotype is necessary but not solely responsible for the development of the disease. Gluten is the main environmental trigger of CD but its intake does not fully explain the onset and clinical expression of the disease. In recent years, other environmental factors influencing the early gut microbiota composition such as type of delivery and milk-feeding, intestinal infections and antibiotic intake, have also been associated with the risk of developing CD (6-11).

Colonization of the newborn intestine is thought to contribute to proper development of the host's immune function and to determine susceptibility to immune-mediated disorders in early and later life (12, 13). Most studies in CD patients report imbalances in the intestinal microbiota (14) with a few exceptions $(15,16)$. In our own studies, the microbiota of $\mathrm{CD}$ patients was characterized by decreased numbers of Bifidobacterium spp. and increased numbers of Bacteroides spp. in feces and intestinal biopsies (17, 18). Intestinal dysbiosis was not completely restored after adherence to a gluten-free diet suggesting that some changes in microbiota are not secondary to the inflammatory milieu of the active phase of the disease, but could play a primary role in predisposition to $\mathrm{CD}$ development. To date, we have a limited understanding of the host genotype's influence on the intestinal microbiota composition, but a few studies have been done in relation to chronic inflammatory bowel disorders (19-21). In the case of CD, 
there is only one study in a cohort of infants at family risk of developing the disease that has reported reliable associations between the HLA-DQ genotype and the composition of the intestinal microbiota, assessed by fluorescent in situ hybridization (FISH) and real-time polymerase chain reaction (PCR) (22-23). Nevertheless, these preliminary associations could be confounded by diverse environmental variables (e.g. type of milk-feeding, type of delivery, etc). Furthermore, the abovementioned studies were limited by their use of molecular techniques, which can only detect a small number of intestinal bacterial groups for which primers and probes are available. However, this problem can be now overcome by analyzing $16 \mathrm{~S}$ rRNA gene fragments from the whole fecal DNA (metagenome) by next generation sequencing (NGS) techniques, which help to study the intestinal ecosystem in greater depth (24).

The objective of this study was to characterize the microbiota of exclusively breast-fed and vaginally delivered infants at family risk of developing $\mathrm{CD}$ to reveal possible associations between the HLADQ2 genotype, the early microbiota composition and the ecological interactions between relevant taxa. The broader aim is to gain a greater understanding of the genetic and environmental factors influencing the early colonization process of the newborn intestine, and their impact on the risk of developing CD.

\section{MATERIALS AND METHODS}

\section{Subjects and sampling}

A subset $(\mathrm{n}=22)$ of one-month-old, exclusively breast-fed and vaginally delivered infants with either high genetic risk (HLA-DQ2 genotype, including homozygous HLA-DQ2.5 or heterozygous DQ2.5/DQ2.2 and DQ2.2/DQ7.5 carriers) or low genetic risk (non-HLA-DQ2/8 genotype) of developing $\mathrm{CD}$ were selected from a cohort of healthy infants with at least one first-degree relative with $\mathrm{CD}$ participating in a larger prospective study (23). The risk of developing $\mathrm{CD}$ was determined by PCR-SSP DQB1 and DQA1 typing as previously described (23). The group of 11 infants classified as high risk (HR) represented the highest probability (>20\%) of developing $\mathrm{CD}$ and included those carrying the DQ2.5 haplotype (DQA1*05:01$\left.\mathrm{DQB} 1^{*} 02: 01\right)$ in homozygosis and the DQ2.5/DQ2.2 or the DQ2.2/ DQ7.5 haplotypes in heterozygosis (Supplementary table 1). The low risk (LR) group included those individuals with other common genotypes unassociated with $\mathrm{CD}$, thus having the lowest probability $(<1 \%)$ of developing CD. None of the infants included in the study received antibiotics during the sampling period.

The study was approved by the local Ethic Committees and written 
informed consent was obtained from the parents of infants included in the study.

\section{DNA extraction}

For DNA extraction, $0.2 \mathrm{~g}$ of fecal sample was homogenized in $15 \mathrm{~mL}$ of phosphate buffer saline (PBS) (130 mM sodium chloride, $10 \mathrm{mM}$ sodium phosphate buffered saline, $\mathrm{pH}$ 7.4). Afterwards, the suspension was filtered through a $100 \mu \mathrm{m}$ nylon filter, washed twice with PBS and resuspended in tris-EDTA (TE) buffer (10 mM Tris, 1 mM EDTA, pH 8.0 $[\mathrm{HCl}])$. One $\mathrm{mL}$ of the suspension was added to $2 \mathrm{~mL}$ of lysozyme $(2.5$ $\mathrm{mg} / \mathrm{mL}$ ) and incubated at $37{ }^{\circ} \mathrm{C}$ for 1 hour. After adding $0.67 \mathrm{mg}$ of proteinase $\mathrm{K}$, the mix was incubated at $55^{\circ} \mathrm{C}$ for $10 \mathrm{~min}$. A volume of $400 \mu \mathrm{L} 10 \%(\mathrm{w} / \mathrm{v})$ sodium dodecyl sulfate (SDS) was added to the mix and samples were incubated at $55^{\circ} \mathrm{C}$ for 1 hour under gentle shaking. One aliquot of the mix was used for DNA extraction following the DNeasy Blood and Tissue kit protocol (Qiagen, Hilden. Germany)

\section{Sequencing the 16S rDNA amplicons}

The extracted metagenomic DNAs were used to amplify the V5 and V6 hypervariable regions of the $16 \mathrm{~S}$ rRNA using the primers 784F 5'-AGGATTAGATACCCTGGTA$3^{\prime}$ and 1061R 5'-CRRCACGAGCT GACGAC-3' by PCR, as previously described (25). The forward primer contained the sequence of the
Titanium A adaptor 5'-CCATCTCA TCCCTGCGTGTCTCCGACTC AG-3' and the barcode sequence. For each sample, a PCR mix of $100 \mu \mathrm{L}$ was prepared containing 1× PCR buffer, $2 \mathrm{U}$ of KAPA HiFi Hotstart polymerase blend and deoxynucleotide triphosphates (dNTPs) (Kapa biosystems, Wilmington, USA), $300 \mathrm{nM}$ primers (Eurogentec, Liege, Belgium), and 60 ng gDNA. Thermal cycling consisted of initial denaturation at $95{ }^{\circ} \mathrm{C}$ for $5 \mathrm{~min}$, followed by 25 cycles of denaturation at $98{ }^{\circ} \mathrm{C}$ for $20 \mathrm{~s}$, annealing at $56{ }^{\circ} \mathrm{C}$ for 40 $\mathrm{s}$, and extension at $72{ }^{\circ} \mathrm{C}$ for $20 \mathrm{~s}$, with a final extension of $5 \mathrm{~min}$ at 72 ${ }^{\circ} \mathrm{C}$. Then $3 \mu \mathrm{l}$ of PCR product were added to a new PCR mix (identical to the first round of PCR) for the nested PCR of 15 cycles. Amplicons were visualized on $1 \%$ agarose gels using GelGreen Nucleic Acid gel stain in $1 \mathrm{x}$ tris-acetate-EDTA (TAE) buffer (Biotium, Hayward, USA) and were cleaned using the Wizard SV Gel and PCR Clean-up System (Promega, Madison, USA) according to the manufacturer's instructions. Amplicon DNA concentrations were determined using the Quant-iT PicoGreen dsDNA reagent and kit (Life Tech, Carlsbad, USA) following the manufacturer's instructions. Assays were carried out using $2 \mu \mathrm{L}$ cleaned PCR product in a total reaction volume of $200 \mu \mathrm{L}$ in black, 96-well microtiter plates. Following quantitation, cleaned amplicons were combined in equimolar ratios 
into a single tube. The final pool of DNA was eluted in a volume of $100 \mu \mathrm{L}$ nuclease-free water, purified using Agencourt Ampure XP Purification systems (Agencourt Biosciences Corporation-Beckman coulter, Beverly, USA) and then resuspended in $100 \mu \mathrm{l}$ of TE $1 \mathrm{x}$. The concentration of the purified pooled DNA was determined using the Quant-iT PicoGreen dsDN reagent and kit (Life Tech, Carlsbad, USA) following the manufacturer's instructions. Pyrosequencing was carried out using primer A on a 454 Life Sciences Genome Sequencer FLX instrument (Roche, Basel, Switzerland) with titanium chemistry. 16S rDNA amplicons were sequenced by DNA Vision Agrifood S.A. (Liège, Belgium).

\section{Sequence and clustering analysis}

Original reads were filtered by length (> $240 \mathrm{bp}$ ) and quality (average Phred value > 25) and then for chimeras using UCHIME (26) resulting in $12,188 \pm 3,191$ sequence reads per sample on average. Reads were identified at phylum, family and genus level at an $80 \%$ confidence level using the Ribosomal Database Project (RDP) multiclassifier tool. Rarefaction curves and cluster analysis were calculated with the mothur package using 1000 randomizations (27). For analysis of Clostridia sequences the Living Tree Project dataset available from www.arb-silva.de was used and the respective reads were subjected to a BlastN search against a database of microbial 16S rRNA gene sequences (SILVA 111, www.arb-silva.de).

Similarity of the subject's microbiota was evaluated by cluster analysis of Bray-Curtis distances between individuals, considering the relative abundances of different genera. Decimal logarithms of raw abundance data were classified according to an arithmetic progression in a scale from 0 to 7 (28). Logarithms were obtained adding 1 to each raw value, 0 corresponded to absence of the genera and 7 was fixed as the maximum raw datum considering all genera and individuals. Bray-Curtis distances between subjects were computed and agglomerative nesting cluster (AgNes function of the cluster package of R) analysis was applied to obtain the distances (28). Weighted UniFrac analysis was performed with a set of 258 dereplicated sequences with abundances of at least 100 reads (26) using QIIME and the FastUniFrac tool at the URL http:// unifrac.colorado.edu.

\section{Richness and diversity index}

Microbial biodiversity and richness were analyzed for each sample. Both parameters are based on operational taxonomic units (OTUs), which are clusters of reads defined by their inter-distance using the Chao index. Richness is directly related to the number of observed OTUs whereas the Shannon diversity index depends on the distribution of sequence abundances in the observed OTUs. 
The Simpson index is a measure of the probability of randomly resampling an OTU. Microbial richness, Shannon, and Simpson indices were calculated with the mothur package (27).

\section{Correlation analyses}

To study possible ecological interactions between different bacterial taxa, we established correlations within the bacterial groups identified in the low and high genetic risk groups of infants. We considered only those genera present in at least nine of the 11 infants in each group. The weighted number of reads for each infant was expressed as a logarithm and cases with double zero (absence of both bacteria compared) were dismissed. The significance ( $P$ value) of the correlation coefficients between abundance of any two genera was estimated by a permutation test, performing 1,000 simulations for each coefficient (29). Only positive correlations with $|1-P|<0.100$ and negative correlations with $P<0.100$ were considered. Additionally, we considered possible correlations among the genera Bifidobacterium, Corynebacterium, Gemella, Clostridium sensu stricto and Raoultella because they enabled us to discriminate between both groups of infants in previous analyses.

\section{Real time quantitative PCR (qPCR)}

DNA was amplified using group- and genus-specific primers as described previously $(30,31)$ to quantify different bacterial groups in the intestinal microbiota. Each reaction mixture consisted of $7.5 \mu \mathrm{L}$ of SYBR Green PCR Master Mix (Roche), $3.5 \mu \mathrm{L}$ of DNase RNase free water, $0.75 \mu \mathrm{L}$ of each of the specific primers $(10 \mu \mathrm{M})$ (Isogen, Barcelona, Spain), and $2.5 \mu \mathrm{L}$ of template DNA. PCR amplification and detection were performed using a Light Cycler LC480 (Roche). Gene copy numbers of each bacterial group were calculated by comparing the cycle threshold $(\mathrm{Ct})$ values obtained with those from a standard curve. Standard curves were generated from serial dilutions of a known copy number of the 16S rRNA gene cloned into a pGEM-T Easy Vector System (Promega). E. coli DH5 $\alpha$ was transformed with the recombinant plasmids and plasmid DNA was extracted by the miniprep method (32).

\section{Data processing and statistical analyses}

Of the demographic data, the categorical variables (number of first-degree relatives with $\mathrm{CD}$ ) were analysed using the Chi-Square test and the continuous variables (size, weight and weeks of gestation at birth) using a t-test since data distribution was normal as assessed with ShapiroWilk W test (SPSS software V19). Data of microbiota composition was not normally distributed as assessed by the same test. Comparisons of data 
from qPCR were done by applying the non-parametric Mann-Whitney $U$ test (SPSS software V19). Read numbers for each taxon obtained for each infant by pyrosequencing were weighted using the mean values of the total reads for all 22 individuals. The recalculated numbers of reads assigned to each taxon for the high $(\mathrm{n}=11)$ and low genetic risk $(\mathrm{n}=11)$ groups of infants were compared using permutation analyses (DAAG package of $\mathrm{R}$ software). To compare diversity indices we implemented the R-software Wilcoxon test. Correlations between the data obtained by pyrosequencing and qPCR were analyzed using Pearson correlation coefficient (SPSS software V19). In all cases, statistically significant differences were established at $P<0.050$.

\section{RESULTS}

Characteristics of the infants included in the study

The demographic characteristics and the HLA genotype of the study infants are included in Table 1. No statistical differences ( $P>0.050)$ were observed in size, weight and weeks of gestation at birth or in the number of first-degree relatives with $\mathrm{CD}$ (mother, father, brother or/and sister) between the two infant groups.

\section{Microbiota composition by $16 \mathrm{~S}$ rRNA gene sequencing}

The pyrosequencing analysis detected sequences belonging to four phyla in all samples: Actinobacteria, Bacteroidetes, Firmicutes and Proteobacteria (Figure 1a). The intestinal microbiota of infants with low genetic risk of developing CD was characterized by a very high proportion of Actinobacteria (mean [SD] 79.6 [19.1]\%), a moderate proportion of Firmicutes (14.9 [16.6]\%) and a low proportion of Proteobacteria and Bacteroidetes (3.3 [7.3] and 2.2 [6.2]\%, respectively). Infants at high genetic risk of developing $\mathrm{CD}$ showed a more heterogeneous and evenly distributed microbiota among the phyla Actinobacteria, Firmicutes and Proteobacteria (36.1 [39.5], $38.2[28.2]$ and 22.6 [28.8]\%, respectively), with a small proportion of Bacteroidetes (3.0 [9.9]\%). High SD values revealed notable inter-individual variability of the microbiota composition (Figure 1b). Infants with a high risk of developing CD showed significantly higher proportions of Firmicutes $(P=0.026)$ and Proteobacteria $(P=0.039)$ and a lower proportion of Actinobacteria $(P=0.005)$ than those with low genetic risk. The high risk group of infants also presented higher proportions of Bacteroidetes than the low risk group (3.0 [9.9] versus 2.2 [6.2]\%) but the differences were not statistically significant $(P=0.954)$.

In Figure $\mathbf{2}$ is shown a schematic representation of the principal families characterizing the microbiota in the low and high genetic risk 
Table 1: Demographic characteristics and genotype of the infants included in the study.

\begin{tabular}{ccccccc}
\hline ID & $\begin{array}{c}\text { First-degree } \\
\text { relatives } \\
\text { with CD }\end{array}$ & Genotype & $\begin{array}{c}\text { Size } \\
(\mathbf{c m})\end{array}$ & $\begin{array}{c}\text { Weight } \\
(\mathbf{g})\end{array}$ & $\begin{array}{c}\text { Gestation } \\
\text { (weeks) }\end{array}$ & ${ }^{* *}$ Hospital \\
\hline LR1 & brother & DQ7.5/DQ5.1 & 47.0 & 3060 & 40 & 1 \\
LR2 & brother & DQ5.1/(DQ8) & 52.1 & 3850 & 40 & 2 \\
\hline LR3 & sister & (DQ8)/(DQ5) & 54.0 & 4720 & 39 & 3 \\
LR4 & sister & DQ5/DQ7.5 & 51.3 & 4120 & 40 & 1 \\
LR5 & sister & DQ5.1/DQ7.5 & 52.0 & 3980 & 40 & 3 \\
LR6 & sister & DQ7/(DQ5) & 49.0 & 4350 & 41 & 1 \\
LR7 & brother & DQ5/DQ5.3 & 50.4 & 4255 & 35 & 2 \\
\hline LR8 & brother & DQ6.1/DQ4.2 & 53.1 & 3750 & 38 & 1 \\
LR9 & mother & DQ5.1/DQ5.1 & 53.5 & 4600 & 40 & 2 \\
LR10 & sister & DQ6/DQ8 & 52.0 & 4290 & 38 & 4 \\
LR11 & mother & DQ2/DQ4 & 51.0 & 4130 & 39 & 4 \\
\hline Mean & & & 51.4 & 4100.5 & 39.1 & \\
(SE) & & & $(0.6)$ & $(136.2)$ & $(0.5)$ & \\
\hline HR12 & sister & DQ2.5/DQ2.5 & 51.7 & 3800 & 41 & 2 \\
\hline HR13 & sister & DQ2.5/DQ2.5 & 50.0 & 4210 & 40 & 1 \\
\hline HR14 & sister & DQ2.5/DQ2.5 & 50.0 & 4260 & 40 & 2 \\
\hline HR15 & father & DQ2.5/DQ2.5 & 51.5 & 3890 & 39 & 2 \\
\hline HR16 & brother & DQ2.5/DQ2.5 & 53.7 & 4050 & 40 & 2 \\
\hline HR17 & sister & DQ2.5/DQ2.5 & 54.0 & 3680 & 39 & 1 \\
\hline HR18 & mother + sister & DQ2.5/DQ2.2 & 53.5 & 4860 & 40 & 2 \\
\hline HR19 & mother & DQ2.2/DQ7.5 & 48.8 & 3800 & 38 & 2 \\
\hline HR20 & sister & DQ2.5/DQ2.2 & 49.0 & 3680 & 40 & 3 \\
\hline HR21 & mother & DQ2.5/DQ2.2 & 52.6 & 3900 & 39 & 4 \\
\hline HR22 & brother & DQ2.5/DQ2.2 & 54.1 & 4730 & 37 & 4 \\
\hline Mean & & & 51.7 & 4078.2 & 39.4 & \\
(SE) & & & $(0.6)$ & $(121.6)$ & $(0.3)$ & \\
\hline $\boldsymbol{P ~ v a l u e ~ \# ~}$ & 0.590 & & 0.717 & 0.904 & 0.654 & \\
\hline & & & & & \\
\hline
\end{tabular}

* Displayed in parentheses are genotypes inferred from the DQB1 allele. ${ }^{* *} 1$-Hospital La Paz (Madrid); 2-Sant Joan de Reus (Tarragona); 3- Hospital Niño Jesús (Madrid); 4-Nuestra Señora de la Candelaría (Canarias) \# Differences for the categorical variables between the low (LR) and high risk (HR) infant groups were analyzed using the Chi-Square test and for the continuous variables with the t-test. In all cases differences were established at a $P$ value $<0.050$. 


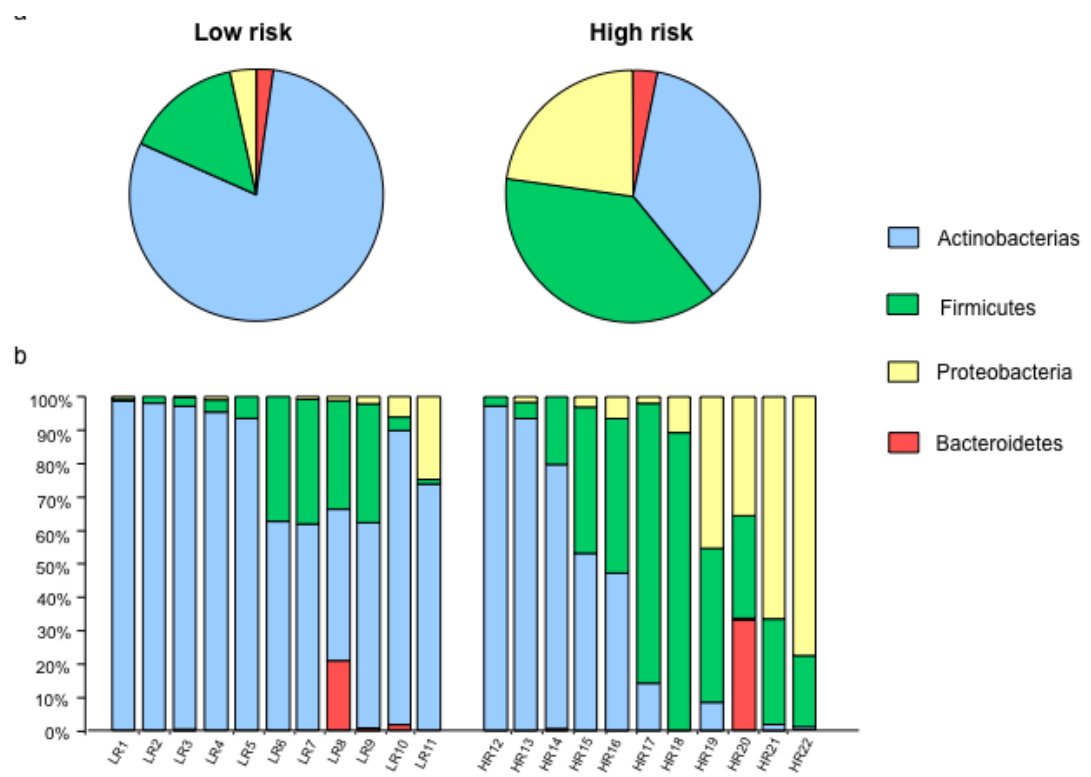

Figure 1: Microbiota analysis by pyrosequencing the V5 and V6 hypervariable regions of the $16 S$ rRNA. Mean distribution of the four phyla Actinobacteria, Firmicutes, Proteobacteria and Bacteroidetes detected in the high genetic risk (HR) and low genetic risk (LR) groups of infants (a) and their corresponding_individual percentages in each infant $(\mathbf{b})$.

groups of infants. In infants with low genetic risk of developing $\mathrm{CD}$ the majority $(96.4 \%$ of sequence reads) of the total bacterial population belonged to five families: Bifidobacteriaceae, Streptococcaceae, Lachnospiraceae, Coriobacteriaceae and Enterobacteriaceae. In infants with high genetic risk of developing $\mathrm{CD}$, the majority $(95.9 \%$ of sequence reads) of the total bacterial population belonged to ten families comprising: Bifidobacteriaceae, En t e r o b a c teri a c e a e, Streptococcaceae, Lachnospiraceae, Clostridiaceae 1, Bacteroidaceae, Erysipelotrichaceae, Lactobacillaceae, Actinomycetaceae and Enterococcaceae. In infants with low genetic risk of developing $\mathrm{CD}$, sequences belonging to the phyla Actinobacteria and Firmicutes were mainly represented by the families Bifidobacteriaceae, and Lachnospiraceae plus Streptococcaceae, respectively. However, in infants with high genetic risk of developing $\mathrm{CD}$, sequences belonging to the phyla Actinobacteria, Proteobacteria and Firmicutes were mainly represented by the families Bifidobacteriaceae, Enterobacteriaceae and Lachnospiraceae, Streptococcaceae plus Clostridiaceae, respectively. Infants with a high risk of developing $\mathrm{CD}$ had significantly higher abundance of Clostridiaceae $1(P<$ 


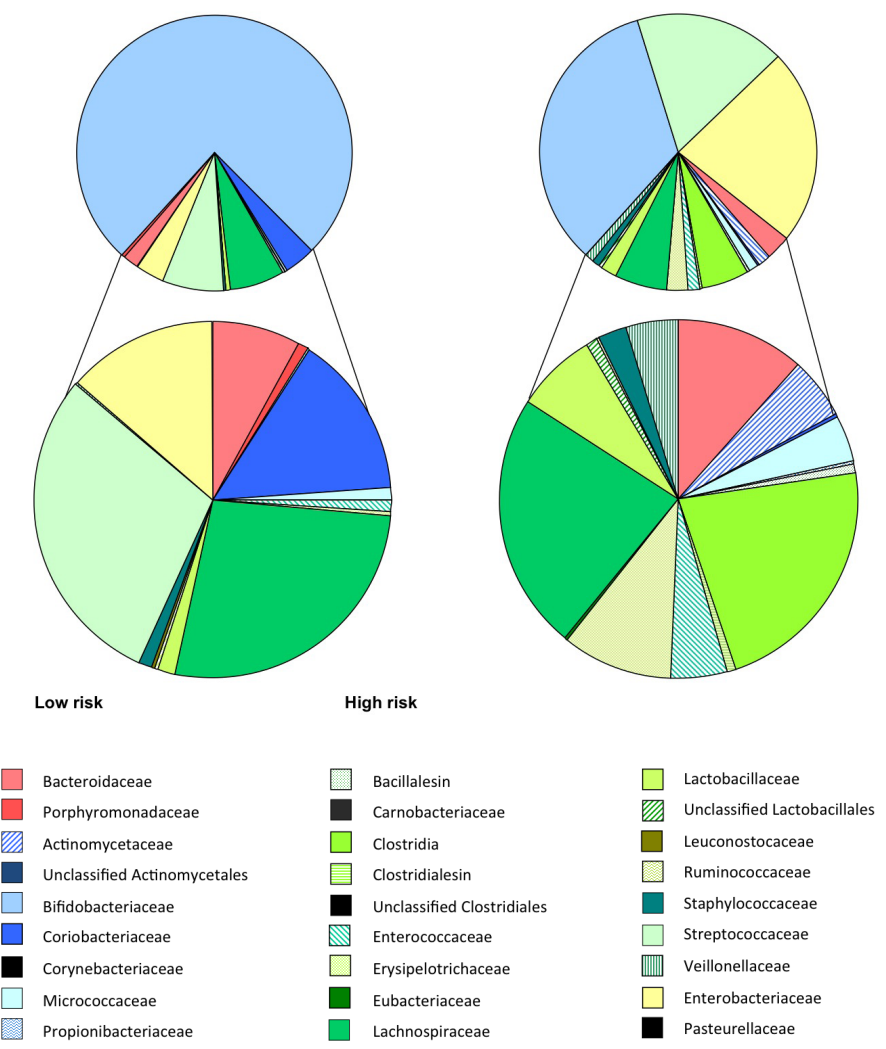

Figure 2: Percentages of the average values of the different families detected in the high and low genetic risk groups of infants. The families are represented with different shades and patterns indicating that they belong to the phyla Actinobacteria (blue), Firmicutes (green), Proteobacteria (yellow) and Bacteroidetes (red). Families shaded black in the figure had abundances below $0.1 \%$ and thus their shares are not visible.

0.001), Bacillales Incertae Sedis XI $(P=0.009)$, Enterobacteriaceae $(P=0.039)$, Corynebacteriaceae $(P=0.050)$ and unclassified Clostridiaceae $(P=0.012)$; and lower abundance of Bifidobacteriaceae $(P=$ $0.010)$ than those with low genetic risk.

At genus level, high risk infants had significantly increased proportions of Corynebacterium ( $P=0.050)$, Gemella
( $P=0.009)$, Clostridium sensu stricto $(P<0.001)$, Raoultella $(P=0.035)$, unclassified Clostridiaceae $(P=0.013)$ and unclassified Enterobacteriaceae $(P=0.009)$ and decreased proportions of Bifidobacterium $(P=0.010)$ and unclassified Bifidobacteriaceae $(P=$ $0.011)$ compared to low risk infants (Table 2).

$\mathrm{AgNes}$ cluster dendrogram based on Bray-Curtis distances showed that at 
Table 2: Mean, standard desviation, median, Q25, Q75 values and ranges of the number of reads in each infants weighted using the total number of reads of all the infants

\begin{tabular}{|c|c|c|c|c|c|c|c|c|c|c|c|c|c|}
\hline \multirow{2}{*}{ GENUS level } & \multicolumn{6}{|c|}{ LOW RISK } & \multicolumn{6}{|c|}{ HIGH RISK } & \multirow{2}{*}{$P$} \\
\hline & Mean & SD & Median & Q25 & Q75 & Range & Mean & SD & Median & Q25 & Q75 & Range & \\
\hline Bacteroides & 226.61 & 674.77 & 0 & 0 & 0 & $0-2253$ & 351.49 & 1163.33 & 0 & 0 & 0 & $0-3859$ & 0.945 \\
\hline Parabacteroides & 25.39 & 59.98 & 0 & 0 & 0 & $0-192$ & 0.11 & 0.36 & 0 & 0 & & $0-1$ & 0.214 \\
\hline Bifidobacterium & 8811.79 & 2834.90 & 10287 & 6853 & 10287 & $\begin{array}{l}3399- \\
11479\end{array}$ & 3903.72 & 4777.42 & 19 & 6 & 19 & 1-11395 & 0.010 \\
\hline Parascardovia & 5.57 & 18.48 & 0 & 0 & 0 & $0-61$ & 0.07 & 0.24 & 0 & 0 & 0 & $0-1$ & 1.000 \\
\hline Unclassified Bifidobacteriaceae & 81.71 & 45.10 & 89 & 46 & 90 & $0-157$ & 27.26 & 43.46 & 0 & 0 & 0 & $0-143$ & 0.011 \\
\hline Propionibacterium & 2.82 & 8.97 & 0 & 0 & 0 & $0-30$ & 4.64 & 14.62 & 0 & 0 & 0 & $0-49$ & 0.738 \\
\hline Rothia & 27.43 & 45.06 & 1 & 0 & 1 & $0-131$ & 126.92 & 276.16 & 35 & 2 & 35 & $0-942$ & 0.225 \\
\hline Corynebacterium & 0.44 & 0.62 & 0 & 0 & 0 & $0-1$ & 3.23 & 6.13 & 1 & 0 & 1 & $0-21$ & 0.050 \\
\hline Actinobaculum & 0.11 & 0.37 & 0 & 0 & 0 & $0-1$ & 19.39 & 64.32 & 0. & 0 & 0 & $0-213$ & 1.000 \\
\hline Actinomyces & 9.56 & 27.79 & 0 & 0 & 0 & $0-93$ & 146.83 & 438.71 & 4 & 0 & 4 & $1468-0$ & 0.351 \\
\hline Eggerthella & 3.44 & 6.08 & 0 & 0 & 0 & $0-18$ & 3.17 & 10.52 & 0 & 0 & 0 & $0-35$ & 0.935 \\
\hline Atopobium & 2.62 & 7.37 & 0 & 0 & 0 & $0-25$ & 1.29 & 2.13 & 0 & 0 & 0 & $0-6$ & 0.913 \\
\hline Collinsella & 412.68 & 1130.39 & 0 & 0 & 0 & $0-3789$ & 0.65 & 1.05 & 0 & 0 & 0 & $0-3$ & 0.214 \\
\hline Streptococcus & 833.16 & 1520.25 & 174 & 82 & 173 & $4-4029$ & 2024.71 & 3446.25 & 371 & 80 & 371 & $29-10243$ & 0.351 \\
\hline Unclassified Streptococcaceae & 7.72 & 15.94 & 0 & 0 & 0 & $0-41$ & 8.19 & 13.67 & 3 & 0 & 3 & $0-43$ & 0.939 \\
\hline Lactococcus & 2.04 & 5.15 & 0 & 0 & 0 & $0-17$ & 5.80 & 16.83 & 1 & 0 & 1 & $0-56$ & 0.704 \\
\hline Lactobacillus & 41.65 & 80.71 & 11 & 0 & 11 & $0-276$ & 212.42 & 463.85 & 1 & 0 & 1 & $0-1531$ & 0.279 \\
\hline Unclassified Lactobacillaceae & 0.32 & 1.07 & 0 & 0 & 0 & $0-4$ & 2.01 & 4.20 & 0 & 0 & 0 & $0-14$ & 0.270 \\
\hline Enterococcus & 30.18 & 49.47 & 2 & 0 & 2 & $0-119$ & 139.15 & 274.49 & 16 & 7 & 16 & $0-931$ & 0.175 \\
\hline Unclassified Enterococcaceae & 2.06 & 3.55 & 0 & 0 & 0 & $0-9$ & 6.37 & 12.51 & 1 & 0 & 1 & $0-42$ & 0.358 \\
\hline Leuconostoc & 3.25 & 10.36 & 0 & 0 & 0 & $0-34$ & 0.00 & 0.00 & 0 & 0 & 0 & $0-0$ & 0.476 \\
\hline Fructobacillus & 1.88 & 6.24 & 0 & 0 & 0 & $0-21$ & 0.00 & 0.00 & 0 & 0 & 0 & $0-0$ & 1.000 \\
\hline Granulicatella & 0.52 & 1.73 & 0 & 0 & 0 & $0-6$ & 3.59 & 11.90 & 0 & 0 & 0 & $0-39$ & 1.000 \\
\hline Staphylococcus & 32.05 & 64.21 & 5 & 0 & 5 & $0-205$ & 74.62 & 82.23 & 41 & 5 & 41 & $0-194$ & 0.194 \\
\hline Gemella & 0.32 & 0.76 & 0 & 0 & 0 & $0-2$ & 23.85 & 54.89 & 8 & 0 & 8 & $0-186$ & 0.009 \\
\hline Anaerococcus & 0.00 & 0.00 & 0 & 0 & 0 & $0-0$ & 26.55 & 87.77 & 0 & 0 & 0 & $0-291$ & 0.476 \\
\hline Lachnospiracea incertae sedis & 34.92 & 86.34 & 0 & 0 & 0 & $0-278$ & 114.64 & 364.60 & 0 & 0 & 0 & $0-1213$ & 0.807 \\
\hline Blautia & 47.11 & 155.88 & 0 & 0 & 0 & $0-517$ & 0.00 & 0.00 & 0 & 0 & 0 & $0-0$ & 0.476 \\
\hline Unclassified Lachnospiraceae & 561.95 & 1274.64 & 1 & 0 & 1 & $0-3714$ & 591.07 & 1266.05 & 1 & 0 & 1 & $0-4239$ & 0.995 \\
\hline Clostridium XlVb & 0.27 & 0.91 & 0 & 0 & 0 & $0-3$ & 1.18 & 3.62 & 0 & 0 & 0 & $0-12$ & 0.738 \\
\hline Dorea & 121.16 & 401.85 & 0 & 0 & 0 & $0-1333$ & 0.21 & 0.71 & 0 & 0 & 0 & $0-2$ & 1.000 \\
\hline Clostridium sensu stricto & 0.00 & 0.00 & 0 & 0 & 0 & $0-0$ & 642.65 & 1079.04 & 103 & 27 & 103 & $0-3308$ & $<0.001$ \\
\hline Clostridium IV & 0.00 & 0.00 & 0 & 0 & 0 & $0-0$ & 12.48 & 41.38 & 0 & 0 & 0 & $0-137$ & 1.000 \\
\hline Clostridium XVIII & 6.85 & 15.01 & 0 & 0 & 0 & $0-38$ & 306.12 & 1009.16 & 0 & 0 & 0 & $0-3349$ & 0.843 \\
\hline Unclassified Clostridiaceae & 0.00 & 0.00 & 0 & 0 & 0 & $0-0$ & 18.64 & 38.45 & 1 & 0 & 1 & $0-110$ & 0.013 \\
\hline Unclassified Eubacteriaceae & 0.00 & 0.00 & 0 & 0 & 0 & $0-0$ & 10.28 & 34.11 & 0 & 0 & 0 & $0-113$ & 1.000 \\
\hline Veillonella & 2.23 & 6.79 & 0 & 0 & 0 & $0-23$ & 137.45 & 439.45 & 1 & 0 & 1 & $0-1462$ & 0.225 \\
\hline Escherichia/Shigella & 345.32 & 828.59 & 46 & 8 & 46 & $0-2790$ & 1950.50 & 3355.77 & 79 & 2 & 79 & $0-8941$ & 0.151 \\
\hline Klebsiella & 2.55 & 7.18 & 0 & 0 & 0 & $0-24$ & 426.16 & 1395.66 & 0 & 0 & 0 & $0-4634$ & 0.269 \\
\hline Serratia & 0.82 & 2.73 & 0 & 0 & 0 & $0-9$ & 5.72 & 18.15 & 0 & 0 & 0 & $0-60$ & 0.738 \\
\hline Raoultella & 0.00 & 0.00 & 0 & 0 & 0 & $0-0$ & 20.52 & 42.06 & 0 & 0 & 0 & $0-134$ & 0.035 \\
\hline Unclassified Enterobacteriaceae & 40.73 & 55.09 & 3 & 1 & 3 & $0-135$ & 247.94 & 261.58 & 179 & 59 & 179 & $1-657$ & 0.009 \\
\hline
\end{tabular}

Statistical differences between the two risk groups were established at $P<0.050$ using permutation analyses.

genus level the microbiota of infants can be partially differentiated based on their HLA-DQ genotype and cluster together with a few exceptions (Figure 3). A weighted UniFrac analysis clustered the microbiota according to predominant bacterial genera in each case. Consistent with the AgNes clustering the basic differentiation was between samples containing or not bifidobacteria. Six high risk infants dominated either by more than 40\% Enterobacteriaceae reads (Escherichia or Klebsiella, subcluster C) or by more than $50 \%$ Streptococcus (subcluster D) and both not containing bifidobacteria $(\leq 0.2 \%)$ grouped with each other. A large group of samples (subcluster A) comprising seven from low risk 

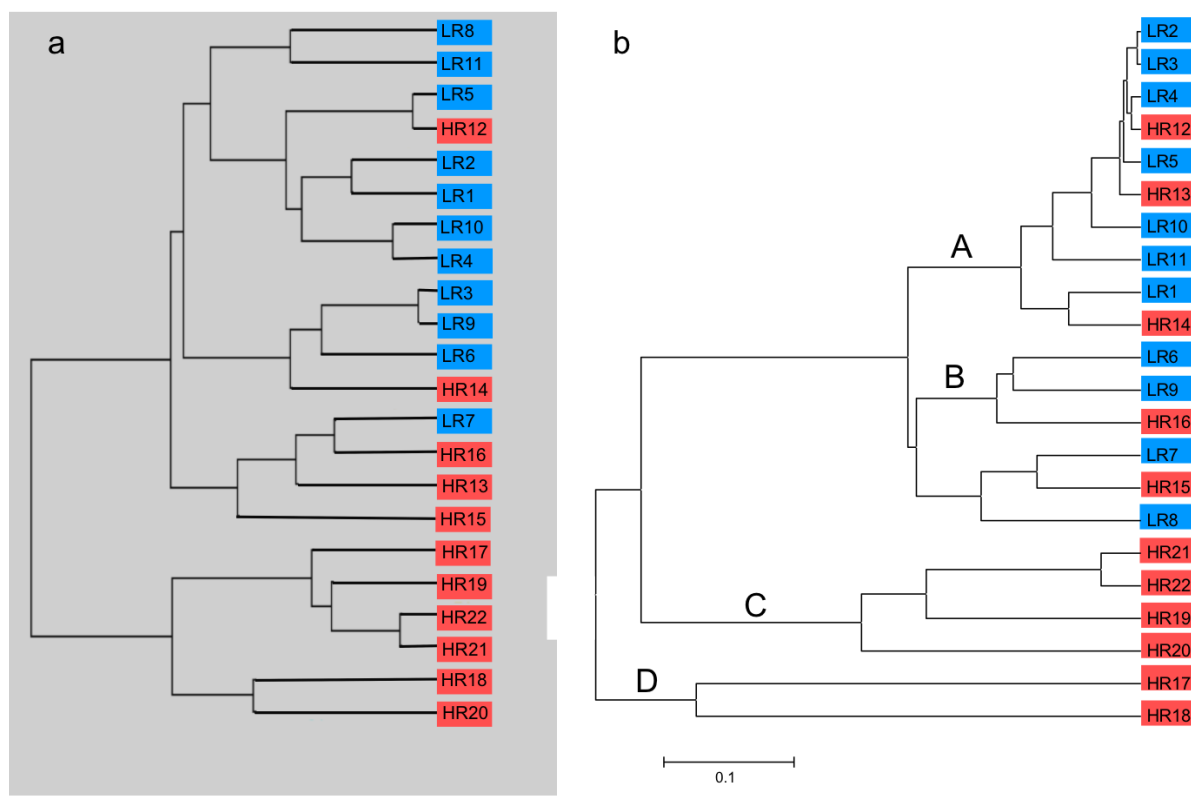

Figure 3: (a) AgNes dendrogram shows the clustering of the infants based on Bray-Curtis distances calculated on the basis of the abundance data (number of $16 \mathrm{~S}$ rRNA gene sequence reads) at genus level. (b) Weighted UniFrac clustering of 166,799 reads (representing $64.4 \%$ of all reads) based on a set of 258 sequences with total abundances between 16577 and 100. Capital letters indicate subclusters of infants according to common dominant bacterial genera in their microbiota. (A): Bifidobacterium spp. $>$ 80\%, (B): unclassified Lachnospiraceae 25 - 40\%, (C): Enterobacteriaceae $>40 \%$, and (D): Streptococcus $>50 \%$. Low risk (LR) individuals are shown in blue and high risk (HR) in red.

infants and three from high risk infants (HR12, HR13 and HR14) all containing $72-98 \%$ Bifidobacterium spp. grouped closely whereas three samples sharing the presence of 25 - 40\% unclassified Lachnospiraceae (subcluster B) clustered together.

Rarefaction curves for each group indicate that the total bacterial diversity was well represented since clustering curves for all individuals, except HR16, approached saturation at $90 \%$ (Data not shown).

\section{Richness and diversity analysis}

Differences in richness and Simpson index between the high and low genetic risk groups of infants showed a borderline statistical significance $(P=0.065)$ (Table 3). Richness was 18.1 [6.2] (mean [SD]) for the low genetic risk group and 27.0 [10.3] for the high genetic risk group. The respective Simpson indices were 0.68 [0.26] and $0.56[0.23]$.

\section{Correlation analysis}

The possible interactions between 
Table 3: Number of sequences obtained in samples from the low genetic risk (LR) and high genetic risk (HR) groups and percentage of reads assigned at the phylum, family and genus level.

\begin{tabular}{cccccccc}
\hline Sample & $\begin{array}{c}\text { No. of } \\
\text { sequences }\end{array}$ & $\begin{array}{c}\text { \%assig. } \\
\text { Phylum }\end{array}$ & $\begin{array}{c}\text { \%assig. } \\
\text { Family }\end{array}$ & $\begin{array}{c}\text { \%assig. } \\
\text { Genus }\end{array}$ & $\begin{array}{c}\text { No. } \\
\text { OTUs }\end{array}$ & $\begin{array}{c}\text { Shannon } \\
\text { index }\end{array}$ & $\begin{array}{c}\text { Simpson } \\
\text { index }\end{array}$ \\
\hline LR1 & 8594 & 96.2 & 96.0 & 95.9 & 9 & 0.095 & 0.971 \\
\hline LR2 & 9513 & 98.5 & 98.5 & 98.3 & 13 & 0.104 & 0.962 \\
LR3 & 10147 & 98.2 & 98.1 & 98.0 & 23 & 0.332 & 0.888 \\
LR4 & 12248 & 99.6 & 99.6 & 99.6 & 10 & 0.252 & 0.909 \\
\hline LR5 & 9963 & 95.4 & 95.4 & 95.2 & 16 & 0.334 & 0.869 \\
\hline LR6 & 9770 & 93.6 & 93.5 & 93.4 & 21 & 0.886 & 0.475 \\
LR7 & 9881 & 97.1 & 97.0 & 96.9 & 22 & 0.931 & 0.482 \\
\hline LR8 & 10628 & 96.2 & 95.9 & 95.6 & 22 & 1.215 & 0.343 \\
\hline LR9 & 7909 & 98.5 & 98.4 & 98.4 & 28 & 1.512 & 0.255 \\
\hline LR10 & 9896 & 99.7 & 99.7 & 99.7 & 13 & 0.540 & 0.775 \\
\hline LR11 & 12210 & 96.7 & 96.6 & 96.5 & 22 & 0.741 & 0.582 \\
\hline HR12 & 11568 & 92.7 & 86.9 & 85.3 & 8 & 0.152 & 0.947 \\
\hline HR13 & 13126 & 95.5 & 94.6 & 94.3 & 22 & 0.483 & 0.825 \\
\hline HR14 & 10267 & 95.9 & 95.7 & 95.4 & 21 & 0.710 & 0.657 \\
\hline HR15 & 10067 & 99.1 & 99.0 & 98.9 & 21 & 1.272 & 0.372 \\
\hline HR16 & 15726 & 88.7 & 88.2 & 87.1 & 42 & 1.300 & 0.360 \\
\hline HR17 & 17080 & 96.7 & 96.5 & 96.3 & 29 & 0.984 & 0.518 \\
\hline HR18 & 20010 & 97.3 & 97.1 & 97.1 & 16 & 0.399 & 0.795 \\
\hline HR19 & 17660 & 94.4 & 94.0 & 93.6 & 33 & 1.646 & 0.262 \\
\hline HR20 & 13284 & 99.4 & 99.3 & 99.3 & 31 & 1.225 & 0.320 \\
\hline HR21 & 13869 & 96.8 & 96.6 & 96.5 & 37 & 1.121 & 0.474 \\
\hline HR22 & 14732 & 98.4 & 98.3 & 98.1 & 37 & 0.810 & 0.624 \\
\hline
\end{tabular}

OTU numbers and Shannon and Simpson indices were calculated at a clustering level of $90 \%$.

the bacterial genera detected in infants at low genetic risk are summarized in Figure 4a. Nine interactions involving nine bacteria were selected that comprise only one positive correlation between RothiaStreptococcus $(\mathrm{r}=0.630,1-P=0.029)$. The highest negative correlations were between BacteroidesEnterococcus $(\mathrm{r}=-0.756, P=0.014)$, and Bifidobacterium-Eggerthella ( $\mathrm{r}=$ $-0.613, P=0.024)$. The increased diversity in the microbiota of high risk infants resulted in a higher number of significant correlations (a total of 35) involving 14 different bacterial genera (Figure $\mathbf{4 b}$ ). Bifidobacterium showed a significant negative correlation with Veillonela $(\mathrm{r}=-0.590, P=0.010)$, Rothia $(\mathrm{r}=$ -0.800, $P=0.004)$, Streptococcus $(\mathrm{r}=$ -0.761, $P=0.007$ ) and borderline significant with Escherichial Shigella $(\mathrm{r}=-0.497, P=0.059)$ and Clostridium $(\mathrm{r}=-0.397, P=0.121)$. Of bacterial genera that enabled to discriminate between the two groups of infants, Bifidobacterium 
a

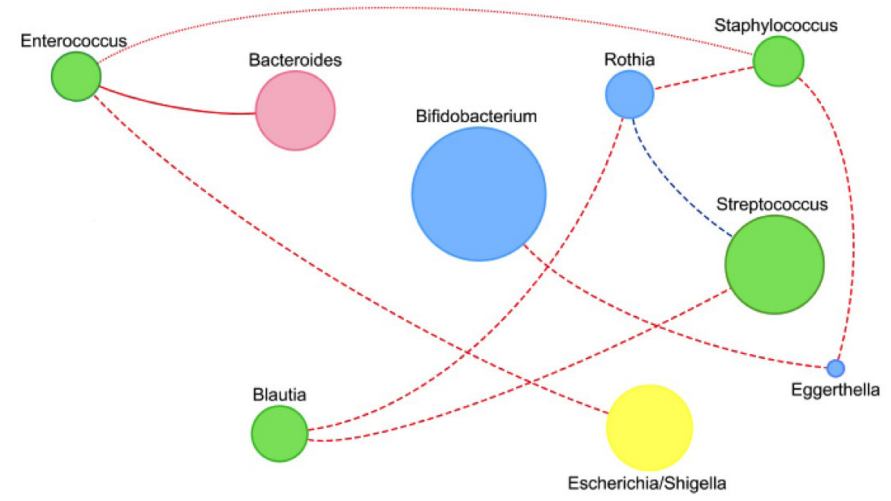

b

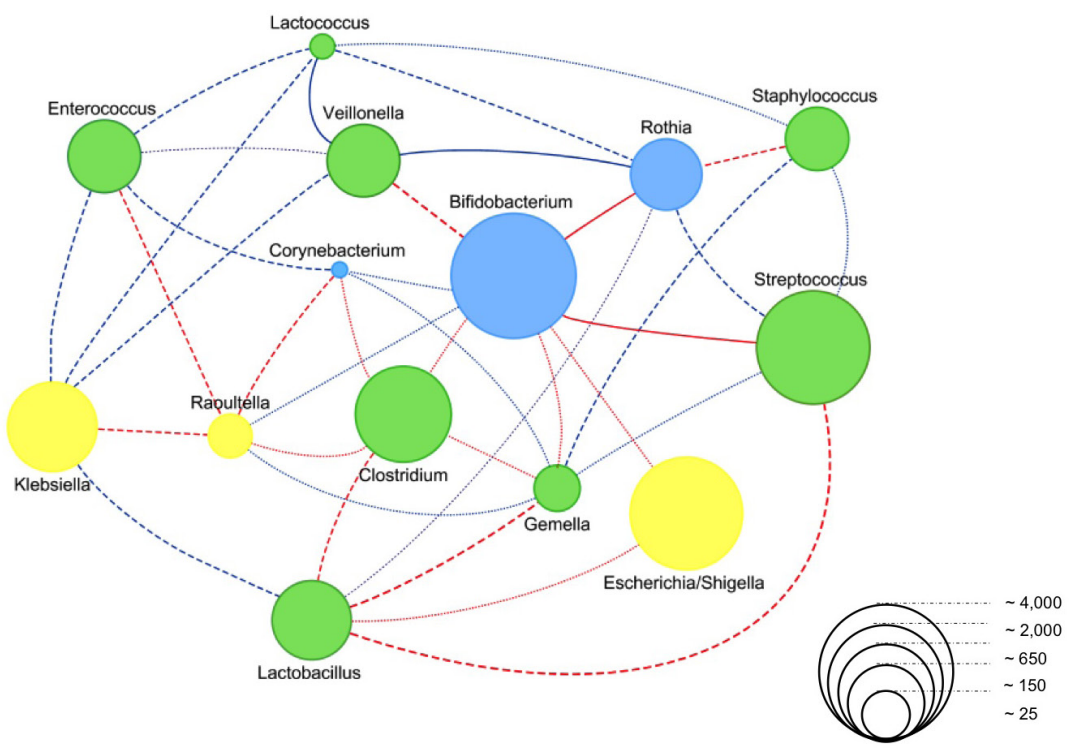

Figure 4: Representation of the correlations among bacterial genera that met the criteria $\mid 1$ $P \mid<0.100$ (positive correlation) or $P<0.100$ (negative correlations) in low (a) and high genetic risks groups (b) of infants. The color of the different genera indicate they belong to the phyla Actinobacteria (blue), Firmicutes (green), Proteobacteria (yellow) and Bacteroidetes (red). Circle sizes are relative to the logarithm of the mean weighted number of reads (see scale). Blue or red node colors indicate positive and negative correlations, respectively. Node style represents the correlation coefficient as continuous line $(R \geq 0.75$ or $\leq-0.75)$, discontinuous line $(|R|=0.75-0.1)$ and weak line $(0.1>\mathrm{R}>-0.1)$ 
showed a no significant positive correlation with Corynebacterium ( $\mathrm{r}=$ $0.103,1-P=0.627)$ and Raoutella $(\mathrm{r}=0.070,1-P=0.582)$ and negative with Gemella $(\mathrm{r}=-0.206, P=0.270)$. Clostridium spp. showed a statistically significant negative correlation with Lactobacillus $(\mathrm{r}=-0.573, P=0.041)$, but not with Corynebacterium ( $\mathrm{r}=$ -0.130, $P=0.379)$, Gemella $(\mathrm{r}=$ -0.212, $P=0.268)$ and Raoultella $(\mathrm{r}=$ $-0.057, P=0.438)$.

\section{Prevalence of Clostridium sensu stricto discriminates between the infant groups}

The genus Clostridium sensu stricto was considered indicative of differences in the microbiota between low and high genetic risk groups, because its proportions were quantitatively different between both groups and it was present in nine individuals of the high genetic risk group but in none of the low genetic risk group. Therefore, the composition of this genus was analyzed in more detail.

Clostridium sensu stricto was present in three high risk group individuals representing 28.1 (HR20), 14.0 (HR21) and 13.3\% (HR17) of all reads and in five more representing between 0.4 and $1.4 \%$. The 10,173 reads classified in this genus were therefore further analyzed. In total, these represented 1,879 different sequence types. BlastN comparisons showed nine Clostridium species as best hits (Table 4). Three of them were dominant, to which
9,577 reads (94.1\%) belonged to Clostridium paraputrificum (41.2\%), C. chartatabidum (33.2\%) and C. perfringens (19.8\%) with average sequence similarities to the reference sequences $\mathrm{X} 75907, \mathrm{X} 71850$, and CP000246 of $97.8,98.3$ and $99.2 \%$, respectively. $C$. perfringens was present in five individuals, proving the most widely distributed species. The highest diversity of Clostridium was found in individuals HR20 and HR21, with seven and five of the nine species identified, respectively. Interestingly, two closely related species (C. paraputrificium and $C$. chartatabidum) were coexisting in HR20, both in relatively high numbers. On the contrary, the presence of $C$. perfringens was practically exclusive.

\section{Real time quantitative PCR (qPCR)}

The characterization of the microbiota composition by qPCR (Table 5) revealed that infants in the high genetic risk group had reduced gene copy numbers of Bifidobacterium spp. (median log values [interquartil] $6.86[6.36-11.28]$ versus 11.00 [10.73-11.42] $P=0.018)$ compared to the low genetic risk group according to pyrosequencing data. The high genetic risk group also had reduced gene copy numbers of Bacteroides fragilis group and Blautia (C. coccoides) group compared to the low genetic risk group (> 1 log unit difference), but the latter differences did not reach statistical significance 
Table 4: Distribution of pyrosequencing reads classified as Clostridium sensu stricto.

\begin{tabular}{|c|c|c|c|c|c|c|c|c|c|c|c|}
\hline \multicolumn{3}{|l|}{ Best hit } & \multicolumn{9}{|c|}{ Individual samples* } \\
\hline & & All & HR & HR & HR & HR & HR & HR & HR & HR & HR \\
\hline Species & Acc. no. & indiv. & 13 & 14 & 15 & 16 & 17 & 19 & 20 & 21 & 22 \\
\hline C. paraputificium & X75907 & 4190 & 2 & & & 5 & & 60 & 4118 & 5 & \\
\hline C. chartatabidum & X71850 & 3376 & & & & & & & 1268 & 2108 & \\
\hline C. perfringens & СР000246 & 2011 & 203 & 84 & & 81 & 1461 & & & & 182 \\
\hline C. vincentii & X97432 & 306 & & & & & & & 79 & 227 & \\
\hline C. isatidis & X98395 & 140 & & & & & & & 42 & 98 & \\
\hline C. sartagoforme & Y18175 & 106 & & & & & & & 106 & & \\
\hline C. roseum & Y18171 & 34 & & & & & & & 27 & 7 & \\
\hline C. butyricum & AJ458420 & 9 & & & 9 & & & & & & \\
\hline \multirow[t]{2}{*}{ C. tertium } & Y18174 & 1 & & & & & & & 1 & & \\
\hline & All types & 10173 & 205 & 84 & 9 & 86 & 1461 & 60 & 5641 & 2445 & 182 \\
\hline
\end{tabular}

Results of BlastN matches against reference sequences from the LTP-Silva database.

*Samples HR12 and HR18 did not contain reads classified into this genus.

Table 5: Fecal microbiota of infants with high or low genetic risk of developing CD determined by qPCR.

\begin{tabular}{lccc}
\hline & $\begin{array}{c}\text { Low genetic risk group } \\
\text { Bacterial groups }\end{array}$ & $\begin{array}{c}\text { Hog gene copy numbers/g stools } \\
\text { Median (IQR) }\end{array}$ & *P value \\
\hline Bacteroides fragilis group & $7.62(5.86-8.11)$ & $6.04(5.53-8.03)$ & 0.336 \\
Bifidobacterium spp. & $11.00(10.73-11.42)$ & $6.86(6.36-11.28)$ & $\mathbf{0 . 0 1 8}$ \\
Lactobacillus group & $6.80(5.15-9.45)$ & $6.43(5.28-9.69)$ & 0.470 \\
Staphylococcus spp. & $6.81(5.78-7.20)$ & $8.41(5.96-9.41)$ & 0.142 \\
Enterococcus spp. & $8.15(6.67-9.08)$ & $8.26(6.92-8.83)$ & 0.922 \\
Streptococcus spp. & $8.90(7.90-8.99)$ & $8.98(7.64-9.81)$ & 0.563 \\
C. leptum group & $5.28(4.12-6.53)$ & $4.68(4.13-8.92)$ & 0.555 \\
Blautia ${ }^{* *}$ group & $8.20(5.42-10.13)$ & $6.88(6.02-10.34)$ & 0.630 \\
\hline
\end{tabular}

*Statistically differences were established at $\mathrm{P}<0.050$ applying the Mann-Whitney $\mathrm{U}$ test.

** Formely Clostridium coccoides group. 
( $P=0.336$ and 0.630 , respectively). The high genetic risk group of infants also showed increased gene copy numbers of Staphylococcus spp. compared to the low genetic risk group; however, the difference was not statistically significant $(P=$ 0.142 ).

Statistically significant correlations between the data obtained by qPCR and pyrosequencing were detected for Bacteroides fragilis group $(\mathrm{r}=0.998$, $P<0.001)$, Bifidobacterium spp. $(\mathrm{r}=$ $0.469, P=0.037)$ and Lactobacillus group $(\mathrm{r}=0.869, \quad P<0.001)$. No significant correlation between the data obtained by the two techniques was detected for the other bacterial groups analyzed by qPCR.

\section{DISCUSSION}

Emerging evidence supports the hypothesis that host genotype influences gut microbiota composition, but there is a limited number of studies revealing these interactions (33). The present study is the first to demonstrate by high-throughput sequencing of $16 \mathrm{~S}$ rRNA genes that the HLADQ2 genotype per se influences the intestinal bacterial community structure of infants at family risk of developing CD. Indeed, compared to low risk infants, the intestinal microbiota of high risk infants was characterized by increased Firmicutes and Proteobacteria proportions but reduced Actinobacteria proportions. The increased Firmicutes proportions were reflected by increased proportions of the genera Clostridium (Clostridium sensu stricto and unclassified Clostridiaceae) and Gemella. The higher abundances of Proteobacteria were due to increases in Raoultella and unclassified Enterobacteriaceae. The reduced proportions of Actinobacteria were due to decreases of the genera Bifidobacterium and Corynebacterium.

Reductions in Bifidobacterium spp. have also been detected previously in duodenal biopsies and feces of subjects with the disease, even after long-term adherence to a gluten-free diet, indicating that this bacterial group could contribute to the etiopathogenesis of $\mathrm{CD}(17,18)$. Previous studies have investigated the influence of the HLA-DQ2/8 genotype on the intestinal microbiota composition of this cohort of infants with a family history of $\mathrm{CD}$, but they used molecular techniques with a more limited resolution such as FISH, qPCR and denaturing gradient gel electrophoresis (22, 23, 34). Notwithstanding, initial results revealed that although both the HLA-DQ2/8 genotype and milk-feeding type (breast-milk or formula) influence the infant's gut colonization, infants with higher genetic risk (HLA-DQ2/8 positives) had lower Bifidobacterium spp. and $B$. longum numbers, and higher Staphylococcus spp. numbers irrespective of milk-feeding type 
(23). However, our present study conducted in exclusively breast-fed infants did not reveal differences in Bacteriodes spp., confirming the hypothesis that breast-feeding attenuated the HLA-DQ-driven microbiota differences in this bacterial group, which were detected only in the formula-fed infants in our previous study by qPCR.

Our present pyrosequencing data also revealed that the HLA-DQ2 genotype influences colonization by Clostridium spp. (Clostridium sensu stricto and unclassified Clostridiaceae). Clostridium sensu stricto was detected in nine out of 11 samples from high risk infants, while it was absent in samples from low risk infants. C. perfringens was the species showing the highest prevalence (in five out of nine cases). A recent study that analyzed the intestinal microbiota by $16 \mathrm{~S}$ rRNA gene pyrosequencing in children with the HLA-DQB1 (DQB1*02, DQB1*03:02) genotype, $\beta$-cell autoimmunity was positively associated with $C$. perfringens (35). However, this association could not be related to the HLA genotype because this was similar in children with $\beta$-cell autoimmunity (defined as positive diabetes-associated autoantibodies at least twice) and in those negative for the autoantibody. Also Clostridium diffcile (cluster XI) infection, defined as positive toxin detection, has been associated with the NOD2 genotype and phenotype of patients with Crohn's disease (21).
In the present study, correlation analyses for high risk infants also revealed negative correlations between Bifidobacterium spp. and Clostridium spp., which might explain the absence of Clostridium spp. in low risk infants where Bifidobacterium spp. are clearly dominant. Data from a previous prospective study reported that a lower ratio of Bifidobacterium to Clostridium counts in the fecal microbiota of infants was associated with atopic disease (15).

Our pyrosequencing study has also been the first to detect differences in proportions of the genera Corynebacterium, Gemella and Raoultella as a function of the HLADQ2 genotype in the infant's gut. Although the biological role of these genera is not well-documented, mice with alcoholic liver disease also showed increases in Corynebacterium and Alcaligenes (36). The authors proposed that these changes in microbiota might contribute to the disease by increasing intestinal permeability via alterations in tightjunction related protein expression (zonula occludens-1 and claudin-1), which could be prevented by probiotic administration (36). In the light of our results, we cannot disregard the possibility that specific microbiota alterations (e.g. Corynebacterium spp.) may also contribute to this phenomenon in $\mathrm{CD}$ as increased intestinal permeability is also characteristic of the active phase of $\mathrm{CD}$ and is considered a potential pre-developmental event (37). 
Another study analyzed the microbiota of a small subset of subjects (eight per group) by pyrosequencing to investigate how early (from 6 months on) or late (after 12 months) gluten introduction into the infant diet affected CD development in genetically predisposed infants (HLA-DQ2/8) (38). The authors reported that the microbiota of HLA-DQ2/8 carriers was characterized by higher abundance of Firmicutes and lower abundance of Bacteroidetes (1\% to undetectable) as compared to data from another study on non-genotyped healthy infants (39). However, samples from each of the aforementioned studies were analyzed using different techniques (SSU rDNA microarray versus 454 pyrosequencing) which could explain the differences that the authors attributed to the HLADQ genotype (38). Differences in sample handling (storage time and temperature) and processing (e.g. DNA extraction method) could also lead to different results from massive sequencing analysis; therefore, studies using different methodologies are considered non cross-comparable (40). Furthermore, the genotype of infants included in the Palmer study was unknown (39), thus there may have been HLA-DQ carriers, because they represent up to $40 \%$ of the general population (5).

Another prospective study that analyzed possible associations between the intestinal microbiota composition and the risk of developing neonatal sepsis or systemic inflammation revealed a dominance of Proteobacteria in infants who developed the disease (12) as in the case of our high genetic risk infants. Furthermore, correlation analyses in high risk infants also revealed negative correlations between Bifidobacterium spp. and Proteobacteria (Escherichia/Shigella), which might explain reduced levels of the latter in low risk infants whose microbiota was dominated by bifidobacteria. Also, the phenotype of patients with inflammatory bowel diseases (Crohn's disease and ulcerative colitis), and the NOD2 and ATG16L1T300A genotypes have been associated with compositional shifts in the phylum Proteobacteria in intestinal biopsies (41).

In the present study, statistically significant correlation between pyrosequencing and qPCR data was only obtained for bifidobacteria, bacteroides and lactobacilli. This can be partially explained by differences between the range of bacteria targeted by the qPCR primers used, and the classification of the corresponding taxa by pyrosequencing, as previously reported (40).

Several studies have attempted to establish relationships between gut microbiota diversity and health status, but conclusions have been rather inconsistent to date. It is well known that breast-fed babies have a low diverse microbiota, mainly dominated by the genus Bifidobacterium, and breast-feeding 
exerts a positive effect over infants' health $(42,43)$. In our present study, infants with low genetic risk of developing CD also had lower bacterial diversity compared to high risk infants. Especially, in those high risk infants in which bifidobacteria were absent or present in only small numbers, the microbiota was much more diverse. Other studies report that decreased gut microbiota diversity is associated with diseases such as necrotizing enterocolitis (44) and type 1 diabetes (45) in infants, and with obesity in adults (46). A prospective study of neonatal infants also showed that those who developed sepsis or systemic inflammation presented low microbial diversity, from the meconium through to disease onset (12). One of the reasons that can explain the controversial conclusions regarding the relationship between microbial diversity and disease reported in infants is that some of the previous studies have used primers that are not appropriate for detection of bifidobacteria (12, 44, 45 ), which is the bacterial group that mainly determine gut microbiota diversity early in life. Underrepresentation of bifidobacteria in $16 \mathrm{~S}$ rRNA pyrosequencing analyses has been described and led to the design of alternative wobbled PCR amplification primers that improve the detection of bifidobacteria (47) and that were used in our study.

In conclusion, the results of our study based on high-throughput sequencing reveal that the HLADQ2 genotype strongly influences the intestinal colonization of infants at family risk of developing CD. Infants with high genetic risk of developing the disease (HLA-DQ2 carriers) show reduced abundance of Actinobacteria (Bifidobacterium spp.) and increased abundance of Firmicutes (Clostridium sensu stricto and unclassified Clostridiaceae and Gemella) and Proteobacteria (Raoultella and unclassified Enterobacteriaceae). Some of these bacterial groups were negatively correlated, suggesting that one excludes the others. Follow-up of this study cohort is underway to determine whether the microbiota changes dictated by the HLA-DQ genotype precede the development of CD in later life.

\section{Acknowledgements}

The authors want to thank Juanjo Abellán for his assistance with the $\mathrm{R}$ software.

\section{REFERENCES}

1. Lars-Egil Fallang, Elin Bergseng, Kinya Hotta et al. (2009) Differences in the risk of celiac disease associated with HLA-DQ2.5 or HLA-DQ2.2 are related to sustained gluten antigen presentation. Nature Immunology 10 , 1096-1201.

2. Dubois PC, van Heel DA (2008) Translational mini-review series on the immunogenetics of gut disease: immunogenetics of coeliac disease. Clin Exp Immunol 153, 162-173.

3. Di Sabatino A, Corazza GR (2009) Coeliac 
disease. Lancet 373, 1480-1493.

4. Rossi M, Schwartz KB (2010). Editorial: Celiac disease and intestinal bacteria: not only gluten? J Leukoc Biol 87, 749-751.

5. Romanos J, Rosén A, Kumar V et al. (2013) PreventCD Group. Improving coeliac disease risk prediction by testing non-HLA variants additional to HLA variants. Gut, doi:10.1136/gutjnl-2012-304110.

6. Ivarsson A, Hernell O, Stenlund $\mathrm{H}$, et al. (2002) Breast-feeding protects against celiac disease. Am J Clin Nutr 75, 914-921.

7. Sandberg-Bennich S, Dahlquist G, Källén

B (2002). Coeliac disease is associated with intrauterine growth and neonatal infections. Acta Paediatr 91, 30-33.

8. Sanz Y, De Palma G, Laparra M (2011) Unraveling the ties between celiac disease and intestinal microbiota. Int Rev Immunol 30, 207-218.

9. Sellitto M, Guoyun B, Serena G et al. (2012) A. Proof of Concept of MicrobiomeMetabolome Analysis and Delayed Gluten Exposure on Celiac Disease Autoimmunity in Genetically At-Risk Infants. PLoS One 7, e33387.

10. Mårild K, Stephansson O, Montgomery $S$ et al. (2012) Pregnancy outcome and risk of celiac disease in offspring: a nationwide casecontrol study. Gastroenterology 142, 39-45.

11. Mårild K, Ye W, Lebwohl B et al. (2013) Antibiotic exposure and the development of coeliac disease: a nationwide case-control study. BMC Gastroenterol 13, 109.

12. Madan JC, Salari RC, Saxena D et al. (2012) Gut microbial colonization in premature neonates predicts neonatal sepsis. Arch Dis Child Fetal Neonatal Ed 97, F456462.

13. El Aidy S, Hooiveld G, Tremaroli V et al. (2013) The gut microbiota and mucosal homeostasis: colonized at birth or at adulthood, does it matter? Gut Microbes 4, 118-124.

14. Laparra M, Olivares M, Sanz Y (2013). Role of Gut Microbes in Celiac Disease Risk and Pathogenesis. In: Rampertab DS, Mullin
GE, eds. Celiac Disease. New York: Springer, 81-94.

15. Kalliomaki M, Kirjavainen P, Eerola E et al. (2001) Distinct patterns of neonatal gut microflora in infants in whom atopy was and was not developing. J Allergy Clin Immunol 107, 129-134.

16. de Meij TG, Budding AE, Grasman ME et al. (2013) Composition and diversity of the duodenal mucosa-associated microbiome in children with untreated coeliac disease. Scand J Gastrenterol 48, 530-536.

17. Nadal I, Donat E, Ribes-Koninckx C et al. (2007) Imbalance in the composition of the duodenal microbiota of children with coelic disease. J Med Microbiol 56, 16691674 .

18. Collado MC, Donat E, Ribes-Koninckx C et al. (2009) Specific duodenal and faecal bacterial groups are associated with pediatric celiac disease. J Clin Pathol 62, 264-269.

19. Bourma G, Strober W (2003) The immunological and genetics basis of inflammatory bowel disease. Nat Rev Immunol 3, 521-533.

20. Elinav E, Strowig T, Kau AL, et al. (2011) NLRP\& inflammasone regulates colonic microbial ecology and risk for colitis. Cell 145, 745-757.

21. Li E, Hamm CM, Gulati AS et al. (2012) Inflammatory bowel diseases phenotypt, $C$. difficile and NOD2 genotype are associated with shifts in human ileum associated microbial composition. PLoS One 7, e26284. 22. De Palma G, Capilla A, Nadal I et al. (2010) Interplay Between Human Leukocyte antigen Genes and Microbial Colonization Process of the Newborn Intestine. Curr Issues Mol Biol 12, 1-10.

23. De Palma G, Capilla A, Nova E, et al. (2012) Influence of Milk-Feeding Type and Genetic Risk of Developing Coeliac Disease on Intestinal Microbiota of Infants: The PROFICEL study. PLoS One 7, e30791.

24. Faust K, Raes J (2012) Microbial interactions: from networks to models. Nat Rev Microbiol 10, 538-550.

25. Andersson AF, Lindberg M, Jakobsoon $\mathrm{H}$ et al (2008) Comparative analysis of human gut microbiota by barcoded pyrosequencing. 
PLoS One 3, e2836.

26. Edgar RC, Haas BJ, Clemente, JC et al. (2011) UCHIME improves sensitivity and speed of chimera detection. Bioinformatics 27, 2194-200.

27. Schloss PD, Westcott SL, Ryabin T et al. (2009) Introducing mothur: Opensource, platform-independent, communitysupported software for describing and comparing microbial communities. Appl Environ Microbiol 75, 7537-7541.

28. Legendre P, Legendre A (1998). Ecological resemblance. In: Legendre P, Legendre A, eds. Numerical Ecology. Amsterdam, Elsevier, 247-302.

29. Legendre P, Legendre A (1998) Ecological resemblance. In: Legendre P, Legendre A, eds. Numerical Ecology. Amsterdam, Elsevier, $1-48$.

30. Matsuki T, Watanabe K, Fujimoto J et al. (2002) Development of $16 \mathrm{~S}$ rRNAgene-targeted group-specific primers for the detection and identification of predominant bacteria in human feces. Appl Environ Microbiol 68, 5445-5451.

31. Malinen E, Kassinen A, Rinttila T et al. (2003) Comparison of real-time PCR with SYBR Green I or 59-nuclease assays and dot-blot hybridization with rDNA-targeted oligonucleotide probes in quantification of selected faecal bacteria. Microbiology 149, 269-277.

32. Birnboim HC, Doly J (1979) A rapid alkaline extraction procedure for screening recombinant plasmid DNA. Nucleic Acids Res 7, 1513-1523.

33. Olivares M, Laparra JM, Sanz Y (2012) Host genotype, intestinal microbiota and inflammatory disorders. Br J Nutr 14, 1-6.

34. Sánchez E, De Palma G, Capilla A et al. (2011) Influence of environmental and genetic factors linked to celiac disease risk on infant gut colonization by Bacteroides species. Appl Environ Microbiol 77, 5316-5323.

35. de Goffau MC, Luopajärvi K, Knip M et al. (2013) Fecal microbiota composition differs between children with $\beta$-cell autoimmunity and those without. Diabetes $62,1238-1244$.
36. Bull-Otterson L, Feng W, Kirpich I et al. (2013) Metagenomic analyses of alcohol induced pathogenic alterations in the intestinal microbiome and the effect of Lactobacillus rhamnosus GG treatment. PLoS One 8, e53028.

37. Sander GR, Cummins AG, Henshall T et al. (2005) Rapid disruption of intestinal barrier function by gliadin involves altered expression of apical junctional proteins. FEBS Lett 579, 4851-4865.

38. Sellitto M, Bai G, Serena G et al. (2012) Proof of concept of microbiome-metabolome analysis and delayed gluten exposure on celiac disease autoimmunity in genetically atrisk infants. PLoS One 7, e33387.

39. Palmer C, Bik EM, DiGiulio DB et al. (2007) Development of the Human Infant Intestinal Microbiota. PLoS Biol 5, e177.

40. Kennedy N, Walker AK, Berry S et al. (2014) The impact of different DNA extraction kits and laboratories upon the assessment of human gut microbiota composition by $16 \mathrm{~S}$ rRNA gene sequencing (2014) PLoS ONE 9, e88982.

41. Frank DN, Robertson CE, Hamm CM et al. (2011) Disease phenotype and genotype are associated with shifts in intestinalassociated microbiota in inflammatory bowel diseases. Inflamm Bowel Dis 17, 179-184.

42. Bezirtzoglou E, Tsiotsias A, Welling GW (2011) Microbiota profile in feces of breast- and formula-fed newborns by using fluorescence in situ hybridization (FISH). Anaerobe 17, 478-482.

43. Fan W, Huo G, Li X et al. (2013) Diversity of the intestinal microbiota in different patterns of feeding infants by Illumina high-throughput sequencing. World J Microbiol Biotechnol 29, 2365-2372.

44. Wang Y, Hoenig JD, Malin KJ, et al. (2009) 16S rRNA gene-based analysis of fecal microbiota from preterm infants with and without necrotizing enterocolitis investigation. ISME J3, 944-954. 
45. Giongo A, Gano KA, Crabb DB et al. (2011) Toward defining the autoimmune microbiome for type 1 diabetes. ISME J 5 , 82-91.

46. Turnbaugh PJ, Hamady M, Yatsunenko $\mathrm{T}$ et al. (2009) A core gut microbiome in obese and lean twins. Nature 457, 480e4. 47. Sim K, Cox MJ, Wopereis $\mathrm{H}$ et al. (2011) Improved Detection of Bifidobacteria with Optimised 16S rRNA-Gene Based Pyrosequencing. PLoS ONE 7, e32543. 


\section{SUPPLEMENTARY TABLE}

Sup. table 1: List of haplotypes and their respective DQA1 and DQB1 genotype.

\begin{tabular}{|c|c|}
\hline Haplotype & HLA genotype \\
\hline DQ2 & DQB1*02 \\
\hline \multirow{2}{*}{ DQ2.2 } & DQA1*02:01 \\
\hline & DQB1*02:02 \\
\hline \multirow{2}{*}{ DQ2.5 } & DQA1*05:01 \\
\hline & DQB1*02:01 \\
\hline DQ4 & DQB1*04 \\
\hline \multirow{2}{*}{ DQ4.2 } & DQA1*04:01 \\
\hline & DQB1*04:02 \\
\hline \multirow{2}{*}{ DQ5 } & DQA1*01 \\
\hline & DQB $1 * 05$ \\
\hline \multirow{2}{*}{ DQ5.1 } & DQA1*01:01 \\
\hline & DQB1*05:01 \\
\hline \multirow{2}{*}{ DQ5.3 } & DQA1*01:04 \\
\hline & DQB1*05:03 \\
\hline \multirow{2}{*}{ DQ6 } & DQA1*01 \\
\hline & DQB1*06 \\
\hline \multirow{2}{*}{ DQ6.1 } & DQA1*01:03 \\
\hline & DQB1*06:01 \\
\hline \multirow{2}{*}{ DQ7 } & DQA1*05 \\
\hline & DQB1*0301 \\
\hline \multirow{2}{*}{ DQ7.5 } & DQA1*05:05 \\
\hline & DQB1*03:01 \\
\hline \multirow{2}{*}{ DQ8 } & DQA1*03:01 \\
\hline & DQB1*03:02 \\
\hline
\end{tabular}




\section{Chapter 4}

- Double-blind, randomized, placebo-controlled intervention trial to evaluate the effects of Bifidobacterium longum CECT 7347 on children with newly diagnosed celiac disease 


\section{Double-blind, randomized, placebo- controlled intervention trial to evaluate the effects of Bifidobacterium longum CECT 7347 on children with newly diagnosed celiac disease}

Marta Olivares ${ }^{1}$, Gemma Castillejo ${ }^{2}$, Vicente Varea ${ }^{3}$, and Yolanda Sanz ${ }^{1}$

Br J Nutr (2014) 112, 30-40

${ }^{1}$ Microbial Ecology, Nutrition \& Health. Institute of Agrochemistry and Food Technology. National Research Council (IATA-CSIC). Valencia, Spain. ${ }^{2}$ Paediatric Gastroenterology Unit, Hospital Universitari Sant Joan de Reus, Universitat Rovira i Virgili. Tarragona, Spain. ${ }^{3}$ Paediatric Gastroenterology, Nutrition and Hepatology. Hospital Universitario Sant Joan de Deu. Barcelona, Spain. 


\section{ABSTRACT}

Interactions between immune system and intestinal microbiota may play a role in celiac disease (CD). The potential effects of Bifidobacterium longum CECT 7347 on children with newly diagnosed CD were evaluated. A double-blind, randomized, placebo-controlled trial was conducted in 33 children that received a capsule containing either $B$. longum CECT7347 ( $10^{9}$ colony-forming units) or placebo (excipients) daily for 3 months in parallel to the gluten-free diet. Outcome measures (baseline and after intervention) included immune phenotype of peripheral-blood cells, serum cytokines, faecal secretory immunoglobulin A (sIgA), anthropometric parameters and intestinal microbiota. Comparisons between groups revealed greater height percentile increases $(P=0.048)$ in the B. longum CECT 7347 group than in the placebo group, as well as decreased peripheral $\mathrm{CD}^{+}$T-lymphocytes $(P=0.004)$ and slightly reduced tumour necrosis factor (TNF)- $a$ concentration $(P=0.067)$. Within group comparisons of baseline and final values did not reveal differences in T-lymphocytes and cytokines in the placebo group, while decreased $\mathrm{CD}^{+}(P=0.013)$ and HLA-DR ${ }^{+} \mathrm{T}$ lymphocytes $(P=0.029)$ and slightly reduced TNF-a concentration $(P=0.085)$ were detected in the $B$. longum CECT 7347 group. Comparison between groups showed that $B$. longum CECT 7347 administration reduced Bacteroides fragilis group numbers $(P=0.020)$ and stool sIgA $(P=0.011)$ in comparison with the placebo. Although this is a first exploratory intervention with limitations, the findings suggest that $B$. longum CECT 7347 could help to improve the health status of CD patients, who tend to show alterations in gut microbiota composition and a biased-immune response even on a GFD.

Keywords: celiac disease, Bifidobacterium longum CECT 7347, probiotics, gluten-free diet. 


\section{INTRODUCTION}

Celiac disease (CD) is an autoimmune enteropathy caused by a permanent intolerance to dietary proteins of wheat, barley and rye in genetically predisposed (human leukocyte antigen (HLA)-DQ2/8) individuals. In $\mathrm{CD}$ patients, gluten proteins induce a deregulated immune response that typically leads to severe small intestine mucosal injury, malabsorption and gastrointestinal symptoms (1). Gluten proteins are the main environmental factor involved in CD pathogenesis; however, recent studies have shown that other factors influencing the interplay between the gut microbiota and the mucosal immune system, including breastfeeding and gastrointestinal infections, could contribute to determining the disease onset (2). Observational studies conducted so far have reported associations between intestinal dysbiosis and celiac disease (3), with a few exceptions $(4,5)$. Our own studies reported that the duodenal and faecal microbiota of $\mathrm{CD}$ patients is unbalanced with decreased numbers of Bifidobacterium spp. and increased numbers of Bacteroides spp. and $E$. coli clones with higher virulence features, which are only partially normalized after a long-term glutenfree diet (GFD) (6-8). One of the most recent studies has also reported that $\mathrm{CD}$ patients with gastrointestinal symptoms had different microbiota composition in comparison with controls and patients with dermatitis herpetiformis, suggesting that the microbiota may play a role in the manifestation of the disease (9). In vitro and animal studies have demonstrated that the dysbiotic gut microbiota of $\mathrm{CD}$ patients and specific isolates may potentially enhance the inflammatory response elicited by gluten and contribute to increasing intestinal epithelial permeability and gliadin peptide translocation (10-13). In contrast, Bifidobacterium longum CECT 7347 has been shown to attenuate the inflammatory effects of the dysbiotic gut microbiota of $\mathrm{CD}$ patients on peripheral blood mononuclear cells (PBMCs) partially via induction of interleukin (IL)-10 production $(10,14)$. This strain has also been proven to reduce the cytotoxic and inflammatory effects of gliadin peptides on epithelial cells in vitro via degradation of gliadin peptides $(15,16)$. B. longum CECT 7347 administration has also been shown to reduce the numbers of peripheral $\mathrm{T}$ CD4+ cells, and increase IL-10 and reduce tumour necrosis factor (TNF)-a production in jejunal sections in an animal model of gliadin-induced enteropathy (17).

The only current treatment for CD is adherence to a strict GFD, which usually results in symptomatic, serologic and histological remission $(18,19)$. However, compliance with a strict GFD is very difficult due to the presence of gluten in 
most processed foods and the social restriction implied; thus overall the GFD is far from optimal. In practice, $\mathrm{CD}$ patients may continue suffering from clinical symptoms, nutritional deficiencies and higher health risks (20-22). For example, it has been reported that even under GFD, CD children (23) and women (24) have a much higher prevalence of gastrointestinal symptoms than do controls, and they also use healthcare services more often (22). Whether or not this is due to residual chronic inflammation, exposure to minimum amounts of gluten and/or intestinal dysbiosis remains unknown. Whether complete normalization of lymphocyte subsets in peripheral blood can be achieved remains unclear $(19,25)$. Other studies also indicate that small intestine bacteria overgrowth is often associated with non-responsive CD (26). The duodenal and faecal microbiota of CD patients has also been shown not to be completely normalized after adherence to a GFD, which can also contribute to the lack of complete restoration of the intestinal immune homeostasis in the patients $(6,7)$. Therefore, adjunctive strategies that can improve the effects of a GFD are being investigated (27).

The aim of this study was to conduct a three-month double-blind randomized placebo-controlled trial on children with newly diagnosed CD following a GFD in order to evaluate the effects of $B$. longum CECT 7347 administration on immune and anthropometric parameters, and on the intestinal microbiota composition.

\section{MATERIAL AND METHODS}

\section{Subjects and study design}

A total of 36 children were recruited at the Hospital Universitari Sant Joan (Reus, Tarragona) and Hospital Universitario Sant Joan de Deu (Barcelona) from November 2011 to June 2012. The inclusion criteria were children aged 2-17 years with newly diagnosed $\mathrm{CD}$ according to the European Society of Pedriatric Gastroenterology Hepatology and Nutrition (ESPGHAN) criteria, based on symptoms, positive antitissue transglutaminase antibodies quantified using tTG-IgA ELISA kit (Pharmacia Diagnostics GmbH, Freiburg, Germany) and duodenal biopsy demonstrating villous atrophy. The exclusion criteria did not allow subjects enrolled in another clinic study, treated with antibiotics 30 days before starting the study, and/or with food allergy or others pathologies. Demographic and clinical characteristics of the subjects included in the study are shown in Table 1.

A double-blind, randomized, placebo-controlled intervention trial was conducted. A graphic representation of the study protocol is shown in Figure 1. All children recruited $(\mathrm{n}=36)$ met the inclusion criteria and were randomly assigned 
Table 1. Clinical characteristics of the subjects of the two study groups

\begin{tabular}{|c|c|c|c|}
\hline \multirow[b]{2}{*}{ Characteristics } & \multicolumn{2}{|c|}{ Study group } & \multirow[b]{2}{*}{$* P$ value } \\
\hline & Placebo & $\begin{array}{c}\text { B. longum } \text { CECT } \\
7347\end{array}$ & \\
\hline Number of cases & 16 & 17 & \\
\hline Male/Female & $8 / 8$ & $7 / 10$ & 0.437 \\
\hline Age, $[$ mean $(\mathrm{SE})]$ & $8.5(1.2)$ & $6.8(0.9)$ & 0.265 \\
\hline Baseline height $(\mathrm{cm})[$ mean $(\mathrm{SE})]$ & $26.5(3.8)$ & $21.8(3.4)$ & 0.301 \\
\hline Baseline weight $(\mathrm{kg})$ [mean (SE)] & $119.8(5.7)$ & $109.3(6.4)$ & 0.449 \\
\hline Height percentile baseline/post-treatment & & & $0.530 / 0.530$ \\
\hline Children up percentile 50 & $2 / 2$ & $3 / 3$ & \\
\hline Children at percentile 50 & $0 / 0$ & $0 / 0$ & \\
\hline Children under percentile 50 & $14 / 14$ & $14 / 14$ & \\
\hline \multicolumn{4}{|l|}{ Increased height percentile } \\
\hline Mean (SE) & $7.0(1.5)$ & $7.8(2.2)$ & 0.591 \\
\hline Post-treatment-baseline/baseline [median (IQR)] & $0.30(0.1-0.53)$ & $1.29(0.22-2.85)$ & $0.048^{*}$ \\
\hline Weight percentile baseline/post-treatment & & & $0.530 / 0.365$ \\
\hline Children up percentile 50 & $3 / 3$ & $4 / 6$ & \\
\hline Children at percentile 50 & $0 / 1$ & $0 / 0$ & \\
\hline Children under percentile 50 & $13 / 12$ & $13 / 11$ & \\
\hline \multicolumn{4}{|l|}{ Increased weight percentile } \\
\hline Mean (SE) & $3.2(1.7)$ & $5.7(1.8)$ & 0.186 \\
\hline Post-treatment-baseline/baseline [median (IQR)] & $0.22(0.09-0.47)$ & $0.26(0.14-1.64)$ & 0.234 \\
\hline Histology (Marsh categorization) ${ }^{* *}$ & & & 0.701 \\
\hline Marsh 1 & 0 & 1 & \\
\hline Marsh 2 & 0 & 1 & \\
\hline Marsh 3a & 5 & 3 & \\
\hline Marsh 3b & 8 & 10 & \\
\hline Marsh 3c & 3 & 2 & \\
\hline $\begin{array}{l}\text { Anti-transglutaminase antibodies } \\
\text { (post-treatment-baseline/baseline) } \\
\text { [median (IQR)] }\end{array}$ & $\begin{array}{c}-0.60 \\
(-0.88 \text { to }-0.61)\end{array}$ & $\begin{array}{c}-0.84 \\
(-0.88 \text { to }-0.75)\end{array}$ & 0.418 \\
\hline
\end{tabular}

*Categorical variables were analysed using the Fisher test and continuous variables were analysed using the t-test except for few exceptions for which the Mann-Whitney $U$ test was applied (increased height and weight percentile expressed as quotient of post-treatment-baseline/baseline and changes in the anti-transglutaminase antibodies content) for comparison between groups (placebo versus $B$. longum CECT 7347). In all the cases differences were established at a $P$ value $<0.050$.

** Histological data were obtained only at the diagnosis stage.

to the B. longum CECT 7347 ( $\mathrm{n}=18$ ) or the placebo $(\mathrm{n}=18)$ group. The randomization design was generated using the SAS module PROC PLAN (9.1.3 version, service pack 2) multiple of two sized blocks and 1:1 pattern through a centralized randomization list. The test group received B. longum CECT 7347
(109 CFU per capsule daily) and the placebo group received an indistinguishable capsule containing only the excipient (skimmed milk with $30 \%$ sucrose and $0.5 \%$ vitamin $\mathrm{C}$ daily) taken at lunch time or with other food intake, for 3 months after $\mathrm{CD}$ diagnosis and in parallel to the GFD. Capsule groups were labelled 


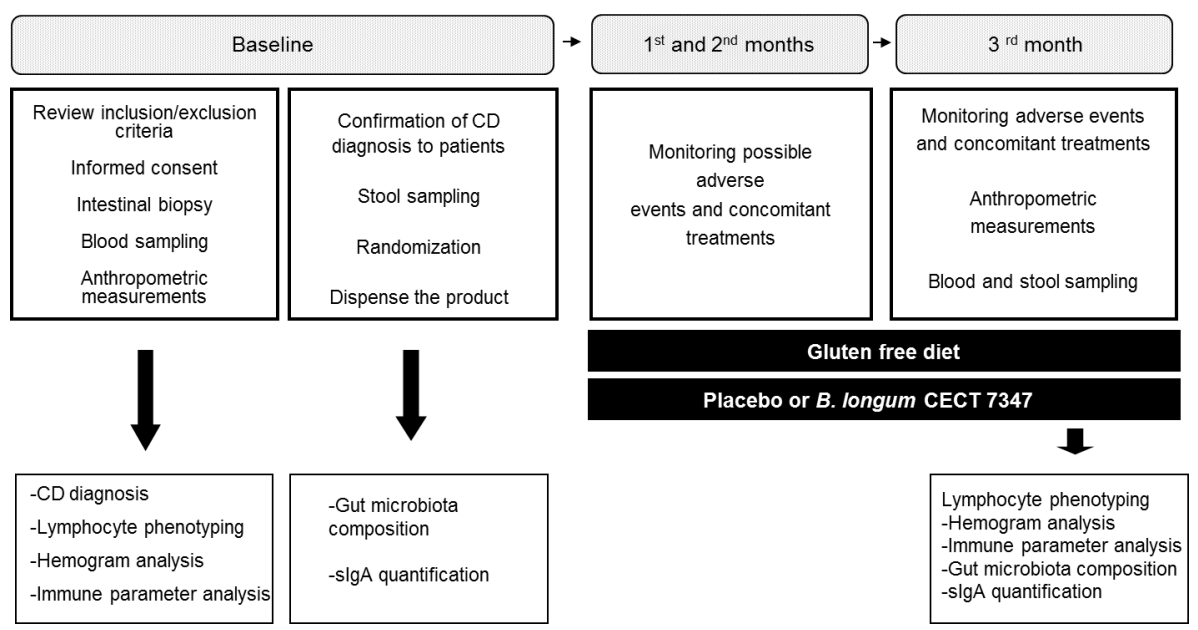

Figure 1: Graphical representation of the study protocol and the timing of sample collection and asseessments during the 3 months of intervention.

with codes consisting of a letter and 3 numbers assigned randomly by an external scientist involved in bacterial strain production but not in its evaluation in the present study. Study personnel, including clinicians and research assistants involved in experimental work and data analysis, were naïve as to which treatment these labels represented. All these measures ensured true allocation concealment and proper blinding. Visits to paediatricians and parameters monitored are shown in Figure 1. The trial was not registered because it was a first exploratory study.

\section{Gluten free diet (GFD) and dietary records}

Children adhered to a strict GFD, after confirmation of $\mathrm{CD}$ diagnosis, by replacing gluten-containing foods by equivalent ones certified as gluten free (less than $20 \mathrm{ppm}[\mathrm{mg} /$ $\mathrm{kg}$ ] according to the EC Regulation No41/2009). Dieticians provide dietary counselling to select naturally and certified gluten-free products. They were also advised not to consume prebiotic and probiotic containing foods. To control diet as variable, food diary records were collected for $72 \mathrm{~h}$ (2 weekdays and 1 weekend day) before the start of the intervention and at the end of the 3 months of intervention. At the front of the dairy, detailed information on how to record food and beverages consumed using common household measure was provided. Food diary records were returned to the dietician for their analysis for energy, macronutrient and micronutrients contents based on the CESNID food composition database of Spanish foods (28). 


\section{Clinical assessments}

At baseline and after the threemonth intervention, serologic markers of $\mathrm{CD}$, anthropometric parameters (height and weight) and evolution of clinical symptoms were assessed by paediatricians specialized in gastroenterology. Parents were also instructed to weekly register data on compliance with probiotic intake, gastrointestinal symptoms (presence or absence of vomiting, diarrhoea, constipation or abdominal pain), and concomitant treatments (e.g. antibiotics, drugs interfering with intestinal function, etc.) and serious adverse events (hospitalization, any life-threatening event, etc.) and to report them to the paediatrician at each visit. Compliance was considered to be accomplished when the intake of the test capsules was not interrupted for more than two consecutive days and no more than three times during the whole intervention period (three months). Parents were also provided a roundthe-clock call service and e-mail address for immediate reporting if necessary.

\section{Lymphocyte phenotyping}

At baseline and the end of the three-month trial period, peripheral blood samples were collected in heparin tubes and separated in two aliquots; one was mixed with stabilizing blood Transfix reagent (Cytomark, Buckingham, UK) and sent immediately to IATA-CSIC at room temperature for cytometry analysis. The second blood sample was centrifuged $(1,200 \mathrm{xg}, 10 \mathrm{~min}$, $\left.4{ }^{\circ} \mathrm{C}\right)$ and the serum was stored at $-80^{\circ} \mathrm{C}$. Furthermore, a routine hemogram was carried out with all the blood samples.

Flow cytometry was used to determine the expression of surface markers of different lymphocyte subsets. Aliquots $(100 \mu \mathrm{L})$ of stabilized peripheral blood were incubated with different fluorochrome-conjugated antibodies (eBiosciences, Hattfield, UK) at room temperature for 10 minutes and then prepared for flow cytometry analysis using the Immunoprep kit (Beckman Coulter, USA) according to the manufacturer's instructions. Samples were analysed in a FACSCanto II Deckton Dickinson cytometer (BD Bioscience). To analyse the $T$ lymphocytes subsets cells were stained with the following monoclonal antibodies: CD45phycoerythrin (PE) (clone HI30), CD3-allophycocyanin (APC) (clone OKT3), HLA-DR-fluorescein isothiocyanate (FITC) (clone LN3), CD4-FITC (clone OKT4), Foxp3$\mathrm{APC}$ (clone PCH101) and CD8APC (clone RPA-T8). Lymphocyte subsets were classified based on the pattern of their surface marker expression as $\mathrm{CD} 45+\mathrm{CD} 3+$ (mature T lymphocytes); CD45+HLA-DR+ (late activation marker positive $\mathrm{T}$ lymphocytes); CD45+CD4+ (helper $\mathrm{T}$ cells); CD45+CD4+ and Foxp3+ (regulatory $\mathrm{T}$ cells) and $\mathrm{CD} 45+\mathrm{CD} 8+$ (cytotoxic $\mathrm{T}$ 
cells). Data from 100,000 events were acquired and percentages of each subpopulation related to the gated lymphocytes labelled with the leukocyte marker CD45+ were estimated using the BD FACSDiva ${ }^{\mathrm{TM}}$ software v5.0.

\section{Cytokine and immunoglobulin quantification}

In serum samples, the initial and final content of the pro- and antiinflammatory cytokines (TNF-a, interferon (IFN)- $\gamma, \quad$ IL-13 and IL-10) were quantified using a commercial ELISA kit following the manufacturer's instructions (Catalogue no 31673019, 31333539 and 31330139, Immunotools, Friesoythe, Germany; Catalogue $n^{\circ}$ 430605, Biolegend, Cambridge, UK). Transforming growth factor (TGF)- $\beta 1$ analysis included the activation of the molecule (incubation with $1 \mathrm{~N} \mathrm{HCl}$ for 1 hour and neutralization with $1 \mathrm{~N}$ $\mathrm{NaOH}$ ) prior to its quantification with an ELISA (Catalogue $\mathrm{n}^{\circ}$ 437708, Biolegend, Cambridge, UK). Immunoglobulin (Ig) G1 (Catalogue $\mathrm{n}^{\mathrm{o}}$ ELH-IGG1-001, RayBiotech, Gwinnett, USA) and IgG4 (Catalogue no CSB-E13728h, Cusabio, Wuhan, China) content were also quantified using specific ELISA kits.

\section{Secretory IgA (sIgA) quantification} Faecal samples were collected at baseline and at the end of the trial and stored at $-80{ }^{\circ} \mathrm{C}$. One gram of faecal sample was weighed, diluted 1/10 (w/v) with PBS buffer (130 mM sodium chloride and 10 $\mathrm{mM}$ sodium phosphate buffered saline, $\mathrm{pH}$ 7.4) and homogenized in a stomacher for 5 minutes. The mixture was also homogenized in a tube with glass beads of $5 \mathrm{~mm}$ using a vortex and subjected to low-speed centrifugation $(600 \mathrm{xg}, 2 \mathrm{~min})$. The supernatants were collected for sIgA quantification by ELISA according to the manufacturer's instructions (Catalogue $\mathrm{n}^{\mathrm{o}}$ E80-102, Bethyl, Montgomery, USA) as well as for DNA extraction as described below.

\section{Microbiota analysis by real-time PCR}

DNA was extracted using the QIAamp DNA Stool Mini Kit (Qiagen, Hilden, Germany) following the manufacturer's instructions. Real-time PCR analyses were run to quantify the content of different bacterial groups and Bifidobacterium spp. using specific primers as previously described (Supplementary table 1). PCR amplification was performed in a LightCycler 480 Real-Time PCR System (Roche) in a multi well-plate with $15 \mu \mathrm{L}$ of reaction mixture that consisted of $7.5 \mu \mathrm{L}$ SYBR Green PCR Master Mix (Roche), $3.5 \mu \mathrm{L}$ DNase free water, $0.75 \mu \mathrm{L}$ of each specific primer $(10 \mathrm{mM})$ and $2.5 \mu \mathrm{L}$ of the DNA sample. 16S rRNA gene copy numbers were calculated by comparing the cycle threshold $(\mathrm{Ct})$ values obtained with those from a 
standard curve (29). Standard curves were generated from serial dilutions of a known copy number of the target gene cloned into a plasmid vector. For each reference strain the $16 S$ rRNA gene was cloned into a pGEM-T Easy Vector System (Promega, Madison, USA) and an E. coli $\mathrm{DH} 5 \mathrm{a}$ strain was transformed with the recombinant plasmids. Plasmid DNA was extracted from $E$. coli by the miniprep method (30).

\section{Statistical analysis}

Data distribution of continuous variables was tested using ShapiroWilk W test. When data showed a normal distribution $(P>0.050)$ a t-test for paired sample comparisons was used and results are expressed as mean values and the standard error of the mean [SE]). When no-normal distribution was found, the MannWhitney $U$ test was applied for paired sample comparisons and data are expressed as median and interquartile range (IQR). Microbiological data were transformed from exponential numbers into logarithms to adjust to normal. All parameters measured during the intervention were expressed as the difference between the baseline value and the postintervention value, divided by the baseline value for pair comparisons between the two study groups applying either the t-test or the MannWhitney $U$ test. A generalized linear model was also applied to absolute values of all parameters measured to establish differences between the two study groups and possible time by treatment interactions. Correlations between the microbiota composition data and immunological data were stabilised by applying the Pearson coefficient.

Categorical demographic data of the study subjects (Table 1) and the incidence of gastrointestinal symptoms (Table 2) are expressed as absolute values or proportions and analysed using the Fisher test.

The analyses were conducted using the SPSS software (version 19.0, Inc, Chicago, IL, USA) and in all the cases, statistically significant differences were considered at a $P$ value below 0.050 .

\section{Ethical considerations}

The study was approved by the ethics committees of Consejo Superior de Investigaciones Científicas (CSIC) and the hospitals involved in the study, Hospital Universitario Sant Joan (Reus, Tarragona) and Hospital Universitario Sant Joan de Deu (Barcelona) and conducted in accordance with the Helsinki Declaration of 1975 as revised in 1983. Written informed consent was obtained from the parents of children included in the study.

\section{RESULTS}

\section{Trial subject characteristics}

From November 2011 to June 2012 a group of 36 children newly diagnosed with $\mathrm{CD}$ were enrolled 
in a randomized, double-blind, placebo-controlled intervention trial to evaluate the effects of intervention in the gut ecosystem with $B$. longum CECT 7347 in parallel to those of the GFD. Three withdrawals were registered one due to parents' complaints of the child's reduced appetite and two due to the intake of antibiotics. Two of the withdrawals belonged to the placebo treatment and one to the $B$. longum group. Finally, data from 17 subjects of the probiotic group and 16 of the placebo group were included in the statistical analysis. Taking account the number of the children enrolled, the mean missed doses in the placebo group was 1.3 and in the probiotic 1.9 , which did not differ significantly ( $P=0.193)$.

Dietary records did not revealed significant differences between groups in the intake of energy and specific nutrients ( $P>0.050)$. The adherence to the GFD only led to a slight reduction in the dietary fibre intake in both group of children (Supplementary table 2). Intake of other probiotics or prebiotics was not reported during the study period.

The demographic and clinical characteristics of the child groups are shown in Table 1. Proper randomization was achieved as there were no significant differences in the baseline characteristics between the two groups. The serum antibodies to tissue transglutaminase (tTG)IgA were normalized, decreasing to similar levels $(P=0.418)$ in both groups after 3 months of adherence to a GFD and intervention (Table 1). No adverse events were reported during the intervention. Height and weight data were analysed according to the WHO growth chart percentiles. As is shown in Table 1, at the time of diagnosis $84.8 \%(28 / 33)$ and $78.8 \%(26 / 33)$ of the children enrolled in the study were under percentile 50 (P50) for height and weight, respectively, corresponding to their age. After 3 months of intervention, two children in the $B$. longum CECT 7347 group and one child in the placebo group gained weight so as they were included in the group of children up P50 and in the group of children at P50, respectively. The mean increases in height and weight percentiles (difference in the percentile from baseline and post-treatment) were higher in the B. longum CECT 7347 group $(\Delta 7.8[2.2]$ and $\Delta 5.7$ [1.8], respectively) than in the placebo group $(\Delta 7.0[1.5]$ and $\Delta 3.2$ [1.7], respectively). Comparison of these changes between groups revealed that increases in height percentile were significantly greater in the $B$. longum CECT 7347 group than in the placebo group $(P=0.048)$, while statistically significant differences in weight percentile increases were not detected $(P=0.234)$.

The incidence of gastrointestinal symptoms (diarrhoea, constipation, abdominal pain and vomiting) in the two study groups during the three months of intervention are showed 
in Table 2. No statically differences in the number of cases self-reporting incidence of these symptoms were detected either between groups or within the placebo or $B$. longum group.

\section{Lymphocyte phenotype and hemogram}

The results of immune phenotyping of peripheral blood cells by flow cytometry are shown in Table $\mathbf{3}$ and Figure 2. Within group comparisons did not reveal statistically significant changes in the placebo group during the three-month intervention on comparing baseline with posttreatment values (Table 3). In contrast, B. longum CECT 7347 administration led to significant decreases in $\mathrm{CD} 3+(P=0.013)$ and HLA-DR+ $(P=0.029) \mathrm{T}$ cell populations on comparing baseline with post-treatment values within this group (Table 3). Baseline values of the measured parameters were not significantly different between groups. Comparisons between groups revealed that the administration of B. longum CECT 7347 significantly reduced $(P=0.004) \mathrm{CD} 3+\mathrm{T}$ cell population as compared to the placebo (Figure 2). No statistically significant differences detected in the T lymphocytes subsets HLA-DR+, CD4+, CD4+Foxp3+ and CD8+ between groups $(P=0.328,0.970$, 0.504 and 0.376 , respectively) (Figure 2).

Similar differences were detected between groups by applying a generalized linear model. This model also revealed a significant effect of the B. longum CECT 7347 intervention, consisting in a reduction of the $\mathrm{CD} 3+$ population that was opposite to the effect of the GFD $(P=0.020)$ and a statistically significant time by treatment interaction $(P=0.021)$. Baseline values for $\mathrm{CD} 3+$ were no different between the two groups $(P=$ 0.950).

Table 2. Number of cases self-reporting gastrointestinal symptoms at least once during the threemonth intervention period in parallel to the GFD.

\begin{tabular}{|c|c|c|c|c|c|c|}
\hline & \multicolumn{6}{|c|}{$\mathrm{N}^{o}$ of cases reporting gastrointestinal symptoms } \\
\hline & \multicolumn{2}{|c|}{ Placebo $(n=16)$} & \multirow{2}{*}{$\begin{array}{c}* P- \\
\text { value }\end{array}$} & \multicolumn{2}{|c|}{ B. longum CECT $7347(\mathrm{n}=17)$} & \multirow{2}{*}{$\begin{array}{c}{ }^{*} P- \\
\text { value }\end{array}$} \\
\hline & Initial & Final & & Initial & Final & \\
\hline Diarrhoea & $6 / 16$ & $4 / 16$ & 0.352 & $6 / 17$ & $5 / 17$ & 0.500 \\
\hline Constipation & $3 / 16$ & $2 / 16$ & 0.500 & $3 / 17$ & $2 / 17$ & 0.500 \\
\hline Abdominal pain & $6 / 16$ & $4 / 16$ & 0.352 & $10 / 17$ & $9 / 17$ & 0.500 \\
\hline Vomiting & $5 / 16$ & $1 / 16$ & 0.087 & $4 / 17$ & $1 / 17$ & 0.206 \\
\hline
\end{tabular}

*Data were compared applying the Fisher test and differences were established at $P$ value $<0.05$. 
Table 3. Changes in $\mathrm{CD} 45^{+} \mathrm{T}$ lymphocytes subsets within the placebo group or B. longum CECT 7347 group in the three-month intervention parallel to the GFD.

\begin{tabular}{lccccc}
\hline & \multicolumn{2}{c}{ Baseline } & \multicolumn{2}{c}{ Post-treatment } & \multirow{2}{*}{$*$ * value } \\
\cline { 2 - 5 } & Mean & SE & Mean & SE & \\
\hline Placebo & & & & & \\
\hline CD3 $^{+}$ & 66.96 & 2.85 & 70.03 & 2.17 & 0.144 \\
\hline HLA-DR $^{+}$ & 0.99 & 0.19 & 0.72 & 0.24 & 0.422 \\
\hline CD4 $^{+}$ & 41.78 & 4.37 & 42.60 & 4.89 & 0.898 \\
\hline CD4 $^{+}$Foxp3 $^{+}$ & 2.99 & 0.82 & 3.77 & 1.36 & 0.322 \\
\hline CD8 $^{+}$ & 22.08 & 1.95 & 20.68 & 1.13 & 0.344 \\
\hline
\end{tabular}

B. longum CECT 7347

\begin{tabular}{lccccc}
\hline $\mathrm{CD}^{+}$ & 70.05 & 2.23 & 63.42 & 2.04 & 0.013 \\
\hline $\mathrm{HLA}^{+} \mathrm{DR}^{+}$ & 0.62 & 0.10 & 0.38 & 0.82 & 0.029 \\
\hline $\mathrm{CD}^{+}$ & 44.68 & 2.40 & 45.96 & 3.59 & 0.748 \\
\hline $\mathrm{CD}^{+}$Foxp3 $^{+}$ & 3.13 & 0.66 & 3.45 & 0.73 & 0.728 \\
\hline $\mathrm{CD}^{+}$ & 23.92 & 1.55 & 21.59 & 0.98 & 0.152 \\
\hline
\end{tabular}

*Differences between baseline and post-treatment within the study groups (placebo or B. longum CECT 7347) were established at two-sided $P<0.05$ using the t-test.

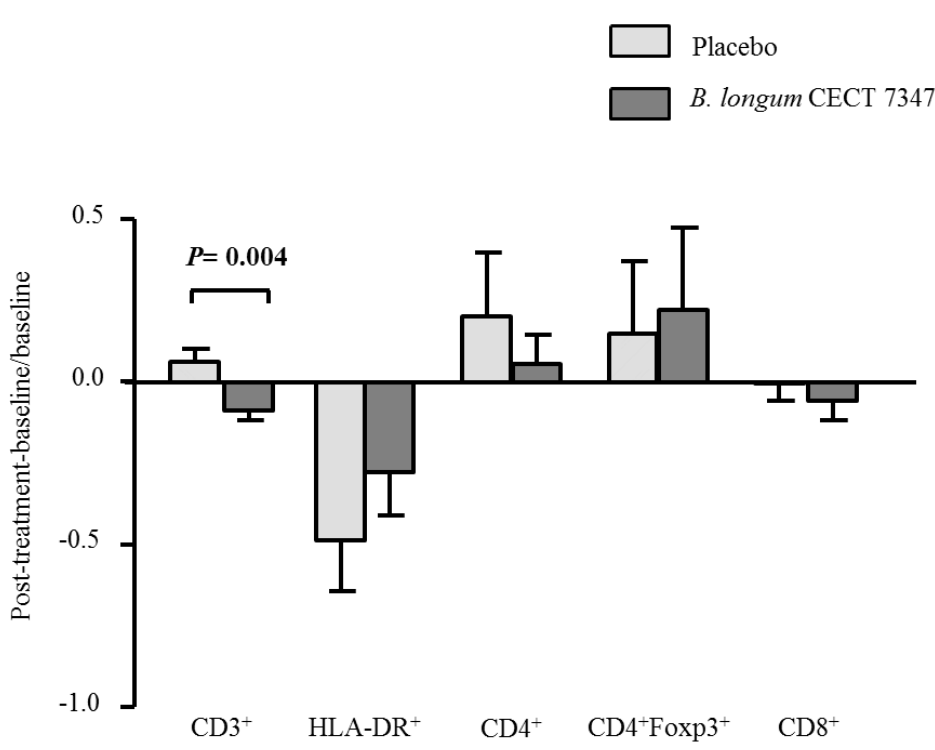

Figure 2. Changes in $\mathrm{CD} 45^{+} \mathrm{T}$ lymphocytes subsets estimated as the difference between the baseline value and the post-intervention value, divided by the baseline value in placebo (light grey colour) and B. longum CECT 7347 (dark grey colour) groups in the three-month intervention parallel to the GFD. Data are expressed as mean and SE. Statistically significant differences between groups were established at two-sided $P<0.05$ using the Mann-Whitney $U$ test. 
No changes in the total leukocyte and leukocyte subtype (lymphocytes, monocytes, granulocytes, eosinophils and basophils) counts or haemoglobin content were observed on analysing the hemogram (data not shown), either within groups or between groups.

\section{Cytokines and immunoglobulin content}

The results of serum cytokines and immunoglobulin concentrations are shown in Table $\mathbf{4}$ and Figure 3. Within group comparisons, revealed that $B$. longum CECT 7347 administration slightly reduced serum TNF-a concentrations, but differences did not reached statistical significance $(P=0.085)$. Changes in other serum cytokines and immunoglobulin concentrations, comparing baseline and posttreatment values within groups, were not significantly different in the B. longum CECT 7347 group or in the placebo group (Table 4). Comparisons between groups $(B$. longum CECT 7347 and placebo) of changes in serum cytokines and immunoglobulin levels are shown in Figure 3. Baseline values of the measured parameters were not significantly different between

Table 4: Changes in the cytokine $(\mathrm{pg} / \mathrm{mL})$ and immunoglobulin $(\mathrm{ng} / \mathrm{mL})$ content within the group placebo (a) or B. longum CECT 7347 (b) in the three-month intervention parallel to the GFD.

\begin{tabular}{lccccc}
\hline & \multicolumn{2}{c}{ Baseline } & \multicolumn{2}{c}{ Post-treatment } & \multirow{2}{*}{$* P$ value } \\
\cline { 2 - 5 } & Mean & SE & Mean & SE & \\
\hline Placebo & & & & & \\
\hline TNF- $\alpha$ & 1669.56 & 338.47 & 1515.24 & 254.34 & 0.443 \\
\hline IFN- $\gamma$ & 306.42 & 32.59 & 297.59 & 36.32 & 0.815 \\
\hline IL-10 & 42.99 & 9.25 & 59.30 & 9.33 & 0.249 \\
\hline IL-13 & 137.71 & 12.85 & 163.86 & 21.16 & 0.239 \\
\hline TGF- $\beta 1$ & 116.43 & 38.62 & 146.63 & 25.71 & 0.537 \\
\hline IgG1 & 441.85 & 84.04 & 477.39 & 94.43 & 0.644 \\
\hline IgG4 & 4.63 & 0.42 & 6.29 & 1.18 & 0.212 \\
\hline
\end{tabular}

B. longum CECT 7347

\begin{tabular}{lccccc}
\hline TNF- $\alpha$ & 1803.29 & 187.95 & 1442.94 & 153.20 & 0.085 \\
\hline IFN- $\gamma$ & 267.02 & 33.52 & 235.49 & 23.97 & 0.423 \\
\hline IL-10 & 69.14 & 12.15 & 52.02 & 5.28 & 0.240 \\
\hline IL-13 & 116.21 & 20.85 & 119.96 & 7.11 & 0.854 \\
\hline TGF- $\beta 1$ & 130.67 & 34.41 & 138.42 & 33.52 & 0.851 \\
\hline IgG1 & 368.91 & 57.51 & 400.82 & 74.43 & 0.590 \\
\hline IgG4 & 4.38 & 0.19 & 4.42 & 0.34 & 0.919 \\
\hline
\end{tabular}

*Differences between baseline and post-treatment values within the group placebo or B. longum CECT 7347 were stabilised at two-sided $P<0.05$ using the t-test. 


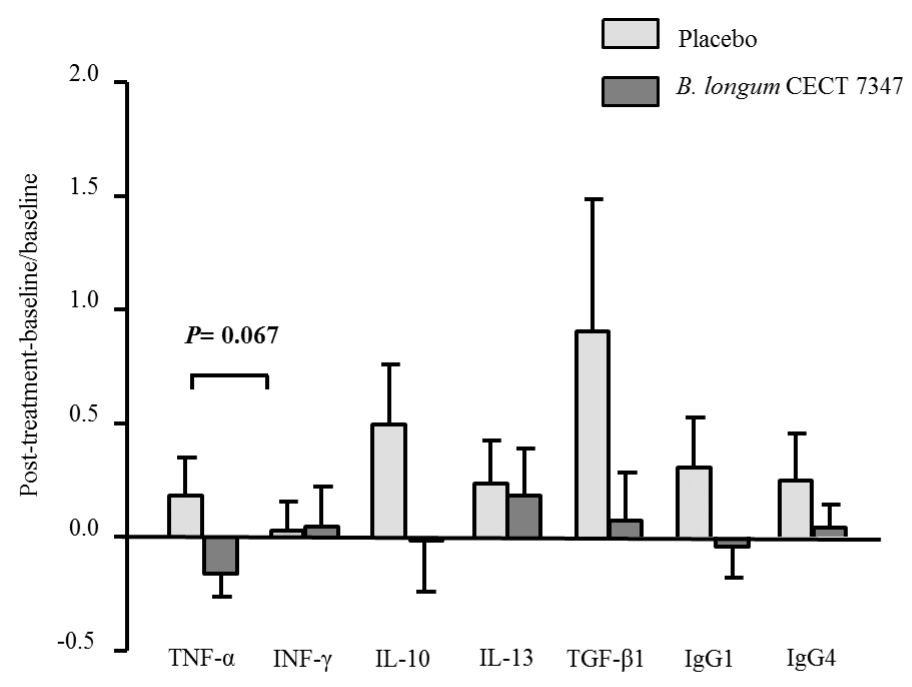

Figure 3. Changes in the cytokine $(\mathrm{pg} / \mathrm{mL})$ and immunoglobulin $(\mathrm{ng} / \mathrm{mL})$ content estimated as the difference between the baseline value and the post-intervention value, divided by the baseline value in placebo (light grey colour) and B. longum CECT 7347 (dark grey colour) groups in the three-month intervention parallel to the GFD. Data are expressed as mean and SE. Statistically significant differences between groups were established at two-sided $P<0.05$ using the t-test.

groups. The administration of B. longum CECT 7347 slightly reduced serum TNF-a concentration compared to the placebo but statistical significance was not reached $(P=$ 0.067). No statistically significant differences were detected in serum IL-10, IFN- $\gamma$, IL-13, TGF- $\beta 1$, IgG1 and IgG4 concentrations between groups.

Applying a generalized linear model significant differences in IgG4 $(P=0.038)$ were detected, showing increased values in the placebo group. Significant effects or interactions were not detected for other parameters.

\section{Microbiota composition and faecal sIgA content}

Within group changes in microbiota composition as a result of the interventions showed that the GFD plus placebo administration caused a statistically significant increase in gene copy numbers of the Bacteroides fragilis group $(P=0.013)$ and in the family Enterobacteriaceae ( $P=$ 0.038) (Table 5). Bifidobacterim spp. gene copy numbers were also slightly reduced as a consequence of the GFD although differences did not reach statistical significance $(P=$ $0.151)$. Within group comparisons also showed that the ratio of Lactobacillus group + Bifidobacterium spp./Bacteroides fragilis group + Enterobacteriaceae was significantly 
Table 5. Changes in intestinal microbiota composition (log of gene copy numbers/g stools) within the group placebo or B. longum CECT 7347 in the three-month intervention parallel to the GFD.

\begin{tabular}{lccccc}
\hline & \multicolumn{2}{c}{ Baseline } & \multicolumn{2}{c}{ Post-treatment } & \multirow{2}{*}{ P value } \\
\cline { 2 - 5 } & Mean & SE & Mean & SE & \\
\hline Placebo & & & & & \\
\hline Total bacteria & 11.10 & 0.14 & 11.15 & 0.18 & 0.689 \\
\hline B. fragilis group & 9.07 & 0.17 & 9.59 & 0.22 & 0.013 \\
\hline Enterobacteriaceae & 6.03 & 0.38 & 6.93 & 0.34 & 0.038 \\
\hline Lactobacillus group & 8.55 & 0.14 & 8.45 & 0.18 & 0.589 \\
\hline Bifidobacterium spp. & 9.37 & 0.19 & 9.01 & 0.24 & 0.151 \\
\hline C. coccoides group & 8.85 & 0.33 & 9.31 & 0.28 & 0.115 \\
\hline C. leptum group & 9.86 & 0.23 & 10.07 & 0.30 & 0.434 \\
\hline sIgA $(\mathrm{mg} / \mathrm{mL})$ & 67.07 & 5.75 & 84.15 & 6.01 & 0.009 \\
\hline
\end{tabular}

B. longum CECT 7347

\begin{tabular}{lccccc}
\hline Total bacteria & 11.27 & 0.15 & 11.08 & 0.16 & 0.393 \\
\hline B. fragilis group & 9.43 & 0.20 & 9.29 & 0.16 & 0.583 \\
\hline Enterobacteriaceae & 5.90 & 0.46 & 6.34 & 0.43 & 0.424 \\
\hline Lactobacillus group & 8.46 & 0.21 & 8.54 & 0.33 & 0.858 \\
\hline Bifidobacterium spp. & 9.08 & 0.27 & 9.16 & 0.42 & 0.875 \\
\hline C. coccoides group & 9.22 & 0.23 & 9.60 & 0.42 & 0.469 \\
\hline C. leptum group & 10,23 & 0,23 & 10.01 & 0.16 & 0.447 \\
\hline sIgA $(\mathrm{mg} / \mathrm{mL})$ & 77.53 & 4.89 & 60.83 & 7.16 & 0.109 \\
\hline
\end{tabular}

* Differences between baseline and post-treatment values within the group placebo or B. longum CECT 7347 were stabilised at two-sided $P<0.05$ using the t-test.

reduced in the placebo group $(1.26$ [0.08] versus 1.00 [0.04]; $P=0.006)$, while $B$. longum CECT 7347 group did not show statistically significant differences (1.19 [0.07] versus 1.16 [0.07]; $P=0.811)$. Comparison between groups revealed that gene copy numbers of the Bacteroides fragilis group increased significantly in the placebo group compared to the $B$. longum CECT 7347 group $(P=0.020)$ (Figure 4$)$. The quantification of sIgA content in faces showed that the treatments caused opposite changes within groups, which were statistically significant for the placebo group, showing an increase in faecal sIgA concentration $(P=0.009)$ (Table 5). Comparisons between groups revealed that $B$. longum CECT 7347 administration led to significant reductions in faecal sIgA compared to the placebo $(P=$ 0.011) (Figure 5).

In the B. longum CECT 7347 group, decreases in stoolsIgA levels correlated 


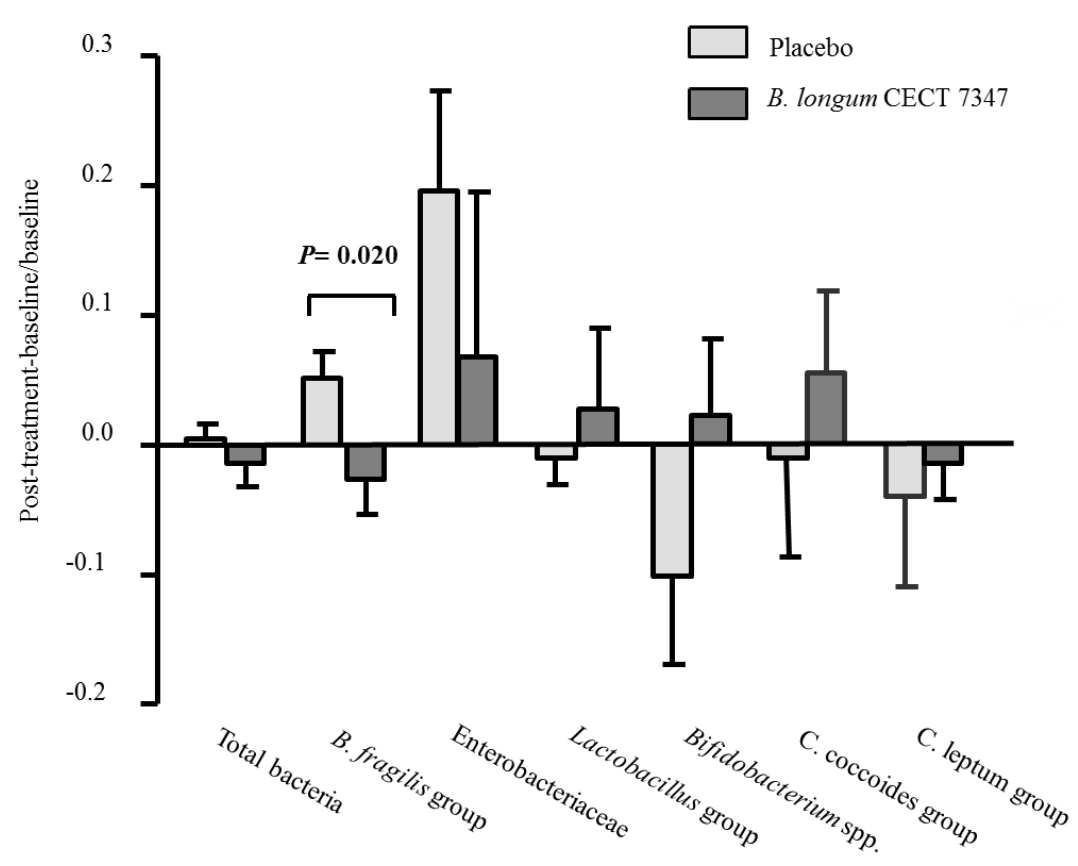

Figure 4. Changes in intestinal microbiota composition (log of gene copy numbers/g stools) estimated as the difference between the baseline value and the post-intervention value, divided by the baseline value in placebo (light grey colour) and B. longum CECT 7347 (dark grey colour) groups in the three-month intervention parallel to the GFD. Data are expressed as mean and SE. Statistically significant differences between groups were established at two-sided $P<0.05$ using the Mann-Whitney $U$ test.

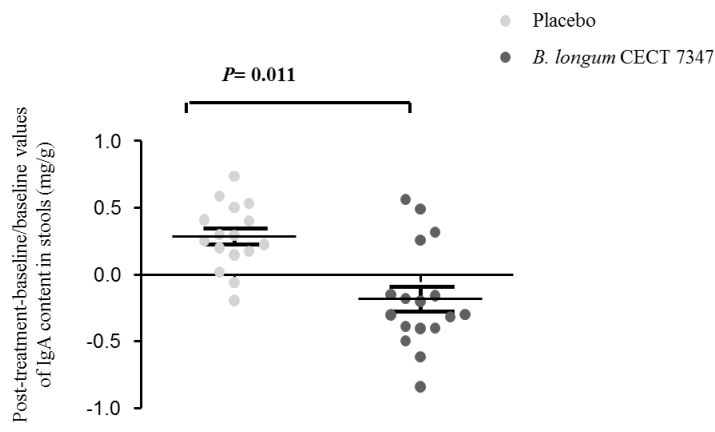

Figure 5. Changes in the sIgA content in stools $(\mathrm{mg} / \mathrm{g})$ estimated as the difference between the baseline value and the post-intervention value, divided by the baseline value in placebo (light grey colour) and B. longum CECT 7347 (dark grey colour) groups in the three-month intervention parallel to the GFD. Bars represent the mean of individual data and SE. Statistically significant differences between groups were established at two-sided $P<0.05$ using the t-test. 
with decreases in total bacteria and the Bacteroides fragilis group gene copy numbers $(P=0.005, \mathrm{r}=0.729$ and $P=0.047, \mathrm{r}=0.522$, respectively, Figure 6). No correlations were found between bacteria and other immune parameters either in the placebo group or in the B. longum group.

Applying a generalized linear model of analysis, the placebo group showed increases in Bacteroides fragilis group numbers of borderline significance compared to the probiotic group $(P=0.055)$. Significant and opposite changes in the $\operatorname{sg} A$ content depending on the treatment were also detected $(P=0.031)$ as well as a time by treatment interaction $(P=0.016)$; faecal sIgA decreased in the $B$. longum CECT 7347 group, while increased in the placebo group. Baseline values for Bacteroides fragilis group numbers and faecal sIgA were no different between the two groups $(P=0.972$ and $P=0.416$, respectively).

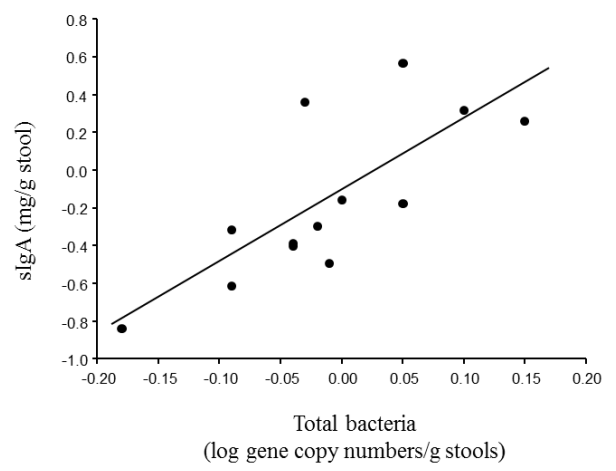

lymphocytes (CD3+) and HLA$\mathrm{DR}+\mathrm{T}$ lymphocytes, according to within group comparisons, while the placebo did not. Moreover, there were reduced mature $\mathrm{T}$ lymphocytes $(\mathrm{CD} 3+)$ in between group comparisons with respect to the placebo. Altogether, these results indicate that the bifidobacterial strain exerted a greater effect on these lymphocyte subsets than the GFD alone, which could presumably contribute to better recovery from the inflammatory status associated with the active phase of the disease, which is characterized by increased $\mathrm{T}$ cell activation that drives an inflammatory response with increased pro-inflammatory cytokine production (33). Statistically significant correlations between the densities of mucosa CD3+ with the serum tTG 2 antibody levels have been established in untreated and treated CD patients, and the number of intraepithelial CD3+ cells was also

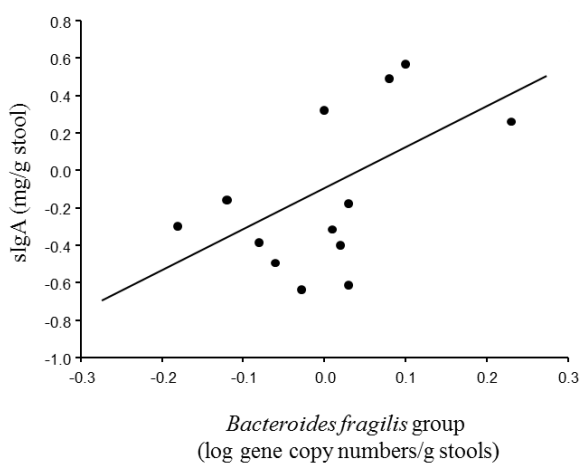

Figure 6. Correlation analyses of the changes between baseline and post-treatment values of sIgA concentrations (ng/g stools) and log gene copy numbers of total bacteria and Bacteroides fragilis group in the group of children treated with B. longum CECT 7347 plus GFD. 
associated with the villous heightcrypt depth ratio(33). Another study in newly diagnosed CD children (aged 2-5) also reported increased peripheral prevalence of HLA-DR+ cells, which was partially reduced after adherence to a GFD(19). This is in agreement with our findings, pointing to an improved effect of the GFD combined with $B$. longum CECT 7347 intake on this lymphocyte subpopulation. In our study, only regulatory (CD4+Foxp3+) $\mathrm{T}$ cells tended to increase in the placebo group, and increased even more in the $B$. longum CECT 7347 group together with helper (CD4+) T cells. Although changes were not statistically significant, this could indicate induction of the regulatory mechanisms controlling the unbalanced inflammatory $\mathrm{T}$ cell response associated with $\mathrm{CD}$.

Compared to the placebo, $B$. longum CECT 7347 administration also tends to decrease serum TNF-a concentration, suggesting this bifidobacterial strain could contribute to reducing the inflammatory status of patients to a greater extent than the GFD alone. This finding is also supported by a recent study in an animal model of gliadin-induced enteropathy, reporting that $B$. longum CECT 7347 administration reduced TNF-a production in the small intestinal tissue but increased IL-10 production (34). Statistically significant positive correlations have been reported between IgA-antitTG and serum TNF-a in subjects

\section{DISCUSSION}

The influence of administering B. longum CECT 7347 orally to children with newly diagnosed CD following a GFD was evaluated in a three-month double-blind randomized placebo-controlled intervention trial. The aim was to assess whether intervention in the gut ecosystem via $B$. longum CECT 7347 administration improved the efficacy of the GFD.

Adherence to the GFD, with and without $B$. longum CECT 7347 supplementation, led to positive effects on growth-related parameters in the children under study, as expected. Furthermore, B. longum CECT 7347 administration led to additional improvements, corresponding to greater increases in the height percentile compared to the placebo. Adherence to a GFD is associated with restoring growth, measured as the increase in height percentile and the decrease in weight deficit, as reported in a cohort of 90 children (aged 0.5-7.5) with the disease (31) The effect of GFD on the growth of a cohort of $60 \mathrm{CD}$ children (aged 2.3-10) in a four-year study also showed that the weightfor-height parameter normalized by the end of first year, while height recovery caught up steadily until the 3rd year of adherence to the GFD, revealing faster catch-up of weight than height (32). The administration of B. longum CECT 7347 caused significant decreases in mature $\mathrm{T}$ 
with both type 1 diabetes mellitus and CD (35). Also patients with newly diagnosed $\mathrm{CD}$ have been reported to have increased TNF-a serum concentration (36). In the context of CD, TNF- $\alpha$ production, together with IFN- $\gamma$, are thought to contribute to increasing intestinal epithelial permeability favouring the access of higher antigen loads to the submucosa and, therefore, aggravating CD pathogenesis (37). Recent studies in intestinal cultures in vitro and ex-vivo have also demonstrated that TNF-a may contribute to exacerbating the pathogenic mechanism of CD by inducing tTG 2 expression, synergically with IFN- $\gamma$ (38).

The present study also demonstrated that in newly diagnosed CD children, imbalances in the microbiota resulting from the GFD were counteracted by parallel administration of $B$. longum CECT 7347. In this respect, in the placebo group the GFD led to significant increases in potentially pathogenic bacteria ( $B$. fragilis group and Enterobacteriaceae) and reductions in the ratio of harmless to potentially harmful bacteria. In agreement with our present findings, increases in the ratio of BacteroidesPrevotella plus E. coli/Bifidobacterium plus Lactobacillus group proportions were detected in stools of untreated and treated CD children with a GFD previously (6). In addition, increases in Bacteroides fragilis numbers in both stools and duodenal biopsies of patients with active and non- active disease have been reported previously (7). Furthermore, it was demonstrated that the abundance of the species Bacteroides fragilis coding for metalloproteases was increased in both untreated and treated CD patients, which could presumably play a pathogenic role in CD (13). In fact, Bacteroides fragilis and the strains producing metalloproteases are frequently involved in opportunistic infections and aggravate colitis in animal models (39). Studies in healthy adults have also shown that the GFD per se shifts gut microbiota composition reducing numbers of Bifidobacterium spp., B. longum and Lactobacillus group, and increasing those of Enterobacteriaceae and E. coli (40). In vitro and animal studies have also shown that these microbiota alterations could contribute to pathogenesis in the active phase of the disease as well as to the lack of complete restoration of immune homeostasis in GFD-treated patients $(10,12,14)$. However in the present study statistically significant changes specifically in numbers of Bifidobacterim spp. were not detected neither associated with the adherence to the GFD nor with the probiotic administration. It has been reported that changes in microbiota resulting from a dietary intervention depend among other factors on the initial microbiota composition and, accordingly, previous studies have indicated that changes in bifidobacterial numbers can be minor after probiotic or prebiotic 
administration in subjects with high initial bifidobacterial counts (41) as it was the case for our study. Also, according to our previous studies, the GFD does not favour the growth of bifidobateria (40).

The changes induced by $B$. longum CECT 7347 administration in the intestinal microbiota were parallel to decreases in faecal sIgA concentration. The sIgA is considered to be the most likely host secretion to affect the localization, growth and composition of gut microbiota, and can restrict colonization of harmful bacteria $(42,43)$. Nevertheless, it is also speculated that gut microbiota composition may influence sIgA concentration and specificities as a result of a bi-directional cross-talk between the host and its microbiota $(42,43)$. The fact that $B$. longum CECT 7347 administration caused a sIgA reduction that was statistically correlated with the lower gene copy numbers of total bacteria and the Bacteroides fragilis group would suggest a reduction in the host sIgAmediated protective response against luminal bacterial antigens due to restoration of the gut ecosystem with decreases in harmful bacteria (44). A recent randomized, double-blind placebo-controlled study evaluated the effect of $B$. infantis NLS in untreated $\mathrm{CD}$ patients consuming gluten to establish the effect of the probiotic independently of the GFD (45). The beneficial properties of $B$. infantis NLS included the reduction of gastrointestinal symptoms, specifically indigestion, constipation and reflux with borderline significance. However, it did not improve diarrhoea or abdominal pain, nor modify intestinal permeability or the pro-inflammatory status as reflected by the analysis of serum cytokines and chemokines (45). Despite the experimental differences, it is presumable that the mechanism behind the effects exerted by $B$. infantis NLS differ from those exerted by B. longum CECT 7347 , as the latter influences inflammatory markers and the gut microbiota and host-related defence mechanisms.

The study reported herein has some limitations partly inherent to exploratory interventions. These include: small population size, lack of previous data for power calculation, inclusion of children with a wide age range, which could increase the variability of immune parameters determined, and a relatively short duration to detect clinical effects. Nonetheless, the findings are interesting enough to encourage further well-powered intervention studies, which would provide sound data on the efficacy of this bifidobacterial strain and shed light on its mode of action in ameliorating inflammatory conditions such as CD.

In conclusion, the oral administration of B. longum CECT 7347 together with the GFD led to shifts in the intestinal microbiota, characterized by reductions in potentially proinflammatory bacteria ( $B$. fragilis 
group) related to $\mathrm{CD}$ in previous human observational studies as well as faecal sIgA. Likewise, $B$. longum CECT 7347 administration led to reductions in activated $\mathrm{T}$ lymphocytes and also tended to reduce inflammatory markers (TNF-a) that may contribute to recovery of the immune homeostasis in patients.

\section{Acknowledgements}

The authors thank the children with celiac disease and their parents for participating in the study, as well as to Dra. Karina Guadalupe Hernández and Dr Francisco Sosa for their collaboration in sample and data collection.

This work was supported by grants CEN20091006 (MICINN, Spain) and Consolider Fun-C-Food CSD2007-00063 from the Spanish Ministry of Science and Innovation (MICINN, Spain). M. Olivares has a JAEpreDoc contract (CSIC, Spain).

\section{REFERENCES}

1. Di Sabatino A \& Corazza GR (2009) Coeliac disease. Lancet 373, 1480-1493.

2. Pozo-Rubio T, Olivares M, Nova E et al. (2012) Immune development and intestinal microbiota in celiac disease. Clin Dev Immunol 2012, 654143. 3. Laparra M, Olivares M, Sanz Y (2013) Role of Gut Microbes in Celiac Disease Risk and Pathogenesis. In: S. Devi Rampertab and Gerand E. Mullin (eds.). Celiac Disease. Chaper 7. Springer.

4. Kalliomäki M, Satokari R, Lähteenoja $\mathrm{H}$ et al. (2012). Expression of microbiota, Toll-like receptors, and their regulators in the small intestinal mucosa in celiac disease. J Pediatr Gastroenterol Nutr 54, 727-732.

5. de Meij TG, Budding AE, Grasman ME et al. (2013) Composition and diversity of the duodenal mucosa-associated microbiome in children with untreated coeliac disease. Scand J Gastroenterol 48, 530-536

6. Nadal I, Donat E, Ribes-Koninckx C et al. (2007) Imbalance in the composition of the duodenal microbiota of children with coeliac disease. J Med Microbiol 56, 1669-1674.

7. Collado MC, Donat E, Ribes-Koninckx C et al. (2008) Imbalances in faecal and duodenal Bifidobacterium species composition in active and non-active coeliac disease. BMC Microbiol 8, 232.

8. Sanz Y, De Palma G, Laparra M (2011) Unraveling the ties between celiac disease and intestinal microbiota. Int Rev Immunol 30(4), 207-218.

9. WacklinP,KaukinenK, TuovinenEetal.(2013) The duodenal microbiota composition of adult celiac disease patients is associated with the clinical manifestation of the disease. Inflammatory Bowel Dis 19(5), 934-941.

10. Medina M, De Palma G, Ribes-Koninckx C et al. (2008) Bifidobacterium Straits suppress in vitro the pro-inflammatory milieu triggered by the large intestinal microbiota of coeliac patients. $J$ Inflammation (London, U.K.) 5, 19.

11. De Palma G, Nadal I, Medina M et al. (2010) Intestinal dysbiosis and reduced immunoglobulincoated bacteria associated with coeliac disease in children. BMC Microbiol 10, 63.

12. Cinova J, De Palma G, Stepankova R et al. (2011) Role of intestinal bacteria in gliadininduced changes in intestinal mucosa: study in germ-free rats. PLoS One 6(1), e16169.

13. Sánchez E, Laparra JM, Sanz Y (2012) Discerning the role of Bacteroides fragilis in celiac disease pathogenesis. Appl Environ Microbiol 78(18), 6507-6515. 
14. De Palma G, Kamanova J, Cinova J et al. (2012) Modulation of phenotypic and functional maturation of dendritic cells by intestinal bacteria and gliadin: relevance for celiac disease. J Leukocyte Biol 92(5), 1043-1054.

15. Laparra JM \& Sanz Y (2010) Bifidobacteria inhibit the inflammatory response induced by gliadins in intestinal epithelial cells via modifications of toxic peptide generation during digestion. J Cell Biochem 109(4), 801-807.

16. Olivares M, Laparra M, Sanz Y (2011) Influence of Bifidobacterium longum CECT 7347 and gliadin peptides on intestinal epithelial cell proteome. J Agric Food Chem 59(14), 7666-7671. 17. Laparra JM, Olivares M, Gallina $\mathrm{O}$ et al. (2012) Bifidobacterium longum CECT 7347 modulates immune responses in a gliadin-induced enteropathy animal model. PLoS One 7(2), e30744.

18. Agardh D, Lynch K, Brundin C et al. (2006)

Reduction of tissue transglutaminase autoantibody levels by gluten-free diet is associated with changes in subsets of peripheral blood lymphocytes in children with newly diagnosed coeliac disease. Clin Exp Immunol 144(1), 67-75.

19. CsehÁ,VásárhelyiB,SzalayB etal.(2011)Immune phenotype of children with newly diagnosed and gluten-free diet-treated celiac disease. Dig Dis Sci 56(3), 792-798.

20. Cosnes J, Cellier C, Viola S et al. (2008) Incidence of autoimmune diseases in celiac disease: protective effect of the gluten-free diet. Clin Gastroenterol Hepatol 6, 753-758.

21. Malandrino N, Capristo E, Farnetti $S$ et al. (2008) Metabolic and nutritional features in adult celiac patients. Dig Dis 26, 128-133.

22. Roos S, Wilhelmsson S, Hallert C (2011) Swedish women with coeliac disease in remission use more health care services than other women: a controlled study. Scand J Gastroenterol 46(1), 1319.
23. Turco R, Boccia G, Miele E et al. (2011) The association of coeliac disease in childhood with functional gastrointestinal disorders: a prospective study in patients fulfilling Rome III criteria. Aliment Pharmacol Ther 7, 783-789.

24. Paavola A, Kurppa K, Ukkola A et al. (2012) Gastrointestinal symptoms and quality of life in screen-detected celiac disease. Dig Liver Dis 10, 814-818.

25. Di Sabatino A, Bertrandi E, Casadei Maldini M et al. (1998) Phenotyping of peripheral blood lymphocyes in adult celiac disease. Immunology 95 , 572-576.

26. Rubio-Tapia A, Barton SH, Rosenblatt JE et al. (2009) Prevalence of small intestine bacterial overgrowth diagnosed by quantitative culture of intestinal aspirate in celiac disease. $J$ Clin Gastroenterol 43(2), 157-161.

27. Sanz Y (2009) Novel perspectives in celiac disease therapy. Mini-Rev Med Chem 9(3), 359367.

28. Farran A, Zamora R ᄀ Cervera P (2004) Tablas de composición de alimentos CESNID (CESNID Food composition tables), 2nd ed. Barcelona: McGraw-Hill/Interamericana.

29. Yu Y, Lee C, Kim J et al. (2005) Group-specific primer and probe sets to detect methanogenic communities using quantitative real-time polymerase chain reaction. Biotechnol Bioeng 89, 670-679.

30. Birnboim HC \& Doly J (1979) A rapid alkaline extraction procedure for screening recombinant plasmid DNA. Nucleic Acids Res 7(6), 1513-1523.

31. Radlović N, Mladenović M, Leković Z et al. (2009) Effect of gluten-free diet on the growth and nutritional status of children with coeliac disease. Srp Arh Celok Lek 137(11-12), 632-637.

32. Damen GM, Boersma B, Wit JM et al. (1994) Catch-up growth in 60 children with celiac disease. J Pediatr Gastroenterol Nutr 19, 394-400.

33. Taavela J, Kurppa K, Collin P et al. (2013) 
Degree of damage to the small bowel and serum antibody titers correlate with clinical presentation of patients with celiac disease. Clin Gastroenterol Hepatol 11(2), 166-171.

34. Myśliwiec M, Balcerska A, Zorena K et al. (2008) Immunologic and biochemical factors of coincident celiac disease and type 1 diabetes mellitus in children. Pediatr Res 64(6), 677-681.

35. Street ME, Volta C, Ziveri MA et al. (2008) Changes and relationships of IGFS and IGFBPS and cytokines in coeliac disease at diagnosis and on gluten-free diet. Clin Endocrinol (Oxf) 68(1), 22-28.

36. Fasano, A \& Shea-Donohue, T (2005) Mechanisms of disease: the role of intestinal barrier function in the pathogenesis of gastrointestinal autoimmune diseases. Nat Clin Pract Gastroenterol Hepatol 2, 416-422.

37. Bayardo M, Punzi F, Bondar C et al. (2012) Transglutaminase 2 expression is enhanced synergistically by interferon-g and tumour necrosis factor-a in human small intestine. Clin Exp Immunol 168(1), 95-104.

38. Rabizadeh S, Rhee KJ, Wu S et al. (2007) Enterotoxigenic Bacteroides fragilis: a potential instigator of colitis. Inflamm Bowel Dis 13, 14751483.

39. De Palma G, Nadal I, Collado MC et al. (2009) Effects of a gluten-free diet on gut microbiota and immune function in healthy adult human subjects. BrJ Nutr 102(8), 1154-1160.

40. Scott KP, Martin JC, Duncan SH et al. (2013) Prebiotic stimulation of human colonic butyrate-producing bacteria and bifidobacteria, in vitro. FEMS Microbiol Ecol. doi: 10.1111/15746941.12186.

41. Peterson DA, McNulty NP, Guruge JL et al. (2007) IgA response to symbiotic bacteria as a mediator of gut homeostasis. Cell Host Microbiobe 2, 328-339.

42. Kawamoto S, Tran TH, Maruya M et al.
(2012) The inhibitory receptor PD-1 regulates IgA selection and bacterial composition in the gut. Science 336, 485-489.

43. Delcenserie V, Martel D, Lamoureux M et al. (2008) Immunomodulatory effects of probiotics in the intestinal tract. Curr Issues Mol Biol 10(1-2), 37-54.

44. Smecuol E, Hwang HJ, Sugai E et al. (2013) Exploratory, randomized, doubleblind, placebo-controlled study on the effects of Bifidobacterium infantis natren life start strain super strain in active celiac disease. J Clin Gastrooenterol 47(2), 139-147. 


\section{SUPPLEMANTARY TABLES}

Sup. table 1: Sequence of the $16 \mathrm{~S}$ rRNA gene target primers used for real time quantitative PCR analyses.

\begin{tabular}{|c|c|c|c|c|}
\hline Targeted bacteria & Sequence $\left(5^{\prime}-3^{\prime}\right)$ & $\begin{array}{c}\mathrm{T}^{\mathrm{a}} \\
\text { anne. }\end{array}$ & $\begin{array}{l}\text { Amplicon } \\
\text { size }(\mathrm{pb})\end{array}$ & Reference \\
\hline Total bacteria & $\begin{array}{l}\text { ACT CCT ACG GGA GGC AGC AG } \\
\text { CTA TTA CCG CGG CTG CTG GCAC }\end{array}$ & 59 & 200 & $\begin{array}{l}\text { Matsuki et al., } \\
2002\end{array}$ \\
\hline Bacteroides fragilis group & $\begin{array}{l}\text { ATA CGG AGG ATC CGA GCG TTA } \\
\text { CTG TTT GAT ACC CAC ACT }\end{array}$ & 48 & 287 & $\begin{array}{l}\text { Matsuki et al., } \\
2002\end{array}$ \\
\hline Enterobacteriaceae & $\begin{array}{l}\text { CAT TGA CGT TAC CCG CAG AAG AAG C } \\
\text { CTC TAC GAG ACT CAA GCT TGC }\end{array}$ & 63 & 195 & $\begin{array}{l}\text { Bartosch et al., } \\
2004\end{array}$ \\
\hline Lactobacillus group & $\begin{array}{l}\text { AGC AGT AGG GAA TCT TCC A } \\
\text { ATT YCA CCG CTA CAC ATG }\end{array}$ & 61 & 340 & $\begin{array}{l}\text { Walter et al., } \\
2000\end{array}$ \\
\hline Bifidobacterium spp. & $\begin{array}{l}\text { CTC CTG GAA ACG GGT GG } \\
\text { GGT GTT CTT CCC GAT ATC TAC A }\end{array}$ & 55 & 550 & $\begin{array}{l}\text { Matsuki et al., } \\
2002\end{array}$ \\
\hline C. coccoides group & $\begin{array}{l}\text { AAA TGA CGG TAC CTG ACT AA } \\
\text { CTT TGA GTT TCA TTC TTG CGA A }\end{array}$ & 50 & 438 & $\begin{array}{l}\text { Matsuki et al., } \\
2002\end{array}$ \\
\hline C. leptum group & $\begin{array}{l}\text { GCA CAA GCA GTG GAG T } \\
\text { CTT CCT CCG TTT TGT CAA }\end{array}$ & 50 & 239 & $\begin{array}{l}\text { Matsuki et al., } \\
2004\end{array}$ \\
\hline
\end{tabular}

\section{References}

Bartosch S, Fite, A, Macfarlane GT et al. (2004) Characterization of bacterial communities in feces from healthy elderly volunteers and hospitalized elderly patients by using real-time PCR and effects of antibiotic treatment on the fecal microbiota. Appl Environ Microbiol 70, 3575-3581.

Matsuki T, Watanabe K, Fujimoto J et al. (2002) Development of 16S rRNA-gene-targeted groupspecific primers for the detection and identification of predominant bacteria in human feces. Appl Environ Microbiol 68, 5445-5451.

Matsuki T, Watanabe K, Fujimoto J et al. (2004) Use of 16S rRNA gene-targeted group-specific primers for real-time PCR analysis of predominant bacteria in human feces. Appl Environ Microbiol 70, 7220-7228.

Walter, J., Tannock, G.W., Tilsala-Timisjarvi, A et al. (2000) Detection and identification of gastrointestinal Lactobacillus species by using denaturing gradient gel electrophoresis and speciesspecific PCR primers. Appl. Environ. Microbiol 66, 297-303. 
Sup. table 2. Nutrient intake in the placebo and B. longum CECT 7347 groups at baseline and during the three-month intervention.

\begin{tabular}{|c|c|c|c|c|c|}
\hline & \multicolumn{2}{|c|}{ Baseline } & \multicolumn{2}{|c|}{ Treatment period } & \multirow{2}{*}{$* P$ value } \\
\hline & Mean & $\mathrm{SE}$ & Mean & $\mathrm{SE}$ & \\
\hline \multicolumn{6}{|l|}{ Placebo } \\
\hline Energy (Kcal) & 1904.98 & 113.40 & 2144.60 & 326.41 & 0.476 \\
\hline Protein $(\mathrm{g})$ & 67.50 & 8.00 & 85.92 & 17.01 & 0.589 \\
\hline Lipids (g) & 92.34 & 5.82 & 104.84 & 17.28 & 0.673 \\
\hline Carbohydrates (g) & 200.98 & 17.15 & 214.34 & 27.58 & 0.576 \\
\hline Phosphorous (mg) & 1053.74 & 141.81 & 1457.70 & 400.54 & 0.458 \\
\hline Magnesium (mg) & 181.04 & 11.69 & 190.58 & 14.81 & 0.583 \\
\hline Calcium (mg) & 939.42 & 174.55 & 1057.02 & 258.03 & 0.767 \\
\hline Iron (mg) & 8.46 & 0.71 & 10.32 & 0.96 & 0.103 \\
\hline Zinc (mg) & 6.66 & 0.75 & 7.68 & 1.04 & 0.553 \\
\hline Vitamin C (mg) & 81.86 & 16.94 & 77.68 & 13.30 & 0.848 \\
\hline Vitamin A (retinol) $(\mu \mathrm{g})$ & 718.04 & 142.76 & 2129.40 & 712.16 & 0.119 \\
\hline Vitamin D $(\mu \mathrm{g})$ & 2.10 & 0.83 & 3.98 & 1.73 & 0.443 \\
\hline Vitamin E (mg) & 7.30 & 1.17 & 9.98 & 1.89 & 0.171 \\
\hline Fibre $(\mathrm{g})$ & 10.80 & 1.35 & 8.56 & 2.45 & 0.355 \\
\hline \multicolumn{6}{|l|}{ B. longum CECT 7347} \\
\hline Energy (Kcal) & 2079.57 & 523.42 & 2087.82 & 414.30 & 0.989 \\
\hline Protein $(\mathrm{g})$ & 78.67 & 17.10 & 78.75 & 15.02 & 0.272 \\
\hline Lipids (g) & 107.17 & 30.65 & 95.82 & 22.39 & 0.447 \\
\hline Carbohydrates (g) & 200.10 & 45.74 & 227.62 & 46.41 & 0.966 \\
\hline Phosphorous (mg) & 1130.05 & 204.61 & 1139.77 & 208.90 & 0.917 \\
\hline Magnesium (mg) & 171.42 & 22.67 & 197.78 & 48.43 & 0.495 \\
\hline Calcium (mg) & 795.60 & 110.08 & 825.55 & 138.82 & 0.493 \\
\hline Iron $(\mathrm{mg})$ & 11.37 & 1.91 & 13.23 & 3.40 & 0.526 \\
\hline Zinc (mg) & 9.08 & 1.98 & 9.62 & 2.25 & 0.672 \\
\hline Vitamin C (mg) & 78.55 & 11.78 & 96.03 & 34.09 & 0.519 \\
\hline Vitamin A (retinol) $(\mu \mathrm{g})$ & 1298.32 & 315.24 & 1237.83 & 395.49 & 0.915 \\
\hline Vitamin D $(\mu \mathrm{g})$ & 3.80 & 1.24 & 5.42 & 1.37 & 0.319 \\
\hline Vitamin E (mg) & 9.12 & 1.33 & 9.33 & 1.80 & 0.903 \\
\hline Fibre $(\mathrm{g})$ & 12.32 & 3.12 & 9.4 & 1.89 & 0.161 \\
\hline
\end{tabular}

*Differences between baseline and post-treatment within the groups (placebo or B. longum CECT 7347) were established at $P<0.05$ using the t-test. 


\section{IV - GENERAL DISCUSSION}

The findings of this Doctoral Thesis, which are presented in the previous four chapters, respond to the common objective of progressing in the understanding of the role of the intestinal microbiota and specific bacterial components in the pathological process of $\mathrm{CD}$, and contributing to the disease prevention and treatment by identifying factors that beneficially modulate gut microbiota composition and function. Figure 7 shows a schematic representation of the different studies carried out during this Thesis and their main findings and scientific contribution.

\section{Background: Imbalances in the intestinal microbiota in $C D$ patients \\ Does the microbiota play a role in $\mathrm{CD}$ onset and pathogenesis?}

In vitro studies

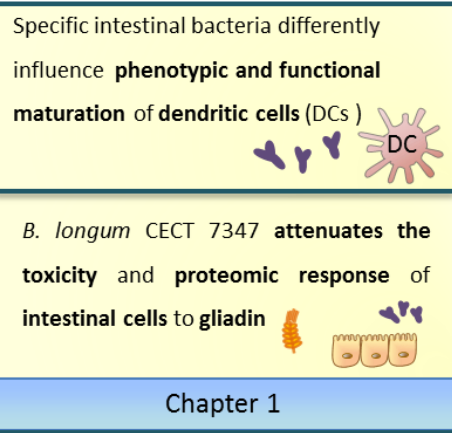

Epidemiological studies

\begin{tabular}{l} 
Reduced TGF- $\beta 1$ and sIgA concentrations \\
in breast milk of CD mothers may \\
diminish the protective effects on \\
the infant. \\
The HLA-DQ2 genotype selects for early \\
gut microbiota composition and, \\
thereby, could contribute \\
to CD risk \\
\hline Chapter 3
\end{tabular}

\section{In vivo animal study}

B. longum CECT 7347 attenuates the production of inflammatory cytokines in the small intestine and the $\mathrm{CD}^{+}{ }^{+} \mathrm{T}$-cell mediated immune response in an animal model of gliadin induced enteropathy

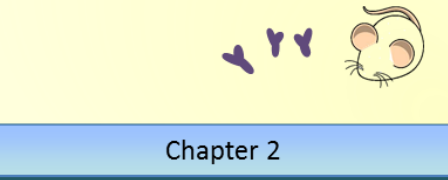

Human intervention study

Administration of B. longum CECT 7347 to children with newly diagnosed $C D$ reduced $B$. fragilis and sigA concentrations in stools and activated $\mathbf{T}$ lymphocytes and slightly TNF- $\alpha$ in blood.

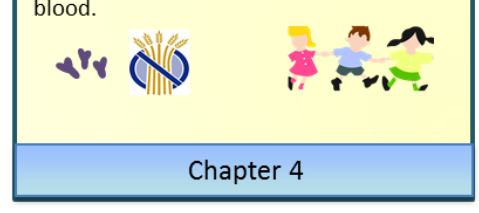

Figure 7: Schematic representation of the studies included in the present Thesis 
Genetic and environmental factors together modulate the early intestinal colonization and may influence the $\mathrm{CD}$ onset

The expression of the HLA-DQ2 or HLA-DQ8 heterodimers and the gluten intake do not explain why some subjects develop CD meanwhile others not (27, 28). Among the environmental factors possibly involved in $\mathrm{CD}$ in addition to gluten, breast feeding is the most intensively investigated but without conclusive results. A protective role of breast-feeding has been reported, mostly based on a few observational, retrospective studies (92-95) which were summarized in a meta-analysis (55) and a systematic review (96). However, not all the studies support a protective effect (97) and any of them clarifies whether breast-feeding provides permanent protection against $\mathrm{CD}$ or simply delays the onset of $\mathrm{CD}$ development.

In the first study included in Chapter 3, the differences between breast-milk composition of healthy mothers and mothers with CD on a GFD have been analyzed for the first time. Mothers with CD presented a decrease in several immune markers (IL-12p70, TGF- $\beta 1$ and sIgA) and in Bifidobacterium spp. in their breast milk. These differences might influence the protective effects of breast-feeding on the infant since it constitutes a source of immunoglobulins and cytokines that compensates the immature immune system of the neonate. These differences in the breast milk composition could also explain, at least in part, the controversy across studies regarding the effects of human milk in the protection against $\mathrm{CD}$. Mothers with the disease also presented a reduction in the Bifidobacterium spp. 16S rRNA gene copy numbers, which could mean a reduction in the transfer of protective bacteria to the newborn. Although more studies are needed, it could be speculated that a reduction in immune protective components $(\operatorname{sg} A$ and TGF- $\beta 1$ ), involved in oral tolerance development, as well as of potential beneficial bacteria could influence the development of the immune system of the neonate and the intestinal colonization patter, that may influence the development of CD later in life.

In the second study of Chapter 3, we have also analyzed the influence of the HLA-DQ genotype on the intestinal microbiota composition of healthy infants 
at family risk of developing CD. This study is part of a larger prospective cohort study aiming to unravel whether alterations in the intestinal microbiota could precede the onset of $\mathrm{CD}$. Our first studies with this cohort of infants using real time qPCR showed that the milk-feeding practices and the HLA-DQ2/DQ8 genotype influence the intestinal colonization (69). To progress beyond this first observation, in the study included in the present Thesis we have analyzed the influence of the genotype on the microbiota in a sub-group of 22 infants including only exclusively breast-fed and vaginally delivered infants to reduce the number of confounding variables, and using $16 \mathrm{~S}$ rRNA gene pyrosequencing. We have observed that the infants with a high genetic risk (HLA-DQ2) of developing CD showed increased proportions of Firmicutes (Clostridium sensu stricto and unclassified Clostridiaceace and Gemella) and Protebacteria (Raoultella and unclassified Enterobacteriacea) and reduced proportions of Actinobacteria (Bifidobacterium) compared to infants with a low genetic risk (non-HLA-DQ2/DQ8). This observation let us to confirm that the HLA-DQ2 genotype per se influences the intestinal microbiota composition, even though the mechanism underlying the association of these imbalances with the later development of the CD remains unknown.

HLA genotype encodes for proteins expressed on the surface of cells that bind to antigen fragments for their presentation to the $\mathrm{T}$ cells. Thus, when $\mathrm{CD}$ patients ingest gluten, HLA molecules recognize gluten peptides and activate $\mathrm{T} \mathrm{CD} 4^{+}$ cells, triggering an aberrant immune response. In order to propose a mechanism by which HLA selects for intestinal microbiota, we can speculate that HLA molecules could present phagocytized antigens of intestinal bacteria, which may then be presented to $\mathrm{T}$ cells. Depending on the antigen presented, effector T-cell activation could contribute to regulating the gut microbes colonizing the gut by activating B cells to secrete protective antibodies directly into the gut mucosa and lumen (98). Bacterial antigens presented via MHC II molecules, could also lead to T cell maturation into effector cells (Th1, Th2 or Th17) or Foxp3 $3^{+}$Treg cells with immunosuppressive activity, which could contribute to developing tolerance towards components of the intestinal microbiota. In this context, studies in rodents indicate that the repertoire of thymus-derived Treg cells, which constitute 
most Treg cells in all lymphoid and intestinal organs including the colon, is heavily influenced by microbiota composition, thus supporting this hypothesis (99).

In summary, from the results presented in Chapter 3, we can conclude that breast-milk from CD mothers and healthy mothers differs in composition and that this could reduce the protective effects of breast-feeding and the transfer of bifidobacteria to the offspring increasing CD risk. In addition, the HLA-DQ2 genotype influences the intestinal microbiota composition of infants at family risk of developing $\mathrm{CD}$, especially reducing the proportion of Actinobacteria (Bifidobacterium) in the gut, which could also be a factor that confers less resilience to disease in this population group. These observations, together with the evidence that bifidobacteria numbers were reduced in $\mathrm{CD}$ patients reported previously (reviewed in 31), seem to indicate that this bacterial genus might play a protective role in $\mathrm{CD}$.

\section{B. longum CECT 7347 as potential probiotic for CD}

The associations between $\mathrm{CD}$ and intestinal dysbiosis and the role attributed to some probiotics in the regulation of the gut barrier function and immune response have motivated investigations of the potential beneficial effect of dietary intervention based on these functional ingredients (reviewed in 100). Some of the studies included in this Doctoral Thesis have been focused on the evaluation of the protective role of B. longum CECT 7347 and its mechanisms of action in $\mathrm{CD}$, which are reported in Chapters 1, 2 and 4.

B. longum CECT 7347 (also called IATA-ES1) was isolated in 2007 from a threemonth old healthy breast-fed infant. This strain of the specie Bifidobacterium longum was selected for its ability to withstand the passage through the digestive tract, a very hostile environment where the acidity and secretion of bile and other compounds kills many bacteria, and also for its in vitro ability to inhibit pathogens isolated from CD patients, immunoregulatory properties and ability to hydrolyse gluten peptides (e.g. the 33-mer). Later studies with this bacterium also demonstrated that $B$. longum CECT 7347 could counteract the pro-inflammatory effects induced by the $\mathrm{CD}$ patients' microbiota in PBMC cultures. In 
particular the co-incubation of B. longum CECT 7347 with PBMCs reduced the production of pro-inflammatory cytokines (IFN- $\gamma$ and TNF- $\alpha$ ) induced by the altered microbiota of CD patients and increase the release of the anti-inflammatory cytokine IL-10 counteracting the Th1-type response (87). In a later study, B. longum CECT 7347 was also demonstrated to be able to hydrolyze gliadin peptides reducing their toxicity and inflammatory properties in Caco-2 cells (91).

The present Thesis has progress in the understanding of the mechanisms by which B. longum CECT 7347 could protect against CD using different and complementary experimental approaches. The Chapter 1 reported the in vitro studies, the Chapter 2 described the in vivo pre-clinical studies in an animal model of the enteropathy and the Chapter $\mathbf{4}$ included a double-blind randomized intervention study in children newly diagnosed with $\mathrm{CD}$ to demonstrate the clinical efficacy of B. longum CECT 7347.

The articles of Chapter 1 were conceived to study whether some specific components of the intestinal microbiota (especially some Bifidobacterium strains) could contribute to ameliorating the response to gluten peptides using in vitro models. To do so, monocytes derived dendritic cells (MDDCs) and Caco-2 cultures were chosen as both cells types are located at the interface between the host and the microbiota, and regulate intestinal barrier function and innate immune responses.

In the first study of Chapter 1, we concluded that specific components of the gut microbiota could define the role of dendritic cells (MDDCs) in T cell activation and the progression of CD, via their influence in the maturation of MDDCs and their interactions with epithelial cells (Caco-2). Specifically, some enterobacteria exerted pathogenic effects similar to the ones exerted by gliadin, contributing to the MDDCs maturation and the induction of pro-inflammatory cytokine release. In contrast, the two Bifidobacterium strains tested (B. bifidum CECT 7365 and B. longum CECT 7347) did not cause gliadin-induced morphological changes of MDDCs and showed reduced inflammatory cytokine release. Furthermore, $B$. longum CECT 7347 reduced the IFN- $\gamma$ release induced by gliadins and increased IL-10 secretion when both stimuli were combined. Also this bacterium reversed the gliadin-reduced ZO-1 expression in Caco-2 cells, which alters permeability. 
Altogether, these data showed that B. longum CECT 7347 could play a role in $\mathrm{CD}$ through the polarization of the immunological response and strengthening the gut barrier function, making this strain the most interesting one for further studies.

In the second in vitro study included in Chapter 1, we evaluated the potential protective properties of $B$. longum CECT 7347 by contributing to the digestion of gliadin peptides and reducing their toxicity on Caco-2 cells using a proteomic approach. To do so, the proteome of Caco- 2 cells exposed to gliadin peptides digested in vitro in the presence or absence of B. longum was evaluated. We observed a higher number of proteins with altered expression when Caco- 2 cells were exposed to gliadin digested without $B$. longum, indicating a higher damage, than when gliadin was digested in the presence of the Bifidobacterium. Some of these proteins were involved in the maintenance of the cell cytoskeleton, cell apoptosis and interactions with the immune cells. Besides, this differential proteomic response was associated with a reduction in cell viability and an increase in TNF- $\alpha$ release. By contrast, when Caco- 2 cells were exposed to gliadin digested in the presence of B. longum CECT 7347, a lower number of proteins were altered and no differences in the inflammatory markers were detected compared to the control. Thus, it was concluded that B. longum CECT 7347 reduced the toxic and the inflammatory effects of gliadin-derived peptides generated during a simulated gastrointestinal digestion. In addition to the proteolytic effect on gliadin peptides, a role of other molecules released by $B$. longum during the digestion process cannot be discarded.

In Chapter 2, we have evaluated the potential effects of B. longum CECT 7347 in an in vivo model of gluten induced enteropathy in newborn rats fed gliadin and sensitized with IFN- $\gamma$. We selected this animal model because it was described that reproduces the $\mathrm{CD}^{+}{ }^{+} \mathrm{T}$ cell mediated enteropathy defined as hyperplasic-infiltrative similar to the one described in $\mathrm{CD}$ patients and the $\mathrm{CD}$ symptoms (101). The results confirmed that the sensitization with IFN- $\gamma$ was necessary to partially reproduce the disease. In previous studies was also shown that sensitization of animals with IFN- $\gamma$ was necessary to cause mucosa damage 
and immunological changes that resemble the enteropathy observed in human, as IFN- $\gamma$ increases the paracellular transport and the activation and priming of macrophages $(102,103)$. In sensitized newborn rats fed gliadin, the administration of B. longum CECT 7347 increased the NF-kB expression and IL-10 concentration and reduced TNF- $\alpha$ production in the small intestine. The administration of $B$. longum CECT 7347 also reduced $\mathrm{CD}^{+}$and $\mathrm{CD} 4^{+} /$Foxp $3^{+}$cell populations and increased $\mathrm{CD}^{+} \mathrm{T}$ cell populations in peripheral blood from sensitized gliadin-fed animals. These results suggest that the Bifidobacterium partially counteract the inflammatory response locally in the gut. However, results from animal models have limitations and the potential beneficial effects should be interpreted with caution.

Finally, Chapter 4 includes the most conclusive study as it evaluated whether B. longum CECT 7347 could help improve the recovery of children with newly diagnosed $\mathrm{CD}$ when administered in addition to the GFD.

When compared between groups after the 3 months of intervention, the administration of B. longum CECT 7347 caused a decrease in peripheral activated $\mathrm{CD}^{+} \mathrm{T}$ lymphocytes and a slightly reduction in the TNF- $\alpha$ concentration. In the gut, the administration of $B$. longum was associated with a reduction of sIgA and Bacteroides fragilis numbers, which could contribute to restoring the gut ecosystem since bacteroides are known to be increased in the microbiota of $\mathrm{CD}$ patients (64). The production of sIgA plays a protector role as it binds harmful antigens (allergens or pathogens) and prevents the colonization and invasion of pathogens, as it can be the case for pathobionts of the genus Bacteroides (104). However, in active CD patients the sIgA may not play a protective role as the abnormal retro-transport of the complex IgA-gluten peptide by the $\mathrm{CD} 71$ receptor has let to consider sIgA as a "Trojan horse" able to promote the entrance of gluten peptides $(104,105)$. Thus, it could be speculated that the reduction observed in the children who received $B$. longum CECT 7347 may reduce the translocation of gluten to the lamina propria, when eventually ingested. It can also be a consequence of reductions in the total load of pathobionts in the intestine, such as Bacteroides fragilis group. 
Despite no differences in the incidence of gastrointestinal symptoms were reported, our findings suggest that $B$. longum CECT 7347 could help to restore the intestinal ecosystem of $\mathrm{CD}$ patients. To date, two more randomized, double-blind placebo-controlled human intervention trials have been conducted in CD patients $(106,107)$. One of this trials has evaluated the effects of the administration of $B$. infantis NLS to untreated CD patients independently of the GFD. This study reported an improvement in some gastrointestinal symptoms (indigestion and constipation) after the administration of B. infantis NLS, but no differences in the permeability or the pro-inflammatory cytokines were found (106). The more recent intervention study published evaluated the effect of a strain combination (B. breve BR03 and B. breve B632), as compared to a placebo in children with CD on a GFD. In this case, the two $B$. breve strains decreased the production of the pro-inflammatory cytokine TNF- $\alpha$ in children with CD on a GFD (107) as detected in our study.

Although these three studies report promising results since the interventions with specific probiotics strains ameliorate the symptoms or the inflammatory status of CD patients, the reproducibility of the effects in larger population groups should be confirm to be able to draw firm conclusions and make recommendations about their use in practice. 


\section{V - CONCLUSIONS}

1. CD mothers' breast milk is characterized by a reduced abundance of immunoprotective compounds (TGF- $\beta 1$ and sIgA) and DNA sequences form Bifidobacterium spp. The reduction in these components could theoretically diminish the protective effects of breast-feeding on the child's future risk of developing CD and explain the controversy across previous epidemiological studies.

2. Infants with high genetic risk of developing CD (HLA-DQ2) have higher proportions of Firmicutes (Clostridium species) and Proteobacteria (Enterobacteriaceae) and lower proportions of Actinobacteria (Bifidobacterium species) than those with low genetic risk (non-HLA-DQ2/DQ8-carriers) in exclusively breast-fed infants. Therefore, the HLA-DQ2 genotype per se influences the early gut microbiota composition in infants at family risk of developing $\mathrm{CD}$ and could be an additional factor that contributes to $\mathrm{CD}$ onset.

3. Specific components of the gut microbiota may influence phenotypic and functional maturation of DCs differently, and their interactions with epithelial cells aggravating (enterobacteria) or protecting (bifidobacteria) from the adverse effects of gluten peptides in vitro.

4. B. bifidum CECT 7365 and B. longum CECT 7347 did not cause gliadininduced morphological changes, and induced adhesion and spreading ability of MDDCs and inflammatory cytokine production to a lesser extent than the enterobacteria. B. longum CECT 7347 reduced IFN- $\gamma$ production induced by gliadins and increased IL-10 secretion and also reversed the gliadin-reduced ZO-1 expression in Caco-2 cells, suggesting that protects from the adverse effects of gluten

5. The presence of B. longum CECT 7347 during the in vitro digestion of gliadin reduces its toxicity, measured as increased cell viability and reduced proinflammatory cytokine secretion. It also modifies the proteomic response of intestinal epithelial cells (Caco-2 cells) to gliadin, reducing the altered protein expression.

6. In an animal model of gliadin-induced enteropathy, the administration of $B$. longum CECT 7347 attenuated the production of inflammatory cytokines in the small intestine and the increased $\mathrm{CD}^{+} \mathrm{T}$-cell mediated immune response in the periphery. 
7. In children newly diagnosed with $\mathrm{CD}$, the oral administration of $B$. longum CECT 7347 together with the GFD reduced the numbers of potentially proinflammatory bacteria ( $B$. fragilis group) related to $\mathrm{CD}$ in previous human observational studies and faecal sIgA concentration. It also led to reductions in activated $T$ lymphocytes and slightly in inflammatory markers (TNF- $\alpha$ ) that may contribute to recovery of the immune homeostasis in $\mathrm{CD}$ patients. 


\section{References}

1.Van de Kamer J, Weijers H, Dicke W (1953) Coeliac disease V. Some experiments on the cause of the harmful effect of wheat gliadin. Acta Paediatr. Scand 42, 223-231.

2.Sakula J, Shiner M (1957) Coeliac disease with atrophy of the small-intestine mucosa. Lancet 273, 876-877. 3.Ferguson A, Murray D (1971). Quantitation of intraepithelial lymphocytes in human jejunum. Gut, 988-99. 4.Carter C, Sheldon W, Walker C (1959) The inheritance of coeliac disease. Ann Hum Genet 23, 266-278.

5.Dieterich W, Ehnis T, Bauer M et al. (1997) Identification of tissue transglutaminase as the autoantigen of celiac disease. Nat Med 3, 797-801.

6. Howell MD, Austin R K, Kelleher D et al. (1986) An HLA-D region restriction fragment length polymorphism associated with celiac disease. J Exp Med 164, 333-338.

7.Sollid LM, Markussen G, Ek J et al. (1989) Evidence for a primary association of celiac disease to a particular HLA-DQ a/b heterodimer. J Exp Med 169, 345-350.

8.Sollid LM (2000) Molecular basis of celiac disease. Annu Rev. Immunol 18, 53-81.

9.Husby S, Koletzko S, Korponay-Szabó IR et al. (2012) ESPGHAN Working Group on Coeliac Disease Diagnosis; ESPGHAN Gastroenterology Committee; European Society for Pediatric Gastroenterology, Hepatology, and Nutrition. European Society for Pediatric Gastroenterology, Hepatology, and Nutrition guidelines for the diagnosis of coeliac disease. J Pediatr Gastroenterol Nutr 54, 136-60.

10.Catassi C, Yachha SK (2008) The global village of celiac disease. In: Fasano A, Troncone R, Branski D, editors. Frontiers in celiac disease. Basel: Switzerland Karger, 23-31.

11.Tommasini A, Not T, Ventura A (2001) Ages of celiac disease: from changing environment to improved diagnostics. World J. Gastroenterol 17, 3665-3671.

12.Dube C, Rostom A, Sy R et al. (2005) The prevalence of celiac disease in average-risk and at-risk Western European populations: a systematic review. Gastroenterology 128, S57-S67.

13.Trynka G, Wijmenga C, van Heel DA (2010) A genetic perspective on coeliac disease. Trends Mol Med $16,537-550$.

14.Catassi C, Kryszak D, Bhatti B (2010) Natural history of celiac disease autoimmunity in a USA cohort followed since 1974. Ann Med 42, 530-538.

15.Pozo-Rubio T, Olivares M, Nova E et al. (2012) Immune development and intestinal microbiota in celiac disease. Clin Dev Immunol 2012, 654143.

16. Greco L, Romino R, Coto I et al. (2002) The first large population base don twin study of coeliac disease. Gut 50, 624-628.

17.Fasano A, Berti I, Gerarduzzi T et al. (2003) Prevalence of celiac disease in at-risk and not-at-risk groups in the United States: a large multicenter study. Arch Intern Med 163, 286-292.

18. Nisticò L, Fagnani C, Coto I et al. (2006) Concordance, disease progression, and heritability of coeliac disease in Italian twins. Gut 6, 803-808.

19.Dieli-Crimi R, Cénit MC, Núñez C (2015) The genetic of celic disease: A comprehensive review of clinical implications. J Autoimmun, S0896-8411.

20.Zannini E, Jones JM, Renzetti S et al. (2012) Functional replacements for gluten. Annu Rev Food Sci Technol 3, 227-245.

21.Shan L, Qiao SQ, Arentz-Hansen H et al. (2005) Identification and analysis of multivalent proteolytically resistant peptides from gluten: implications for celiac sprue. J Proteome Res 4, 1732-1741.

22. Bernardo D, Garrote JA, Nadal I et al. (2009) Is it true that coeliacs do not digest gliadin? Degradation pattern of gliadin in coeliac disease small intestinal mucosa. Gut 58, 886-887.

23.Lammers KM, Lu R, Brownley J et al. (2008) Gliadin induces an increase in intestinal permeability and zonulin release by binding to the chemokine receptor CXCR3. Gastroenterology 135, 194-204.

24.Schumann M, Richter JF, Wedell I et al. (2008) Mechanisms of epithelial translocation of the alpha(2)gliadin-33mer in coeliac sprue. Gut 57, 747-754.

25.Matysiak-Budnik T, Moura IC, Arcos-Fajardo M et al. (2008) Secretory IgA mediates retrotranscytosis of intact gliadin peptides via the transferrin receptor in celiac disease. J Exp Med 205, 143-54.

26. Heyman M, Abed J, Lebreton C et al. (2012) Intestinal permeability in coeliac disease: insight into mechanisms and relevance to pathogenesis. Gut 61, 1355-1364

27. Barisani D, Parafioriti A, Bardella MT et al. (2004) Adaptive changes of duodenal iron transport proteins in celiac disease. Physiol Genomics 17, 316e25.

28. Vriezinga SL, Auricchio R, Bravi E et al. (2014) Randomized feeding intervention in infants at high risk for 
celiac disease. N Engl J Med 371, 1304-1315.

29.Lionetti E, Castellaneta $S$, Francavilla $R$ et al. (2014) Introduction of gluten, HLA status, and the risk of celiac disease in children. N Engl J Med 371, 1295-1303.

30.De Palma G, Vida C, Santacruz A et al. (2014) Impaired responses to gliadin and gut microbes of immune cells from mice with altered stress-related behavior andpremature immune senescence. J Neuroimmunol 276, 47-57.

31. Olivares M, Sanz Y. Intestinal microbiota and Celiac Disease. In "Advances in the understanding of gluten related pathology and the evolution of gluten-free foods”. Ed: Rodrigo L, Peña S, Arranz E, Fernández-Bañares F, Rosell CM. Barcelona, Spain. OmniaScience, 2015, in press.

32.Di Sabatino A, CorazzaGR (2009) Coeliac disease. Lancet 373, 1480-1493.

33. Dieterich W, Ehnis T, Bauer M et al. (1997) Identification of tissue transglutaminase as the autoantigen of celiac disease. Nat Med 3, 797-801.

34. Benahmed M, Meresse B, Arnulf B et al. (2007) Inhibition of TGF-beta signaling by IL-15: a new role for IL-15 in the loss of immune homeostasis in celiac disease. Gastroenterology 132, 994-1008.

35.Kaukinen K, Linfors K, Mäki M (2014) Advances in the treatment of coelic disease: an immunopathogenic perspective. Nat Rev Gastreonterol Hepatol 11, 36-44.

36. Wieser H, Koehler P (2012) Detoxification of gluten by means of enzymatic treatment. J AOAC Int 95, 356-363.

37.Sulic AM, Kurppa K, Rauhavirta T et al. (2015) Transglutaminase as a therapeutic target for celiac disease. Expert Opin Ther Targets 19, 335-348.

38.Hoffmann K, Alminger M, Andlid T et al. (2009) Blocking peptides decrease tissue transglutaminase processing of gliadin in vitro. J Agric Food Chem 57, 10150-10155.

39.Salvati VM, Mazzarella G, Gianfrani C et al. (2005) Recombinant human interleukin 10 suppresses gliadin dependent $T$ cell activation in ex vivo cultured coeliac intestinal mucosa. Gut 54, 46-53.

40. Yokoyama S, Watanabe N, Sato N et al. (2009) Antibody-mediated blockade of IL-15 reverses the autoimmune intestinal damage in transgenic mice that overexpress IL-15 in enterocytes. Proc Natl Acad Sci U S A 106, 15849-15854.

41.Korzenik, JR, Podolsky DK (2006) Evolving knowledge and therapy of inflammatory bowel disease. Nat Rev Drug Discov 5, 197-209.

42.Gill SR, Pop M, Deboy RT et al. (2006). Metagenomic analysis of the human distal gut microbiome. Science 312, 1355-1359.

43.Ventura M, Turroni F, Canchaya C et al. (2009) Microbial diversity in the human intestine and novel insights from metagenomics. Frontiers in Bioscience 14:3214-3863.

44. Grenham S, Clarke G, Cryan JF et al. (2011) Brain-gut-microbe communication in health and disease. Front Physiol 2, 94.

45.Eckburg PB, Bik EM, Bernstein CN et al. (2005). Diversity of the human intestinal microbial flora. Science 308, 1635-1638.

46. Qin JJ, Ruiqiang L, Raes J et al. (2010). A human gut microbial gene catalogue established by metagenomic sequencing. Nature 464, 59-70.

47.Palmer C, Bik EM, DiGiulio DB et al. (2007) Development of the human infant intestinal microbiota. Plos Biology 5, 1556-1573.

48. Bäckhed F, Roswall J, Peng Y et al. (2015). Dynamics and Stabilization of the human gut microbiome during the first year of life. Cell Host Microbe 17, 690-703.

49.Arumugam M, Raes J, Pelletier E et al. (2011). Enterotypes of the human gut microbiome. Nature 473, $174-180$

50.Koenig JE, Spor A, Scalfone N et al. (2011) Succession of microbial consortia in the developing infant gut microbiome. Proc Natl Acad Sci U S A 108, 4578-4585.

51.Madan JC, Salari RC, Saxena D et al. (2012) Gut microbial colonisation in premature neonates predicts neonatal sepsis. Archives of disease in childhood Fetal and neonatal edition 97, F456-62

52. Cenit MC, Olivares M, Codońer P et al. (2015) Intestinal microbiota and Celiac Disease: cause, consequence or co-evolution? Nutrients 7, 6900-6923.

53. Decker E, Engelmann G, Findeisen A et al. (2010) Cesarean delivery is associated with celiac disease but not inflammatory bowel disease in children. Pediatrics 125, e1433-1440

54.Biasucci G, Benenati B, Morelli et al. (2008) Cesarean delivery may affect the early biodiversity of intestinal bacteria. J Nutr 138, 1796S-17800S.

55.Akobeng AK, Ramanan AV, Buchan I et al. (2006) Effect of breast feeding on risk of coeliac disease: a 
systematic review and meta-analysis of observational studies. Arch Dis Child 91, 39-43.

56.Ivarsson A, Myleus A, Norstrom F et al. (2013) Prevalence of childhood celiac disease and changes in infant feeding. Pediatrics 131, e687-94.

57.Norris JM, Barriga K, Hoffenberg EJ et al. (2005) Risk of celiac disease autoimmunity and timing of gluten introduction in the diet of infants at increased risk of disease. JAMA 293, 2343-2351.

58. Welander A, Tjernberg AR, Montgomery SM et al. (2010) Infectious disease and risk of later celiac disease in childhood. Pediatrics 125, e530-536.

59.Martin R, Jimenez E, Heilig H et al. (2009) Isolation of bifidobacteria from breast milk and assessment of the bifidobacterial population by PCR-denaturing gradient gel electrophoresis and quantitative real-time PCR. Appl Environ Microbiol 75, 965-969.

60.Gronlund MM, Gueimonde M, Laitinen K et al. (2007) Maternal breast-milk and intestinal bifidobacteria guide the compositional development of the Bifidobacterium microbiota in infants at risk of allergic disease. Clin Exp Allergy 37, 1764-1772.

61.Fallani M, Young D, Scott J et al. (2010) Intestinal microbiota of 6-week-old infants across Europe: geographic influence beyond delivery mode, breast-feeding, and antibiotics. J Pediatr Gastroenterol Nutr 51 , $77-84$

62.Tannock GW, Lawley B, Munro K et al. (2013) Comparison of the compositions of the stool microbiotas of infants fed goat milk formula, cow milk-based formula, or breast milk. Appl Environ Microbiol 79, 3040-3048 63. Garrido D, Barile D, Mills DA (2012) A molecular basis for bifidobacterial enrichment in the infant gastrointestinal tract. Adv Nutr 3, 415S-4121S.

64.Garofalo R (2010) Cytokines in human milk. J Pediatr 156, S36-40.

65.Mårild K, Ye W, Lebwohl B et al. (2013) Antibiotic exposure and the development of coeliac disease: a nationwide case-control study. BMC Gastroenterol 8, 109.

66.Mårild K, Ludvigsson J, Sanz Y et al. (2014) Antibiotic exposure in pregnancy and risk of coeliac disease in offspring: a cohort study. BMC Gastroenterol 14, 75.

67.Goodrich JK, Waters JL, Poole AC et al. (2014) Human genetics shape the gut microbiome. Cell 159, 789-99.

68.De Palma G, Capilla A, Nadal I et al. (2010) Interplay between human leukocyte antigen genes and the microbial colonization process of the newborn intestine. Curr Issues Mol Biol 12, 1-10.

69.Palma GD, Capilla A, Nova E et al. (2012) Influence of milk-feeding type and genetic risk of developing coeliac disease on intestinal microbiota of infants: the PROFICEL study. PloS one 7, e30791.

70.Sánchez E, De Palma G, Capilla A et al. (2011) Influence of environmental and genetic factors linked to celiac disease risk on infant gut colonization by Bacteroides species. Appl Environ Microbiol 77, 5316-5323.

71.Nadal I, Donat E, Ribes-Koninckx C et al. (2007) Imbalance in the composition of the duodenal microbiota of children with coeliac disease. J Med Microbiology 56, 1669-1674.

72. Collado MC, Donat E, Ribes-Koninckx C et al. (2009) Specific duodenal and faecal bacterial groups associated with pediatric coelic disease. J Clin Pathol 62, 264-269.

73.Shippa S, Iebba V, Barbaro M et al. (2010) A distinctive "microbial signature" in celiac pediatric patients. BMC Microbiol 10, 175.

74.Forsberg G, Fahlgren A, Horstedt et al. (2004) Presence of bacteria and innate immunity of intestinal epithelium in childhood celiac disease. Am J Gastroenterol 99, 894-904.

75.Ou G, Hedberg M, Horstedt P et al. (2009) Proximal small intestinal microbiota and identification of rodshaped bacteria associated with childhood celiac disease. Am J Gastroenterol. 104, 3058-1367.

76. Nistal E, Caminero A, Vivas S et al. (2012) Differences in faecal bacteria populations and faecal bacteria metabolism in healthy adults and celiac disease patients. Biochimie 94, 1724-1729.

77.Di Cagno R, De Angelis M, De Pasquale I et al. (2011) Duodenal and faecal microbiota of celiac children: molecular, phonotype and metabolome characterization. BMC Microbiol 11, 219.

78.De Palma G, Nadal I, Collado MC et al. (2009) Effects of a gluten-free diet on gut microbiota and immune function in healthy adult human subjects. Br J Nutr 102, 1154-1160.

79.Kalliomaki M, Satokari R, Lahteenoja H et al. (2012) Expression of microbiota, Toll-like receptors, and their regulators in the small intestinal mucosa in celiac disease. J Pedriatr Gastroenterol Nutr 54, 727-732.

80.De Meij TG, Budding AE, Grasman ME et al. (2013) Composition and diversity of the duodenal mucosaassociated microbiome in children with untreated coeliac disease. Scand J Gastroenterol 48, 530-536.

81. Wacklin P, Kaukinen K, Tuovinen E et al. (2013) The duodenal microbiota composition of adult celiac disease patients is associated with the clinical manifestation of the disease. Inflamm Bowel Dis 19, 934-941.

82. Wacklin P, Laurikka P, Lindfors K et al. (2014) Altered duodenal microbiota composition in celiac disease 
patients suffering from persistent symptoms on a long-term gluten-free diet. Am J Gastroenterol 109, 19331941.

83. Sánchez E, Nadal I, Donat E et al. (2008) Reduced diversity and increased virulence-gene carriage in intestinal enterobacteria of coeliac children. BMC Gastroenterol 8, 50.

84.Sánchez E, Laparra JM, Sanz Y (2012) Discerning the role of Bacteroides fragilis in celiac disease pathogenesis. Appl Environ Microbiol 78, 6507-6515.

85.Sánchez E, Ribes-Koninckx C, Calabuig M et al. (2012) Intestinal Staphylococcus spp. and virulent features associated with coeliac disease. J Clin Pathol 65, 830-834.

86.Sjoberg V, Sandstrom O, Hedberg M et al. (2013) Intestinal T-cell responses in celiac disease - impact of celiac disease associated bacteria. PloS one 8, e53414.

87.Medina M, De Palma G, Ribes-Koninckx C et al. (2008) Bifidobacterium strains suppress in vitro the pro-inflammatory milieu triggered by the large intestinal microbiota of coeliac patients. Inflamm (Lond) 5,19 .

88. Cinova J, De Palma G, Stepankova R et al. (2011) Role of intestinal bacteria in gliadin-induced changes in intestinal mucosa: study in germ-free rats. PloS one 6, e16169.

89. Orlando A, Linsalata M, Notarnicola M et al. (2014) Lactobacillus GG restoration of the gliadin induced epithelial barrier disruption: the role of cellular polyamines. BMC Microbiol 14, 19

90.Clemente MG, De Virgiliis S, Kang JS et al. (2003) Early effects of gliadin on enterocyte intracellular signalling involved in intestinal barrier function. Gut 52, 218-223.

91.Laparra JM, Sanz Y (2010). Bifidobacteria inhibit the inflammatory response induced by gliadins in intestinal epithelial cells via modifications of toxic peptide generation during digestion. J Cell Biochem 109, 801-807.

92.Ivarsson A, Hernell O, Stenlund $\mathrm{H}$ et al. (2002) Breast-feeding protects against celiac disease. Am J ClinNutr 75, 914-921.

93. Peters U, Schneeweiss S, Trautwein EA et al. (2001) A case-control study of the effect of infant feeding on celiac disease. Ann Nutr Metab 45, 135-142.

94.Greco L, Auricchio S, Mayer M et al. (1988) Case control study on nutri-tional risk factors in celiac disease. J Pediatr Gastroenterol Nutr 7, 395-399.

95.Auricchio S, Follo D, de Ritis G et al. (1983) Does breast feeding protect against the development of clinical symptoms of celiac disease in children? J Pediatr Gastroenterol Nutr 2, 428-433.

96.Szajewska H, Chmielewska A, Pieścik-Lech M et al. (2012) Systematic review: early in-fant feeding and the prevention of coeliac disease. Aliment Pharmacol Ther 36, 607-618

97.Størdal K, White RA, Eggesbø M (2013). Early feeding and risk of celiac disease in a prospective birth cohort. Pediatrics 132 , e1202-e1209.

98.Fagarasan S, Honjo T (2003). Intestinal IgA synthesis: regulation of front-line body defences. Nat Rev Immunol 3, 63-72.

99. Cebula A, Seweryn M, Rempala GA et al. (2013) Thymus-derived regulatory T cells contribute to tolerance to commensal microbiota. Nature 497, 258-262.

100.Sanz Y (2009) Novel perspectives in celiac disease therapy. Mini Rev Med Chem 9, 359-367.

101.Stepánková R, Kofronová O, Tucková L et al. (2003) Experimentally induced gluten enteropathy and protective effect of epidermal growth factor in artificially fed neonatal rats. J Pediatr Gastroenterol Nutr 36, 96-104.

102. Williams JG, Jurkovich GJ, Hahnel GB et al. (1992) Macrophage priming by interferon gamma: a selective process with potentially harmful effects. J Leukoc Biol 52, 579-584.

103.Sütas Y, Autio S, Rantala I et al. (1997) IFN-gamma enhances macromolecular transport across Peyer's patches in suckling rats: implications for natural immune responses to dietary antigens early in life. J Pediatr Gastroenterol Nutr 4, 162-169.

104.Matysiak-Budnik T, Moura IC, Arcos-Fajardo M et al. (2008) Secretory IgA mediates retrotranscytosis of intact gliadin peptides via the transferrin receptor in celiac disease J Exp Med 205,143-154.

105. Ménard S, Cerf-Bensussan N, Heyman M (2010) Multiple facets of intestinal permeability and epithelial handling of dietary antigens. Mucosal Immunol 3, 249-259.

106.Smecuol E, Hwang HJ, Sugai E et al. (2013) Exploratory, randomized, double-blind, placebo-controlled study on the effects of bifidobacterium infantis natren life start strain super strain in active celiac disease. Journal of clinical gastroenterology 47, 139-147.

107.Klemenak, M, Dolinšek J, Langerholc T et al. (2015) Administration of Bifidobacterium breve Decreases the Production of TNF- $\alpha$ in Children with Celiac Disease. Dig Dis Sci. 


\section{Abbreviations}

\begin{tabular}{|c|c|}
\hline $\mathrm{ACN}$ & Acetonitrile \\
\hline Akt/mTOR & Protein kinase $\mathrm{B} /$ mammalian target of rapamycin \\
\hline APAF-1 & Apoptotic protease activating factor 1 \\
\hline APC & Antigen presenting cells \\
\hline APTS & 9-aminopyrene-1,4,6-trisulfonate) \\
\hline $\mathrm{B}$ & To refer proteins modified by $B$. longum CECT 7347 \\
\hline $\mathrm{CD}$ & Celiac disease \\
\hline CE & Common Era \\
\hline CECT & Coleccion española de cultivos tipo \\
\hline CE-LIF & Electrophoresis-laser-induced fluorescence \\
\hline CFU & Colony forming units \\
\hline $\mathrm{CHCA}$ & $\alpha$-Cyano-4-hydroxycinnamic acid \\
\hline $\mathrm{CI}$ & Cell index \\
\hline CK & Cytoskeletal \\
\hline CSIC & Consejo Superior de Investigaciones Científicas \\
\hline $\mathrm{Ct}$ & Cycle threshold \\
\hline $2-\mathrm{D}$ & Two dimensionals \\
\hline DC & Dendritic Cell \\
\hline DFL & Difucosyllactose \\
\hline DF LNH & Difucosyllacto-N-hexaose \\
\hline DGGE & Denaturing gradient gel electrophoresis \\
\hline dNTPs & Deoxynucleotide triphosphates \\
\hline DTT & Dithiotheitol \\
\hline EDTA & Ethylenediaminetetraacetic acid \\
\hline EMA & Endomysial antibodies \\
\hline ESPGHAN & European Society for Pediatric Gastroenterology, Hepatology and Nutrition \\
\hline FISH & Fluorescence in situ hybridization \\
\hline FITC & Fluorescein isothiocyanate \\
\hline FL & Fucosyllactose \\
\hline F LNH & Fucosyllacto-N-hexaose \\
\hline Fuc & Fucose \\
\hline FUT & Fucosyltransferase \\
\hline G & To refer proteins modified by gliadin without $B$. longum \\
\hline Gal & Galactose \\
\hline GB & To refer proteins modified by gliadin with $B$. longum \\
\hline GFD & Gluten-free diet \\
\hline Glu & Glucose \\
\hline GTP & Guanosine triphosphate \\
\hline HLA & Human Leukocyte antigen \\
\hline HMOs & human milk oligosaccharides \\
\hline HR & High risk \\
\hline IAA & Iodoacetamide \\
\hline IELs & Intraepithelial lymphocytes \\
\hline IFN & Interferon \\
\hline $\mathrm{Ig}$ & Immunoglobulin \\
\hline IL & Interleukin \\
\hline IPG & Immobilized $\mathrm{pH}$ gradient \\
\hline
\end{tabular}




\begin{tabular}{|c|c|}
\hline Le & Lewis \\
\hline LGALS3 & Lectin galactoside-binding soluble 3 \\
\hline LIF & Laser-induced fluorescence \\
\hline LNDFH & Lacto-N-difucosylhexaose \\
\hline LNFP & Lacto-N-fucopentose \\
\hline LNT & Lacto-N-tetraose \\
\hline LR & low risk \\
\hline MDDCs & Monocytes Derived Dendritic Cells \\
\hline MRSC & Man-Rogosa-Sharpe cysteine \\
\hline MS & Mass Spectrometry \\
\hline N-Acetyl & N Acetylglucosamine \\
\hline NCBI & National Center for Biotechnology Information; \\
\hline Neu5Ac & sialic acid \\
\hline $\mathrm{NF}-\boldsymbol{\kappa} \mathrm{B}$ & Nuclear factor kappa-B \\
\hline NGS & Next generation sequencing \\
\hline NR & Neutral red \\
\hline OTUs & Operational taxonomic units \\
\hline $\mathrm{P} 50$ & percentile 50 \\
\hline PBMC & Peripheral blood mononuclear cell \\
\hline PBS & Phosphate buffered saline \\
\hline PCR & Polymerase chain reaction \\
\hline PE & phycoerythrin \\
\hline$p I$ & isoelectric point \\
\hline PSLG1 & P-selectin glycoprotein ligand 1 \\
\hline qPCR & quantitative PCR \\
\hline RDP & Ribosomal Database Project (); \\
\hline RT-qPCR & Real time Reverse transcription chain reaction \\
\hline SDS & Sodium dodecyl sulfate \\
\hline $\mathrm{Se}$ & Secretor \\
\hline $\operatorname{sIg} \mathrm{A}$ & Secretory immunoglobulin A \\
\hline SL & Sialyllactose \\
\hline SPTA & Spectrin alpha chain \\
\hline TAE & Tris-acetate-EDTA \\
\hline TE & Tris-EDTA \\
\hline TFA & trifluoroacetic acid \\
\hline TGF & transforming growth factor \\
\hline Th & T helper \\
\hline $\mathrm{TJ}$ & Tight Junction \\
\hline TNF & Tumor necrosis factor \\
\hline TLRs & Toll-like receptors \\
\hline tTG & Tissue transglutaminase \\
\hline tTG-2 & tissue transglutaminase 2 \\
\hline TTGE & temperature gradient gel electrophoresis \\
\hline
\end{tabular}




\section{List of publications}

This Doctoral Thesis compromises six original research papers in indexed journals. Besides, some reviews and book chapters related to the field of this Thesis have been published during the predoctoral period and are listed below.

De Palma G, Kamanova J, Cinova J, Olivares M, Drasarova H, Tuckova L, Sanz Y (2012). Modulation of phenotypic and functional maturation of dendritic cells by intestinal bacteria and gliadin: relevance for celiac disease. J Leukoc Biol 92, 1043-1054.

Olivares M, Laparra M, Sanz Y (2011) Influence of Bifidobacterium longum CECT 7347 and gliadin peptides on intestinal epithelial cell proteome. J Agric Food Chem 59, 7666-7671

Laparra JM, Olivares M, Gallina O, Sanz Y (2012) Bifidobacterium longum CECT 7347 modulates immune responses in a gliadin-induced enteropathy animal model. PLoS One, 7e30744

Olivares M, Albrecht S, De Palma G, Ferrer MD, Castillejo G, Schols HA, Sanz Y (2014) Human milk composition differs in healthy mothers and mothers with celiac disease. Eur J Nutr 54, 119 128.

Olivares M, Neef A, Castillejo G, Palma GD, Varea V, Capilla A, Palau F, Nova E, Marcos A, Polanco I, Ribes-Koninckx C, Ortigosa L, Izquierdo L, Sanz Y (2015) The HLA-DQ2 genotype selects for early intestinal microbiota composition in infants at high risk of developing coeliac disease. Gut 64, 406-417.

Olivares M, Castillejo G, Varea V, Sanz Y (2014). Double-blind, randomised, placebo-controlled intervention trial to evaluate the effects of Bifidobacterium longum CECT 7347 in children with newly diagnosed coeliac disease. Br J Nutr 112, 30-40

Cenit MC, Olivares M, Codoñer P, Sanz Y (2015) Intestinal microbiota and Celiac Disease: cause, consequence or co-evolution?. Nutrients, 7, 6900-6923.

Sanz Y, Olivares M, Moya-Pérez Á, Agostoni C (2015) Understanding the role of gut microbiome in metabolic disease risk. Pediatr Res 77, 236-44.

Olivares M, Laparra JM, Sanz Y (2013) Host genotype, intestinal microbiota and inflammatory disorders. Br J Nutr 109, S76-80.

Pozo-Rubio T, Olivares M, Nova E, De Palma G, Mujico JR, Ferrer MD, Marcos A, Sanz Y (2012) Immune development and intestinal microbiota in celiac disease. Clin Dev Immunol 2012, 654143.

\section{BOOK CHAPTERS}

Olivares M, Sanz Y. Intestinal microbiota and Celiac Disease. In "Advances in the understanding of gluten related pathology and the evolution of gluten-free foods". Ed: Rodrigo L, Peña S, Arranz E, Fernández-Bañares F, Rosell CM. Barcelona, Spain. OmniaScience, 2015, in press. 
Laparra M, Olivares M, Sanz Y. Role of Gut Microbes in Celiac Disease Risk and Pathogenesis. In "Celiac Disease". Ed: S Devi Rampertab, Mullin EG. Humana Press, 2014, 81-94.

Laparra M, Olivares M, Sanz Y. Microbiota intestinal y enfermedad celiaca. In "Enfermedad celíaca y sensibilidad al gluten no celíaca”. Ed: Rodrigo L, Peña S. Barcelona, Spain. OmniaScience, 2013, 479-496. 